\title{
Evaluation of particle and fibre degradation during processing of wood plastic composites (WPC) using dynamic image analysis
}

\author{
Dissertation \\ In Partial Fulfilment of the Requirements for the Doctoral Degree (Dr. rer. nat.) \\ of the Faculty of Forest Sciences and Forest Ecology \\ Georg-August-University Göttingen
}

Submitted by

Laura Teuber

born in Delmenhorst, Germany 
1. Referee: Prof. Holger Militz

2. Referee: Prof. Andreas Krause

Examiners:

1. Prof. Holger Militz

2. Prof. Andreas Krause

3. Prof. Carsten Mai

4. Prof. Kai Zhang

Date of oral examination: $2^{\text {th }}$ June 2016 
"The most exciting phrase to hear in science, the one that heralds the most discoveries, is not 'Eureka!' but 'That's funny....'"

- Isaac Asimov - 

"Een kruimeltje is ook brood"

Dutch proverb 



\section{Danksagung}

Nun ist sie fertig, meine Doktorarbeit. Am Anfang erschien der Weg lang. Rückblickend bleiben viele Erfahrungen, Erkenntnisse und Eindrücke, die ich nicht mehr missen möchte.

Auf dem Weg der letzten vier Jahre, vom Anfang bis zum Hier und Heute, haben mich viele Menschen begleitet. Sie haben mich in der einen oder anderen Art und Weise unterstützt, inspiriert, motiviert und zum erfolgreichen Abschluss dieser Arbeit beigetragen. Ihnen allen möchte ich von ganzem Herzen nur eines sagen:

Danke! 



\section{Zusammenfassung}

Die vorliegende Arbeit wurde im Rahmen des DFG Graduiertenkollegs 1703 „Ressourceneffizienz in Unternehmensnetzwerken - Methoden zur betrieblichen und überbetrieblichen Planung für die Nutzung erneuerbarer Rohstoffe" durchgeführt. Es wurde der Einfluss verschiedener Prozessparameter auf die Morphologie der Holzkomponente von Holz-Kunststoff-Kompositen (Wood Plastic Composites WPC) untersucht. Die Ergebnisse wurden bereits anderswo publiziert bzw. zur Publikation eingereicht (insgesamt vier Publikationen) und werden innerhalb individueller Kapitel der vorliegenden Arbeit wiedergegeben.

WPC vereinen die Eigenschaften von Holz als Füllstoff mit den Eigenschaften von Polymeren als Matrixmaterial. Aktuelle Literatur und Forschungsarbeiten wurden gesichtet, um Möglichkeiten zu identifizieren, wie WPC zu einer effizienten Ressourcennutzung beitragen kann. Die Ergebnisse zeigen, dass eine Vielzahl von Abfall- und Nebenprodukten aus Holz- und Agrarwirtschaft zur Herstellung von WPC verwendet werden kann, z.B. Sägespäne, Reststoffe aus der Plattenproduktion und Schlämme aus der Faserstoffproduktion. Darüber hinaus können auch Kunststoff-Rezyklate und Biokunststoffe als Rohstoff dienen.

Für die Eigenschaften von WPC spielt die Morphologie der Holzkomponente Fasern oder Partikel - eine entscheidende Rolle. Während der Verarbeitung von WPC treten hohe Temperaturen und Scherkräfte auf, welche zur Zerkleinerung der Holzkomponente führen. Um die Zerkleinerung während der Verarbeitung analysieren zu können, wurde die Eignung der Partikelcharakterisierung mittels dynamischer Bildanalyse zur Größenbestimmung von WPC-Füllstoffen geprüft. Dafür wurden Holzpartikel aus der Polymermatrix gelöst und ihre Morphologie vor und nach der Verarbeitung verglichen. Es zeigte sich, dass eine Auswertung bezüglich der längenbasierten Größenverteilung am besten geeignet ist, um Prozess-Effekte zu analysieren, da Partikel an beiden Enden der Größenverteilung gut abgebildet werden.

Die Effekte von Prozessparametern wie Holzanteil, Beschickungsmethode, Vorwärmen des Holzes, Polymerviskosität, Rotor-/Schneckendrehzahl, Förderrate und Schneckenkonfiguration auf die Holzzerkleinerung wurden untersucht. Dazu wurden Fichtenholz-Partikel (Picea abies) entweder unter Verwendung eines Innenmischers oder eines Doppelschnecken-Extruders mit Polypropylen (PP) compoundiert. Zur Bestimmung des Einflusses der Polymerviskosität wurden verschiedene Sorten PP und schwachverzweigtes Polyethylen (HDPE) verwendet, welche sich in ihrem Schmelzflussindex (melt flow rate - MFR) unterscheiden.

Nach dem Compoundieren betrug die Partikelgröße nur noch $<3 \%$ der ursprünglichen Größe. Bei den PP-Kompositen nahm die Partikelzerkleinerung sowohl im Innenmischer als auch im Extruder mit zunehmendem Holzanteil zu. 
Auch eine zunehmende Anzahl an Knetelementen im Schneckenprofil führte zu einer stärkeren Partikelzerstörung. Bei den HDPE-Kompositen war der Einfluss des Holzanteils nur gering. Wurden die Holzpartikel und das Polymer dem Prozess gleichzeitig zugeführt, war die Partikelzerstörung intensiver als wenn die Partikel dem bereits geschmolzenen Polymer zugegeben wurden. Auch ein Vorwärmen der Partikel führte zu einer stärkeren Zerkleinerung. Die Zerkleinerung konnte unter Verwendung eines Matrixpolymers mit hohem MFR reduziert werden. Zum einen variierte der Einfluss der Förderrate mit der Schneckendrehzahl, zum anderen variierte der Einfluss von Förderrate und Schneckendrehzahl auch mit dem Holzanteil.

Da die Bedingungen des Compoundierprozesses im Labormaßstab üblicherweise nicht mit Bedingungen im Industriemaßstab vergleichbar sind, wurden die Prozessparameter an einem Labor-Extruder so gewählt, dass sie industrielle Bedingungen imitieren. Die Einkürzung von Kiefernholzfasern (Pinus radiata) wurde mit der Einkürzung von Glasfasern verglichen, da diese ein Standardmaterial in der industriellen Kompositfertigung darstellen. Mittels sogenannter „Dead-stop“Versuche und Probennahme entlang der Extruderschnecken wurde der Einfluss von Schneckenkonfiguration, Schneckendrehzahl und Förderrate analysiert. Prozesseinstellungen, die einen geringeren Anteil an spezifischer mechanischer Energie ins Material eintrugen, sowie eine schonende Schneckenkonfiguration verzögerten die Fasereinkürzung entlang der Extruderschnecken. Für eingangs längere Glasfasern war dieser Effekt ausgeprägter als für eingangs kürzere Holzfasern. Die Faserlänge im Endprodukt zeigte jedoch keine Unterschiede bezüglich der Prozesseinstellungen. Glasfasern zeigten deutlichere Unterschiede in der Faserlänge aufgrund der Schneckenkonfiguration als Holzfasern. Diese spiegelten sich auch in den mechanischen Eigenschaften wieder: ein aggressiveres Schneckenprofil resultierte in geringeren Festigkeiten bei den Glasfaser-Kompositen, jedoch nicht bei den Holzfaser-Kompositen. 


\section{Abstract}

This work was performed within the scope of the DFG Research Training Group 1703 "Resource Efficiency in Interorganizational Networks - Planning Methods to Utilize Renewable Resources". The aim of this work was to investigate the influence of different processing parameters on the filler morphology of Wood Plastic Composites (WPC). The results have partially been published or are submitted for publication elsewhere (four publications in total) and are reproduced within individual chapters of this work.

WPC are a group of materials that combine the properties of a wood filler material with those of a polymer matrix. A review of recent research was conducted to identify the potential of WPC to contribute to efficient resource utilisation. The results show that a variety of waste and by-products from wood and agricultural industry, e.g. offcuts, sawdust, residues from board manufacturing, pulping sludge, can be used for the production of WPC. Also recycled polymers and biopolymers can serve as raw materials.

In defining the final WPC properties, the morphology of the filler material, i.e. fibres or particles, plays an important role. During processing the material is subject to high temperature and shear leading to degradation of the wood filler. The use of dynamic particle analysis for the characterisation of WPC filler material was introduced to verify its suitability for the analysis of filler degradation during processing. The polymer was dissolved and extracted from the compound and particle morphologies before and after processing were compared. The length-based size distribution proved to be most suitable for the analysis of processing effects since particles on both ends of the distribution are well represented.

The effects of process parameters like filler content, feeding method, pre-heating of filler material, polymer viscosity, rotor/screw speed, feed rate and screw design on filler degradation were studied. Therefore, Norway spruce (Picea abies) wood particles were compounded with polypropylene (PP) either in an internal mixer or in a twin-screw extruder (TSE). To study the influence of polymer viscosity different grades of PP and high density polyethylene (HDPE) having different melt flow rates (MFR) were used.

After compounding, overall particle size was reduced by $>97 \%$. For PP composites, particle degradation increased with increasing filler content in both internal mixing and extrusion, and for higher number of kneading elements in the extruder screw. For HDPE composites, the effect of filler content was only marginal. Feeding wood particles and polymer as a dry-blend resulted in smaller particles compared to feeding the wood into the polymer melt. Also pre-heating the particles to prevent melt freezing caused stronger degradation. Particle degradation was reduced when 
polymer matrices with high MFR were used. The effect of screw speed and feed rate varied with filler content and screw design.

Since the compounding conditions on the laboratory scale are not comparable to industrial scale processes, industrial scale compounding conditions were mimicked on a laboratory scale TSE to study the effect of realistic processing. The degradation of radiata pine (Pinus radiata) wood fibres was compared to glass fibres since they are a standard filler in composite industry. Via dead-stop experiments and sampling along the screws the influence of screw design, screw speed, and feed rate was analysed. Process conditions related to low specific mechanical energy (SME) input and gentle screw design led to more gradual fibre length reduction along the screw. This effect was more distinct for initially longer glass fibres than for initially shorter wood fibres. Final fibre lengths at the end of the screws showed no dependence on process settings. A difference in final length due to screw design was more distinct for glass fibres than for wood fibres and was also represented in the composite properties. A more severe screw design resulted in lower composite strength for glass fibre compounds but not for wood fibre compounds. 


\section{Table of Contents}

Danksagung ..................................................................................... VII

Zusammenfassung ....................................................................... IX

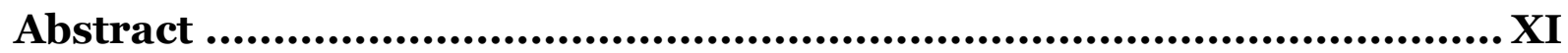

Table of Contents ............................................................................ XIII

Chapter 1 Introduction ......................................................................... 1

1.1 Wood Plastic Composites (WPC) ………………….......................................

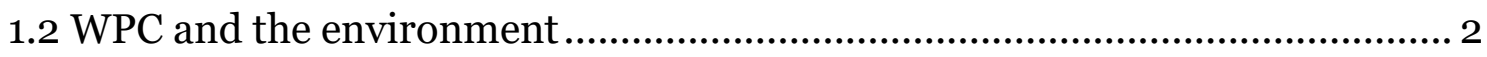

1.3 Wood as a filler material for polymers.......................................................... 2

1.4 The role of filler morphology in WPC ............................................................. 3

1.5 The changeability of filler morphology during processing ................................ 5

1.6 Characterisation of wood particle/fibre morphology ....................................... 6

1.7 Objectives and outline of the thesis ............................................................. 10

Chapter 2 Materials and Methods....................................................... 13

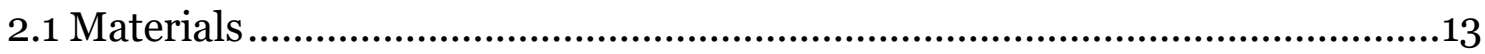

2.1.1 Particles ..................................................................................................13

2.1.2 Fibres ..........................................................................................13

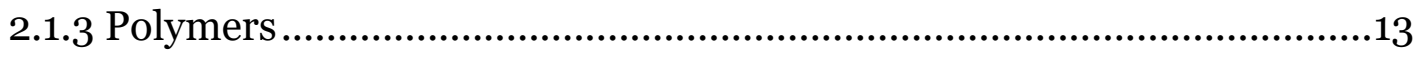

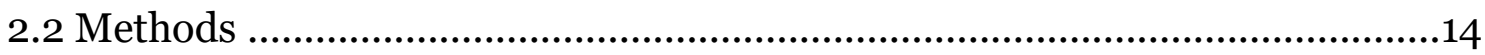

2.2.1 Batch compounding via internal mixer ....................................................14

2.2.2 Continuous compounding via twin-screw extruder.................................15

2.2.3 Dynamic particle/fibre analysis using QICPIC .....................................17

Chapter 3 Wood polymer composites and their contribution to cascading utilisation .................................................................. 19

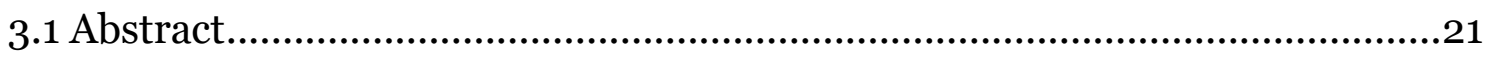

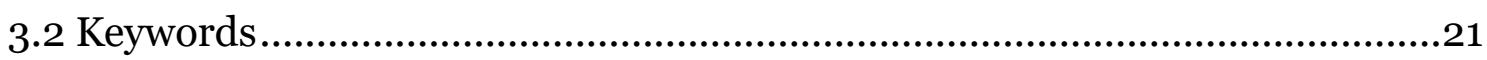

3.3 Introduction ......................................................................................... 22

3.4 General composition and fields of application............................................. 22

3.5 Contribution to cascading utilisation .............................................................24

3.5.1 Wood component .................................................................................. 24 


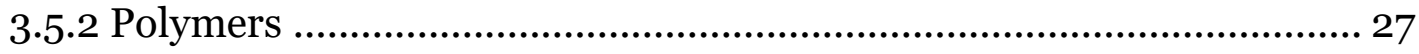

3.5.3 Recycling of WPC ................................................................ 28

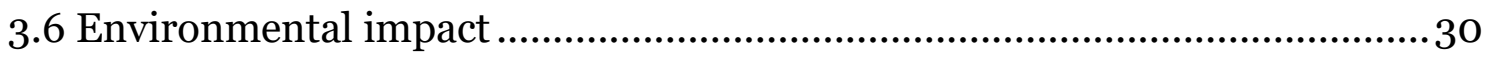

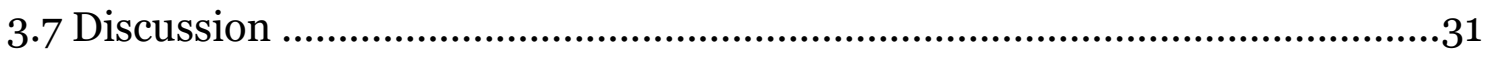

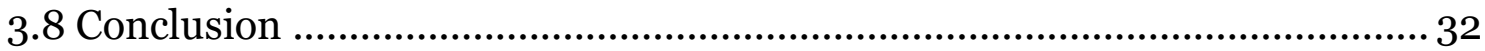

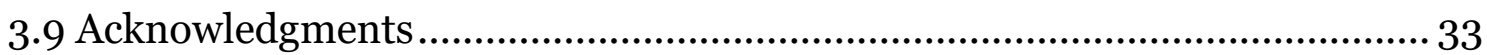

Chapter 4 Dynamic particle analysis for the evaluation of particle degradation during compounding of wood plastic composites ....... 35

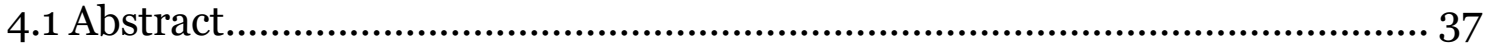

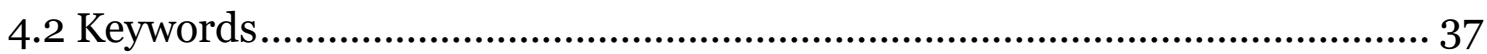

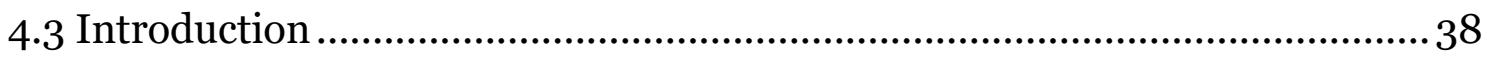

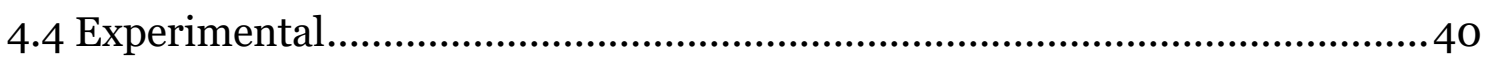

4.4.1 Materials and composite preparation..............................................40

4.4.2 Particle characterization .............................................................41

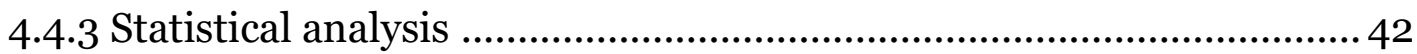

4.5 Results and Discussion ................................................................ 42

4.5.1 Sensitivity of types of quantity to represent influence of processing on particle size ............................................................ 42

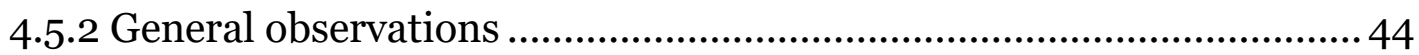

4.5.3 Effect of wood content ............................................................ 44

4.5.4 Effect of process conditions........................................................ 46

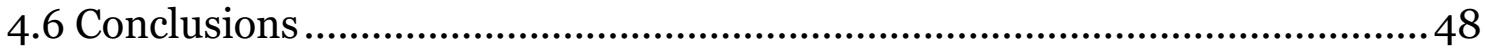

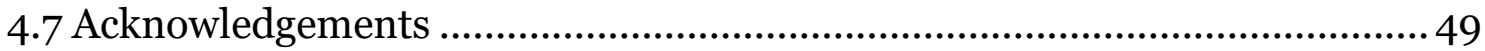

Chapter 5 Processing of wood plastic composites: the influence of feeding method and polymer melt flow rate on particle

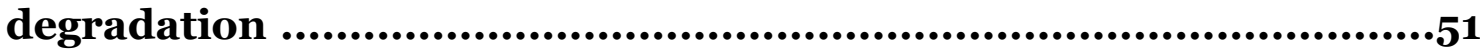

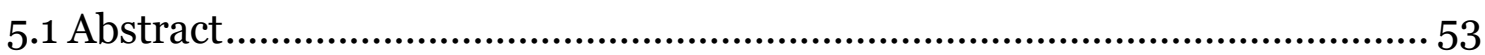

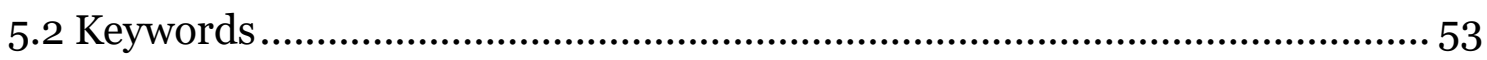

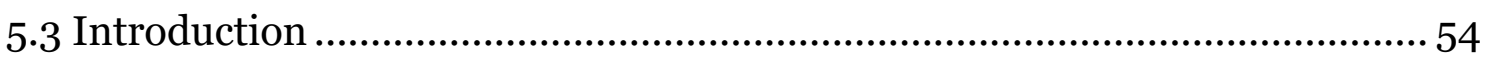

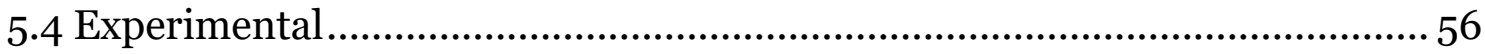

5.4.1 Wood particle production …........................................................... 56

5.4.2 Composite preparation .............................................................. 56

5.4.3 Particle extraction and characterization ...................................... 56

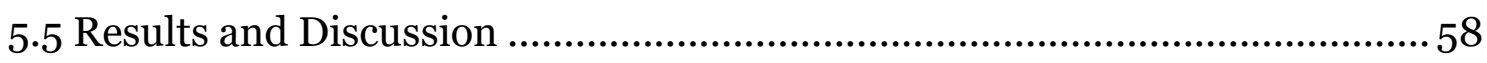

5.5 .1 Initial particle size and shape ..................................................... 58 
5.5.2 Effects of process conditions ..................................................... 58

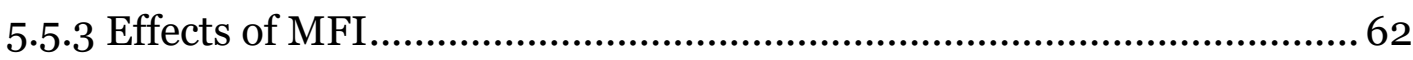

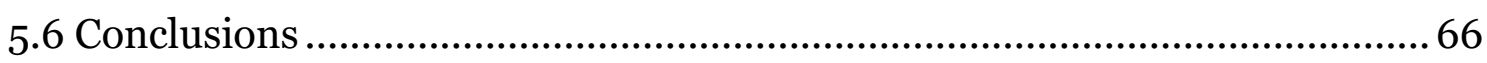

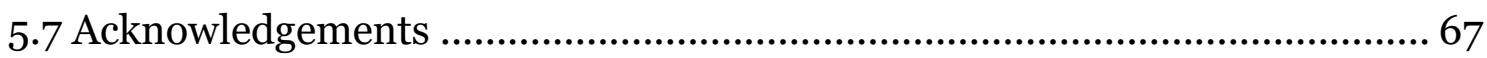

Chapter 6 Mimicking industrial scale twin-screw compounding of wood and glass fibres: effect of process conditions on fibre length...................................................................................69

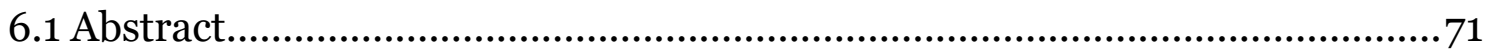

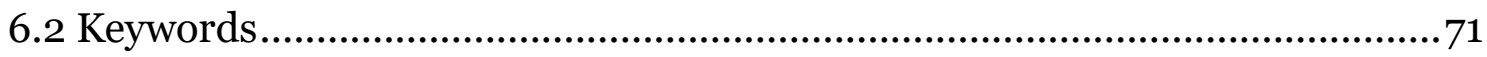

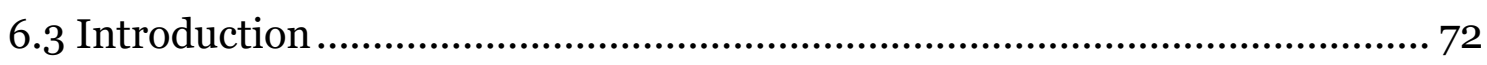

6.3.1 Specific mechanical energy (SME) .............................................. 72

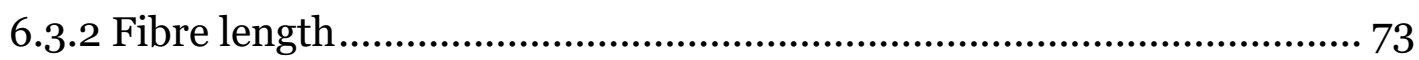

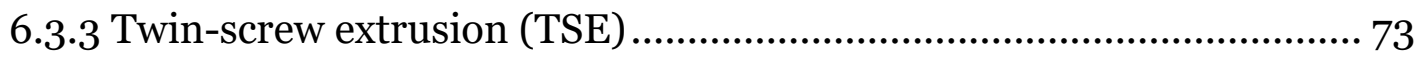

6.3.4 Project design ........................................................................ 74

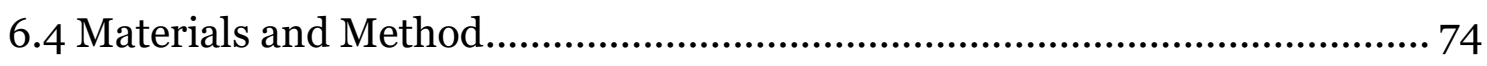

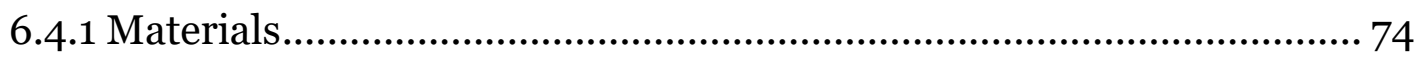

6.4.2 Composite preparation ............................................................. 75

6.4.3 Fibre extraction and characterisation ............................................ 76

6.4.4 Composite characterisation ..........................................................77

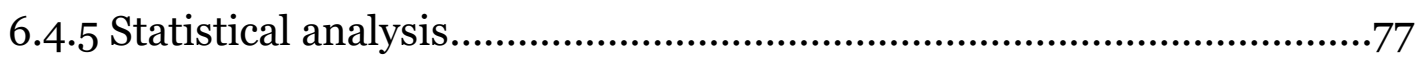

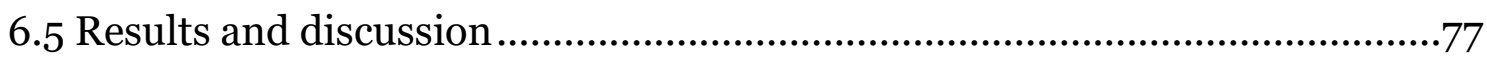

6.5.1 Initial fibre characteristics ...........................................................77

6.5.2 Effect of process conditions and SME on fibre length ....................... 78

6.5.3 Effect of screw design on fibre length degradation........................... 79

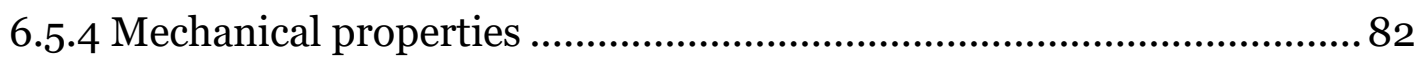

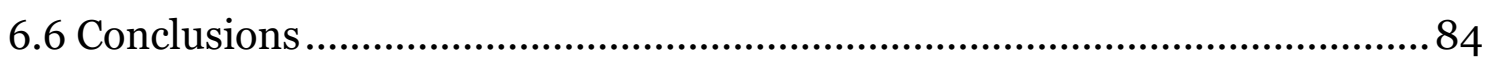

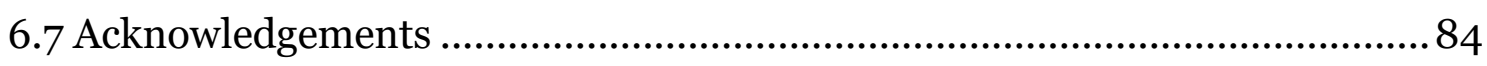

Chapter 7 Results and Discussion ............................................. 85

7.1 Method of filler morphology characterisation ......................................... 85

7.2 Comparability of internal mixer and TSE............................................. 87

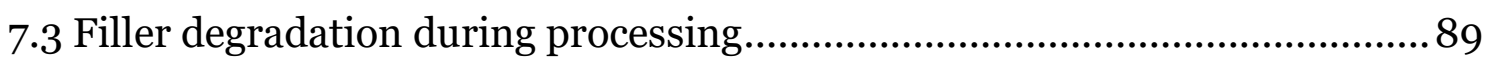

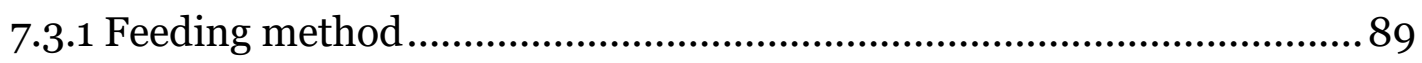

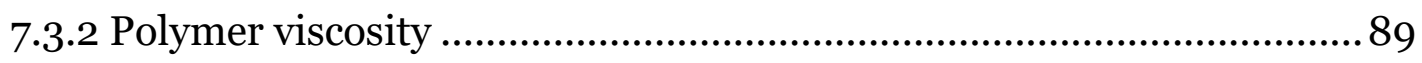

7.3.3 Interrelation of process parameters .............................................8 89 
7.3.4 Screw design ............................................................................91

7.3.5 Laboratory scale vs. industrial scale TSE ......................................91

7.3.6 Final filler size ........................................................................ 92

7.4 Alternative raw materials............................................................... 93

7.5 Prediction of process conditions and final fibre length............................. 94

7.6 Effect of filler size on composite properties ............................................ 95

Chapter 8 Conclusions \& Outlook ............................................... 97

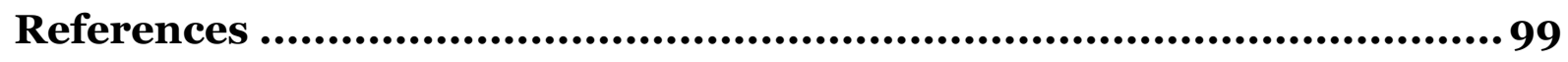

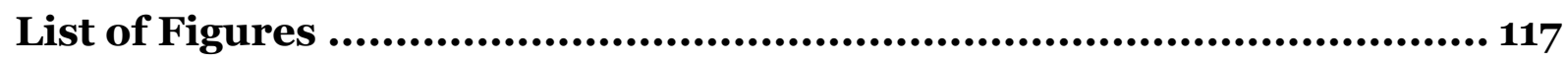

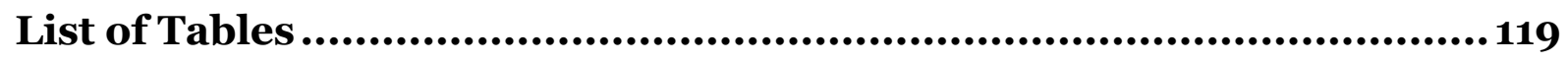

Appendix A.............................................................................. 121

Appendix B...........................................................................135 


\section{Chapter 1}

\section{Introduction}

\subsection{Wood Plastic Composites (WPC)}

Wood plastic composites (WPC) (or wood polymer composites) are a group of materials that combine wood as filler material with a polymeric matrix. According to the definition of nova-Institut, WPCs are composites that exhibit thermoplastic processing behaviour, that consist of variable amounts of wood, polymer and additives, and that can be processed with thermoplastic shaping processes like extrusion, injection moulding and compression moulding (Vogt et al. 2006). Other definitions include thermoset processing behaviour and any kind of plant fibre (Ashori 2008, Clemons 2002). In the present thesis, the focus lies on WPC containing wood in a thermoplastic matrix.

Adding a filler to a polymer is not new in the plastics industry. Traditionally, inorganic fillers as talc, calcium carbonate, mica, and glass and carbon fibres are used to alter the polymer performance (Ashori 2008, Clemons 2002). Compared to some of these conventional fillers, wood fillers have the advantage of being less expensive, having a low density and therefore reducing weight, being less abrasive to the processing equipment and reaching high possible filling levels (Ashori 2008, Clemons 2002). Filling levels of more than $80 \%$ are possible (Klyosov 2007). The most common thermoplastic polymers used for WPC are polyethylene (PE), polypropylene (PP), and polyvinyl chloride (PVC). Additives are used to modify the processing and composite performance. For example, coupling agents provide for a good adhesion between the polar wood filler and the non-polar matrix polymer to increase stress transfer and enhance the mechanical properties. Pigments and UV stabilizers alter the visual appearance. Other additives comprise lubricants, foaming agents and fungicides. Compared to neat plastics, WPC have higher stiffness and decreased thermal expansion. Compared to solid wood, moisture sorption is reduced and decelerated, and resistance to fungal decay and dimensional stability in the presence of moisture are improved (Klyosov 2007).

The main areas of application of WPC are deckings and automotive parts, followed by siding and fencing, technical applications, furniture, and consumer goods. In 2012, 26,000 t of WPC were produced in the EU and the production is expected to grow by approximately $10 \%$ per year (Carus et al. 2014). The main drivers responsible for the increase in market share are rising costs for neat plastics and environmental considerations (Rowell 2007). The application of WPC in the automotive industry is led by the need to find material alternatives to meet the recycling requirements specified in the EC directive for automotive parts (Ashori 
2008, Baillie 2004). On the decking market, the environmental impact of treating chemicals for solid wood and an effective marketing increased the builder acceptance of WPC (Rowell 2007) and promoted its higher durability and reduced maintenance in the public perception (Winandy et al. 2004).

\subsection{WPC and the environment}

Products made from renewable raw materials are perceived as "environmentally friendly" by the public (Ashori 2008). This is partly also true for WPC. Because WPC combines the renewable raw material "wood" with the (mainly) synthetic material "plastic", WPC products take up an intermediate position in the environmental concerns of consumers when compared to products made of solid wood or neat plastics (Osburg et al. 2015). To evaluate the environmental impact of WPC is complex since it is dependent on all of its very different components. Several life cycle assessments have been published comparing the environmental impact of using WPC to either using solid wood or neat plastics for specific applications and a lot of research is done on possible raw material alternatives for the wood and the polymer component of WPC (Teuber et al. 2016). Resource efficiency in the wood industry as well as in the plastics industry can be enhanced by using waste and by-products for the production of WPC. A detailed literature review on the possible contribution of WPC to cascading material utilisation and on its environmental impact was published by Teuber et al. (2016) and is reproduced in Chapter 3 of the present thesis.

\subsection{Wood as a filler material for polymers}

In WPC wood is used as a filler material to form a composite with polymers. But wood itself is also a composite material. It is mainly composed of cellulose, hemicelluloses and lignin that together form a complex network to build the wood cell walls. Dependent on wood species, the ratio of cell wall components can vary between $40-60 \%$ of cellulose, $6-35 \%$ of hemicelluloses and $18-41 \%$ of lignin (Grosser 1987, Lohmann 1987). To a small amount wood also contains extractives (1$3 \%$ ) and ash (01-0.5 \%) (Grosser 1987). Cellulose is a crystalline substance with a highly regular structure and is responsible for the stability and tensile strength of the wood cells together with the hemicelluloses (Clemons 2008, Grosser 1987). Hemicelluloses are amorphous substances consisting of branched molecules that connect the cellulosic regions of the cell wall with the lignin (Grosser 1987). Lignin is a highly complex molecule with a diverse structure that strongly depends on wood species. Lignin stiffens the cell wall, serves for the woods' compression strength and acts like glue between the wood cells (Rowell et al. 2005). The chemical components of wood contain a high amount of hydroxyl groups that determine the polar hydrophilic nature of the wood surface and make the use of coupling agents necessary when compounding wood with non-polar hydrophobic matrix polymers and seeking high composite strengths (Oksman Niska \& Sanadi 2008). The chosen matrix polymers for WPC often have processing temperatures below $200^{\circ} \mathrm{C}$ due to the low 
thermal stability of the wood components (Clemons 2002). Lignin starts to soften at approx. $165-175^{\circ} \mathrm{C}$ (Bodig \& Jayne 1993) and begins to decompose at about $200^{\circ} \mathrm{C}$ (Rowell \& LeVan-Green 2005). Thermal decomposition of hemicelluloses begins at approx. $150-175^{\circ} \mathrm{C}$ and is completed by approx. $273-280^{\circ} \mathrm{C}$ (Beall \& Eickner 1970).

Softwoods (spruce, pine, fir) and hardwoods (oak, maple) in the shape of particles, flour (fine particles) or fibres are used for WPC (Vogt et al. 2006). The term wood fibre thereby refers to the anatomical structural unit of a single wood cell, i.e. softwood tracheids or hardwood libriform fibres and fibre tracheids (Schirp \& Stender 2010). Fibres can be obtained from wood by different chemical or (thermo-)mechanical pulping and refining methods. Thereby, the lignin that connects the cells is either removed or softened to ease fibre separation (Schirp \& Stender 2010, Shmulsky \& Jones 2011). Fibre length can be 500-8000 $\mu \mathrm{m}$ and fibre diameter 15$45 \mu \mathrm{m}$ dependent on wood species. Fibre aspect ratio (ratio of length to diameter) can reach values of 10:1 to 130:1 (Clemons 2008, Klyosov 2007, Vogt et al. 2006, Wiedenhoeft \& Miller 2005).

In contrast to wood fibres, wood flour and particles have aspect ratios of 1:1 to 4:1 and comprise fibre bundles (Klyosov 2007, Vogt et al. 2006). They are obtained by grinding and screening of various scrap wood from solid wood processing, e.g. sawdust and shavings. Typically, wood particles with a size of $300-400 \mu \mathrm{m}$ are used for WPC but grades between 50-700 $\mu \mathrm{m}$ are also possible (Klyosov 2007).

Unfortunately, the terms wood fibre, wood flour and wood particle are often used interchangeably among experts and in the literature (Vogt et al. 2006). This might lead to misunderstandings, misinterpretation of data, and difficulties in the comparison of different studies, since the morphology of the wood filler influences different aspects of WPC processing and properties. In this thesis, the terms particle and fibre will be applied according to the descriptions given above. If the information given in the cited literature does not allow such a classification, the term used in the specific piece of literature will be adopted. The term filler will refer to any kind of shape.

\subsection{The role of filler morphology in WPC}

The morphology of the wood filler, i.e. its size and shape, plays an important role for the compounding process and the final composite properties. The bulk density of wood fillers for WPC can vary between 70 and $350 \mathrm{~kg} / \mathrm{m}^{3}$ (Schwendemann 2008). Particles, especially fine flour, thereby cover the upper end of this range (Klyosov 2007). Due to their free flowing behaviour, feeding and metering them to the compounding process can be realized with standard mechanical conveying and gravimetric feeding equipment of the plastics industry used for powders (Clemons 2008, Le Baillif \& Echtermeyer 2010, Schwendemann 2008). Fibres comprise the lower end of the range of bulk density and their fluffy nature and tendency to entangle makes feeding and metering more difficult (Ashori et al. 2011). Preceding pelletizing processes have recently been developed to facilitate their handling (Le Baillif \& Echtermeyer 2010, Warnes \& Fernyhough 2011). 
When a filler material is added to a polymer, the rheological properties of the composite melt differ to that of the neat polymer. Polymer melts are non-Newtonian fluids. Their viscosity decreases with increasing temperature and shear rate (Shaw 2012). This shear-thinning behaviour increases when a filler is added and the overall viscosity increases with increasing filler content (Hristov \& Vlachopoulos 2007, Li \& Wolcott 2005). The flow behaviour of the composite melt is a key parameter during processing and affects final product quality (Englund \& Wolcott 2008). The influence of filler size on WPC melt viscosity is not fully understood, yet. Some authors showed that composite viscosity decreased with increasing filler size (Hristov \& Vlachopoulos 2008, Li \& Wolcott 2005, Stark \& Berger 1997). Others found that lower viscosities were achieved with smaller sized fillers (Akdogan \& Vanli 2013, Zhang et al. 2007). Yuan et al. (2008) also stated the latter, although they were using the same wood filler material as Stark \& Berger (1997).

Adding wood particles to a polymer generally increases the polymer's stiffness and brittleness (Clemons 2002). The resulting composite properties thereby depend on the filler morphology. Several studies on particle filled WPC report an increase in tensile and flexural modulus, elongation at break, and unnotched impact strength with decreasing particle size (Akdogan \& Vanli 2013, Khalil et al. 2006, Leu et al. 2012, Nourbakhsh et al. 2010, Ratanawilai et al. 2014). This was explained with smaller sized fillers being easier to disperse in the matrix polymer and therefore resulting in more homogeneous materials without agglomerations acting as defects (Khalil et al. 2006, Ratanawilai et al. 2014, Schirp et al. 2014, Yam et al. 1990). However, other authors report improving mechanical properties with increasing particle size (Bouafif et al. 2009, Gozdecki et al. 2011a, Li 2012, Stark \& Berger 1997, Stark \& Rowlands 2003). Zaini et al. (1996) also found better mechanical properties for bigger particles but in addition, they related these findings to higher aspect ratios. Filler aspect ratio has a greater influence on composite mechanical properties than filler size (Gozdecki et al. 2011a, Nourbakhsh et al. 2010, Stark \& Rowlands 2003). Therefore the use of fibres in WPC results in better mechanical properties than the use of particles (Ashori et al. 2011, Stark 1999, Stark \& Rowlands 2003). Wood fibres can have a reinforcing effect in polymers provided that the fibres are well dispersed in the matrix and fibre/matrix-adhesion is good (Migneault et al. 2008). Reinforcement occurs when the fibres have a minimum (critical) length $l_{c}$ that allows stress transfer from the matrix to the fibre to result in maximum fibre loading. Below $l_{c}$ the reinforcing potential of the fibres is not fully exploited. Above $l_{c}$, the average stress $\bar{\sigma}_{f}$ in the fibre increases with increasing fibre length and enhances the reinforcement (Figure 1.1). Thereby, $l_{c}$ is dependent on fibre strength and diameter and fibre/matrix-adhesion (Sain \& Pervaiz 2008). For fibre reinforced WPC, improving mechanical properties have been observed for increasing fibre length and aspect ratio (Migneault et al. 2008, Migneault et al. 2009). Tiny fibres with high aspect ratios are recommended for the use in WPC as they are distributed more homogeneously in the matrix than long fibres and provide a larger specific surface area for stress transfer (Ashori 2008). 


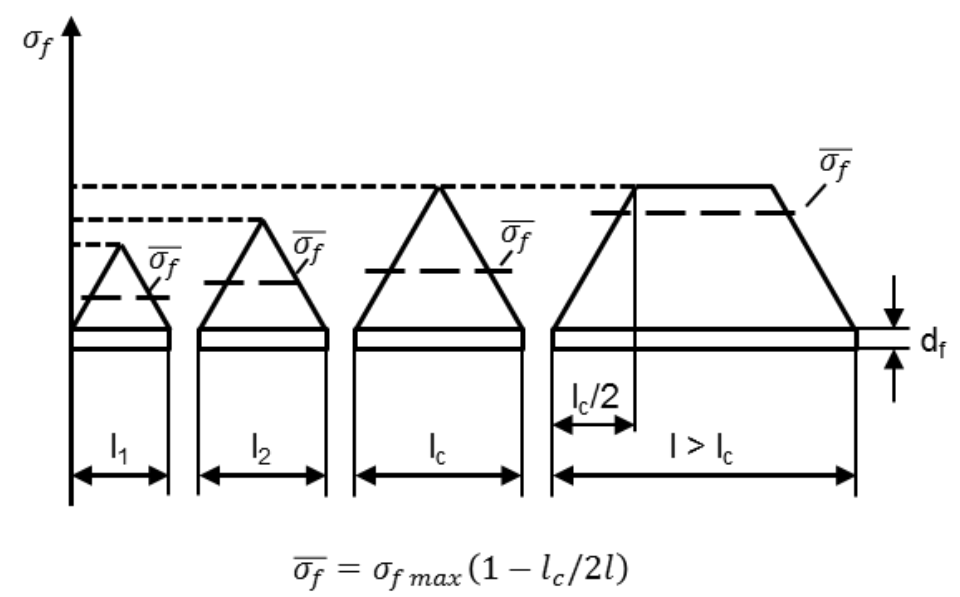

Figure 1.1: Relationship between fibre length $l$, critical fibre length $l_{c}$ and average stress in the fibre $\bar{\sigma}_{f}$ (modified from Ehrenstein, 2006).

Further WPC properties affected by wood filler morphology are related to dimensional stability and degradation. Water uptake and thickness swelling increase with increasing filler size (Chen et al. 2006, Khalil et al. 2006, Migneault et al. 2008, Migneault et al. 2009) and raise the sensitivity to fungal decay (Verhey \& Laks 2002). Mould shrinkage decreases up to a certain filler size (Stark \& Berger 1997) but thermal stability decreases with increasing filler size (Bouza et al. 2011).

\subsection{The changeability of filler morphology during processing}

Most of the studies analysing the influence of filler size and shape on the properties of WPC relate the composite properties to filler attributes that were determined before processing. But during processing the filler morphology undergoes severe changes. The compounding and shaping processes for WPC, e.g. extrusion, injection moulding and compression moulding, are processes of high temperature and shear. Although polymers with processing temperatures below $200^{\circ} \mathrm{C}$ are used for WPC, the bulk temperature of the material can locally be higher during processing (Beaugrand \& Berzin 2013). A long residence time at this high temperature leads to thermal degradation of wood cell wall components followed by a weakening of the cell wall and loss in mechanical strength resulting in a lower resistance of the filler against shear (Beaugrand \& Berzin 2013, Quijano-Solis et al. 2009). The main mechanisms causing subsequent filler breakage (valid for particles and fibres) are: (i) particleparticle interaction, (ii) particle-polymer interaction and (iii) interaction of the particles with the surface of the processing equipment (Beaugrand \& Berzin 2013, Berton et al. 2010, Fu et al. 1999). With increasing filler content the possibility of particle collision increases (Azizi \& Ghasemi 2009, Gallagher \& McDonald 2013). Filler size is reduced by shortening of particles and individual fibres and by dissociation of fibre bundles (Ville et al. 2013). The fibre-polymer interaction is related to viscous forces transferred from the polymer melt to the filler via shear. It is dependent on melt viscosity and the shear induced by the processing equipment 
(Berton et al. 2010, González-Sánchez \& González-Quesada 2015, Peltola et al. 2014). The type of process, the individual process settings as well as the material composition, e.g. wood content, wood species, use of coupling agents etc., influence the process conditions and thereby the rate of filler degradation (Gamon et al. 2013, Hristov \& Vlachopoulos 2007, Teuber et al. 2013a, Teuber et al. 2013b and Appendix $\mathrm{B}$ and A). The compounding step of WPC processing, especially when using extrusion, has been identified to cause the most filler degradation (Burgstaller 2007, Gamon et al. 2013, Teuber et al. 2013b and Appendix A). In extrusion, screw speed and feed rate are directly related to shear rate and residence time and have a strong influence on filler degradation (Beaugrand \& Berzin 2013, Berzin et al. 2014).

As it was explained previously, fillers having high aspect ratios are preferable when seeking a reinforcing effect in WPC. To maintain the initial benefits of the chosen filler material, the processing conditions have to be chosen in a way that minimizes filler degradation while providing the formation of a homogeneous compound.

\subsection{Characterisation of wood particle/fibre morphology}

Talking about the size and shape of particles and fibres, e.g. their length or diameter, is not trivial. The meaning of the terms size, length, diameter or shape depends on the physical principle used by the measurement equipment and on the method of measurement, i.e. the definition of the equivalent size parameter. Often the size of the objects in a sample of particles/fibres is not uniform but rather covers a range of sizes (Stark \& Berger 1997). This size distribution then is condensed to an average value representing the size of the entire sample (Le Moigne et al. 2011). More information on size distributions can be found in Chapter 4 of this thesis.

In wood industry a common method to determine the size of wood particles or flours is sieve fractionation (Plinke et al. 2012). Thereby, a sample of defined weight has to pass a cascade of shaking sieves with decreasing mesh size. The size distribution is obtained by weighting the residue on each sieve (Merkus 2009). The mesh size is the equivalent size parameter describing the particle size. It represents rather the particle diameter than the particle length and it does not give any information about the particle shape. Dry sieve fractionation is not suitable for the characterisation of fibres due to their tendency to entangle during shaking (Plinke et al. 2012). An equivalent classification method exists for pulp fibres in which they are diluted before they have to pass screens of different mesh size (TAPPI T 233 1995).

For the characterisation of wood pulp fibres light polarization also is a common method (Cöpür \& Makkonen 2007, Ferreira et al. 1999, Quijano-Solis et al. 2009, Stark 1999). Light polarization methods use the ability of pulp fibres to change the direction of polarized light. The fibres are passed in front of a polarized light source in aqueous solution. Due to their birefringence they generate an image on a sensor from which the fibre length is measured. Objects smaller than $200 \mu \mathrm{m}$ are excluded from the results (ISO/FDIS 16065-1 2013). 


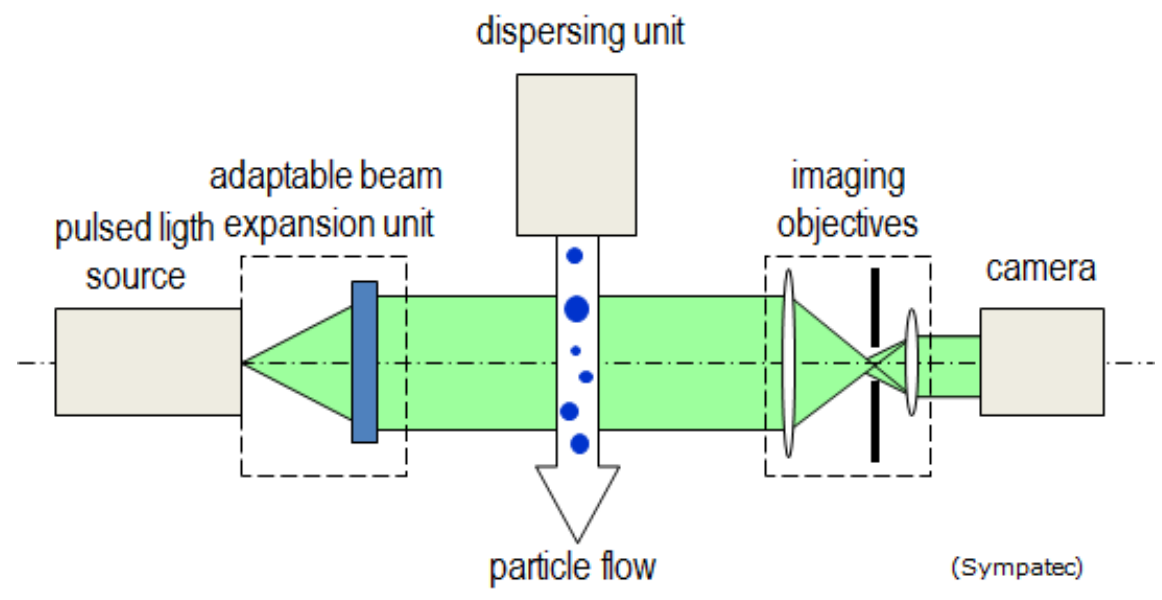

Figure 1.2: Schematic set-up of the measuring principle as realized in the QICPIC (Sympatec $\mathrm{GmbH}$ ).

In research, image analysis is often used as the sole method to determine the size and shape of particles and fibres or to verify and complement results derived from other methods. The image acquisition is realized by different microscopy techniques, e.g. light microscopy (Burgstaller 2007, Ferreira et al. 1999, Puglia et al. 2008), transmission light microscopy (Le Moigne et al. 2011), fluorescence microscopy (González-Sánchez \& González-Quesada 2015), scanning electron microscopy (Gomez Yepes \& Cremades 2011), by x-ray tomography (Alemdar et al. 2008) or by techniques involving scanners (Plinke et al. 2012, Schirp et al. 2014). These static methods require a good dispersion of the particles or fibres to avoid agglomeration and overlapping (Ferreira et al. 1999). The size and shape parameters are determined from the projected image of the individual objects either manually or automated (González-Sánchez \& González-Quesada 2015, Le Moigne et al. 2011). The methods to measure length, diameter and shape are diverse. A choice of common definitions for size and shape parameters is listed in Table 1.1.

Apart from static methods for image acquisition, dynamic methods, where images are taken from moving objects, are also available. A variety of devices using dynamic image analysis are commercially available for the characterisation of particulate and fibrous materials. Some examples are listed in Table 1.2. The basic set-up of these devices (Figure 1.2) comprises a dispersion unit which separates the particles from each other before they pass the measuring zone in random orientation. In the measuring zone the particles are illuminated by a pulsed light source to reduce motion blur. Their dark silhouettes are projected onto a camera sensor opposite to the light source. Dependent on the resolution of the camera objective, different size ranges can be covered in a measurement. The camera images are converted into binary images which are subsequently processed by a computer software to analyse the projected particle areas. The commercially available devices mainly differ in the possible size range and in the dispersion method. For free-flowing materials dry dispersion via a vibrating dispersion unit combined with passive (free fall) or active (compressed air) dispersion is possible. Wet dispersion is suitable for very fine 
Table 1.1: Examples of size parameters and shape factors to describe the morphology of particles and fibres (modified from DIN ISO 9276-6 2008 and WINDOX Manual 2010).

\begin{tabular}{|c|c|}
\hline & Size parameters \\
\hline $\begin{array}{l}\text { diameter of a circle of } \\
\text { equal projection area } \\
x_{A}\end{array}$ & 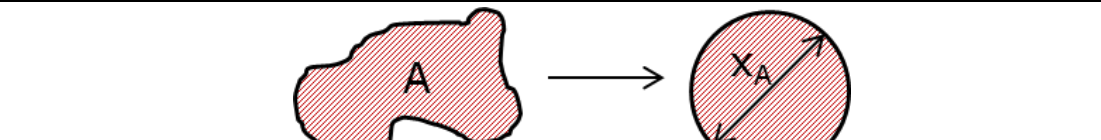 \\
\hline $\begin{array}{l}\text { diameter of a circle of } \\
\text { equal perimeter } \\
x_{P}\end{array}$ & \\
\hline $\begin{array}{l}\text { principal axes } a \text { and } b \\
\text { of Legendre ellipse of } \\
\text { inertia }\end{array}$ & \\
\hline & $\begin{array}{l}\text { An ellipse with the centre in the particle's centre of gravity and } \\
\text { with the same geometric moments (up to the } 2^{\text {nd }} \text { order) like the } \\
\text { original particle area. }\end{array}$ \\
\hline $\begin{array}{l}\text { Feret diameter } \\
x_{F \max }, x_{F \min }\end{array}$ & 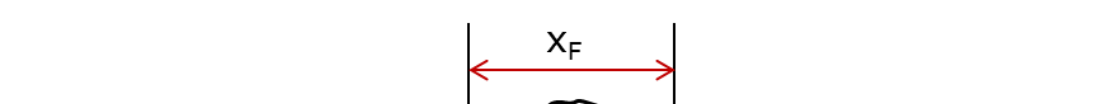 \\
\hline & minimum and maximum distance between two parallel tangents \\
\hline length $x_{F}$ & Feret diameter perpendicular to $x_{F \min }$ \\
\hline $\begin{array}{l}\text { geodesic length } x_{L G} \\
\text { breadth } x_{E}\end{array}$ & $\stackrel{\downarrow}{t} x_{E}$ \\
\hline & Shape factors \\
\hline aspect ratio & $\begin{array}{c}\text { aspect ratio }=x_{F \min } / x_{F \max } \\
\text { (also often defined as } x_{F \max } / x_{F \min } \text { ) }\end{array}$ \\
\hline elongation & elongation $=x_{E} / x_{L G}$ \\
\hline straightness & straightness $=x_{F \max } / x_{L G}$ \\
\hline circularity & $P_{\text {real }} \quad P_{\text {circle }}$ \\
\hline convexity & convexity $=A /(A+B)$ \\
\hline
\end{tabular}


Table 1.2: Examples of commercially available dynamic image analysis devices for the characterisation of particle size and shape.

\begin{tabular}{|c|c|c|c|}
\hline Model & Manufacturer & Dispersion & Size range $[\mu \mathrm{m}]$ \\
\hline Camsizer XT & Retsch Technology & $\begin{array}{l}\text { dry dispersion } \\
\text { (vibrating chute }+ \text { free } \\
\text { fall or compressed air) or } \\
\text { wet dispersion }\end{array}$ & $1-30,000$ \\
\hline Particle Insight & Micromeritics & wet dispersion & $3-300$ \\
\hline $\begin{array}{l}\text { ANALYSETTE } 28 \\
\text { ImageSizer }\end{array}$ & Fritsch & $\begin{array}{l}\text { dry dispersion } \\
\text { (vibrating chute }+ \text { free } \\
\text { fall) }\end{array}$ & 20-20,000 \\
\hline $\begin{array}{l}\text { ANALYSETTE } 28 \\
\text { ImageTec }\end{array}$ & Fritsch & wet dispersion & $1-2,800$ \\
\hline Sysmex FPIA 3000 & Malvern & wet dispersion & $0.8-300$ \\
\hline XPT-C & $\begin{array}{l}\text { PS Prozesstechnik } \\
\text { GmbH }\end{array}$ & wet dispersion & $\geq 1$ \\
\hline XPT-CP & $\begin{array}{l}\text { PS Prozesstechnik } \\
\text { GmbH }\end{array}$ & $\begin{array}{l}\text { dry dispersion } \\
\text { (vibrating chute }+ \text { free } \\
\text { fall) }\end{array}$ & $1-30,000$ \\
\hline QICPIC & Sympatec GmbH & $\begin{array}{l}\text { dry dispersion } \\
\text { (vibrating chute }+ \\
\text { compressed air) or } \\
\text { wet dispersion }\end{array}$ & $0.55-33,792$ \\
\hline
\end{tabular}

powders. Dynamic image analysis for the characterisation of particles is commonly applied in pharmaceutical industry (Arnold et al. 2011, Czajkowska et al. 2015, Fonteyne et al. 2012, Hamilton et al. 2012, Hamilton et al. 2013, Heinicke \& Schwartz 2006, Heinicke \& Schwartz 2007, Ho et al. 2012, Ho et al. 2009, Kaltenbrunner et al. 2012, Nalluri \& Kuentz 2010, Nalluri et al. 2010, Yu \& Hancock 2008) but also in mineral industry (Tysmans et al. 2007, Ulusoy \& Igathinathane 2014, Ulusoy \& Yekeler 2014), waste water treatment (Govoreanu et al. 2009), food industry (Gaiani et al. 2011, Xu \& Di Guida 2003), and additive manufacturing (Strondl et al. 2015). For the studies of the present work, the QICPIC was chosen for the analysis of wood particle and fibre size distributions. It was designed for characterising any kind of powders or suspensions in the given size range (www.sympatec.com). In research, the QICPIC has been used for e.g. pharmaceutical particles (Hamilton et al. 2012, Hamilton et al. 2013, Li et al. 2013), milk powders (Gaiani et al. 2011), soil samples (Sanetra 2011), polymer pellets (Treffer et al. 2014), and bast fibres (El-Sabbagh et al. 2014, Ramzy et al. 2014). 


\subsection{Objectives and outline of the thesis}

The present research was performed within the scope of the DFG Research Training Group 1703 "Resource Efficiency in Interorganizational Networks - Planning Methods to Utilize Renewable Resources", which aims at developing methods for an efficient utilisation of lignocellulosic biomass. The thesis is assigned to topic A.2 "Characterization of the by-products in the lumber industry concerning their suitability for high quality applications of innovative products”. WPC was chosen as the product of focus due to its recently growing market share.

Because WPC still is a relatively new product, it offers great potential to contribute to enhancing the efficient use of resources by using alternative raw materials, e.g. waste and by-products. To preserve the beneficial properties of potential raw materials that might result in well performing composites, e.g. high aspect ratio fillers, it has to be taken care that these benefits are preserved during processing. To keep changes in filler morphology to a minimum during processing, a thorough understanding of the mechanisms causing filler degradation is necessary. Since lignocellulosic filler materials possess a non-uniform appearance, parameters to describe the morphology have to be chosen in a way that allows comparison of results between different filler types. This requires a characterisation method that is suitable for particulate as well as fibrous materials.

Considering WPC to be an innovative product that could possibly contribute to enhancing resource efficiency, the objectives of this thesis are:

(i) to introduce and evaluate an alternative method for the characterisation of wood particles and fibres and

(ii) to apply this method to help for a better understanding of the interrelation of processing effects on filler degradation during compounding of WPC

Therefore, Chapter 3 of the thesis reviews and discusses recent research on possible raw material alternatives and recycling issues to answer the question of how WPC can contribute to cascading utilisation.

Chapter 4 introduces the use of dynamic particle analysis via QICPIC for the evaluation of wood particle degradation during compounding of WPC. Apart from the suitability of the method to distinguish the effects of different process conditions, basic issues concerning the representation of particle size distributions are discussed.

In Chapter 5 the effect of selected compounding process parameters, i.e. feeding method, filler content, shear rate, polymer type and polymer melt flow rate, on the degradation of particle size and shape are studied. To minimise the number of influencing factors, wood and polymer are compounded in an internal mixer without any additives and under well-defined and directly observable process conditions.

Chapter 6 presents a scale-up from laboratory scale to industrial scale compounding conditions. The processing of wood fibres is compared to the processing of glass fibres, which is standard in composite industry. A commercially available wood fibre 
product is compounded with a polymer matrix under the use of a coupling agent to result in a WPC product with commercially relevant properties. For compounding, a laboratory scale twin-screw extruder is used, but the process settings are chosen to mimic industrial scale extrusion conditions. The influence of screw speed, feed rate and screw design on wood fibre length degradation are analysed and compared to the degradation of glass fibre length.

Chapter 7 includes a comprehensive interpretation of the results from Chapters 3 to 6 for a conjoint discussion.

Each of the Chapters 3 to 6 is a reproduction of a study already published or intended to be published elsewhere. Since each publication was prepared together with co-authors, the contribution of each co-author is evaluated according to the authorship index of Hunt (1991) as modified in Himmel (2015). At the beginning of the respective chapters, authorship was consensually rated in four categories (planning \& design, executing \& data collection, data analysis \& interpretation, literary input) with o to 25 points so that the authorship index can be from o (no contribution) to 100 (closest possible involvement in categories) points in total. Coauthors reach at least 25 points. A detailed description of the nature and scope of each co-author's contribution is also given. 



\section{Chapter 2}

\section{Materials and Methods}

This chapter describes materials and methods which are generally used throughout the studies to point out similarities and differences between the procedures. Specific method descriptions, e.g. material properties testing, and details to process settings and material compositions are given in the respective chapters.

\subsection{Materials}

\subsubsection{Particles}

For the studies in Chapter 4 and Chapter 5 coarse particles of a limited size range were produced. Norway spruce (Picea abies) wood was ground with a cutting mill type FDR 112M/8A (SM200o) (Retsch GmbH, Germany) equipped with a $4 \mathrm{~mm}$ screen. The resulting particles were screened via sieve fractionation to a target size of 1-2 $\mathrm{mm}$. To remove fines sticking to the coarse particles due to electrostatic charging, the target fraction was washed in water between two sieves of mesh size $0.71 \mathrm{~mm}$ and $1.6 \mathrm{~mm}$. Before further processing, the particles were dried in a hot air oven to a moisture content of $<3 \%$.

\subsubsection{Fibres}

For the study in Chapter 6 commercially available wood and glass fibres were used. The wood fibres were thermomechanically pulped fibres made from radiata pine (Pinus radiata) and fixed with binding agents to form cubic pellets. They are commercially available under the trade name Woodforce (Sonae Industria, Portugal) and facilitate fibre feeding compared to loose fibres.

Glass fibres type E were supplied by PolyPacific LtD in the form of chopped strands. Both fibre types were dried in a hot air oven to a moisture content of $<1 \%$ before further processing.

\subsubsection{Polymers}

The different grades of polypropylene (PP) and high density polyethylene (HDPE) used in the studies are listed in Table 2.1. In Chapter 4 and Chapter 5 no coupling agent was used to keep the number of factors influencing particle degradation to a minimum. In Chapter 6 maleic anhydride grafted PP (MAPP) was used as a coupling agent to enhance fibre/matrix-adhesion and to achieve commercially relevant composite properties. 
Table 2.1: Polymer types used in the different studies.

\begin{tabular}{|c|c|c|c|}
\hline Polymer type & $\begin{array}{l}\text { trade name } \\
\text { (supplier) }\end{array}$ & $\begin{array}{l}\text { melt flow rate } \\
(\mathrm{g} / 10 \mathrm{~min})\end{array}$ & used in \\
\hline PP & $575 \mathrm{P}(\mathrm{SABIC})^{1}$ & $11^{\mathrm{a}}$ & Chapter 4 \& 5 \\
\hline PP & $5^{0} 5^{P}(\mathrm{SABIC})^{1}$ & $2^{\mathrm{a}}$ & Chapter 5 \\
\hline PP & $579 \mathrm{~S}(\mathrm{SABIC})^{1}$ & $47^{\mathrm{a}}$ & Chapter 5 \\
\hline HDPE & $\mathrm{CC}_{25}{ }^{2}(\mathrm{SABIC})^{1}$ & $2.2^{\mathrm{b}}$ & Chapter 5 \\
\hline HDPE & o863F (SABIC) ${ }^{1}$ & $8^{b}$ & Chapter 5 \\
\hline HDPE & $\mathrm{CC}_{3054}(\mathrm{SABIC})^{1}$ & $30^{\mathrm{b}}$ & Chapter 5 \\
\hline PP & $\begin{array}{l}\text { AR564 (Sumitomo } \\
\text { Chemical Co., Ltd.) }\end{array}$ & $25^{\mathrm{a}}$ & Chapter 6 \\
\hline MAPP & $\begin{array}{l}\text { G3015 (Eastman } \\
\text { Chemical Company }\end{array}$ & - & Chapter 6 \\
\hline
\end{tabular}

${ }^{1}$ Saudi Basic Industries Corporation; at $230^{\circ} \mathrm{C}$ and $2.16 \mathrm{~kg}$; ${ }^{\text {bat }} 190^{\circ} \mathrm{C}$ and $2.16 \mathrm{~kg}$

\subsection{Methods}

\subsubsection{Batch compounding via internal mixer}

In the study of Chapter 5 a laboratory scale internal batch mixer (HAAKE Rheomix OS 3000, Thermofisher Scientific) with Banbury rotors was used to compound wood particles with different polymers. The mixer consists of an eight-shaped mixing chamber with a hopper at the top and a vertical ram that pushes the material into contact with the rotors (Figure 2.1 A). When using Banbury rotors, the free volume of the mixer is $379 \mathrm{~cm}^{3}$. For temperature regulation the chamber walls can be heated or air-cooled.

Banbury rotors have a pear-shaped cross-section that is spiral around the rotor axis and forms interrupted screw flights in opposite directions (Figure 2.1 B) (Chanda \& Roy 2007, Manas-Zloczower 2009). The rotors are non-intermeshing and counterrotating at a ratio of speed of 2:3 to increase friction. In the large space between the rotors distributive mixing of the materials takes place. Dispersive mixing takes place in the narrow gap between the edge of the rotor wings and the chamber wall (Iannace et al. 2001). The geometry of the Banbury rotors features secondary flows at the rotor edges that disturb the regular flow pattern along the chamber wall and lead to backflows (Salahudeen et al. 2011). 

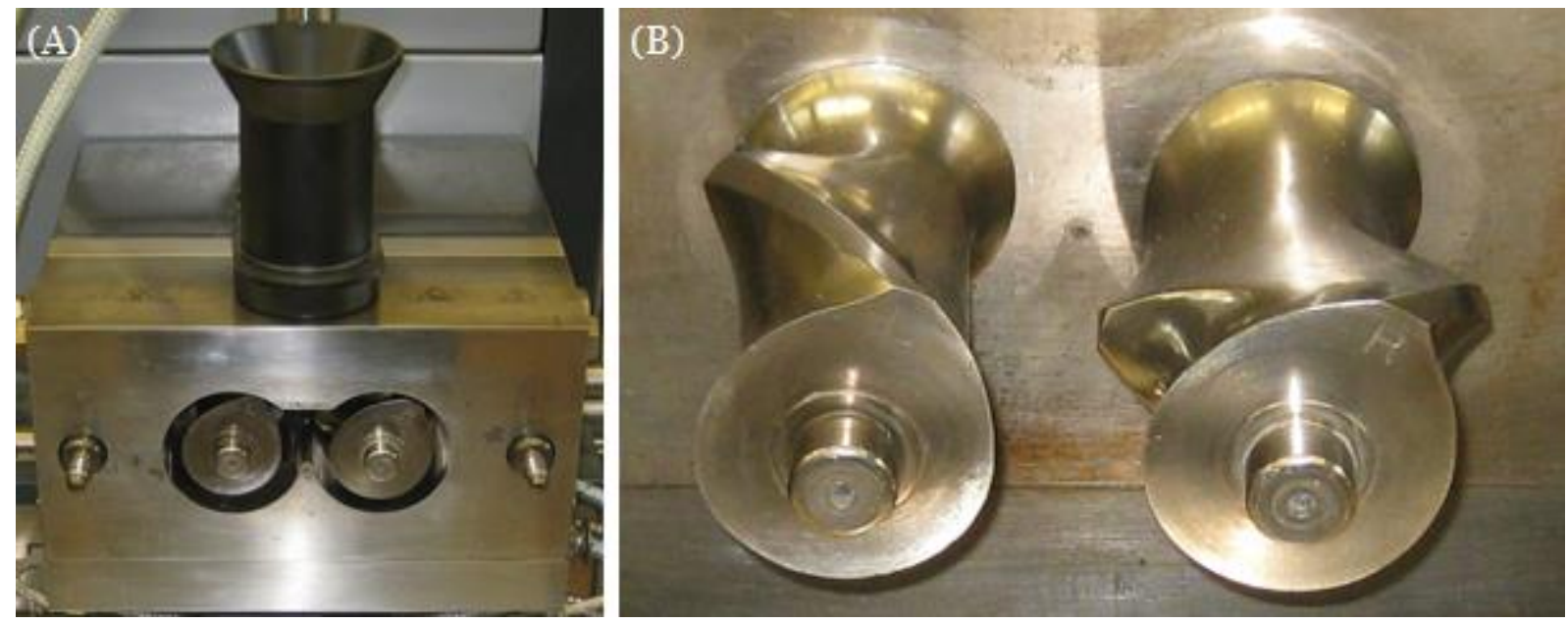

Figure 2.1: Isometric view of the internal batch mixer chamber with hopper (A) and enlarged view of the Banbury rotors (B).

\subsubsection{Continuous compounding via twin-screw extruder}

In the studies of Chapter 4 and Chapter 6 laboratory scale co-rotating intermeshing twin-screw extruders (TSE) (Table 2.2) were used to compound either wood particles or wood and glass fibres with different polymers. The two TSE had double-flighted screws with similar screw diameter and equal length to diameter ratio.

Co-rotating TSE are continuous dynamic mixers for the melting and mixing of thermoplastic polymers, blends, and composites. Barrel and screws of the TSE are segmented allowing for individual designing of different zones fulfilling different tasks, e.g. solids conveying, melting, melt conveying, mixing, degassing, building up pressure. Material transport is realised by positive displacement due to drag forces, i.e. the screw flights push the material into a forward direction. Good conveying efficiency requires the friction between the material and the barrel surface to be

Table 2.2: Extruders and process settings.

\begin{tabular}{|c|c|c|}
\hline & Chapter 4 & Chapter 6 \\
\hline extruder & $\begin{array}{l}\text { Leistritz MICRO27GL/GG 40D } \\
\text { co-rotating twin-screw }\end{array}$ & $\begin{array}{l}\text { LabTech }^{\mathrm{TM}} \text { LTE } 26-40 \\
\text { co-rotating twin-screw }\end{array}$ \\
\hline diameter (D) / length & $27 \mathrm{~mm} / 40 \mathrm{D}$ & $26 \mathrm{~mm} / 40 \mathrm{D}$ \\
\hline screw designs & $\begin{array}{l}\text { A: } 5 \text { kneading blocks }(5.45 \mathrm{D}) \\
\text { B: } 1 \text { kneading block }(6.91 \mathrm{D}) \\
\quad+1 \text { reverse element }\end{array}$ & $\begin{aligned} \text { A: } & 3 \text { kneading blocks } \\
& +2 \text { reverse elements }(5 \cdot 75 \mathrm{D}) \\
\text { B: } & 2 \text { kneading blocks } \\
& +1 \text { reverse element }(3.25 \mathrm{D})\end{aligned}$ \\
\hline screw speeds [rpm] & 80,160 & 200,400 \\
\hline feed rates $\left[\mathrm{kgh}^{-1}\right]$ & 4,8 & $6,12,24$ \\
\hline SDF & $0.05,0.025$ & $0.06,0.03$ \\
\hline
\end{tabular}

SDF: specific degree of filling (feed rate divided by screw speed) 


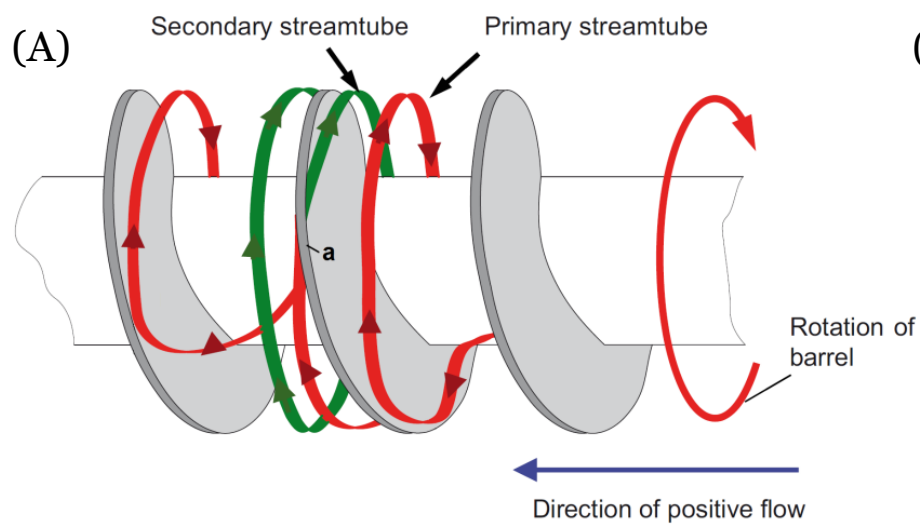

(B)

Figure 2.2: (A) Simplified principle of melt stream splitting in a stationary single screw with rotating barrel. a: Backward leakage melt flow of a primary "streamtube" across the clearance between screw flight tip and barrel wall results in formation of a secondary "streamtube". (B) Material transport in a double-flighted TSE (cross-sectional view) (modified from Kohlgrüber 2008).

higher than the friction between the material and the screw surface (Rauwendaal 2014). Distributive mixing of the composite melt occurs by splitting of the melt flow into partial flows due to backward leakage across the clearance between the flight tips and the barrel wall (Kohlgrüber 2008). A simplified explanation of this principle is given in Figure 2.2 A (for a stationary single screw and a rotating barrel). Distributive mixing is supported by the exchange of material between the partial flows due to the leakage flow and in the intermeshing zone of the TSE (Figure 2.2 B). Dispersive mixing occurs in the regions of high shear at the flight tips (Kohlgrüber 2008).

In Chapter 4 as well as in Chapter 6 different screw designs are used (Figure 4.1 and Figure 6.1). They differ in the length of conveying and mixing sections and partly contain backward-pumping elements (Table 2.2). Conveying elements transport the material along the screws in a figure eight shape, thereby transferring it from one screw channel into the other through the intermeshing zone. The mixing performance of conveying elements is only limited (Rauwendaal 2014). Kneading elements have a better mixing performance since they comprise a certain number of kneading discs that are offset by a certain angle. This offset interrupts the screw flight and increases distributive mixing as the individual tips separate the melt flow. Depending on the staggering angle, kneading elements can be forward conveying, neutral or reversal. The width of the discs determines the degree of dispersive mixing, i.e. with wider discs more material has to pass the high-shear region at the tip. Backwardpumping/reverse elements fill the upstream elements and form a melt seal, often used to separate different extruder zones. They induce axial mixing and create regions of high pressure (Rauwendaal 2014).

Process settings (screw speed, feed rate, and specific degree of filling ${ }^{1}$ (SDF)) differ in Chapter 4 and Chapter 6 (Table 2.2) since in Chapter 4 a stable laboratory scale

\footnotetext{
1 "Specific throughput" in Chapter 6.
} 
process is aimed at while in Chapter 6 the focus lies on mimicking industrial scale process conditions.

\subsubsection{Dynamic particle/fibre analysis using QICPIC}

For the analysis of filler degradation during compounding, particle and fibre size was measured using the dynamic image analysis device QICPIC (Sympatec GmbH, Germany). For a general measurement of free-flowing particulate material, the particles are pre-dispersed by a vibrating chute VIBRI which introduces them into the main dispersion unit RODOS. The main dispersion unit generates a laminar air jet with adjustable pressure in which the particles are dispersed by particle-particle collision, particle-equipment wall collision and centrifugal forces induced by velocity gradients. The particles pass the measuring plane in random orientation. From one side the particle stream is illuminated by a pulsed light source with an exposure time of $<1 \mathrm{~ns}$ to reduce motion blur. From the other side a high speed CMOS camera takes up to 450 pictures per second (Figure 1.2). The objective transmits only those light rays to the camera that are parallel to the optical axis. The greyscale pictures are converted to binary images with the projected particle areas in black and the background in white (QICPIC Manual 2009). The software WINDOX (Sympatec $\mathrm{GmbH}$, Germany) identifies the projected particle areas and then measures size parameters and calculates shape factors and size and shape distributions as specified by the operator. Different size and shape parameters are available (WINDOX Manual 2010).

In the set-up of the QICPIC at University of Göttingen, Section of Wood Biology \& Wood Products the camera has $1024 \times 1024$ pixels. Three objectives are available allowing resolutions of $20 \mu \mathrm{m}, 10 \mu \mathrm{m}$ and $5 \mu \mathrm{m}$. Hence, maximum particle lengths theoretically measurable are approx. $2 \mathrm{~cm}, 1 \mathrm{~cm}$ and $0.5 \mathrm{~cm}$, respectively. For all the
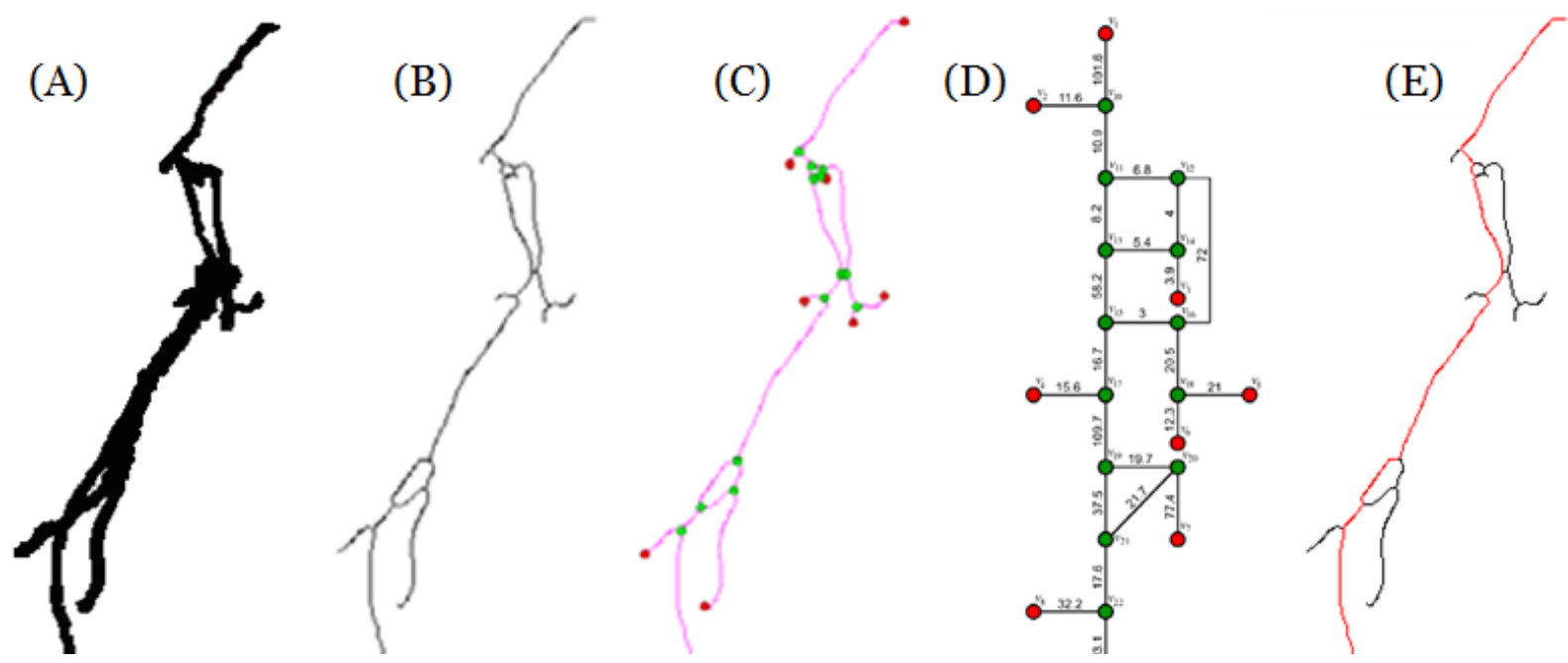

Figure 2.3: Graphical demonstration of the algorithm for the calculation of the geodetic length as realized in the WINDOX software: (A) initial projected area of fibre, (B) skeletonisation, $(C)$ identification of vertexes, (D) graph representing the fibre skeleton with segment lengths, $(E)$ red line represents base for length calculation (longest path between the most distant end points) (modified from Witt et al. 2007). 
measurements in this thesis (Chapter 4 to Chapter 6 and Appendix A and B) the camera frame rate was kept at $450 \mathrm{~Hz}$. The pressure in the dispersion unit RODOS was kept at 1 bar for free-flowing particles that were dosed with the vibrating chute. For non-free-flowing materials, e.g. wood and glass fibres in Chapter 6, it was not possible to use the vibrating chute due to the fibres agglomerating. Instead, the fibres were spread manually on a tray and sucked into the QICPIC via a flexible tube that was attached to the main dispersion unit. The pressure was set to 3 bar to provide sufficient vacuum to overcome the long distance of the tube and to provide dispersion of the fibres.

Throughout this thesis, the geodesic length was used to describe particles and fibres. It is thereby defined as the shortest path between the most distant endpoints of the projected area. For its calculation, the projected particle/fibre area is skeletonized, all end points and vertexes are detected and the length of all segments is measured before the length of the particle/fibre is calculated using graph theory (Figure 2.3). The corresponding diameter is calculated by dividing the projected area by the added length of all segments (Witt et al. 2007). 


\section{Chapter 3}

\section{Wood polymer composites and their contribution to cascading utilisation}

Laura Teubera,*,1 - Victoria-Sophie Osburgb,1 - Waldemar Toporowskib,1 - Holger Militz $^{\mathrm{a}, 1}$ - Andreas Krause $\mathrm{e}^{\mathrm{c}, 1}$

aFaculty of Forest Sciences and Forest Ecology, Dpt. of Wood Biology and Wood Products, University of Göttingen, Büsgenweg 4, D-37077 Göttingen, Germany

bFaculty of Economic Sciences, Chair of Retailing, University of Göttingen, Platz der Göttinger Sieben 3, D-37077 Göttingen, Germany

cInstitute of Mechanical Wood Technology, Dpt. of Wood Sciences, University of Hamburg, Leuschnerstraße 91c, D-21031 Hamburg, Germany

*Corresponding author, email: Laura.Teuber@forst.uni-goettingen.de

${ }^{1}$ DFG Research Training Group "Resource Efficiency in Interorganizational Networks"

Originally published in:

Journal of Cleaner Production, 2016, Vol. 110, pp. 9-15

DOI: 10.1016/j.jclepro.2015.04.009

Received: 30 July 2014 / Received in revised form: 2 March 2015 / Accepted: 5 April 2015 / Available online: 12 April 2015 


\section{Authorship}

Table 3.1: Contribution of co-authors (Himmel 2015 as modified from Hunt 1991)

\begin{tabular}{llllll}
\hline & $\begin{array}{l}\text { Teuber, } \\
\text { L. }\end{array}$ & $\begin{array}{l}\text { Osburg, } \\
\text { V.-S. }\end{array}$ & $\begin{array}{l}\text { Toporowski, } \\
\text { W. }\end{array}$ & $\begin{array}{l}\text { Militz, } \\
\text { H. }\end{array}$ & K. \\
\hline Planning \& Design & 25 & 25 & 15 & 15 & 15 \\
Executing \& Data Collection & 25 & 15 & O & O & O \\
Data Analysis \& Interpretation & 25 & 10 & 5 & 5 & 5 \\
Literary Input & 20 & 10 & 5 & 5 & 5 \\
$\sum$ & $\mathbf{9 5}$ & $\mathbf{6 0}$ & $\mathbf{2 5}$ & $\mathbf{2 5}$ & $\mathbf{2 5}$ \\
\hline
\end{tabular}

Laura Teuber defined the scope of the literature review together with VictoriaSophie Osburg, Waldemar Toporowski, Holger Militz and Andreas Krause. She performed the literature search together with Victoria-Sophie Osburg. In addition, she analysed and interpreted the literature and wrote the manuscript.

Victoria-Sophie Osburg defined the scope of the literature review together with Laura Teuber, Waldemar Toporowski, Holger Militz and Andreas Krause. She performed the literature search together with Laura Teuber. Furthermore, she supported literature interpretation and manuscript writing.

Waldemar Toporowski defined the scope of the literature review together with Laura Teuber, Victoria-Sophie Osburg, Holger Militz and Andreas Krause. He assisted in literature interpretation and edited the manuscript.

Holger Militz defined the scope of the literature review together with Laura Teuber, Victoria-Sophie Osburg, Waldemar Toporowski and Andreas Krause. He assisted in literature interpretation and edited the manuscript.

Andreas Krause defined the scope of the literature review together with Laura Teuber, Victoria-Sophie Osburg, Waldemar Toporowski and Holger Militz. He assisted in literature interpretation and edited the manuscript. 


\subsection{Abstract}

Due to a shortage of resources and a growing competition of land use, sustainable and efficient resource utilisation becomes increasingly important. The application and multiple, cascading utilisation of renewable resources is aimed at to ensure an allocation and future availability of resources. Wood polymer composites (WPCs) are a group of innovative materials consisting of mainly renewable resources. By means of summarizing recent research, it is shown how WPC can potentially contribute to an enhanced cascading utilisation. For the production of WPC, waste materials and by-products from wood and agricultural industry, e.g. offcuts, sawdust, residues from board manufacturing, pulping sludge, can serve as a raw material. Furthermore, the cited literature presents the use of recycled polymers and biopolymers as a potential alternative for the polymer component of WPC. By using biodegradable polymers, a fully biodegradable composite can be formed. In addition to using recycled materials and potentially being biodegradable, it is pointed out that WPC furthermore offers the possibility of being recycled itself, therefore being considered as a "green composite". Although the influence of contaminated waste streams and mixed filler and polymer types on the properties of WPC made with such recyclates is yet not fully understood and no collection systems exist for post-consumer WPC, in-house recycling on the production sites is identified as a promising option as it reduces production costs and enhances resource efficiency and cascading utilisation. On the basis of cited life cycle assessments, the eco friendliness of WPC is assessed resulting in the conclusion that WPC cannot compete with solid wood with respect to environmental impact but is an environmentally friendly alternative to neat plastics in several applications.

\subsection{Keywords}

wood plastic composite, green composite, cascading utilisation, resource efficiency, environmental impact, review 


\subsection{Introduction}

A continuously growing demand for resources makes a sustainable and efficient resource utilisation more and more important (Brown et al. 2011, Elliott 2006). Many existing materials rely on fossil fuels with a prospectively limited availability, which leads to an increasing competition for the scarce resources (Birol 2012). Therefore, an alternative raw material base and a more efficient production are required. As an alternative to materials which are based on fossil fuels, those materials made from renewable resources are promising. They help to ensure future resource allocation due to their renewable character. When comparing traditional, fossil fuel based materials with materials made from renewable resources, the latter show various environmental advantages. An increased usage of renewable resources can at least partially encounter diverse environmental problems humanity is faced with, e.g. climate change and biodiversity threats (Lenzen et al. 2012).

Nevertheless, efficient and sustainable resource utilisation is also required for renewable resources as a competition between different forms of land usage has emerged in recent years, e.g. cultivation of food crops, bioenergy crops or crops for technical applications (Godfray et al. 2010). When considering the realisation of (multiple) material usage of raw materials including their by-products, the principle of cascading utilisation becomes crucial. Developing materials based on by-products is promising, as by-products are often directly converted into energy nowadays (Carus et al. 2008).The strategy of efficient and sustainable resource utilisation is also pursued by green chemistry, an industrial sector that aims at optimising raw material utilisation by minimising waste creation (Ashori 2008). Dealing with waste is an important issue. Waste disposal laws, for example, force the wood processing industry to find applications for by-products and wastes (Migneault et al. 2014).

Wood polymer composites (WPCs) are a group of hybrid materials mainly consisting of renewable resources. They help to realise a more responsible and efficient method of resource utilisation as they contain wood waste materials and byproducts and like this are in line with the principle of cascading utilisation and resource efficiency. WPC is a merger of different components including synthetic ones (e.g. plastics). Therefore it has to be considered that the natural and synthetic components together affect the environmental impact of WPC. Little research has been done yet to investigate how the conflictive combination affects WPC eco friendliness. Nonetheless, this question is crucial for evaluating WPC in light of environmental issues which are increasingly gaining in importance in political discourses, corporate policies and customer requirements. Therefore, the purpose of the present article is to review the possible contribution of WPC to cascading utilisation and to identify factors influencing its eco friendliness.

\subsection{General composition and fields of application}

Wood plastic composites are a group of materials mainly consisting of wood, thermoplastic polymers and, to a small amount, additives. The wood content of the material may vary up to more than 80 \% (Klyosov 2007). Depending on the region of 
manufacture and on the availability, softwoods as well as hardwoods in the form of fibres, particles, or fine flour serve as raw material. The term wood fibre thereby generally corresponds to spindle-shaped wood cells with an aspect ratio (length to diameter ratio) of 10:1 to 25:1 (Klyosov 2007) which are separated by different pulping methods. Wood particles are fibre bundles or, as in the case of fine flour, cell wall fragments with an aspect ratio of 1:1 to 5:1 (Clemons 2008). The constitution of the wood component influences the physical and mechanical properties of the WPC (Clemons 2008). While fibres, having a greater aspect ratio (length/width ratio), enhance the tensile strength (Chen et al. 2006, Klyosov 2007, Stark 1999), particles are easier to dose to the production process and easier to disperse in the polymeric matrix and therefore result in more homogeneous materials (Shahi et al. 2012, Yam et al. 1990). In addition, the properties mentioned beforehand as well as visual properties of the WPC depend on the intrinsic properties of the wood species used (Clemons 2008).

As a thermoplastic matrix material polyvinyl chloride (PVC), polyethylene (PE), and polypropylene (PP) are commonly used for most applications (Ashori 2008, Carus et al. 2014). WPC combines the differing properties of wood and polymer. Wood is strongly hydrophilic and therefore prone to high moisture absorption and swelling rates resulting in decay and dimensional instability, which is disadvantageous especially for outdoor applications. By incorporating the wood into a hydrophobic polymer matrix, the moisture absorption and sensitivity to fungal decay and insect attack is reduced. Simultaneously, the wood enhances the stiffness, thermal stability and creep behaviour of the polymer (Michaud et al. 2009, Shahi et al. 2012). The properties of WPC strongly depend on the compatibility and interfacial adhesion between wood and polymer, which represents one of the main limitations as wood is strongly polar and most matrix polymers are nonpolar (Michaud et al. 2009). To overcome this drawback, particle/fibre surface modifications can be applied (Ashori 2008, Neto et al. 2014) and additives like compatibilisers and coupling agents are used (Adhikary et al. 2008, Kuo et al. 2009). Other additives to tailor the WPC's properties to its destined application comprise, among others, blowing agents for the production of foamed WPC, biocides, pigments to dye the WPC, UV stabilizers, flame retardants, and lubricants as processing aid (Ashori 2008, Satov 2008).

WPCs show a thermoplastic behaviour enabling processing on the same machines and with the same equipment as their unfilled matrix. The main processing methods for the production of WPC products are extrusion and injection moulding, which are both highly productive and economically advantageous (Sykacek et al. 2009), as well as compression moulding and thermoforming. In 2012 the production of WPC amounted to 1,100,000 $t$ in North America and 900,000 $t$ in China. In the EU 260 ,000 t of WPC were produced, $67 \%$ of it in the field of deckings and $24 \%$ in the automotive industry, followed by siding and fencing, technical applications, furniture, and consumer goods (Table 3.2) (Carus et al. 2014). The application in automotive industry comprises trim parts - e.g. door panels, dashboard, and cabin linings - as well as thermo-acoustic insulations (Ashori 2008). The production of WPC in the EU 
Table 3.2: Production of WPC in the European Union 2012 in tonnes (Carus et al. 2014).

\begin{tabular}{lr}
\hline Wood-Plastic Composites & 260,000 \\
\hline Decking & 174,000 \\
Automotive & 60,000 \\
Siding and Fencing & 16,000 \\
Technical Applications & 5,000 \\
Furniture & 2,500 \\
Consumer & 2,500 \\
\hline
\end{tabular}

is expected to grow by approximately $10 \%$ per year, especially in the fields of furniture, technical parts, and consumer goods (Carus et al. 2014).

Initially, wood fibres or particles have been used as cheap fillers for polymers to reduce production costs (Selke \& Wichman 2004). Nowadays, in the light of continuously rising polymer prices and growing ecological awareness of consumers, WPCs with their good and adjustable properties offer an alternative to traditional materials in many fields of application (Carus et al. 2008). Comprising two different materials, namely wood and polymer, WPC opens up possibilities to contribute to a sustainable use of raw materials and an enhanced cascading utilisation.

\subsection{Contribution to cascading utilisation}

\subsubsection{Wood component}

As a variety of types of wood particles or fibres can serve as raw material for WPC (Table 3.3), this material offers an opportunity to enhance the sustainability of the wood processing industry in the form of added value by optimizing the material use and minimizing and recycling wood wastes (Eshun et al. 2012, Migneault et al. 2014). Wood waste can be divided into post-industrial and post-consumer wood waste. While post-consumer wood waste may comprise sources like old newspapers, wood pallets, and building and construction residues, post-industrial wood waste includes sawdust, shavings, chips, milling residue, offcuts, trees, branches, and bark (Daian \& Ozarska 2009, Eshun et al. 2012, Winandy et al. 2004). Buyuksari et al. (2012), for example, successfully used compression wood flour from black pine to reinforce plastics, a type of wood which is preferably not used for commercial timber or pulp and paper due to unsuitable properties. Solid wood offcuts are predominantly free of contaminations whereas wood wastes from the production of derived timber products often contain adhesives, resins, coatings, etc., which might involve subsequent treatments or process adaptions before the introduction to WPC production (Daian \& Ozarska 2009).

Recycling and reprocessing residues from medium density fibre board (MDF) production produces a high amount of fine particles. Due to the increased fibre/particle surface more resins are needed to bond the fibres/particles. This makes them unsuitable for the production of boards (Daian \& Ozarska 2009). However, 
Table 3.3: Overview of exemplary alternative raw materials for the production of WPC.

\begin{tabular}{|c|c|c|c|}
\hline \multicolumn{2}{|l|}{ Wood component } & \multicolumn{2}{|c|}{ Polymer component } \\
\hline wood industry & agriculture & recycled polymer & biopolymer \\
\hline $\begin{array}{l}\text { old newspaper } \\
\text { wood pallet } \\
\text { building/construction } \\
\text { residues } \\
\text { sawdust, shavings, } \\
\text { chips, offcuts } \\
\text { milling residue } \\
\text { trees, branches, bark } \\
\text { reaction wood flour } \\
\text { wood based panel } \\
\text { residues } \\
\text { pulping sludge }\end{array}$ & $\begin{array}{l}\text { cereal straw } \\
\text { corn stalks } \\
\text { corn cob } \\
\text { rice straw } \\
\text { rice husks } \\
\text { sugarcane } \\
\text { bagasse } \\
\text { betel nut husks } \\
\text { soy stalk }\end{array}$ & $\begin{array}{l}\text { grocery bags } \\
\text { pallet wrap } \\
\text { PE bottles } \\
\text { food packaging } \\
\text { agricultural films }\end{array}$ & $\begin{array}{l}\text { TPS } \\
\text { (thermoplastic } \\
\text { starch } \\
\text { PLA (polylactic } \\
\text { acid) }\end{array}$ \\
\hline
\end{tabular}

for the production of WPC they turned out to be suitable as sawn MDF residues containing cured urea-formaldehyde resin applied to reinforce plastics resulted in WPC with a higher hydrophobicity and dimensional stability than control specimens made from virgin MDF fibres (Migneault et al. 2014).

Migneault et al. (2014) tested different wood wastes regarding their suitability to serve as a filler for WPC, namely sawmill sawdust, bark, sawdust from oriented strand boards (OSB) containing methylene diphenyl diisocyanate (MDI) adhesives, laminated veneer lumber (LVL) with phenol formaldehyde (PF) adhesives, deinking sludge, thermomechanical pulp (TMP) (raw material for MDF board production) sludge, and Kraft sludge from pulp and paper industry. They found out that the properties of the resulting WPCs differed significantly depending on the type of fibre used but they differed even more depending on the proportion of fibres. The modulus of elasticity (MOE) was higher for WPCs made from clean wood fibres than for those made from residues. In addition, the MOE rose with increasing wood or cellulose content. Kraft sludge turned out to be well suitable for the production of WPC as it led to partly better properties than birch and spruce wood flour, whereas bark from aspen and spruce and TMP sludge should be avoided. Deinking sludge led to promising results, as well. The authors concluded that contrary to the application of waste materials in other wood derived products, for WPC the contamination and ash content of the raw materials is not a limiting factor (Migneault et al. 2014). Although bark is a residue that occurs in high quantities in wood industry, its suitability for the production of WPC is questionable. Apart from Migneault et al. (2014), several other studies found the properties of bark filled polymer to be inferior to those of wood filled polymer, e.g. lower tensile and flexural properties (Safdari et al. 2011, Sewda \& Maiti 2007, Yemele et al. 2010), lower crystallinity and Izod impact strength (Sewda \& Maiti 2007), higher susceptibility to white and brown rot fungi (Moya-Villablanca et al. 2014). In addition, the bark seems to limit the performance of coupling agents 
like MAPP, when coupling agents are used to improve water uptake and thickness swelling (Najafi et al. 2008).

Soucy et al. (2014) also examined the use of sludge from pulping processes namely TMP, chemithermomechanical pulp (CTMP), and Kraft - for WPC applications. They differentiated between primary sludge (fine particles mechanically removed from waste water mainly containing cellulose, hemicelluloses, lignin, bark, and fillers from paper production) and secondary sludge (remaining solids in waste water after bacterial digestion) and tested the influence of different compositions of the sludge content on the properties of the WPC. Tensile and flexural MOE and strength increased with increasing sludge content, while maximum strain and rupture energy decreased. In consistency to the behaviour of traditional wood flour filled WPC, the stiffness, water swelling and water absorption increased and impact energy and elongation at break decreased with rising sludge content. Increasing the ratio of secondary sludge reduced the tensile strength and flexural properties. The authors draw the conclusion that the use of any pulping sludge will result in competitive properties of the WPC as long as the content of secondary sludge is below $10 \%$. As before, Kraft sludge delivered the best properties from all three types of pulping processes and therefore has a high potential for industrial application in WPC production (Soucy et al. 2014).

Not only wastes from wood processing industry can serve as a filler for WPC but also agricultural residues and by-products like cereal straw, corn stalks, rice straw, rice husks and sugarcane bagasse (Ashori 2008, Ashori \& Nourbakhsh 2009). The further use of such agro-wastes offers a great potential to enhance the economy of cultivation especially in developing countries (Sinha 1982). Neto et al. (2014), filled recycled PE with sugarcane bagasse fibres resulting in an increased tensile and flexural modulus of the material compared to the neat polymer. After acetylation of the fibres, the properties were even enhanced due to better surface compatibility (Neto et al. 2014). Table 3.4 gives more examples of recent research on agro-waste reinforced polymers in developed and developing countries.

Table 3.4: Research related to reinforcing polymers with agricultural by-products.

\begin{tabular}{ll}
\hline agricultural by-product & reference \\
\hline wheat straw & $\begin{array}{l}\text { Ahankari et al. 2011, Ashori \& Nourbakhsh 2009, Le Digabel } \\
\text { et al. 2004, Nyambo et al. 2010, Panthapulakkal \& Sain 2007 }\end{array}$ \\
corn stalk, corn cob & $\begin{array}{l}\text { Flandez et al. 2012, Nourbakhsh \& Ashori 2010, Nyambo et al. } \\
\text { 2010, Ogah \& Afiukwa 2014, Panthapulakkal \& Sain 2007 }\end{array}$ \\
rice straw, rice husks & $\begin{array}{l}\text { Ashori \& Nourbakhsh 2009, Bourne \& Bajwa 2007, Hassan et al. } \\
\text { 2011, Ismail et al. 2011, Ogah \& Afiukwa 2014, Petchwattana, } \\
\text { Covavisaruch \& Chanakul 2012, Wang et al. 2007, Zhao et al. } \\
\text { 2012 } \\
\text { sugarcane bagasse } \\
\text { betel nut husk }\end{array} \quad \begin{array}{l}\text { Yusriah et al. 2014 } \\
\text { soy stalk }\end{array}$ \\
\hline
\end{tabular}




\subsubsection{Polymers}

Apart from substituting the lignocellulosic component of WPC with waste and byproducts from forest and agricultural industries, also the polymeric side offers possibilities to contribute to enhanced resource efficiency and sustainability. As plastics comprise one of the major parts of municipal solid waste, a reduction of polymer use with respect to environmental issues is desirable (Nourbakhsh \& Ashori 2009). On the one hand, recycled polymers can fully or partially substitute virgin polymers in WPC. On the other hand, the use of biopolymers, especially bio-based polymers, instead of traditional fossil based polymers provides the means of decreasing the environmental impact of WPC (Michaud et al. 2009).

\section{Recycled polymers}

Several WPC manufacturers already use recycled polymers which they obtain, for example, from grocery bags and pallet wrap, sometimes even in combination with recycled wood-based materials (Winandy et al. 2004). Scientific research is engaged in investigating how the use of recycled polymers influences the properties of WPC. Nourbakhsh \& Ashori (2009) showed that WPC made from poplar fibres and recycled high density PE (HDPE) meets the minimum property requirements to compete with traditional WPC in some applications. Selke \& Wichman (2004) produced WPC from virgin HDPE and once used milk bottles made from the same material. The properties of the resulting compounds did not differ statistically. When adding $25 \%$ post-consumer polymer (including labels) to the recycled polymeric part of WPC, the composite still had good tensile properties. During recycling of post-consumer plastic bottles a strict separation of HDPE and PP cannot be assured. In WPC, a contamination of HDPE with PP does not influence the material properties markedly (Selke \& Wichman 2004). Ares et al. (2010) found out that adding equal amounts of recycled and virgin PP to PP-based WPC improved the tensile strength compared to WPC with only virgin PP while maintaining the melting and crystallization behaviour. The rheological properties changed only slightly so that processing via extrusion under the same conditions was still possible (Ares et al. 2010). Leu et al. (2012) tried to develop an optimized material composition regarding mechanical and physical properties for WPC made from recycled PP and recycled wood flour. They studied the influence of wood particle size, wood content, coupling agent concentration, and lubricant concentration.

When processing recycled plastics, not only mechanical and physical properties of the resulting products play a role. Also chemical requirements and safety certifications must be met. Especially when post-consumer plastics from food packaging are used for the production of WPC, the odour of the resulting material may limit the applicability. For low density PE (LDPE) and PE/EVA (ethylene vinyl acetate) films used beforehand in agricultural and industrial application, the emission of volatile compounds was greater for the reprocessed materials than for the virgin materials (Felix et al. 2013). These increased emissions result from thermooxidative degradation during repeated recycling. WPC exhibits a characteristic odour profile not only from the degradation of the polymer component but also from the 
lignocellulosic components. It is possible to (partially) mask unpleasant odours by adding additives or aromas (Felix et al. 2013).

\section{Biopolymers}

Biopolymers, either biobased and/or biodegradable, are an answer to decreasing fossil resources and to increasing amounts of plastic waste. Yet, the production costs for biobased polymers are higher than for fossil derived ones, but in the light of rising prices for fossil resources, the market for biopolymers is rapidly growing (Endres \& Siebert-Raths 2009). Especially in the field of short-lived consumer goods, the share of biopolymers increases as the use of durable polymers for those applications is less and less accepted (Agnantopoulou et al. 2012). Combining biopolymers with lignocellulosic fillers brings about several advantages. As wood is a natural, fully biodegradable polymer, manufacturing of WPCs with biodegradable polymers results in likewise biodegradable compounds. For polymers certified as compostable with respect to the withdrawn DIN 54900 (1997) standard, adding up to $49 \%$ of lignocellulosic material does not abate compostability (Sykacek et al. 2009). The incorporation of wood and other natural fibres can help to balance some property and processing limitations of biopolymers. Wood fibres increase the tensile strength of biopolymers, adding wood flour reduces shrink marks and warpages of products manufactured by injection moulding (Sykacek et al. 2009). Starch-based polymers exhibit an affinity to water absorption and poor mechanical properties resulting in a limited long-term stability. By adding wood flour to thermoplastic starch (TPS), Agnantopoulou et al. (2012) succeeded in increasing the tensile strength and MOE and decreasing the elongation at break. The improvement of mechanical properties results from the strong interfacial bonds which wood and TPS form due to their chemical similarity, making coupling agents unnecessary. With increasing wood content the moisture absorption of the composite decreases which enhances the longterm stability. As a result, TPS and wood form a WPC that is well suitable for application in non-humid environments, e.g. indoor applications, and at the same time reduces the environmental impact after disposal (Agnantopoulou et al. 2012).

\subsubsection{Recycling of WPC}

A "green composite" exhibits not only the possibilities of biodegradation and utilisation of recycled materials as raw material, e.g. wood and plastic wastes. A green composite also offers the possibility of being recycled itself (Shahi et al. 2012). WPC for recycling may originate either from post-consumer sources or from waste produced in-house during manufacturing. In-house recycling benefits the saving of resources and the reduction of production costs. Petchwattana, Covavisaruch \& Sanetuntikul (2012) evaluated the influence of multiple processing by extrusion on the properties of WPC made with PVC. As recycling material they used WPC scrap from the start-up process and profiles that did not pass the quality control. From testing different mixing ratios of recycled and virgin WPC they found a ratio of 30:70 recycled:virgin as most suitable regarding flexural properties, impact performance and reduction of material costs. Even after reprocessing seven times the mechanical 
properties stayed relatively unchanged, confirming that in-house recycling of WPC is an opportunity (Petchwattana, Covavisaruch \& Sanetuntikul 2012).

Shahi et al. (2012) investigated the mechanical and physical properties of HDPE filled with $60 \%$ wood flour after re-extrusion. The recycled WPC showed a higher flexural modulus but a lower flexural strength compared to the virgin WPC. The crystallinity did not change significantly. The melting temperature differed only marginally, making adaptions of process conditions unnecessary. The density of recycled WPC decreased compared to virgin WPC while the water absorption increased noticeably, although a reduction of water absorption was expected due to changes in wood particle size and wood composition (decomposition of hydrophilic components through high temperature) and a better dispersion of particles inside the matrix after processing twice (Shahi et al. 2012).

Beg \& Pickering (2008a, 2008b) found different results for WPC made from $50 \%$ Radiata pine kraft fibres. After two recycling steps tensile strength increased due to better fibre dispersion inside the matrix but during further processing tensile strength decreased again caused by fibre damage. As a general result, tensile and flexural strength and modulus, fibre length, and melt temperature decreased while failure strain, hardness, interfacial bonding density, crystallinity, and thermal stability increase with up to eight recycling steps (Beg \& Pickering 2008a). Equilibrium moisture content, diffusion coefficient and thickness swelling decreased as well (Beg \& Pickering 2008b).

Up to now, the recyclability of WPC is insufficiently researched and only few publications are available. One constraint in recycling WPC is the wood component which starts to degrade and emit volatiles on repeated processing at temperatures around $220^{\circ} \mathrm{C}$ (Shahi et al. 2012). Another constraint is the degradation of the polymer. Reprocessing induces thermal and oxidative degradation, i.e. chain scission and decrease of molecular weight (Beg \& Pickering 2008a, Englund \& Villechevrolle 2011, Petchwattana, Covavisaruch \& Sanetuntikul 2012). A thereof resulting change of the viscous behaviour may require modifications of further manufacturing processes.

Englund \& Villechevrolle (2011) investigated the influence of polymer blends on the mechanical and physical properties of WPC, showing that the properties rather depend on the composition of the blend than on the fact of using a blend. Nevertheless, the influence of WPC composition, e.g. wood/fibre type, polymer type, mixing ratio of wood, polymer and WPC types, on the recyclability of WPC is not sufficiently investigated yet. The great variability of WPC compositions in the waste stream, especially of post-consumer WPC, complicates recycling and necessitates the development of collection and in-line monitoring systems on the part of recyclers and manufacturers (Winandy et al. 2004). The composition of the recycled WPC predominantly in-grade or as a mixture containing different types of polymers, wood, etc. - will determine if it is suitable as a base for high quality products or applications requiring only lower qualities. 


\subsection{Environmental impact}

When evaluating the environmental impact of a composite material, it has to compete with at least one of its pure constituents. In the case of WPC and depending on the application, solid wood and neat plastics are the competitors. For the decking market a growth of WPC deckings over solid wood deckings was predicted in consequence of customers perceiving WPC as being more durable and of low maintenance, and of a restricted use of timber treated with chromated copper arsenate (CCA) (Winandy et al. 2004). To substitute CCA, an alkaline copper quaternary treatment (ACQ) is used. Bolin \& Smith (2011) conducted a life cycle assessment (LCA) to quantify and compare the environmental impact of decking made from ACQ treated timber and from WPC. The WPC was made from $50 \%$ recycled wood fibre and recycled and virgin HDPE (25\% each). Although WPC producers market their products as environmentally friendlier than treated timber (Winandy et al. 2004), the LCA showed that the use of WPC has a higher environmental impact, for example three times more greenhouse gas emissions and 8.5 times higher total energy use (Bolin \& Smith 2011).

Bergman et al. (2013) compared the environmental impact of California redwood (Sequoia sempervirens) deckings to deckings made from foamed PVC and WPC made from either virgin or recycled PE. This study, as well, attributed the lowest environmental burden to solid wood, while foamed PVC exhibits the highest environmental burden. However, the study indicated that producing WPC from recycled polymer has strong environmental benefits compared to using virgin polymers (Bergman et al. 2013). Mahalle et al. (2014) undertook an LCA on the laboratory scale production of WPC made from the biobased polymer polylactic acid (PLA) and MDF fibres compared to neat PP. Except for the eutrophication potential, the WPC achieved better results concerning the environmental impact compared to PP, especially with respect to energy use. On the part of the biocomposite, PLA transport represented the greatest share in environmental impact. When blending PLA with locally available TPS, the environmental burden of the biocomposite was even reduced (Mahalle et al. 2014).

To the best of our knowledge, no studies are available on how the origin of the wood component influences the environmental impact of WPC. Derreza-Greeven et al. (2013) conducted an LCA that compares deckings made of WPC with deckings made of solid wood from different origins, i.e. hard and soft wood from Germany, tropical wood from Southeast Asia (from illegal clear-cutting and sustainable forestry), and with deckings made from non-certified WPC pellets imported from China. The results indicate that the origin of the wood plays an important role in defining the environmental impact, especially when transport and land use are considered. Therefore a detailed study on the environmental impact of WPC depending on the origin of its wood component, including recycled wood and wood wastes, would be desirable (Derreza-Greeven et al. 2013).

Kim \& Song (2014) state that wood products made from wood wastes possess greater carbon storage capabilities than the amount of carbon discharged during their 
production. They evaluated the global warming potential of using wood waste either for the production of particle boards or the energy recovery via combined heat and power generation. The particle board production turned out to be environmentally more beneficial with regard to temporary carbon storage. From their findings the authors suggest to use wood waste of good quality for the production of particle boards while wood waste of low quality should be used for energy recovery (Kim \& Song 2014). Using low quality wood waste for producing WPC might also be an option and should be evaluated with respect to the environmental impact.

\subsection{Discussion}

The aim of cascading utilisation is to enhance the multiple material use of resources and by-products from production processes before finally converting them to energy. The recovery of wood wastes and by-products from wood industry provides a great secondary resource for producing new materials (Eshun et al. 2012). Reusing wood industry waste is not only advantageous for the industry by supplying a new fibre source and reducing production costs. It also benefits the environment by reducing the accumulation and discarding of wood waste and by recycling an industrial waste to high value products (Chavooshi et al. 2014, Soucy et al. 2014).

Considering the variety of wood wastes and by-products mentioned in section 3.5.1 utilised to produce WPC, WPC can be valued as a suitable intermediate step in the utilisation cascade of wood and agricultural industry. Nevertheless, it should be mentioned that the use of alternative raw materials for the production of WPC is not always without problems. Deinking sludge, for example, was presented as a possible resource for WPC. Deinking sludge typically contains heavy metals which might impose limitations on the industrial scale processing and the application of the final product with respect to environmental and health aspects. Other lignocellulosic sources might need special treatment to meet property requirements of the WPC. Especially in the case of enhancing compatibility of filler and matrix, chemical modification and grafting have to be evaluated regarding the environmental impact (Michaud et al. 2009). The environmental impact of using additives to tailor WPC properties has been excluded from this overview but should be included when it comes to evaluating the environmental profile of WPC. WPC can be fully eco-friendly only if all of its single components are eco-friendly.

In comparison to solid wood, WPC will loose with respect to environmental burden in many applications as wood itself has a neutral $\mathrm{CO}_{2}$ balance and the $\mathrm{CO}_{2}$ impact of processing wood is lower than of processing WPC (Bergman et al. 2013, Kim \& Song 2014, Mahalle et al. 2014). But in comparison to neat plastics WPC represents an ecofriendly alternative especially if recycling materials and biopolymers are used (Bergman et al. 2013, Mahalle et al. 2014). To produce fully biodegradable WPC is possible, if it is feasible for the specific application. However, it should be mentioned that the eco friendliness of biopolymers currently is subject to great controversy. Yates \& Barlow (2013) reviewed several LCAs concerning the environmental impact of biopolymers. They report that most LCAs concentrate on global warming potential (GWP) and non-renewable energy use (NREU) as impact categories and attest 
biopolymers to have a lower impact compared to petrochemical polymers. Some LCAs also include other categories like acidification potential (AP) and eutrophication potential (EP). Biopolymers show a higher impact in those categories due to the intensive agricultural land use (Yates \& Barlow 2013). Hottle et al. (2013) confirm those findings with their review of sustainability assessments of bio-based polymers. Another point of discussion are the discrepancies in data bases available for novel materials like biopolymers which make the reliability of LCAs questionable (Hermann et al. 2010, Hottle et al. 2013, Yates \& Barlow 2013).

As mentioned above, "green composites" are not only biodegradable and suitable for the manufacture from recycled products. Even more, they can be recycled themselves. The cited literature attests that from a material side of view WPC offers the possibility of recycling. Up to date, the amount of WPC waste is still low, though it is expected to be growing in future. But so far, there has been no economic incentive to realize recycling of post-consumer WPC. Furthermore, the factors influencing the resulting material properties are not yet understood. As there are multiple types of WPC on the market, research has to be conducted on how material properties of recycled WPC are affected by waste stream contaminations like mixed filler type or polymer type. Being a composite of natural and synthetic materials, WPC itself is not covered as a separate material by waste disposal or recycling regulations. The German Waste Wood Ordinance (Altholzverordnung, Stand 24.2.2012), for example, treats WPC as "waste wood" only if it contains more than $50 \%$ by mass of wood. Injection moulded parts mostly containing less than $50 \%$ of wood are not covered. Therefore it has to be checked how a nationwide collection system could be designed and implemented and if classification systems depending for example on filler type or polymer type are necessary.

In contrast, in-house recycling on-site of the WPC production plants definitely is an option already performed by several producers as waste streams are easy to monitor. It reduces production costs and helps to enhance a sustainable resource utilisation.

\subsection{Conclusion}

Due to a continuously growing resource demand sustainable and efficient utilisation of resources comes into focus in many sectors. In the wood and agricultural industry the goal is to increase material recycling of wastes and by-products before feeding them to energy recovery systems. The present review illustrated the role WPC could possibly play in the utilisation cascade of wood industry under consideration of environmental issues. The cited literature on current research showed that a variety of wood wastes and by-products could serve as raw materials for WPC. Also on the polymer component side a utilisation of recycled materials as well as biopolymers is feasible. When using biodegradable polymers, the production of a fully biodegradable composite is possible.

From a material point of view, WPC offers the opportunity of being recycled itself but nationwide recycling systems are still missing. Although it cannot compete with solid wood in terms of environmental impact, WPC represents an eco-friendly alternative to neat plastics by enhancing efficient resource utilisation. 


\subsection{Acknowledgments}

This research was supported by the German Research Foundation (DFG), grant GRK 1703/1 for the Research Training Group "Resource Efficiency in Interorganizational Networks - Planning Methods to Utilize Renewable Resources" 



\section{Chapter 4 \\ Dynamic particle analysis for the evaluation of particle degradation during compounding of wood plastic composites}

Laura Teuber ${ }^{\mathrm{a}, *, 1}$ - Holger Militz ${ }^{\mathrm{a}, 1}$ - Andreas Krause $\mathrm{b}^{\mathrm{b}} \mathrm{1}$

aFaculty of Forest Sciences and Forest Ecology, Dpt. of Wood Biology and Wood Products, University of Göttingen, Büsgenweg 4, D-37077 Göttingen, Germany DFG Research Training Group "Resource Efficiency in Interorganizational Networks" cInstitute of Mechanical Wood Technology, Dpt. of Wood Sciences, University of Hamburg, Leuschnerstraße 91c, D-21031 Hamburg, Germany

*Corresponding author, email: Laura.Teuber@forst.uni-goettingen.de

${ }^{1}$ DFG Research Training Group "Resource Efficiency in Interorganizational Networks"

Originally published in:

Composites Part A: Applied Science and Manufacturing, 2016, Vol. 84, pp. 464-471 DOI: 10.1016/j.compositesa.2016.02.028

Received: 26 September 2015 / Received in revised form: 22 February 2016 / Accepted: 24 February 2016 / Available online: 3 March 2016 


\section{Authorship}

Table 4.1: Contribution of co-authors (Himmel 2015 as modified from Hunt 1991)

\begin{tabular}{lccc}
\hline & Teuber, L. & Militz, H. & Krause, A. \\
\hline Planning \& Design & 25 & 10 & 15 \\
Executing \& Data Collection & 25 & 0 & 5 \\
Data Analysis \& Interpretation & 25 & 10 & 15 \\
Literary Input & 25 & 5 & 10 \\
$\sum$ & $\mathbf{1 0 0}$ & $\mathbf{2 5}$ & $\mathbf{4 5}$ \\
\hline
\end{tabular}

Laura Teuber prepared the experimental design together with Holger Militz and Andreas Krause. She performed data collection, analysis and interpretation of data and wrote the manuscript.

Holger Militz prepared the experimental design together with Laura Teuber and Andreas Krause. He supported data interpretation and edited the manuscript.

Andreas Krause prepared the experimental design together with Laura Teuber and Holger Militz. He assisted in data collection and supported data interpretation and manuscript writing. 


\subsection{Abstract}

A dynamic image analysis method was applied for particle characterisation to study the effect of different process conditions during twin-screw compounding of WPC. The use of distributions based on different types of quantity is discussed with respect to their sensitivity to reveal the effects of different process conditions on particle degradation. Distributions based on length proved to be most suitable to represent the initially broad length distribution of the particles before processing. Sensitivity was strong enough to show differences in particle size after processing depending on process conditions. Particle size was reduced by more than $97 \%$ compared to initial size. Degradation was stronger with increasing wood content and when the screw design contained more mixing elements. The effect of screw speed and feed rate was dependent on filler content and screw design.

\subsection{Keywords}

A. Wood fibres, A. Wood, B. Microstructures, E. Extrusion 


\subsection{Introduction}

In recent years, wood polymer composites (WPC) have gained in importance on the materials market. Their most important areas of application are deckings and automotive interior parts but also construction parts, furniture and consumer goods (Carus et al. 2014). WPC are made of thermoplastic polymers, wood-derived fillers and additives (e.g. coupling agents, UV stabilizers). Due to their thermoplastic nature they can be processed on the same machines as neat thermoplastic materials (Balasuriya et al. 2001). The most common commercially used filler material for WPC is wood flour (Stark \& Berger 1997) but also wood fibres are applied (Carus et al. 2008). The size and shape of the wood filler is an important factor influencing the properties of WPC (Clemons 2008). Commercial wood flours often contain a broad distribution of particle sizes (Stark \& Berger 1997). Particles of bigger size are rarely used as they can lead to inhomogeneous materials and difficulties during processing, especially injection moulding (Gozdecki et al. 2011a). Research has focused on the effect of particle size and shape on the properties of WPC, e.g. rheology (Azizi \& Ghasemi 2009, Kumari et al. 2007, Stark \& Berger 1997), mechanical properties (Bouafif et al. 2009, Fasihi \& Garmabi 2011, Gozdecki et al. 2011a, Leu et al. 2012, Nourbakhsh et al. 2010, Stark 1999, Stark \& Rowlands 2003), density (Chen et al. 2006, Leu et al. 2012, Stark \& Berger 1997), moisture absorption and swelling (Leu et al. 2012, Steckel et al. 2007), and fungal decay (Verhey \& Laks 2002). Some authors state that increasing particle size increases mechanical properties (Bouafif et al. 2009). Others found out that smaller particles improve mechanical properties (Nourbakhsh et al. 2010) like tensile and flexural strength (Leu et al. 2012), and reduce moisture absorption and thickness swelling (Leu et al. 2012). Decreasing particle size also enlarges the specific filler surface influencing the effectiveness of e.g. coupling agents (Krause \& Krause 2012). In addition, very fine particles tend to form agglomerates when insufficiently dispersed, which can lead to failure due to stress concentration effects (Ramani et al. 1995). Some authors indicate that particle aspect ratio (ratio of length to diameter) is more important than particle size (Migneault et al. 2008, Stark \& Rowlands 2003). Therefore, wood fibres better enhance the mechanical properties than wood flour (Gozdecki et al. 2011b).

All these studies have in common that particle size and shape were analysed before compounding and the WPC properties were related to the initial filler morphology. However, the filler morphology is prone to changes during processing due to particlepolymer interaction, particle-particle interaction and interaction of particles with the processing equipment surface (Berton et al. 2010, Fu et al. 1999). Gamon et al. (2013), for example, showed that a low screw speed and feed rate during twin-screw extrusion degrade the length of miscanthus fibre bundles while Beaugrand \& Berzin (2013) showed that an increasing screw speed increases fibre damage of hemp fibres. The WPC properties therefore should be related to the morphology of the filler after processing.

The methods to determine particle or fibre size distribution are diverse. A common method in wood industry (Plinke et al. 2012) is sieve fractionation where a particle 
sample of defined weight has to pass a cascade of shaking sieves with decreasing mesh sizes. The size distribution is derived from the weight fractions of residues on the sieves (Merkus 2009). The descriptive parameter for the particle size, the mesh size, corresponds to the particle diameter rather than to the particle length and no information on particle shape is gained. Sieve fractionation is only suitable for particles and not for fibres because fibres tend to agglomerate during shaking (Plinke et al. 2012). In addition to sieve fractionation (Khalil et al. 2006, Kociszewski et al. 2012, Segerholm 2007, Stark \& Berger 1997) other methods applied in research to characterise particle/fibre size are light polarisation (Cöpür \& Makkonen 2007, Ferreira et al. 1999, Stark 1999), light scattering (Saarinen \& Muinonen 2001) and xray tomography (Alemdar et al. 2008). The definition of the term size thereby strongly depends on the physical principle and method of the measurement and should be clearly stated when presenting size distributions.

To receive good quality results, static techniques involving scanners (Plinke et al. 2012, Schirp et al. 2014) or microscopy (Burgstaller 2007, Ferreira et al. 1999, Gomez Yepes \& Cremades 2011, Puglia et al. 2008, Quijano-Solis et al. 2009) require a thorough sample preparation to ensure good particle/fibre dispersion and to avoid agglomeration and overlapping (Ferreira et al. 1999). Size and shape measurement follows either manually or automated (González-Sánchez \& González-Quesada 2015, Le Moigne et al. 2011). Manual methods are very time-consuming when seeking a statistically relevant sample size and they are strongly user-dependent. Sample sizes usually range from several hundreds to a few thousands. Le Moigne et al. (2011) compared in detail a manual and an automatic method for the fibre length measurement from optical transmission light microscopy. The manual method led to an underestimation of the proportion of short fibres because the human eye tended to select larger objects. But also automated methods sometimes exclude fines from the analysis and the upper size limit for fines is not consistent between different studies but varies between $75 \mu \mathrm{m}$ and $300 \mu \mathrm{m}$ (Ferreira et al. 1999). Excluding fines might impose problems on understanding processing effects and composite properties due to the role of fines mentioned above (Le Moigne et al. 2011).

When analysing particle size measurements, the size distributions are often condensed to only one representing parameter, e.g. average particle length. Depending on the type of distribution and on the definition of "average" length, the results may differ (Le Moigne et al. 2011). For symmetrical distributions the arithmetic mean, either number-weighted, length-weighted, or mass-weighted, is a good representative (ISO/FDIS 16065-1 2013). For non-symmetrical distributions the median (alternatively in combination with quartiles and deciles) might proof a better choice (Le Moigne et al. 2011). The median represents the particle length of the distribution where $50 \%$ of the particles are smaller and 50\% are larger. The type of quantity on which the distribution is based is also crucial. While a number-based length distribution uses the number of particles in a size class as the crucial quantity, the length-based length distribution uses the length of the fibres in a size class. Areabased and volume-based distributions are also possible (Leschonski 1984). When reducing a size distribution to only one parameter, a lot of information gets lost. For 
example, when examining the effect of different process conditions, factors influencing the upper or lower end of the particle size distribution might not be represented by changes in that parameter. Inceoglu et al. (2011) showed for glass fibres that mainly the long fibres are prone to degradation during processing. This was represented by a decrease in maximum fibre length while the change in mean length was only slight and the change in minimum length was even less.

The present study uses a time-efficient dynamic image analysis method to characterise the change in particle size when processing WPC. Coarse wood particles were compounded with polypropylene via twin-screw extrusion using different filler contents, screw speeds and feed rates. Subsequently, they were separated from the matrix via Soxhlet extraction and analysed with respect to their length and diameter to demonstrate the sensitivity of the particle size distribution when it is based on different types of quantity and when it is reduced to one representing parameter.

\subsection{Experimental}

\subsubsection{Materials and composite preparation}

Norway spruce (Picea abies) wood was ground with a cutting mill (FDR 112M/8A (SM 2000), Retsch GmbH, Germany) with an aperture size of $4 \mathrm{~mm}$. The resulting wood particles were fractionated via sieve separation using two sieves of $2 \mathrm{~mm}$ and 1 $\mathrm{mm}$ mesh size. The residual particles on the $1 \mathrm{~mm}$ mesh were washed in water between two sieves with mesh size $0.71 \mathrm{~mm}$ and $1.6 \mathrm{~mm}$ to remove dust. After drying in a hot air oven to a moisture content of $<3 \%$ the wood particles were compounded with polypropylene (PP) (Sabic PP 575P, Saudi Basic Industries Corporation, Saudi Arabia) in a Leistritz MICRO27GL/GG 40D co-rotating twin-screw extruder (Leistritz Extrusionstechnik $\mathrm{GmbH}$, Germany) with gravimetric feeders and a die-face pelletiser. The temperature profile ranged from $150^{\circ} \mathrm{C}$ to $180^{\circ} \mathrm{C}$ and the die temperature was $136^{\circ} \mathrm{C}$. Two different screw designs were used (Figure 4.1). Screw profile A contained five blocks of kneading elements which were equally distributed along the screw. The total length of kneading elements constituted $14 \%$ of the screw length $(\approx 5.45 \mathrm{D})$. In screw profile B the total length of kneading elements amounted to approx. $18 \%$ of the screw length $(\approx 6.91 \mathrm{D})$ and they were combined to form a kneading zone after the feeding zone. In addition, screw B contained a reverse element before the second vent.

(A)

(B)

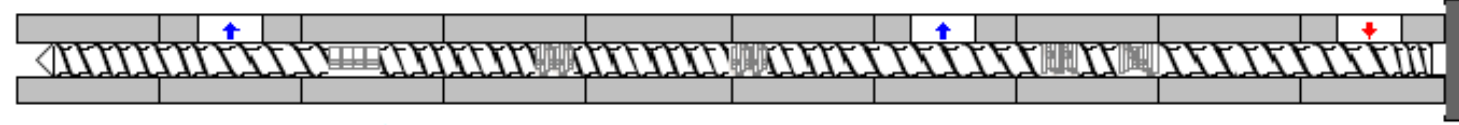

)

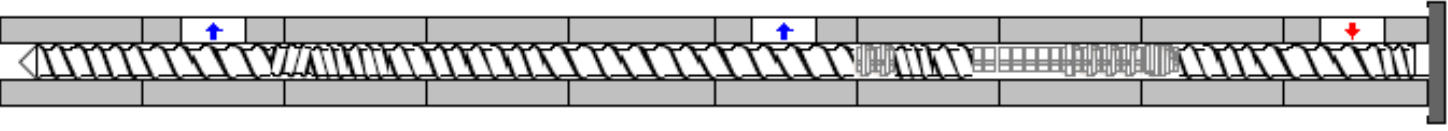

Figure 4.1: Screw designs A and B (kneading elements in grey). 
Table 4.2: Parameters of the compounding process.

\begin{tabular}{|c|c|c|c|c|}
\hline $\begin{array}{l}\text { wood } \\
\text { content } \\
\text { [wt\%] }\end{array}$ & $\begin{array}{l}\text { screw } \\
\text { speed n } \\
{[\text { rpm] }}\end{array}$ & $\begin{array}{l}\text { feed rate } \\
\mathrm{Q} \\
{\left[\mathrm{kgh}^{-1}\right]}\end{array}$ & SDF & $\begin{array}{l}\text { screw } \\
\text { design }\end{array}$ \\
\hline \multicolumn{5}{|l|}{30} \\
\hline & 80 & 4 & 0.05 & $A$ and $B$ \\
\hline & 160 & 8 & 0.05 & $A$ and $B$ \\
\hline & 160 & 4 & 0.025 & B \\
\hline \multicolumn{5}{|l|}{50} \\
\hline & 80 & 4 & 0.05 & $A$ and $B$ \\
\hline & 160 & 8 & 0.05 & $A$ and $B$ \\
\hline & 160 & 4 & 0.025 & B \\
\hline \multicolumn{5}{|l|}{70} \\
\hline & 80 & 4 & 0.05 & $A$ and $B$ \\
\hline & 160 & 8 & 0.05 & $A$ and $B$ \\
\hline & 160 & 4 & 0.025 & $\mathrm{~A}$ and $\mathrm{B}$ \\
\hline
\end{tabular}

Composite samples were produced with varying wood content (30 \%, $50 \%$ and $70 \%$ by weight), screw rotation speed $\mathrm{n}(80 \mathrm{rpm}$ and $160 \mathrm{rpm})$ and feed rate $\mathrm{Q}$ ( $4 \mathrm{~kg} / \mathrm{h}$ and $8 \mathrm{~kg} / \mathrm{h}$ ) as described in Table 4.2. The ratio of $\mathrm{Q}$ to $\mathrm{n}$ represents the specific degree of filling (SDF) (Koplin et al. 2013). For screw A SDF was generally kept at a constant level of 0.05. For screw B additional runs with a lower SDF of 0.025 at a high screw speed were included.

\subsubsection{Particle characterization}

To separate the wood particles from the PP the compound samples were Soxhlet extracted in hot xylene for $8 \mathrm{~h}$. Subsequently, the particles were dried overnight at $103^{\circ} \mathrm{C}$ to remove excess solvent and moisture. To exclude any influence of the extracting method on particle morphology, unprocessed particles underwent the extraction process, too, and their size and shape were compared to the initial values. For particle size and shape measurement the dynamic particle analysis system QICPIC combined with vibrating chute VIBRI and dry dispersion unit RODOS (Sympatec GmbH, Germany) was used. The QICPIC disperses the particles in an accelerated laminar air jet and takes pictures from the particle stream with a high speed camera. The pressure of the air jet breaks up agglomerations and ensures that the particles enter the measurement zone in a random orientation. For measuring the particle size and shape from the projected particle area of binary pictures and for calculating the size and shape distributions, the software WINDOX (Sympatec $\mathrm{GmbH}$, Germany) was used. Particles before and after extrusion were measured with a resolution of $20 \mu \mathrm{m}$ and $10 \mu \mathrm{m}$, respectively. The number of particles analysed per measurement varied between 30,000 and 1.7 million $(<100,000$ for samples with $30 \%$ wood content processed with screw A and $>300,000$ for all others). As described by (Witt et al. 2007) particle length was defined as the shortest path between the most distant end points of the particle after skeletonising its projected area. The particle diameter was calculated by dividing the projected area by the added length of all skeleton paths. To investigate the sensitivity of different types of quantity the

(C) 2016 Elsevier Ltd. All rights reserved. 
number- $\left(\mathrm{Q}_{0}\right)$, length- $\left(\mathrm{Q}_{1}\right)$, area- $\left(\mathrm{Q}_{2}\right)$, and volume-based $\left(\mathrm{Q}_{3}\right)$ cumulative distributions (DIN ISO 9276-1 2004, Leschonski 1984) were compared. For a number-based distribution, the number of particles in each size class is counted and its percentage of the total number of particles in the sample is calculated. For a length-based distribution, the added length of particles in each size class is measured and its percentage of the total added length of all particles in the sample is calculated. When the particles are laid end to end to form a line, the median of a length-based distribution thereby represents the particle at one half of the length of that line. Areaand volume-based distributions are formed accordingly by using e.g. the projected area or the volume of particles in each size class as the crucial type of quantity (Leschonski 1984).

For the calculation of $\mathrm{Q}_{2}$ and $\mathrm{Q}_{3}$ the WINDOX software uses the length in the power of two or three, respectively, instead of using the particles' real surface/projected area or volume. All samples were measured in triplicates. Further detailed analysis for all particles was done with respect to the length-based length and diameter distributions $\left(\mathrm{Q}_{1}\right)$ and focusing on the median $\left(\mathrm{x}_{50}\right)$ and the 1oth and 9oth percentile $\left(\mathrm{x}_{10}\right.$ and $\left.\mathrm{x}_{90}\right)$ (averages out of three measurements).

The WINDOX software provides the elongation as one parameter to describe particle shape. It is defined as the ratio of particle diameter to particle length and therefore represents the reciprocal of the commonly used aspect ratio. Particle elongation was analysed with respect to the number-based distribution including only particles with a length of at least $5 \mathrm{x}$ resolution (length $>100 \mu \mathrm{m}$ and $>50 \mu \mathrm{m}$ for particles before and after extrusion, respectively).

\subsubsection{Statistical analysis}

All error bars shown in the graphs are based on $\pm 95 \%$ confidence intervals. In order to assess the significance of differences among $\mathrm{x}_{10}, \mathrm{x}_{50}$, and $\mathrm{x}_{90}$ values of particle length, diameter and elongation distribution a single factor analysis of variance (ANOVA) was conducted at a level of significance of $\alpha=0.05$ followed by a GamesHowell test for groups of samples processed with the same screw design and a Mannand-Whitney test for pairs of samples processed with different screw designs.

\subsection{Results and Discussion}

\subsubsection{Sensitivity of types of quantity to represent influence of processing on particle size}

Figure 4.2 shows cumulative particle length distributions based on number, length, area, and volume for the particles before processing and for two process variants. Initial particle length reached from $20 \mu \mathrm{m}$ up to $14,000 \mu \mathrm{m}$. Although the particles have been washed to remove dust, they still contained a large amount of fines represented by the steep incline of the number-based distribution Qo. With a median particle length $\mathrm{x}_{50}$ of $42 \mu \mathrm{m}$ and a 9oth percentile at $298 \mu \mathrm{m}$ for the Qo-distribution, short particles are over-represented. When comparing the $\mathrm{Q}_{0}$-distribution for initial 

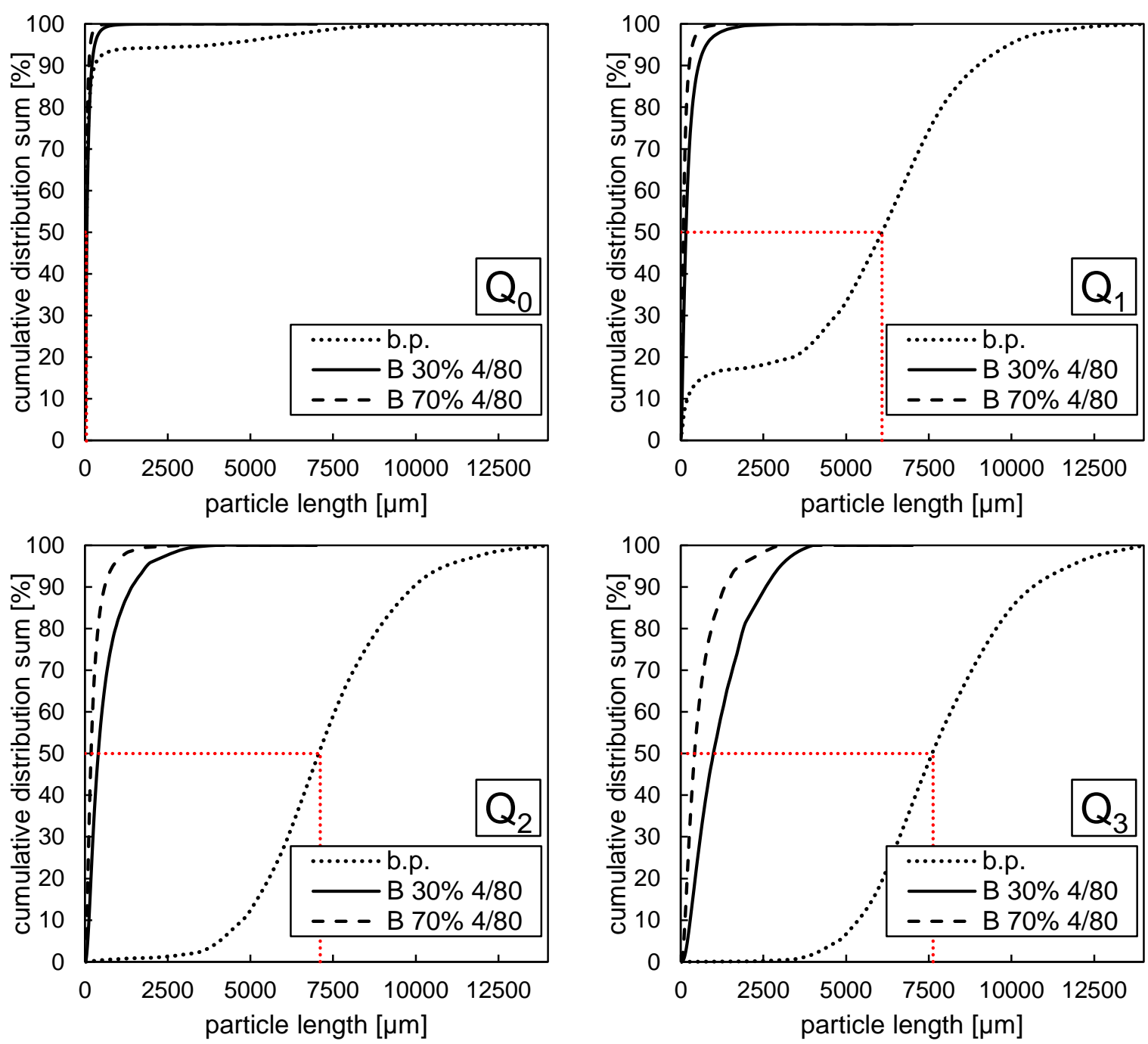

Figure 4.2: Particle length distribution based on number $\left(Q_{o}\right)$, length $\left(Q_{1}\right)$, area, $\left(Q_{2}\right)$, and volume $\left(Q_{3}\right)$ for particles before processing (b.p.) and after two different process variants (screw design $B$ at $4 \mathrm{~kg} / \mathrm{h}$ and $80 \mathrm{rpm}$ with $30 \%$ and $70 \%$ wood content, respectively). The dotted red lines mark the initial median particle length $x_{50}$.

particle length and length after processing, $90 \%$ of the distributions are very similar. Due to the over-representation of fine particles the effect of processing is visible only for the longest $10 \%$ of the particles and no obvious difference between process conditions can be seen. Weighting the distribution by length $\left(\mathrm{Q}_{1}\right)$ shifts the initial median to $6080 \mu \mathrm{m}$ and provides a good representation of the coarse proportion of particles $\left(\mathrm{x}_{90}=9238 \mu \mathrm{m}\right)$ without neglecting the fines $\left(\mathrm{x}_{10}=202 \mu \mathrm{m}\right)$. For the distributions of particle length after processing the shift is smaller and the shape of the curves changes only marginally, indicating that the proportion of large particles is relatively low compared to the initial distribution. The different effect of the two process variants is more obvious for the Q1-distribution than for the $\mathrm{Q}_{0}$-distribution. When weighting by area $\left(\mathrm{Q}_{2}\right)$ or volume $\left(\mathrm{Q}_{3}\right)$ the distributions after processing become irregular above $90 \%$, which denotes the insufficient amount of particles representing this length region. The median is shifted to even higher particle lengths and the influence of fines on the initial length distribution is almost eliminated. 
For further analysis of particle size the use of the length-based size distribution $\mathrm{Q}_{1}$ was preferred, as it is based on a type of quantity that is directly measured (compared to area and volume which are calculated and do not represent a real property of the particles). In addition, it gives a good representation of initial particle size without neglecting the fines which play an important role in processing WPC and in defining the material properties.

\subsubsection{General observations}

After compounding with polypropylene at different screw speeds and feed rates and with two different screw designs, spruce wood particles were characterised with respect to length, diameter and elongation distribution. The results are summarized in Table 4.3. Compared to the initial particle size, particle length was reduced by 97$99 \%$ depending on wood content and process conditions. With a median length of 81-163 $\mu \mathrm{m}$ the particles after processing were in a size range commonly excluded from particle/fibre analysis in composites (Ferreira et al. 1999). Their size was also comparable to wood raw materials used for the commercial production of WPC (Klyosov 2007). Facing these results, cost intensive extra screening of commercial wood flours to narrow their particle size distribution (Stark \& Berger 1997) appears to be less important with respect to composite homogeneity and further processing as the large particles on one end of the distribution are reduced in size during compounding.

For chemical and thermomechanical pulp fibres it was reported that they are only reduced in length when processed (Peltola et al. 2014). Here, not only a decrease in length but also in diameter could be shown, namely by $64-72 \%$ for the median diameter. This decrease in diameter was attributed to fibre bundle separation (Puglia et al. 2008). As the reduction of length was stronger than the reduction of diameter, the particle elongation increased.

\subsubsection{Effect of wood content}

For cellulose pulp fibres it has been observed that the reduction in fibre length during compounding with polymers is increasing with increasing fibre content (Puglia et al. 2008). Similar results were obtained in the present study. Figure 4.3 shows the change in $\mathrm{x}_{10}, \mathrm{x}_{50}$ and $\mathrm{x}_{90}$ of the particle length and diameter distributions dependent on wood content. With increasing wood content particle length and diameter decreased (compare also Table 4.3). Adding filler to a polymer increases the viscosity of the material (Kumari et al. 2007). Increasing the wood content increases the viscosity and causes higher shear forces in the polymeric melt (Peltola et al. 2014). In addition, the particle-particle interaction is stronger when the wood content is increased, therefore leading to a stronger particle size degradation (Azizi \& Ghasemi 2009). The decrease in length was stronger than the decrease in diameter. This stands in contrast to the results of Puglia et al. (2008), who observed a stronger reduction of diameter for cellulose pulp fibres when the fibre concentration was increased. 


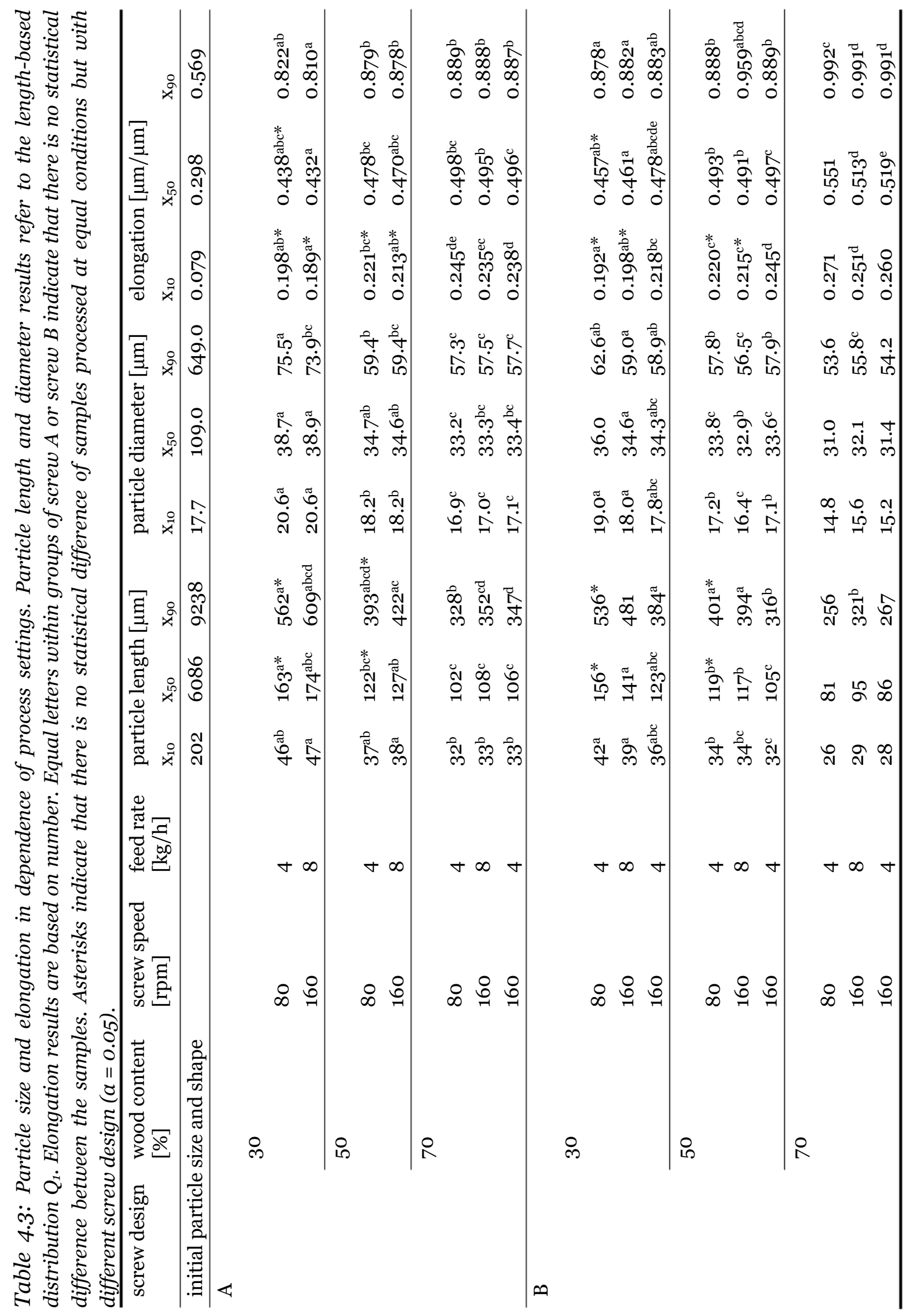


The change depending on wood content was much stronger for the $\mathrm{x}_{90}$ than for the $\mathrm{x}_{50}$ and $\mathrm{x}_{10}$ (e.g. $-58 \%$ in length for $\mathrm{x}_{90}$ compared to $-38 \%$ for $\mathrm{x}_{50}$ and $-30 \%$ for $\mathrm{x}_{10}$ when increasing the wood content from $30 \%$ to $70 \%$ in Figure 4.3 ). This confirms that coarse particles are more affected by increasing the wood content than small particles (Inceoglu et al. 2011). This effect, which occurs only on one end of the distribution, would not have been detected by looking only at an average particle size, e.g. the $\mathrm{x}_{5}$. Therefore, it is necessary to initially consider the entire particle size distribution in order to identify important influencing factors.

\subsubsection{Effect of process conditions}

As can be seen from Table 4.3 particle length and diameter reduction was in general significantly greater for screw B than for screw A. Screw B contained more kneading elements. Kneading elements with wide discs and large staggering angles cause dispersive mixing during extrusion by introducing high shear forces to the polymer melt to break down agglomerations (Zhang et al. 2009). In addition, screw B contained a reverse element. A certain level of pressure has to be build up in the polymer melt to overcome this type of element, also leading to a higher amount of shear (Rauwendaal 2014). These additional sources of shear stress led to a more severe particle length degradation and particle defibration for screw B compared to screw A. Furthermore, when the material reached the first kneading elements, there might still have been unmelted polymer granules inducing a milling effect on the particles. This effect was more pronounced for screw B as the first kneading elements were closer to the infeed and they were concentrated in the melting zone. Screw A had only two kneading blocks in the melting zone with the first one further away from the infeed. The remaining kneading blocks were reached by the material after the polymer was fully melted.

Figure 4.4 shows a decreasing trend in particle size reduction with screw A when the screw speed and feed rate were increased simultaneously (SDF kept constant). The same is true for $70 \%$ wood content processed with screw B. For $30 \%$ and $50 \%$ wood content the trend is opposite. Increasing the screw speed has a twofold effect on the polymer melt: On the one hand, the increase in rotation speed increases the shear rate. On the other hand, it reduces the viscosity of the polymer and thereby reduces shear (Ville et al. 2013). In the present study, the one or the other seemed to be the dominant effect, dependent on screw design and wood content. With screw A the decrease in viscosity seemed to have reduced the shear at a higher rate than the shear increased due to faster screw rotation. With the more severe design of screw B the shear induced by the increased screw speed at $30 \%$ and $50 \%$ wood content exceeded the change in viscosity. At higher filler content the effects were different again. However, rheological measurements during compounding are necessary to verify these considerations. 

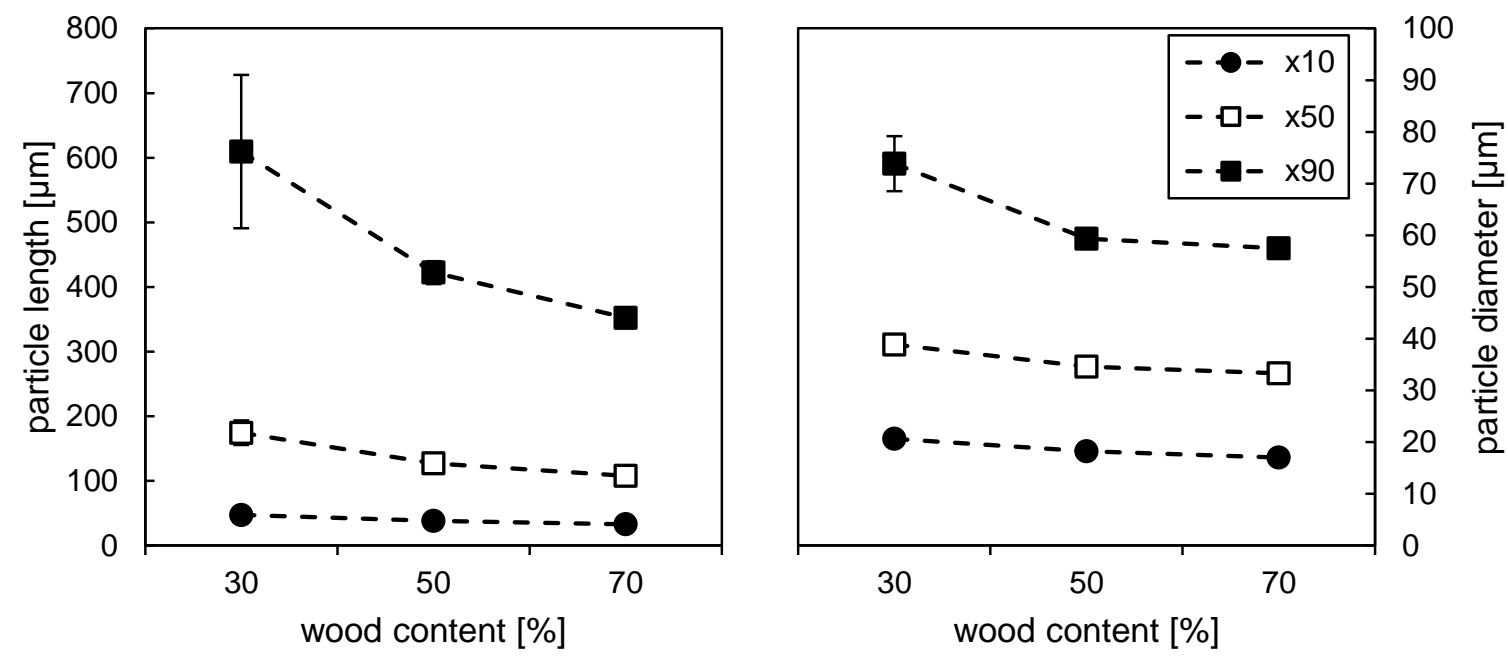

Figure 4.3: Change in particle length (left) and diameter (right) distribution values $x_{10}, x_{50}$ (median) and $x_{90}$. Particles processed with screw design $A$ at $8 \mathrm{~kg} / \mathrm{h}$ and $160 \mathrm{rpm}$. Error bars $= \pm 95 \%$ confidence intervals (generally small and obscured by the symbols).
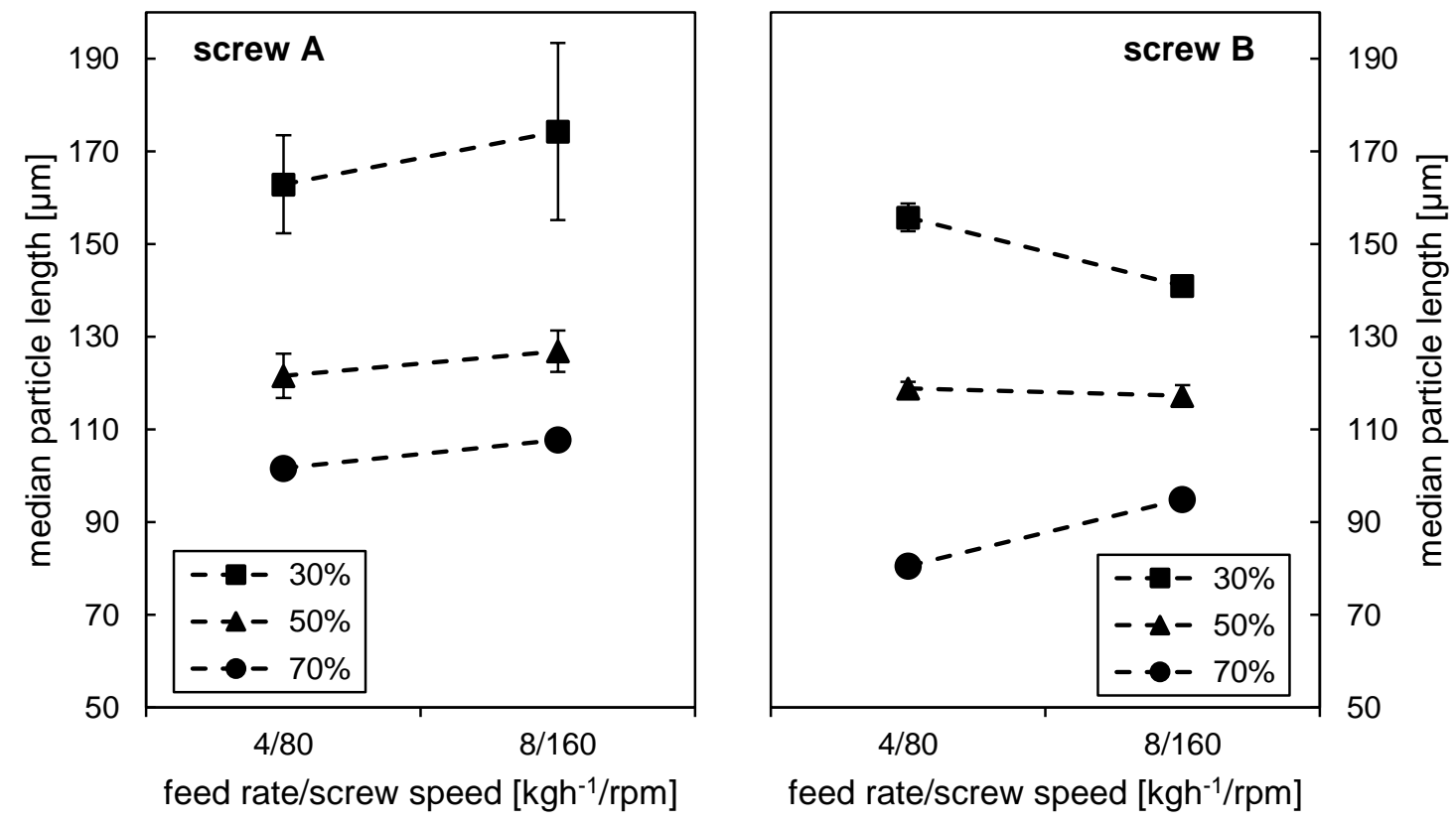

Figure 4.4: Change in median particle length $x_{50}$ for $30 \%, 50 \%$, and $70 \%$ filled composites when increasing feed rate and screw speed simultaneously. Error bars $= \pm 95 \%$ confidence intervals (generally small and obscured by the symbols). 

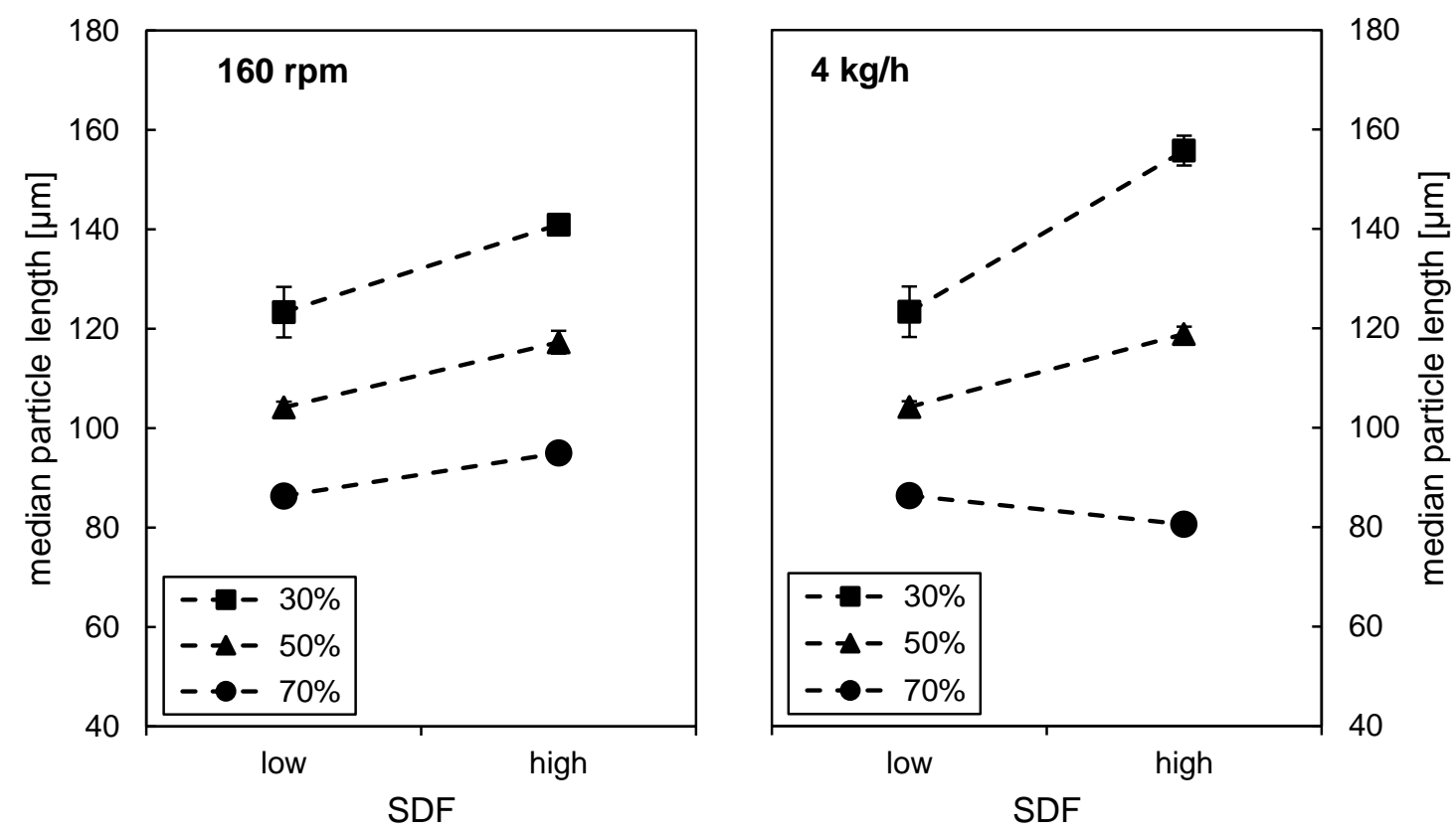

Figure 4.5: Change in median particle length $x_{50}$ for $30 \%, 50 \%$, and $70 \%$ filled composites when increasing the SDF at constant screw speed (left) and constant feed rate (right). Particles processed with screw B. Error bars $= \pm 95 \%$ confidence intervals (generally small and obscured by the symbols).

Increasing the SDF at constant screw speed of $160 \mathrm{rpm}$ by increasing the feed rate from $4 \mathrm{~kg} / \mathrm{h}$ to $8 \mathrm{~kg} / \mathrm{h}$ led to less particle degradation (Figure 4.5 ). A high feed rate represents a shorter residence time of the material inside the extruder and therefore a shorter exposure of the particles to stress (Ville et al. 2013). An increase in SDF also led to less particle degradation when the screw speed was decreased at a constant feed rate of $4 \mathrm{~kg} / \mathrm{h}$, but only for $30 \%$ and $50 \%$ wood content. For a wood content of $70 \%$ the degradation increased.

The results illustrate that the conditions during compounding of wood particles with a thermoplastic matrix in an extruder are very complex. The process parameters influence each other and depending on their combination they can lead to different effects on particle degradation.

\subsection{Conclusions}

The use of an automated dynamic image analysis method to evaluate the particle degradation that occurs during processing of WPC was presented and the analysis of particle size distributions based on different types of quantity was discussed. The particle measurements resulted in size distributions based on sample sizes larger than commonly reported in the literature. It was shown that the number-based particle size distribution tend to over-estimate fines content. The length-based distribution proofed to be well representing broad size distributions including fine and coarse particles. Its sensitivity was sufficient to reveal different effects of varying process conditions on particle degradation. Degradation was stronger with increasing wood content and a larger number of mixing elements in the screw. The influence of 
processing was stronger on large particles than on small particles. The effects of screw speed and feed rate differed dependent on screw speed and feed rate.

\subsection{Acknowledgements}

This research was supported by the German Research Foundation (DFG), grant GRK 1703/1 for the Research Training Group "Resource Efficiency in Interorganizational Networks - Planning Methods to Utilize Renewable Resources”. 



\section{Chapter 5}

\section{Processing of wood plastic composites: the influence of feeding method and polymer melt flow rate on particle degradation}

Laura Teubera, ${ }^{\mathrm{a}, 1,1}$ - Holger Militza,1 - Andreas Krause $\mathrm{e}^{\mathrm{b}, 1}$

aFaculty of Forest Sciences and Forest Ecology, Dpt. of Wood Biology and Wood Products, University of Göttingen, Büsgenweg 4, D-37077 Göttingen, Germany

cInstitute of Mechanical Wood Technology, Dpt. of Wood Sciences, University of Hamburg, Leuschnerstraße 91c, D-21031 Hamburg, Germany

*Corresponding author, email: Laura.Teuber@forst.uni-goettingen.de

${ }^{1}$ DFG Research Training Group "Resource Efficiency in Interorganizational Networks"

Originally published in:

Journal of Applied Polymer Science, 2016, Vol. 133 (13), pp. n.a. - n.a.

DOI: 10.1002/APP.43231

Received: 14 October 2015 / Accepted: 17 November 2015 


\section{Authorship}

Table 5.1: Contribution of co-authors (Himmel 2015 as modified from Hunt 1991)

\begin{tabular}{llll}
\hline & Teuber, L. & Militz, H. & Krause, A. \\
\hline Planning \& Design & 25 & 10 & 15 \\
Executing \& Data Collection & 25 & 0 & 0 \\
Data Analysis \& Interpretation & 25 & 10 & 15 \\
Literary Input & 25 & 5 & 10 \\
$\sum$ & $\mathbf{1 0 0}$ & $\mathbf{2 5}$ & $\mathbf{4 0}$ \\
\hline
\end{tabular}

Laura Teuber prepared the experimental design together with Holger Militz and Andreas Krause. She performed data collection, analysis and interpretation of data and wrote the manuscript.

Holger Militz prepared the experimental design together with Laura Teuber and Andreas Krause. He supported data interpretation and edited the manuscript.

Andreas Krause prepared the experimental design together with Laura Teuber and Holger Militz. He supported data interpretation and manuscript writing. 


\subsection{Abstract}

Spruce wood particle (WP)/polypropylene (PP) compounds were prepared in an internal mixer using different rotor speeds. To analyse the effect of feeding method on particle degradation, WP and PP were either fed as dry-blend or WP were fed into the PP melt. To prevent melt freezing, pre-heated WP were used as comparison to cold WP. In addition, WP were compounded with different grades of PP or high density polyethylene (HDPE) to analyse the effect of polymer matrix melt flow rate (MFR) on particle degradation. Mixing behaviour of compounds containing $30 \%$ and $70 \%(\mathrm{w} / \mathrm{w})$ WP depended on feeding method, represented by a changing relation of final torque values. Feeding as dry-blend and using pre-heated particles led to stronger WP degradation. Degradation decreased with increasing polymer MFR. For PP compounds, particle degradation was stronger when containing $70 \% \mathrm{WP}$, for HDPE the difference due to WP content was only marginal.

\subsection{Keywords}

thermoplastics, composites, cellulose and other wood products, morphology, degradation 


\subsection{Introduction}

The interest in wood plastic composites (WPC) as partly bio-based materials for automotive, construction and consumer applications has experienced an increase represented by a recent growth in market share in the European Union (Carus et al. 2014). WPC consists of a polymer matrix - commonly polypropylene (PP), polyethylene (PE) or polyvinyl chloride (PVC) -, a wood filler in the form of fibres, particles or flour, and additives (e.g. coupling agents, pigments and UV-stabilizers) (Klyosov 2007). Due to their thermoplastic nature, it is possible to process WPCs on the same equipment as neat thermoplastics (Balasuriya et al. 2001). The material composition and production process have to be chosen and optimized in such a way that the resulting composite properties match the requirements specific to the field of application. One factor that has been identified to influence the composite properties is the size and shape of the filler (Clemons 2008). For example, particles with their low length to diameter ratio lead to more homogenous materials as they are easier to disperse in the polymeric matrix (Shahi et al. 2012, Yam et al. 1990). But compared to particles, fibres have a high length to diameter ratio and therefore better enhance the tensile and flexural strength (Stark 1999). Also the rheological properties of a polymer are dependent on filler morphology, making amendments of the compounding process necessary. Polymer melts possess non-Newtonian flow behaviour. Their viscosity is not constant but underlies shear-thinning behaviour, i.e. it decreases when the shear rate increases (Shaw 2012). Several studies demonstrated that the polymer viscosity is generally higher when filler is added and it increases with increasing filler content (Ausias et al. 2013, Balasuriya et al. 2001, Bengtsson et al. 2007, Gallagher \& McDonald 2013, Hristov \& Vlachopoulos 2007, Li \& Wolcott 2005). Also the degree of shear-thinning becomes stronger with increasing filler content (Dong et al. 1992, Li \& Wolcott 2005). Zhang et al. (2007) and Yuan et al. (2008) found out that viscosity is not dependent only on filler content but also on filler size. In their studies, long wood fibres in the composite resulted in higher viscosities whereas a higher amount of short fibres lead to lower composite viscosities. Huber et al. (2015) made similar observations when wood particles were used as filler. Stark \& Berger (1997) stated an opposite trend for wood fibre filled composites.

However, it has been shown that initial filler morphology is not constant throughout processing, but it is prone to changes due to shear forces and high temperature (Stark et al. 2004). The extent of filler degradation in extrusion compounding, for example, was found to depend on process settings like degree of filling, screw design, screw rotation speed, and feed rate (Beaugrand \& Berzin 2013, Berzin et al. 2014, El-Sabbagh et al. 2014, Gamon et al. 2013, Gunning et al. 2014, Yeh \& Gupta 2008).

While the influence of filler morphology on polymer properties, e.g. polymer rheology, was studied to a vast extent, there are only few studies that directly analyse the effect of polymer rheological properties, e.g. polymer melt flow rate (MFR), on wood filler size. Balasuriya et al. (2001) compounded wood flakes and HDPE with 
different MFR to study the effect on flake distribution and wetting by the matrix and to analyse the mechanical properties resulting thereof. Peltola et al. (2014) compounded wood fibres with polylactic acid (PLA) and PP and concluded that differences in fibre degradation result from the higher viscosity of the PLA matrix. Ren \& Dai (2014) found for glass fibre/PP composites that fibre length degradation decreases with increasing MFR of the matrix polymer.

Also the way of feeding the wood filler to the compounding process can play a role in filler degradation. The wood filler is either fed to the process at the same time as the polymer granules, forming a dry-blend before the polymer starts to melt, or the wood is introduced into the already molten polymer (Rowell 2007). Feeding as a dryblend simplifies the machine setup as only one infeed is needed. But it can also lead to severe filler size reduction due to increased particle-particle interaction with the unmolten polymer granules. This effect can be overcome by introducing the wood into the molten polymer. In twin-screw compounding a side-feeder can be used to introduce the filler further downstream of the extruder. Though, side-feeding can lead to poorer filler dispersion due to a shorter mixing time (Le Baillif \& Echtermeyer 2010). When the filler is introduced into the polymer melt, there is a huge temperature difference between the two materials. When the filler comes into contact with the polymer melt, it will primarily be heated by the latter. This leads to a loss in temperature of the melt which will be balanced by the heating of the processing equipment further on. Due to the loss in temperature, the viscosity of the melt will increase (Shaw 2012). This will increase the shear forces acting on the filler material (Peltola et al. 2014). When considering a specific heat capacity of $1.35 \mathrm{~kJ} /(\mathrm{kgK})$ for spruce wood (at a moisture content of o\%) (Niemz 1993) and $1.7 \mathrm{~kJ} /(\mathrm{kgK})$ for PP (Domininghaus 2012), and a target filler content of at least 50\%, the temperature of the polymer might drop below the melting point causing a local freezing of the melt. The presence of solid polymer can again lead to an increase in filler degradation (Wolf 1994).

The present study analyses the dependency of wood filler degradation on feeding method and polymer MFR using an internal mixer, which allows to record torque and temperature development during processing. In the first part of the study, wood particles were compounded with PP with varying wood content and rotor speed and by (i) feeding wood and polymer as dry-blend and (ii) feeding the particles into the polymer melt. Also pre-heating of the wood particles was considered. In the second part of the study, wood particles were compounded with different grades of PP and HDPE having low, medium and high MRF to study the influence of polymer type and MFR on wood particle degradation. 


\subsection{Experimental}

\subsubsection{Wood particle production}

Norway spruce (Picea abies) wood was ground with a cutting mill with aperture size of $4 \mathrm{~mm}$ and subsequently screened via sieve separation to a fraction of 1-2 $\mathrm{mm}$ particle size. The resulting wood particles (WP) were washed in water between two sieves with mesh size $0.71 \mathrm{~mm}$ and $1.6 \mathrm{~mm}$ to remove fines. Afterwards the WP were dried in a hot air oven to a moisture content of $<2 \%$.

\subsubsection{Composite preparation}

Mixing of WP and polymer was done with HAAKE Polylab OS Rheodrive 7 combined with the HAAKE Rheomix OS 3000 (Thermofischer Scientific) laboratory mixer with Banbury rotors. The degree of filling of the free volume was set to $60 \%$ and processing temperature was $180^{\circ} \mathrm{C}$. Mixer torque and mass temperature were recorded with HAAKE Polysoft OS software version 2.4.0.28.

For the first part of the study, WP were mixed with polypropylene (PP) SABIC PP $575 \mathrm{P}$ (Saudi Basic Industries Corporation, Saudi Arabia) at varying wood content (30 $\%$ and $70 \%$ by weight) and rotor speed (20,60, and $120 \mathrm{rpm})$. Each run was carried out with two different feeding methods. On the one hand, polymer and WP were dryblended prior to mixing and fed to the mixer together. On the other hand, the polymer was mixed until steady torque was reached and the WP were added to the polymer melt. At a rotor speed of $120 \mathrm{rpm}$ additional runs with WP pre-heated to $140^{\circ} \mathrm{C}$ were carried out. Details concerning the different process variants are listed in Table 5.2. When the temperature reached $195^{\circ} \mathrm{C}$ for the first time, the mixer was opened for a few seconds to lower the temperature again to prevent thermal wood degradation. This was necessary only with $70 \%$ wood content mixed at $120 \mathrm{rpm}$. To eliminate the effect of residence time in the mixer on WP degradation, mixing was stopped for both feeding methods 17.2 minutes after WP introduction and the compound was removed from the mixer to cool down to room temperature.

For the second part of the study, WP were mixed with different types of PP and HDPE with varying melt flow rate (MFR) (Table 5.3). All polymers were supplied by SABIC (Saudi Basic Industries Corporation, Saudi Arabia). Rotor speed was $60 \mathrm{rpm}$. Compounds were produced with a wood content of $30 \%$ and $70 \%$ by weight. The WP were fed into the polymer melt without pre-heating. Mixing time was set to 7.5 minutes after WP introduction to reduce the influence of residence time on particle degradation since the first part of the study showed that mixing conditions for these process settings are already stable after this time.

\subsubsection{Particle extraction and characterization}

To separate the WP from the polymer matrix the compounds were Soxhlet extracted in hot xylene for $8 \mathrm{~h}$. Afterwards the WP were kept at room temperature for excess solvent to evaporate. To exclude any influence of the extracting method on particle morphology, unprocessed particles underwent the extraction process, too, and their size and shape were compared to the initial values. WP size and shape were deter- 
Table 5.2: Process variants.

\begin{tabular}{|c|c|c|c|}
\hline $\begin{array}{l}\text { wood content } \\
{[\mathrm{wt} \%]}\end{array}$ & $\begin{array}{l}\text { feeding } \\
\text { method }\end{array}$ & $\begin{array}{l}\text { rotor speed } \\
{[\mathrm{rpm}]}\end{array}$ & pre-heating \\
\hline \multirow{6}{*}{30} & $\mathrm{~s}$ & 20 & $\mathrm{c}$ \\
\hline & & 60 & c \\
\hline & & 120 & $\mathrm{c}, \mathrm{h}$ \\
\hline & $\mathrm{t}$ & 20 & c \\
\hline & & 60 & c \\
\hline & & 120 & $\mathrm{c}, \mathrm{h}$ \\
\hline \multirow[t]{6}{*}{70} & $\mathrm{~S}$ & 20 & c \\
\hline & & 60 & c \\
\hline & & 120 & $\mathrm{c}, \mathrm{h}$ \\
\hline & $\mathrm{t}$ & 20 & c \\
\hline & & 60 & c \\
\hline & & 120 & $\mathrm{c}, \mathrm{h}$ \\
\hline
\end{tabular}

Feeding: $\mathrm{s}=$ separately, $\mathrm{t}=$ together; pre-heating: $\mathrm{c}=$ "cold", $\mathrm{h}=$ "hot"

mined via the dynamic image analysis system QICPIC combined with vibrating chute VIBRI and dry dispersion unit RODOS (Sympatec GmbH, Germany). In the QICPIC the particles are dispersed in an accelerated air jet and a high speed camera takes pictures of the particle stream. Measuring particle size and shape from the projected particle area of binary pictures and calculating size and shape distributions was done by the software WINDOX (Sympatec GmbH, Germany). Particles before and after processing were measured with a resolution of $20 \mu \mathrm{m}$ and $10 \mu \mathrm{m}$, respectively. Particle length was characterised with respect to the median and quartiles of the length-based particle length distribution (Q1) (DIN ISO 9276-1 2004). Thereby, particle length was defined as the shortest path between the most distant end points of the particle after skeletonising its projected area (Witt et al. 2007). Particle elongation was analysed with respect to the median and the quartiles of the numberbased distribution including only particles with a length of at least $5 \mathrm{x}$ resolution (length $>100 \mu \mathrm{m}$ and $>50 \mu \mathrm{m}$ for particles before and after processing, respectively). Elongation was defined as the ratio of particle diameter to particle length with the diameter being the projected area divided by the added length of all skeleton paths. The number of particles analysed was approx. 6.800 for the particles before processing and varied between 0.5 million and 4 million per composite sample.

Table 5.3: Polymers used in the study. All polymers obtained from SABIC. MFR as specified in the product data sheets and determined at $230^{\circ} \mathrm{C}$ and $2.16 \mathrm{~kg}$ for $P P$ and at $190^{\circ} \mathrm{C}$ and $2.16 \mathrm{~kg}$ for $\mathrm{HDPE}$.

\begin{tabular}{lll}
\hline brand name & MFR [g/10 min] & sample name \\
\hline PP 505P & 2 & PP2.0 \\
PP 575P & 11 & PP11 \\
PP 579S & 47 & PP47 \\
HDPE CC252 & 2.2 & PE2.2 \\
HDPE 0863F & 8 & PE8 \\
HDPE CC3054 & 30 & PE30 \\
\hline
\end{tabular}




\subsection{Results and Discussion}

\subsubsection{Initial particle size and shape}

Figure 5.1 shows the initial particle length and elongation distributions. The particle length distribution was relatively narrow with a median length of $6068 \mu \mathrm{m}$ and the 25\%- and 75\%-quartiles at $4153 \mu \mathrm{m}$ and $7613 \mu \mathrm{m}$. Although the WP were washed in water to remove dust, they still contained fines represented by a 10\%-decile at 202 $\mu \mathrm{m}$. The elongation was ranging from 0.079 to 0.569 with a median of 0.298 .

\subsubsection{Effects of process conditions}

A summary of the results representing the effects of process conditions on particle size and shape and final torque and temperature is given in Table 5.4. Figure 5.2 exemplarily shows the change in temperature and torque during mixing after adding wood particles for some process variants, among them the two variants with cold and pre-heated particles containing $30 \% \mathrm{WP}$, fed into the polymer melt and processed at $120 \mathrm{rpm}$. While all processes reached a plateau temperature and torque, the curves for the two variants mentioned above were still sloping at the end of the mixing time, indicating that the mixing process was not completed yet. Due to this deviating mixing behaviour, these two variants will be excluded from further analyses with respect to final torque and temperature.

\section{Final torque and temperature}

As can be seen in Figure 5.3, torque and temperature increased with increasing rotor speed for both feeding methods. Increasing the rotor speed requires a higher torque from the mixer motor. The increase in torque was not linear with rotor speed but was higher for lower rotor speeds and lower for higher rotor speeds. Due to the shearthinning behaviour of the melt, its resistance to flow decreases when the shear rate, i.e. rotor speed, is increased (Shaw 2012). In turn, the decrease in flow resistance reduces the rate of increase in mixer motor torque to obtain higher rotor speeds. The increase in melt temperature with increasing rotor speed results from the growth of viscous energy dissipation in the polymer (Campanelli et al. 2004).

When WP and PP were fed as dry-blend, the torque was higher for composites containing 70 \% WP compared to $30 \% \mathrm{WP}$ (Figure 5.3A). This can be attributed to the higher viscosity of composites having higher filler contents. At a higher filler concentration the flow of the polymer is restrained by the particles and particleparticle interaction increases (Gallagher \& McDonald 2013, Zhang et al. 2007).

However, when the WP were fed into the polymer melt, the torque was lower for $70 \%$ wood content compared to $30 \%$ wood content (Figure $5.3 \mathrm{~B}$ ). It was even lower than for $70 \%$ wood content dry-blend. In the dry-blend, the small fraction of polymer granules was equally distributed between the wood particles, providing a uniform wetting of the filler when the polymer started to melt. The rheological behaviour of the composite melt and the measurable torque were then related to viscous interactions between the particles (Akkoyun et al. 2014). Polymer melts and especially filled polymers are known for their wall-slip behaviour, which was also 


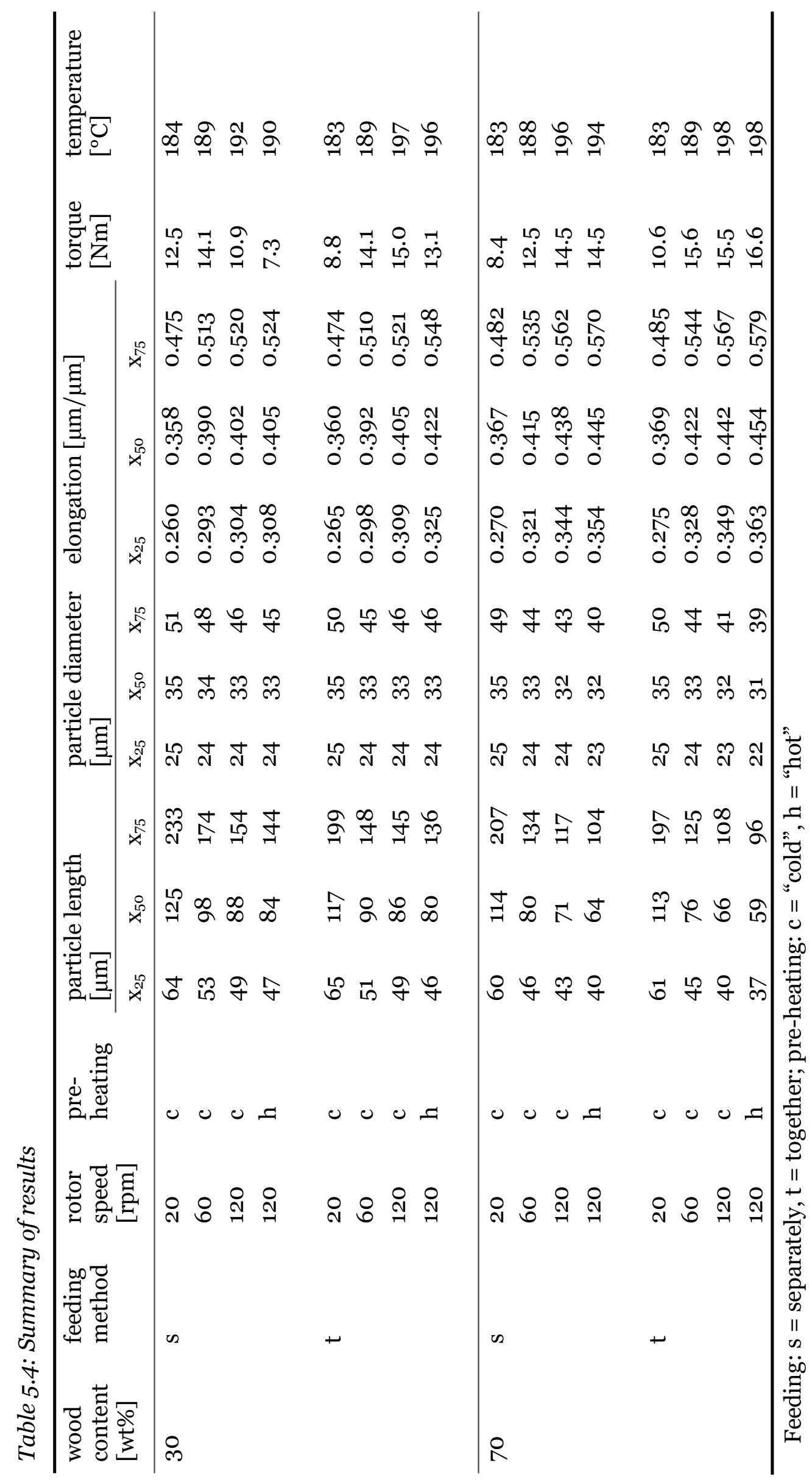




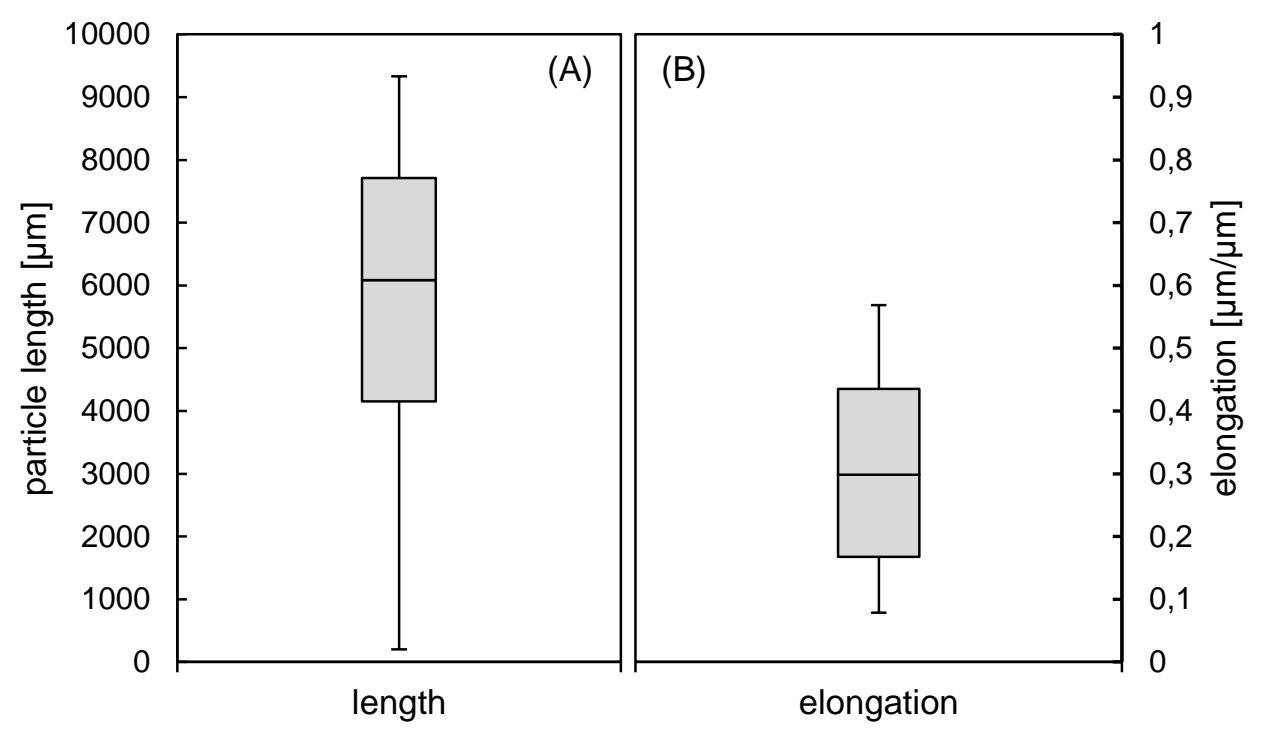

Figure 5.1: Size distributions of initial particle length (A) and elongation (B) as boxwhisker-plots. The bottom and top of the box represent the $25 \%$ and $75 \%$ quartile. The ends of the whiskers represent the $10 \%$ and $90 \%$ quantile.
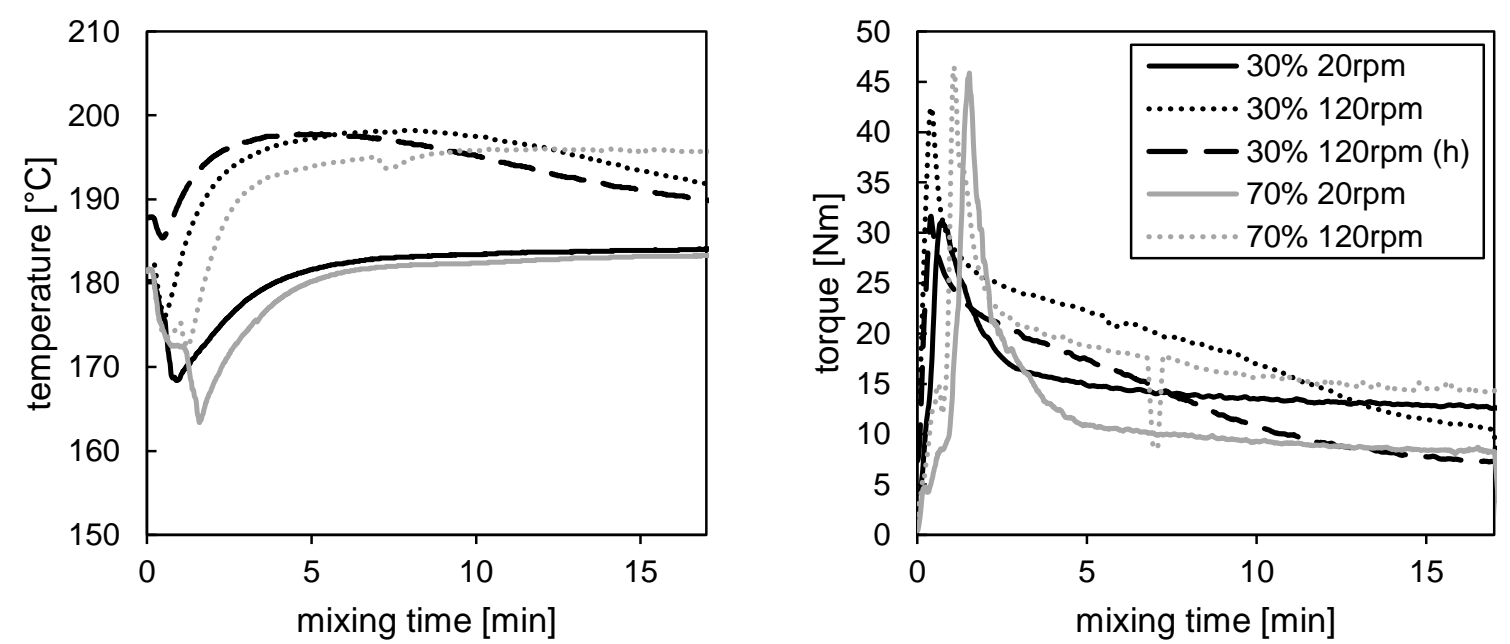

Figure 5.2: Progression of temperature and torque for selected process variants after adding WP into the polymer melt (h: preheated particles).

reported for WPC (Li \& Wolcott 2004). During mixing they develop a matrix dominated layer close to the processing equipment wall. The viscosity of this layer is lower than the composite melt viscosity and therefore results in slippage of the bulk material (Hristov \& Vlachopoulos 2008, Shaw 2012). In WPC, the thickness and velocity of the slip layer depend on various factors, e.g. wood species, filler size, filler content. But the mechanisms of slip layer formation are yet not fully understood (Li \& Wolcott 2004). In the present study, the wall-slip phenomenon might explain the different mixing behaviours dependent on feeding method. The separate feeding of polymer and WP might have promoted the formation of a slip layer for the compound filled with $70 \%$ wood content. When the low fraction of polymer was introduced to the mixer without the filler, the melt was able to spread on the walls of the mixing chamber and the rotors. Adding the high fraction of WP to the low fraction of 

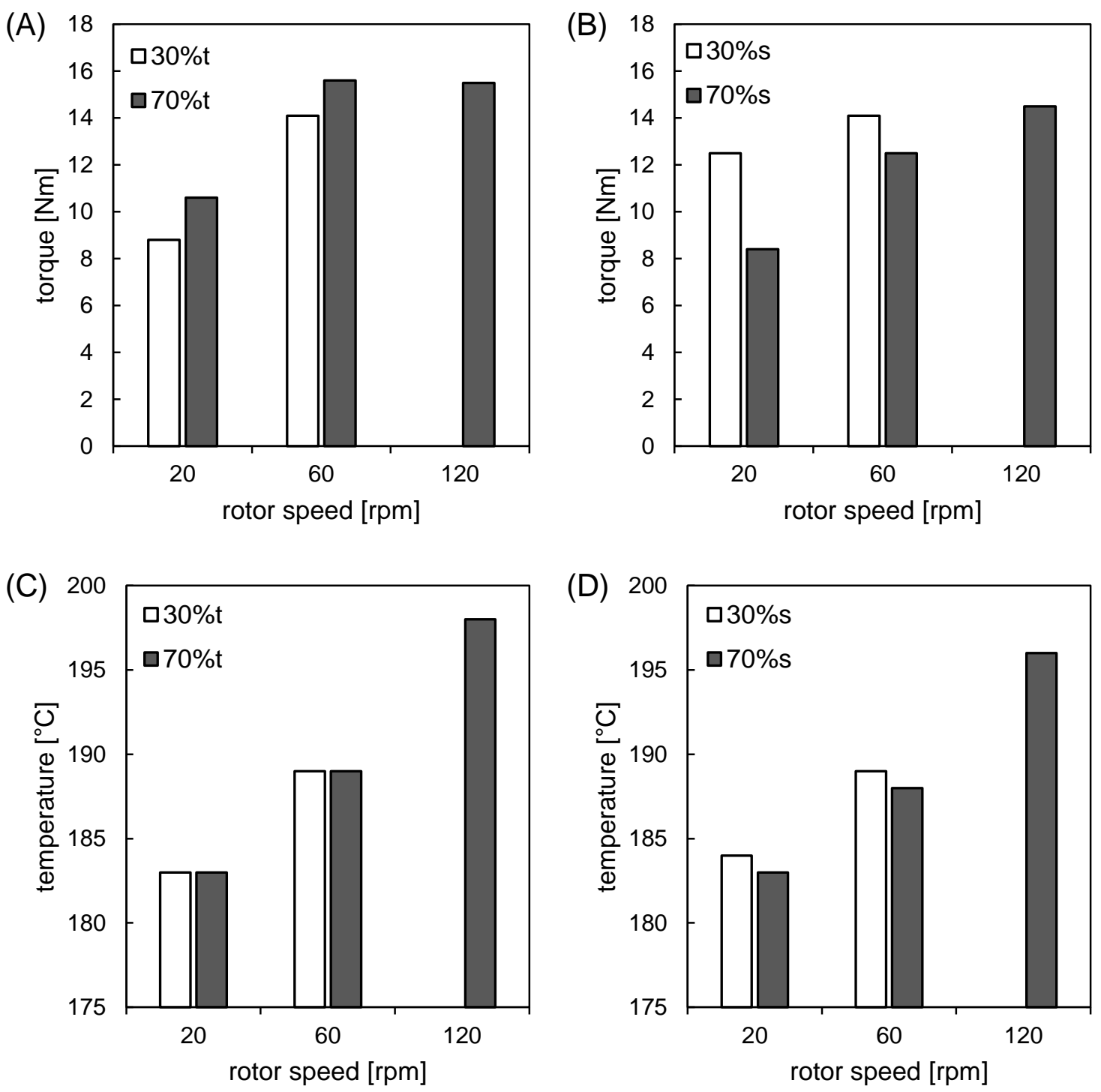

Figure 5.3: Final torque $(A, B)$ and temperature $(C, D)$ after 16.5 minutes of mixing when polymer and WP are fed together $(A, C)$ or separately $(B, D)$.

polymer melt might have led to a non-uniform wetting of the filler thereby maintaining the slip layer at the mixing chamber walls and leading to a lower apparent viscosity. In addition, the non-uniform wetting might have caused the compounds' rheological properties to be more related to solid friction resulting in lower torque values (Akkoyun et al. 2014). For the composites containing 30 \% WP, the amount of polymer was sufficient to ensure uniform filler wetting and similar flow properties independent of feeding method. However, the formation of a slip layer was not verified and a more detailed study would be necessary to analyse the conditions inside the mixer, which is beyond the scope of the present study. 


\section{Particle size and shape}

Figure 5.4 shows the median particle length and elongation of WP after processing under different process conditions. Median particle length was reduced by more than $98 \%$ of initial length regardless of process conditions reaching values between $64 \mu \mathrm{m}$ and $125 \mu \mathrm{m}$. The $25 \%$ - and $75 \%$-quartiles of the particle length distribution decreased at a similar rate, i.e., by more than $98 \%$ and $96 \%$, respectively. Particle length decreased with increasing rotor speed while elongation increased. Increasing the rotor speed increases the shear forces inside the polymer melt causing the WP to break (Ville et al. 2013). In addition, the number of rotations and the distance travelled by the particles inside the mixer increases with increasing rotor speed when mixing time is kept constant. The increase in elongation shows that particle length was more affected by shear than particle diameter.

A strong effect of WP content on particle length and elongation was visible, especially at high rotor speeds. Particles were $1-26 \%$ shorter with respect to the median length in composites containing $70 \%$ compared to $30 \% \mathrm{WP}$ due to the stronger particle-particle interaction at high filler contents (Azizi \& Ghasemi 2009).

Analysing the effect of feeding method on particle length revealed that feeding WP and PP as a dry-blend lead to $1-8 \%$ shorter particles with respect to the median length compared to feeding WP into the polymer melt. This confirmed the assumption of a milling effect by the solid polymer granules acting like grindstones before they start to soften and melt. This milling effect was overcome when the WP were fed into the polymer melt and particle length degradation was reduced.

WP were pre-heated to prevent possible freezing of the polymer melt, thereby attempting to additionally reduce particle degradation. However, the results showed that pre-heating led to stronger particle degradation represented by WP being up to $11 \%$ shorter with respect to the median length and having an elongation that was up to $4 \%$ higher with respect to the median elongation compared to the cold particles. Pre-heating the WP before processing prolonged their residence time at high temperatures. Wood it is known to experience a significant decrease in mechanical properties when exposed to high temperatures This is caused by the thermal degradation and structural change of cell wall substances, which already starts at temperatures $>105^{\circ} \mathrm{C}$ (Niemz 1993). In the present study, the loss in WP mechanical strength resulted in a lower resistance of the particles to shear stresses from processing. This effect seemed to have outbalanced the advantage of preventing meltfreezing and led to stronger degradation of the pre-heated WP compared to the cold WP.

\subsubsection{Effects of MFI}

\section{Final torque and temperature}

WP were added into the polymer melt and processed with a rotor speed of $60 \mathrm{rpm}$ to study the influence of polymer type and MFR on final torque and temperature. The overall trends of the results were consistent with the results from the first part of the study for this combination of feeding method and rotor speed. As shown in Figure 5.5, final torque and temperature were higher for compounds containing $30 \% \mathrm{WP}$ 

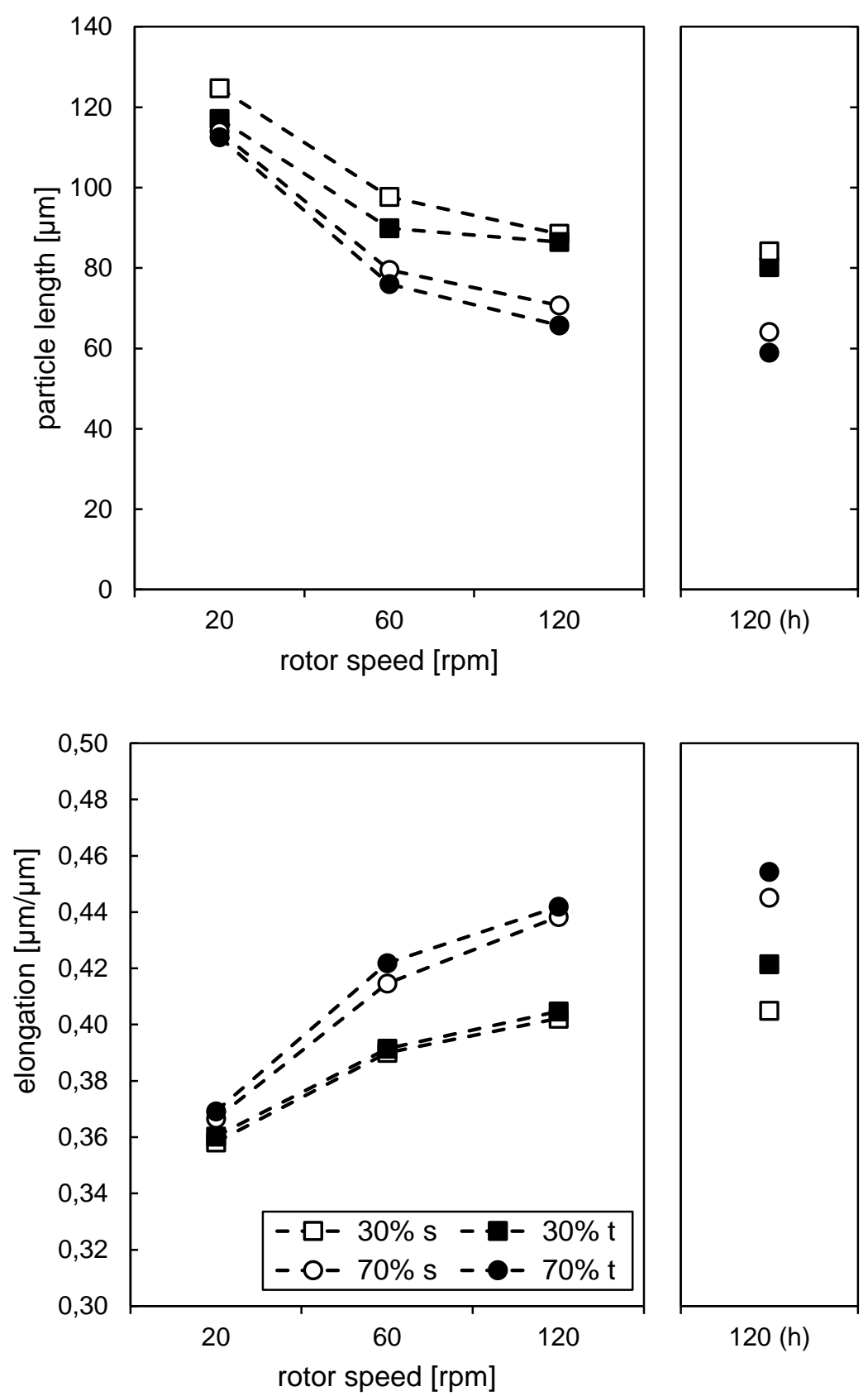

Figure 5.4: WP length and elongation after mixing (h: preheated particles).

than for compounds containing $70 \% \mathrm{WP}$. For equal filler content, final torque and temperature decreased with increasing MFR for both PP and HDPE compounds. This decrease was caused by a lower composite viscosity when a high MFR matrix polymer is used (Yuan et al. 2008). An increase in matrix polymer MFR can balance the decrease of composite MFR caused by filler incorporation (Balasuriya et al. 2001, Yuan et al. 2008). This effect was also responsible for the torque and temperature values being lower for HDPE compounds compared to PP compounds when both contained 70 \% WP. The HDPE and PP grades in this study were chosen with respect to their similar range of MFR. But as the MFR of the HDPE grades was determined at a lower temperature than the MFR of the PP grades, their actual MFR during processing was accordingly higher (and their viscosity lower) than that of PP. 

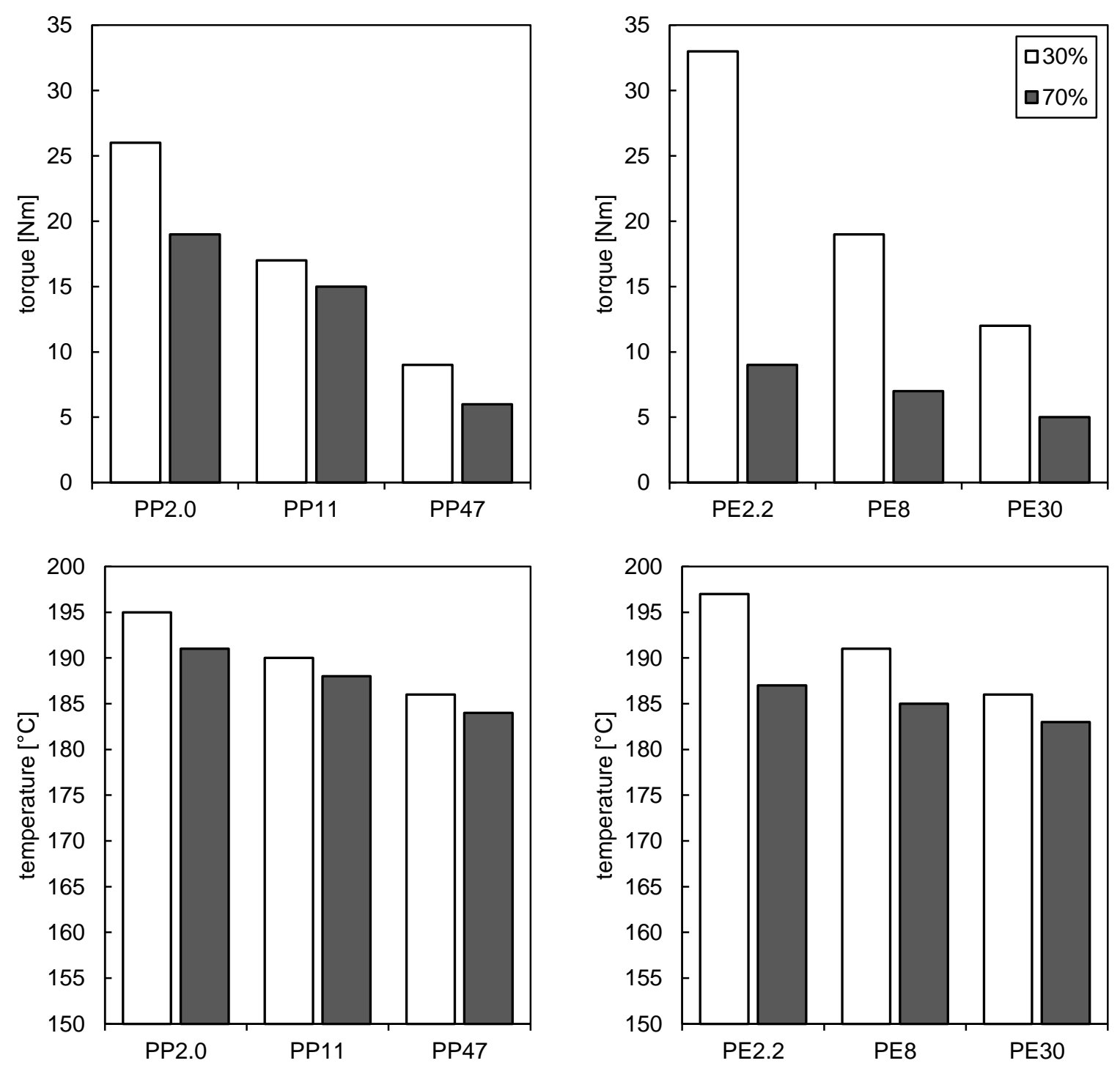

Figure 5.5: Final torque and temperature after 7.5 minutes of mixing.

However, at a WP content of $30 \%$, torque and temperature were higher for HDPE than for PP compounds. As discussed previously, the low WP fraction was properly wetted by the larger polymer fraction. Filler wetting is even increased with high MFR polymers (Balasuriya et al. 2001, Ren \& Dai 2014, Yuan et al. 2008) and thereby composites resistance to shear is enhanced, leading to a larger relative decrease of composite MFR caused by filler incorporation (Hristov \& Vlachopoulos 2007). Due to the higher actual MFR of HDPE during processing, the effect of increased filler wetting seemed to be dominant for the HDPE compounds with $30 \%$ WP content when compared to PP compounds. The resulting higher shear resistance led to higher torque values. 

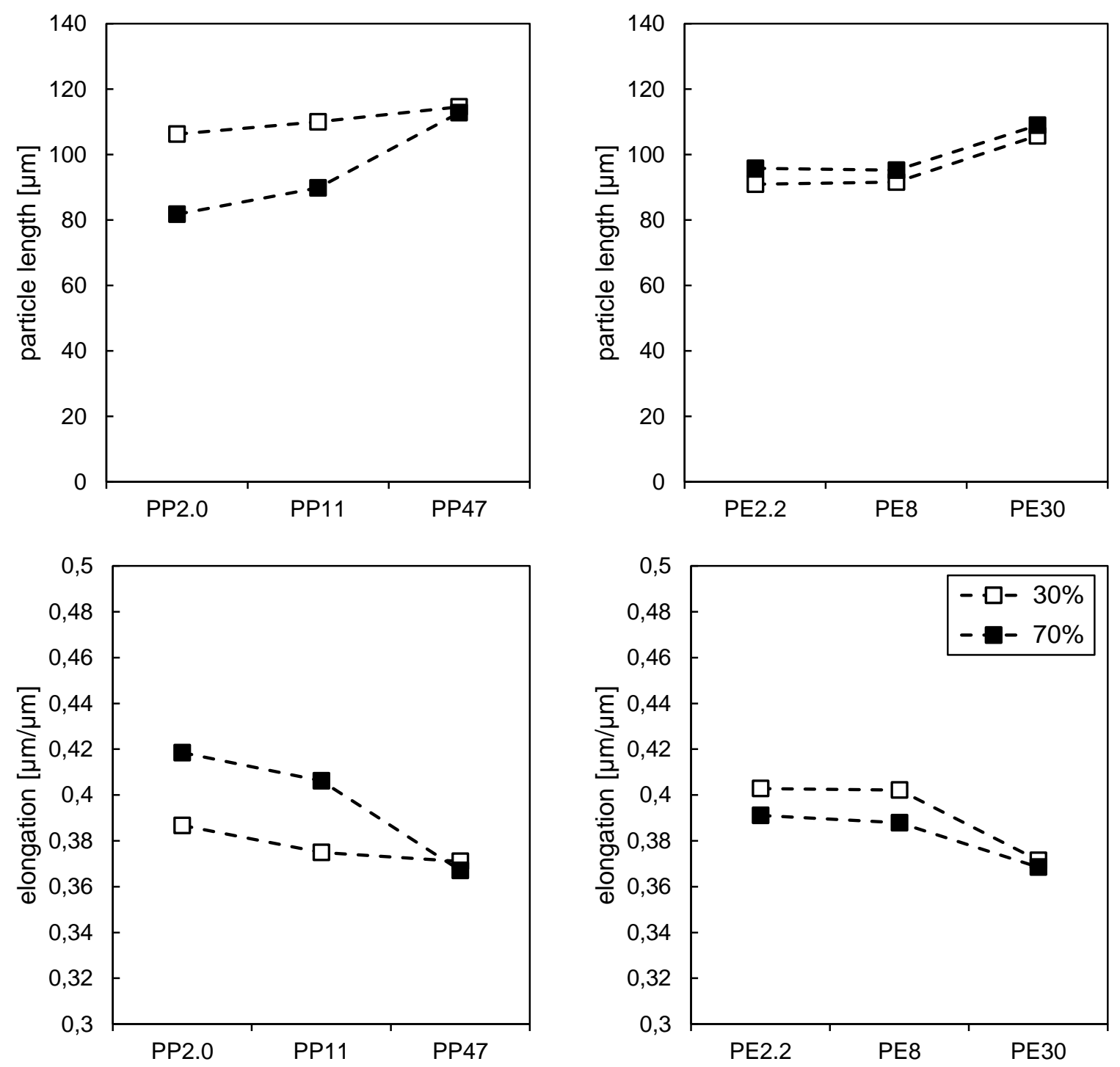

Figure 5.6: WP length and elongation depending on wood content and polymer matrix $M F R$.

\section{Particle degradation}

The median WP length and elongation after processing and dependent on matrix polymer MFR are represented in Figure 5.6. The quartiles and the particle diameters are summarized in Table 5.5. For PP as well as HDPE the particle degradation decreased with increasing MFR. The use of higher MFR matrix polymers lead to lower composite viscosities, which was demonstrated by the lower final torque values. The decrease in viscosity reduced the shear stresses acting on the WP resulting in less severe length reduction.

For the PP compounds there was an obvious difference in particle length and elongation dependent on wood content. Although the viscosity was apparently higher for $30 \%$ filler composites (represented by lower torque values), this was not represented by the particle length results, supporting the assumption of different wall-slip conditions for the present feeding method. For low and medium MFR, WP were $23 \%$ and $18 \%$ shorter with respect to the median length when processed at 
$70 \%$ filler content compared to WP processed at $30 \%$. The higher filler content increased the particle-particle interaction and the composite viscosity. When using a high MFR polymer (PP47) resulting particle length was similar for both filler contents. The high MFR matrix polymer must have provided a better wetting of WP due to its enhanced flowability, leading to reduced friction between the WP. This is also represented by the similar elongation for both filler contents with this matrix polymer.

For the HDPE compounds the difference in resulting particle length dependent on wood content was only marginal with slightly shorter particles when processed at low wood content. Due to its linear structure and high MFR during processing, HDPE can reach high rates of impregnation and penetrate into the lumens and cracks of WP forming a strong physical interlock between filler and matrix (Balasuriya et al. 2001, Yuan et al. 2008). This physical interlock between HDPE and WP, led to severe particle degradation also at $30 \%$ wood content.

\subsection{Conclusions}

WPC based on WP and either PP or HDPE were compounded in an internal mixer to study the dependency of WP degradation on feeding method and polymer MFR. Although the compounding conditions of an internal mixer are not directly comparable to industrially relevant processes, e.g., twin-screw extrusion, general conclusion can be drawn from the results of the present study that could help to reduce filler degradation during WPC compounding.

The feeding method influenced the final torque when WP were compounded with PP. The relation of torque values between $30 \%$ and $70 \%$ filled compounds was reversed when WP were fed into the polymer melt compared to feeding as dry-blend. This indicated that the mixing behaviour of compounds was dependent on feeding

Table 5.5: Particle size and elongation after process with different matrix polymers.

\begin{tabular}{|c|c|c|c|c|c|c|c|c|c|c|}
\hline \multirow{2}{*}{$\begin{array}{l}\text { wood } \\
\text { content } \\
\text { [wt\%] }\end{array}$} & \multirow[t]{2}{*}{ polymer } & \multicolumn{3}{|c|}{$\begin{array}{l}\text { particle length } \\
{[\mu \mathrm{m}]}\end{array}$} & \multicolumn{3}{|c|}{$\begin{array}{l}\text { particle diameter } \\
{[\mu \mathrm{m}]}\end{array}$} & \multicolumn{3}{|c|}{ elongation $[\mu \mathrm{m} / \mu \mathrm{m}]$} \\
\hline & & $\mathrm{X}_{25}$ & $\mathrm{x}_{50}$ & $\mathrm{x}_{75}$ & $\mathrm{X}_{25}$ & $\mathrm{x}_{50}$ & $\mathrm{x}_{75}$ & $\mathrm{x}_{25}$ & $\mathrm{x}_{50}$ & $\mathrm{x}_{75}$ \\
\hline \multirow[t]{6}{*}{30} & PP2.0 & 57 & 106 & 190 & 25 & 35 & 50 & 0.291 & 0.387 & 0.508 \\
\hline & PP11 & 58 & 110 & 199 & 25 & 35 & 49 & 0.279 & 0.375 & 0.928 \\
\hline & $\mathrm{PP}_{47}$ & 59 & 115 & 213 & 25 & 35 & 49 & 0.273 & 0.371 & 0.491 \\
\hline & PE2.2 & 51 & 91 & 156 & 24 & 34 & 47 & 0.306 & 0.403 & 0.519 \\
\hline & PE8 & 51 & 92 & 159 & 24 & 34 & 47 & 0.305 & 0.402 & 0.523 \\
\hline & PE30 & 57 & 106 & 184 & 25 & 34 & 47 & 0.277 & 0.372 & 0.488 \\
\hline \multirow[t]{6}{*}{70} & PP2.0 & 48 & 82 & 137 & 24 & 33 & 46 & 0.324 & 0.419 & 0.542 \\
\hline & PP11 & 50 & 90 & 155 & 24 & 34 & 47 & 0.309 & 0.406 & 0.524 \\
\hline & $\mathrm{PP}_{47}$ & 59 & 113 & 204 & 25 & 34 & 49 & 0.271 & 0.367 & 0.482 \\
\hline & PE2.2 & 53 & 96 & 163 & 25 & 34 & 47 & 0.296 & 0.391 & 0.511 \\
\hline & PE8 & 53 & 95 & 162 & 24 & 34 & 46 & 0.292 & 0.388 & 0.507 \\
\hline & PE30 & 58 & 109 & 191 & 25 & 34 & 48 & 0.272 & 0.369 & 0.484 \\
\hline
\end{tabular}


method. Regardless of filler content, feeding as dry-blend led to stronger particle degradation compared to separate feeding, confirming that the polymer granules were acting like grindstones. Pre-heating of WP prior to compounding increased particle degradation. This was explained by the longer residence time at elevated temperatures leading to reduced mechanical strength of the wood. Particle degradation was reduced by using high MFR matrix polymers. While there was a strong dependence of particle length on filler content for PP compounds, the difference was only marginal for HDPE.

\subsection{Acknowledgements}

This research was supported by the German Research Foundation (DFG), grant GRK 1703/1 for the Research Training Group "Resource Efficiency in Interorganizational Networks - Planning Methods to Utilize Renewable Resources”. 



\section{Chapter 6}

\section{Mimicking industrial scale twin-screw compounding of wood and glass fibres: effect of process conditions on fibre length}

Laura Teubera,*,1 - Damien Even ${ }^{\mathrm{b}}$ - Alan R. Dickson ${ }^{\mathrm{b}}$ - David Sandquist ${ }^{\mathrm{b}, \mathrm{c}}$ - Holger Militz $^{\mathrm{a}, 1}$ - Andreas Kraused,1

aFaculty of Forest Sciences and Forest Ecology, Dpt. of Wood Biology and Wood Products, University of Göttingen, Büsgenweg 4, D-37077 Göttingen, Germany

bScion, Private Bag 3020, Rotorua 3046, New Zealand

cVTT Technical Research Center of Finland LTD, P.O. Box 1000, 02044 VTT, Finland

dInstitute of Mechanical Wood Technology, Department of Wood Science, University of Hamburg, Leuschnerstraße 91c, D-21031 Hamburg, Germany

${ }^{*}$ Corresponding author, email: Laura.Teuber@forst.uni-goettingen.de

${ }^{1}$ DFG Research Training Group "Resource Efficiency in Interorganizational Networks"

Submitted to:

Composites Part A: Applied Science and Manufacturing 


\section{Authorship}

Table 6.1: Contribution of co-authors (Himmel 2015 as modified from Hunt 1991)

\begin{tabular}{lllllll}
\hline & \multicolumn{2}{l}{ Teuber, } & Even, & Dickson, & Sandquist, & Militz, \\
& L. & D. & A. R. & D. & H. & A. \\
\hline Planning \& Design & 20 & 25 & 15 & 15 & 10 & 10 \\
Executing \& Data Collection & 25 & 10 & 0 & 0 & 0 & 0 \\
Data Analysis \& Interpretation & 25 & 10 & 20 & 10 & 10 & 10 \\
Literary Input & 20 & 10 & 15 & 5 & 5 & 5 \\
$\sum$ & $\mathbf{9 0}$ & $\mathbf{5 5}$ & $\mathbf{5 0}$ & $\mathbf{3 0}$ & $\mathbf{2 5}$ & $\mathbf{2 5}$ \\
\hline
\end{tabular}

Laura Teuber prepared the experimental design together with Damien Even, Alan R. Dickson, David Sandquist, Holger Militz and Andreas Krause. She performed the data collection, analysis and interpretation of data and wrote the manuscript.

Damien Even prepared the experimental design together with Laura Teuber, Alan R. Dickson, David Sandquist, Holger Militz and Andreas Krause. He performed data collection and supported analysis and interpretation of data, and wrote the manuscript.

Alan R. Dickson prepared the experimental design together with Laura Teuber, Damien Even, David Sandquist, Holger Militz and Andreas Krause. He assisted in data analysis and interpretation and wrote the manuscript.

David Sandquist prepared the experimental design together with Laura Teuber, Damien Even, Alan R. Dickson, Holger Militz and Andreas Krause. He supported data analysis and interpretation and edited the manuscript.

Holger Militz prepared the experimental design together with Laura Teuber, Damien Even, Alan R. Dickson, David Sandquist and Andreas Krause. He supported data analysis and interpretation and edited the manuscript.

Andreas Krause prepared the experimental design together with Laura Teuber, Damien Even, Alan R. Dickson, David Sandquist and Holger Militz. He supported data analysis and interpretation and edited the manuscript. 


\subsection{Abstract}

The effect of extrusion processing on fibre length was investigated by mimicking industrial scale conditions using a laboratory twin-screw extruder. Wood fibres (WF) and glass fibres (GF) were compounded with polypropylene using different screw designs and varying feed rates and screw speeds. Samples were taken sequentially along the screws after a dead-stop. Fibres were extracted from the compound for length analysis. A gentle screw design and process conditions related to low specific mechanical energy generally resulted in a reduction in fibre length that was more evenly distributed along the length of the screw, rather than concentrated towards the infeed. GF had a higher percentage length reduction and the effect of screw design on fibre breakage was more distinct than for WF. Composite strength was higher for GF composites processed with a gentle screw design. WF fibre length and composite properties appeared less susceptible to different process conditions compared to GF.

\subsection{Keywords}

A. Fibres, A. Polymer-matrix composites, B. Fragmentation, E. Extrusion 


\subsection{Introduction}

Reinforcing polymers with fibres to enhance mechanical properties has been common industrial practice for several decades. Glass fibre (GF) and carbon fibre reinforced polymers are typically used as lightweight materials in the construction, automobile and aircraft industries (Ehrenstein 2006). In recent years, cellulosic fibres, e.g. wood fibres (WF), hemp and flax, have increased in importance as an alternative to synthetic reinforcing fibres. In 2012, the market share of cellulosic fibre reinforced composites in the European Union was $15 \%$ and was expected to grow (Carus et al. 2014). Their renewable character, lightweight behaviour, low cost and competitive mechanical properties, compared to GF, make them desirable for many industrial applications (Faruk et al. 2014).

To date, most investigations on the extrusion processing of cellulosic fibres have used low feed rates at the laboratory scale (Table 6.2) as the feeding of fibres remains challenging due to their low bulk density, non-free flowing behaviour and tendency to entangle and form bridges in the feeding and metering equipment (Diemert 2013). In contrast, industrial scale processing generally requires higher feed rates to obtain an economic production level. As the operating conditions in laboratory and industrial scale processing are quite different and can incorporate different screw designs, making a comparison or scale-up from the laboratory can be difficult or unrealistic. Inceoglu et al. (2011) investigated the effect of screw speed and feed rates on GF reinforced polyamide at both laboratory and industrial scale. They showed less fibre length reduction with increasing feed rate and decreasing screw speed in twin-screw extrusion (TSE). The industrial scale process caused less fibre breakage and the influence of screw speed was less significant compared to laboratory scale processing.

\subsubsection{Specific mechanical energy (SME)}

Altering feed rates and screw speeds changes the SME of processing (Kohlgrüber 2008). The SME represents the mechanical energy input per unit mass that is transferred from the extruder motor to the material through the screws by friction and shear (Godavarti \& Karwe 1997). SME is commercially relevant as a direct measure of the process energy efficiency (Abeykoon et al. 2014). During scale-up, the comparability of process conditions is greater if the laboratory scale SME is in the same range as the commercial scale (Giles et al. 2005, Rauwendaal 2014). It is generally desirable to keep SME to a minimum to avoid wasting energy and overworking the material leading to fibre attrition and thermal degradation due to shear heating. This is particularly relevant for thermally sensitive materials such as cellulosic fibres during scale-up (Andersen 2013). With a laboratory scale extruder, heat from the melt can be extracted by conduction through efficient barrel heat transfer, counter-balancing the shear heating. The same thermal transfer mechanism is drastically reduced on larger extruders due to the higher volume/surface ratio resulting in a higher temperature of the melt (Kohlgrüber 2008, Lowinger 2011). Processing parameters that minimise the SME and shear heating at the laboratory scale help in controlling the temperature of the melt during scale-up (Cicerchi 2012). 


\subsubsection{Fibre length}

The preservation of fibre length during processing is a major focus of fibre composites processing due to the well-known fact that long fibres, with high aspect ratios, provide greater mechanical strength (Chen et al. 2006, Stark 1999). There are three main effects that cause fibre breakage during processing: (i) fibre-fibre interaction, (ii) fibre-polymer interaction, and (iii) fibre-surface interaction with the processing equipment (Berton et al. 2010, Fu et al. 1999). GF and cellulosic fibres differ in shape and stiffness which leads to different deformation behaviours during processing. GF have a rod-like shape and high stiffness and they tend to keep their rod-like shape after processing. In contrast, cellulosic fibres are more flexible and may be curved (Newman et al. 2014). GF break as soon as the shear induced bending stress exceeds the fibre bending strength (Béreaux et al. 2008), whereas cellulosic fibres tend to break progressively under repeated exposure to bending stresses (Le Duc et al. 2011).

\subsubsection{Twin-screw extrusion (TSE)}

Many studies have been carried out to investigate the effect of TSE compounding on fibre degradation of GF and cellulosic fibres. For GF, Mondadori et al. (2008) observed similar fibre lengths after TSE and single screw extrusion (with a barrier screw) compounding. Ramani et al. (1995) performed an extruder dead-stop experiment to analyse the effect of screw design and screw elements on the fibre length. They found that although most of the fibre length reduction takes place in the mixing section, longer fibres continue to degrade downstream of the screw.

There have been a number of studies investigating extrusion process parameters like feed rate, screw speed and screw design on fibre breakage in cellulosic fibre compounds. Non-wood fibres have been investigated in polylactic acid (Gamon et al. 2013, Gunning et al. 2014) and polycaprolactone (Beaugrand \& Berzin 2013, Berzin et al. 2014). For wood fibres, polypropylene (PP) has been the main polymer matrix (González-Sánchez \& González-Quesada 2015, Le Baillif \& Oksman 2009, Peltola et al. 2014). The study of González-Sánchez \& González-Quesada (2015) had particular relevance to the effect of screw design, showing that fibre length is best retained by avoiding mixing blocks in the compression zone of the extruder. As these studies were conducted using a range of different fibre types and polymer matrices they came to different conclusions and direct comparisons between them are problematic. A factor in common with the above studies is that most of them were conducted using feed rates of $10 \mathrm{~kg} / \mathrm{h}$ or less (Table 6.2). For efficient scale-up it is recommended that commercially relevant production rates are used during laboratory evaluation (Cicerchi 2012). 
Table 6.2: Feed rates, screw speeds, SME and extruder screw diameters for twin-screw extrusion of lignocellulosic fibre compounds in the literature.

\begin{tabular}{|c|c|c|c|c|c|}
\hline $\begin{array}{l}\text { feed rate } \\
(\mathrm{kg} / \mathrm{h})\end{array}$ & $\begin{array}{l}\text { screw speed } \\
(\mathrm{rpm})\end{array}$ & $\begin{array}{l}\text { SME } \\
(\mathrm{kWh} / \mathrm{t})\end{array}$ & $\begin{array}{l}\text { extruder screw } \\
\text { diameter }(\mathrm{mm})\end{array}$ & fibre type & Reference \\
\hline $0.85-1.5$ & $100-400$ & $300-1700$ & 25 & hemp & $\begin{array}{l}\text { Beaugrand \& } \\
\text { Berzin (2013) }\end{array}$ \\
\hline $1-3$ & $100-300$ & $300-1100$ & 25 & hemp & $\begin{array}{l}\text { Berzin et al. } \\
(2014)\end{array}$ \\
\hline $13-40$ & $100-300$ & $130-184$ & 28.3 & $\begin{array}{l}\text { miscanthus, } \\
\text { bamboo }\end{array}$ & $\begin{array}{l}\text { Gamon et al. } \\
\text { (2013) }\end{array}$ \\
\hline 2.6 & 150 & - & 25 & $\begin{array}{l}\text { bleached } \\
\text { eucalyptus Kraft } \\
\text { pulp }\end{array}$ & $\begin{array}{l}\text { González-Sánchez } \\
\text { \& González- } \\
\text { Quesada (2015) }\end{array}$ \\
\hline 10 & 200 & - & 27 & jute & $\begin{array}{l}\text { Gunning et al. } \\
\text { (2014) }\end{array}$ \\
\hline 8 & $100-300$ & - & 25 & $\begin{array}{l}\text { bleached sulphite } \\
\text { cellulose }\end{array}$ & $\begin{array}{l}\text { Le Baillif \& } \\
\text { Oksman (2009) }\end{array}$ \\
\hline 2.5 & 200 & - & 25 & $\begin{array}{l}\text { bleached Kraft } \\
\text { pulp (pine, spruce, } \\
\text { eucalyptus, birch), } \\
\text { thermomechanical } \\
\text { spruce pulp }\end{array}$ & $\begin{array}{l}\text { Peltola et al. } \\
(2014)\end{array}$ \\
\hline
\end{tabular}

\subsubsection{Project design}

In the present study we use a laboratory scale TSE to compound wood thermomechanical pulp fibres with polypropylene (PP). The screw speed and feed rates are designed to mimic realistic industrial scale conditions. By using compressed wood fibre dice (Warnes \& Fernyhough 2011) fibre entanglement and bridging (Diemert 2013) is minimised and extrusion throughput is maximized enabling lower SME. To investigate the effect of screw design, dead-stop experiments are carried out to measure the change in fibre length along two different screw profiles. The resulting fibre length profiles are analysed with respect to differences resulting from process conditions and SME as well as screw design. Comparisons are also made to stiff rodlike glass fibres under the same process conditions with the same formulation (as opposed to curly and flexible wood fibres).

\subsection{Materials and Method}

\subsubsection{Materials}

The matrix material for this study was an injection moulding grade copolymer PP type AR564 with a melt flow index of $25 \mathrm{~g} / 10 \mathrm{~min}$ at $230^{\circ} \mathrm{C}$ supplied by Sumitomo Chemical Co., Ltd. Maleic anhydride grafted polypropylene (MAPP) type Eastman ${ }^{\mathrm{TM}}$ G3015 supplied by Eastman Chemical Company was used as a coupling agent.

Two types of fibres were used: (i) glass fibres (GF) type E supplied by PolyPacific Ltd in the form of chopped strands and (ii) wood fibres (WF) commercially available under the trade name Woodforce supplied by Sonae Industria. Woodforce is made 
from thermomechanical pulp fibres fixed with binding agents and formed into pellets using a method described in a patent (Warnes \& Fernyhough 2011). The GF and WF were dried to a moisture content of less than $1 \%$ before compounding. In the compounds the ratio of the materials was set to $67 \%(w / w)$ PP, $3 \%(w / w)$ MAPP, and $30 \%(w / w)$ GF or WF.

\subsubsection{Composite preparation}

The polymer and fibres were compounded in a LabTech ${ }^{\text {TM }}$ LTE $26-40$ (D $=26 \mathrm{~mm}$; $\mathrm{L} / \mathrm{D}=40$ ) co-rotating twin-screw extruder with a four-strand die, a subsequent water bath and a strand pelletizer (pellet length $=3 \mathrm{~mm}$ ). The extruder barrel temperature ranged from $210^{\circ} \mathrm{C}$ (polymer feed) to $180^{\circ} \mathrm{C}$ (before the die) with a die temperature of $190^{\circ} \mathrm{C}$. Two atmospheric and one crammer vacuum vent were used. PP and MAPP were dry-blended and fed into the main infeed using a Weightbatch ${ }^{\mathrm{TM}}$ gravimetric feeder. Fibres were fed into the molten polymer via a side feeder by using a K-Tron twin-screw gravimetric feeder. The extruder screw speed $\mathrm{N}$ (rpm) and feed rate Q $(\mathrm{kg} / \mathrm{h})$ were chosen and combined according to Table 6.3 with the specific throughput (ratio of Q to N) kept constant for different screw speeds. The feed rate of $24 \mathrm{~kg} / \mathrm{h}$ was the maximum achievable for the extruder and WF loading. The screw speeds were selected to provide full fibre dispersion and production stability. Two different screw designs were tested (Figure 6.1). Screw design A was more severe. The mixing section contained three blocks of kneading elements and two reverse elements that had a combined length of 5.75D after the side feeder. Screw design B was gentler with only two blocks of kneading elements and one reverse element with a combined length of the mixing section of $3.25 \mathrm{D} ; 43 \%$ shorter compared to screw design A. Screw design $B$ had additional conveying length to keep a constant total length for the two screw designs.

The compound was collected after running the extruder for 30 minutes. The extruder was allowed to stabilise for the first $15 \mathrm{~min}$, after which the total energy consumed by the motor was recorded for the following 15 minutes. The process was ended by a dead-stop (the extruder and all feeders where stopped at once). The screws were extracted from the barrel and composite samples were collected along the screws at positions $\mathrm{P}_{1}$ to $\mathrm{P}_{7}$ as indicated in Figure 1. Each collection position comprised the length of one screw element. The differences in screw design were before P1 where design A had a kneading element (and B did not), and between P2 and $\mathrm{P}_{3}$ where design A had a reverse element (and B did not). The SME in $\mathrm{kWh} / \mathrm{t}$ was derived from the energy consumed by the motor according to equation 1 :

$$
\mathrm{SME}=\frac{\mathrm{E}}{\mathrm{t}_{\mathrm{c}} \mathrm{Q}} \times 1000
$$

with $\mathrm{E}(\mathrm{kWh})$ being the energy consumed by the motor in compounding time $t_{c}(\mathrm{~h})$ and $\mathrm{Q}(\mathrm{kg} / \mathrm{h})$ being the feed rate. 


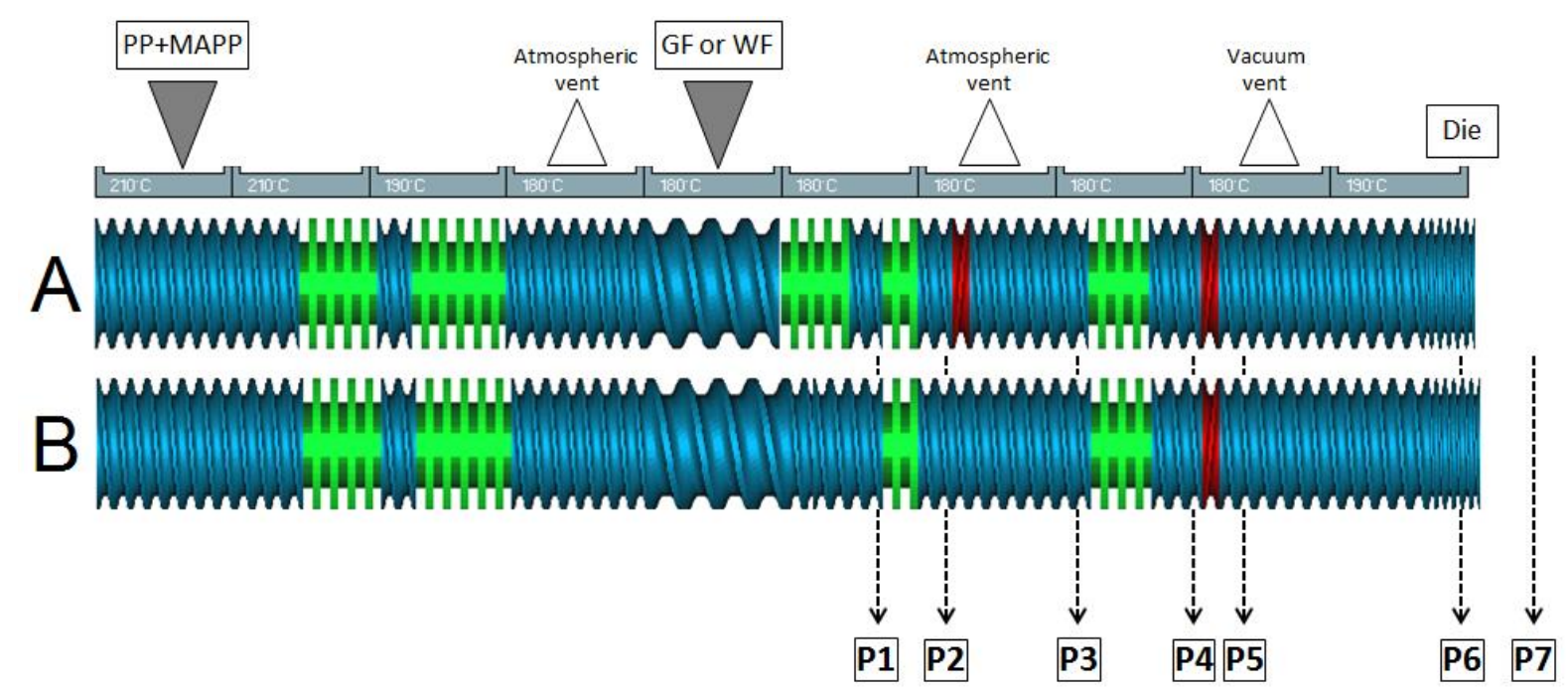

Figure 6.1: Severe screw design A (top) and gentle screw design B (bottom) and sampling points along the screws (P1-P6; P7 represents the compound pellets). Kneading elements in green and reverse elements in red.

\subsubsection{Fibre extraction and characterisation}

The fibres were separated from the matrix via Soxhlet extraction in hot xylene for $8 \mathrm{~h}$. Subsequently, they were kept at room temperature for the xylene to evaporate. In a preliminary study the unprocessed fibres were subjected to the extraction method to ascertain that the extraction did not influence fibre size distribution, i.e. fibre size distributions were identical before and after extraction. For fibre characterisation, the dynamic image analysis device QICPIC (Sympatec GmbH, Germany) with a RODOS dry dispersion unit was used. The fibres were spread manually on a tray and sucked into the device via a flexible tube attached to the RODOS. The fibres were well dispersed in an accelerated air jet when passing the measuring plane. Due to their small diameter, GF had to be measured at a resolution of $5 \mu \mathrm{m}$ (length and width) while for WF a resolution of $10 \mu \mathrm{m}$ was sufficient. The number of objects measured per sample position was approx. 4,000 and 15,000 for GF and WF before compounding and varied between approx. 29,000 and 377,000 for fibres after compounding. The amount of measurable extracted fibres per sample position depended on the degree of filling of the screws at the specific sampling position. Due to a limited amount of extracted fibre and to avoid measurement errors due to nonuniform separation of a sample, all available material was processed in a single run per sample. The fibre length and length distributions were calculated from the

Table 6.3: Combinations of feed rate and screw speed chosen in this study.

\begin{tabular}{cccc}
\hline process condition & $\begin{array}{c}\text { feed rate Q } \\
(\mathrm{kg} / \mathrm{h})\end{array}$ & $\begin{array}{c}\text { screw speed N } \\
(\mathrm{rpm})\end{array}$ & $\begin{array}{c}\text { specific throughput } \\
\mathrm{Q} / \mathrm{N}\end{array}$ \\
\hline $\mathrm{A}$ & 24 & 400 & 0.06 \\
$\mathrm{C}$ & 12 & 200 & 0.06 \\
$\mathrm{~B}$ & 12 & 400 & 0.03 \\
$\mathrm{D}$ & 6 & 200 & 0.03 \\
\hline
\end{tabular}


projected fibre area of binary pictures with the WINDOX 5.8.o.o software (Sympatec $\mathrm{GmbH}$, Germany). Fibre length is defined (Witt et al. 2007) as the shortest path along the fibre between the most distant endpoints of the fibre after skeletonising its projected area and identifying all fibre branches. Fibre lengths are presented using their length-based length distributions $\mathrm{Q}_{1}$ (DIN ISO 9276-1 2004). In contrast to a number-based length distribution, where the number of fibres in a size class is the crucial quantity, the length-based length distribution uses the length of the fibres in a size class as the crucial quantity (Leschonski 1984). As the present fibre length distributions are not normally distributed, the arithmetic mean length is not a good representation of fibre length (Le Moigne et al. 2011). Instead we use the median length $\left(\mathrm{x}_{50}\right)$ (Leschonski 1984) which represents the 50\%-quartile of the cumulative distribution. In the case of the length-based length distribution, the $\mathrm{x}_{50}$ (50\%quartile) divides the added length of all fibres by half.

\subsubsection{Composite characterisation}

Pellets of the final compound were injection moulded to standard test specimens type 1A (ISO 527-2 1993) with a BOY 35M injection moulding machine. Tensile properties were measured for all composites according to (ISO 527-2 1993) on an Instron 5566 universal testing machine. Young's modulus was determined at a crosshead speed of $1 \mathrm{~mm} / \mathrm{min}$, maximum tensile strength at $50 \mathrm{~mm} / \mathrm{min}$. A minimum of 10 specimens per composite were tested. Flexural modulus and maximum flexural strength were measured according to (ISO 178 2010) at a crosshead speed of $1.7 \mathrm{~mm} / \mathrm{min}$ and 8.5 $\mathrm{mm} / \mathrm{min}$, respectively, for 10 specimens. Notched and unnotched Izod impact strength were measured according to (ISO 180 2000) on a CEAST Resil impactor 6957 for 10 specimens. The composite density was determined by the water displacement method for 5 specimens. Flexural and impact properties, and density were measured only for composites processed at $24 \mathrm{~kg} / \mathrm{h}$ with $400 \mathrm{rpm}$ and at $6 \mathrm{~kg} / \mathrm{h}$ with $200 \mathrm{rpm}$.

\subsubsection{Statistical analysis}

For statistical analysis of the composites' mechanical properties and densities, a single factor analysis of variance (ANOVA) followed by a Games-Howell test was conducted at a level of significance of $\alpha=0.05$. The analysis was done with MS Excel 2010 using the Real Statistics Resource Pack software (Release 3.8.1) (Zaiontz 2015).

\subsection{Results and discussion}

\subsubsection{Initial fibre characteristics}

The initial length-based fibre length distributions of GF and WF used in this study are shown as boxplots in Figure 6.2. The $\mathrm{x}_{50}$ of GF was $3180 \mu \mathrm{m}$. The length distribution was relatively narrow with a $25 \%$-quartile $\left(\mathrm{x}_{25}\right)$ of $2485 \mu \mathrm{m}$ and a $75 \%$-quartile $\left(\mathrm{x}_{75}\right)$ of $3497 \mu \mathrm{m}$ and only few very short fibres ( $\mathrm{x}_{10}$ at $1012 \mu \mathrm{m}$ ). The WF were generally much shorter than the GF and the interquartile range was wider. The $\mathrm{x}_{50}$ was $1157 \mu \mathrm{m}$ and the $\left(\mathrm{x}_{25}\right)$ and $\left(\mathrm{x}_{75}\right)$ were $541 \mu \mathrm{m}$ and $1994 \mu \mathrm{m}$, respectively. 


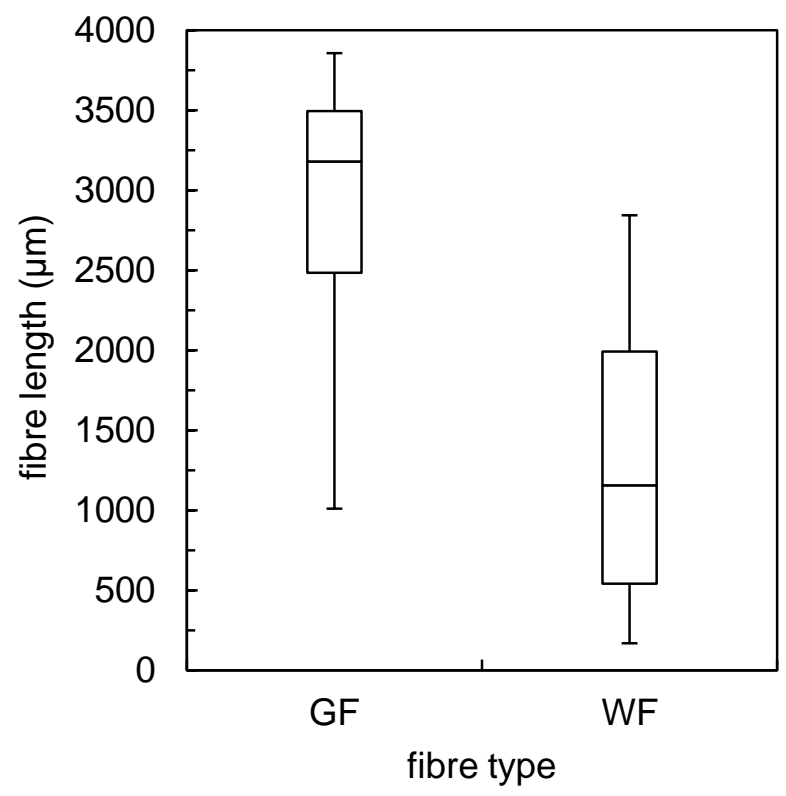

Figure 6.2: Initial length-based fibre length distributions of glass fibres (GF) and wood fibres (WF).The upper and lower bounds of the box represent the $x_{75}$ and $x_{25}$ respectively. The $x_{50}$ crosses the box. The whiskers represent the $x_{10}$ and $x_{90}$.

\subsubsection{Effect of process conditions and SME on fibre length}

All the extrusion runs had SME values between 170 and $287 \mathrm{kWh} / \mathrm{t}$ (Figure 6.3). In contrast, Beaugrand \& Berzin (2013), Inceoglu et al. (2011) and Berzin et al. (2014) reported SME values of approx. $15-85 \mathrm{kWh} / \mathrm{t}, 300-1750 \mathrm{kWh} / \mathrm{t}$ and $375-800 \mathrm{kWh} / \mathrm{t}$, respectively. The SME of industrial scale processes is generally in a range of approx.120-300 kWh/t (Kohlgrüber 2008). This confirms that the SME values of the present study are in a good commercial range and allow for scale-up of the results.

Within the narrow range of SME values in this study there were differences in SME related to feed rate and screw speed. The SME was lower for higher specific throughput (24 kg/h with $400 \mathrm{rpm}$ and $12 \mathrm{~kg} / \mathrm{h}$ with $200 \mathrm{rpm}$ ) and it increased with screw speed at constant feed rate $(12 \mathrm{~kg} / \mathrm{h})$. Beaugrand \& Berzin (2013), Berzin et al. (2014) and Koplin et al. (2013) reported similar trends in their ranges of SME. As the SME represents a direct measure for the mechanical energy imposed on the material during the compounding process (Koplin et al. 2013), these differences in SME were expected to be reflected by differences in degree of fibre breakage for different process settings.

Figure 6.4 shows the change of fibre length along screw designs A and B for different process conditions. For both fibre types and screw designs fibre length showed large reductions of the initial $\mathrm{x}_{50}$ at $\mathrm{P} 1$. For GF the length was reduced to 27$74 \%$ of the initial length and for WF it was reduced to $39-50 \%$. Severe length reductions right after fibre introduction and before any mixing takes place are expected (Ramani et al. 1995, Ville et al. 2013). Further along the screw, process conditions related to high SME (and increasing screw speed) generally resulted in lower fibre lengths, especially in the early stages of mixing ( $\left.\mathrm{P}_{2}-\mathrm{P}_{3}\right)$. 


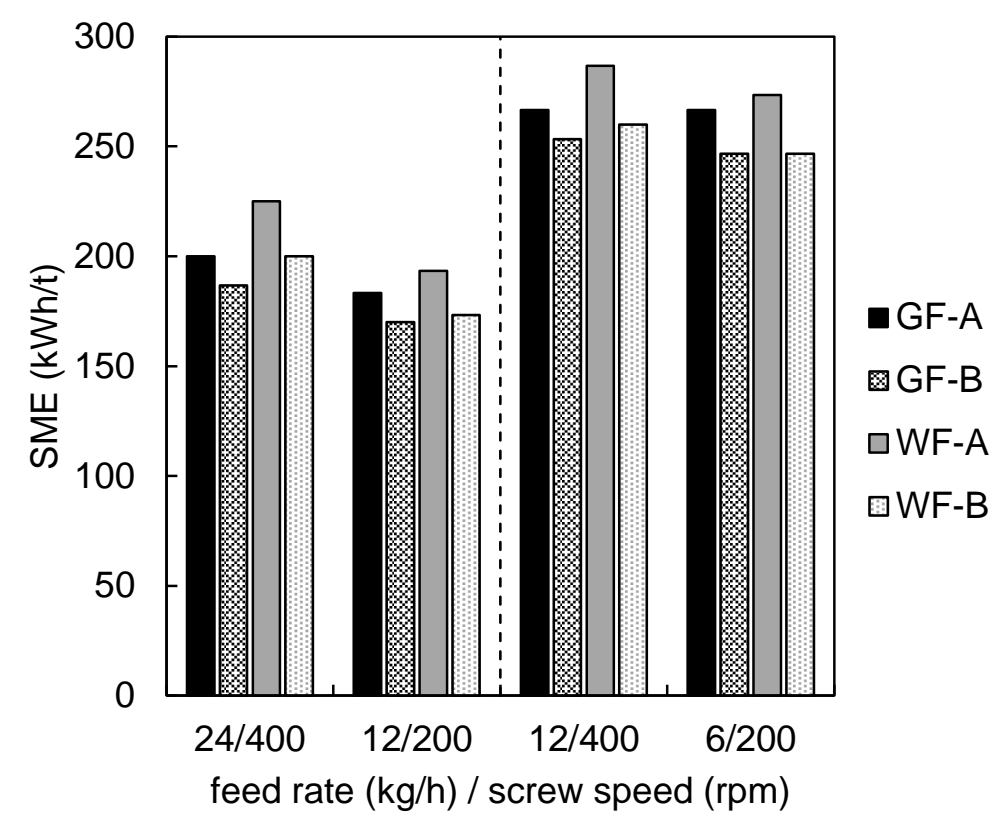

Figure 6.3: SME for the processing of GF and WF for screw A and B at high (left) and low (right) specific throughput.

Decreasing fibre length with increasing SME was also shown by Beaugrand \& Berzin (2013) and Inceoglu et al. (2011). Increasing screw speeds resulted in decreasing lengths of GF (Hirata et al. 2013, Inceoglu et al. 2011, Ville et al. 2013) and cellulosic fibres (Beaugrand \& Berzin 2013, Berzin et al. 2014, Yeh \& Gupta 2008). The effect of screw speed is twofold: On the one hand, an increase in screw speed leads to an increase in shear rate. On the other hand, it reduces the viscosity of the thermoplastic polymer melt and thereby reduces shear (Inceoglu et al. 2011). A decrease in fibre length was also reported with decreasing feed rate (Beaugrand \& Berzin 2013, Berzin et al. 2014, Inceoglu et al. 2011, Ville et al. 2013, Yeh \& Gupta 2008). Low feed rate means a longer residence time and therefore a longer exposure of the fibres to stress (Inceoglu et al. 2011).

Although the present study showed that fibres in the early part of the screw ( $\left.\mathrm{P}_{2}-\mathrm{P}_{3}\right)$ were generally shorter when processed under conditions related to high SME, these differences were not evident in the final compound ( $\left.\mathrm{P}_{7}\right)$. In agreement with studies of Gamon et al. (2013), Joffre et al. (2014) and Le Baillif \& Oksman (2009), there were little or no differences in final fibre length due to process conditions. Final median lengths of GF at 408-494 $\mu \mathrm{m}$ corresponded to $13-16 \%$ of the initial $\mathrm{x}_{50}$. Final median lengths of WF at 223-279 $\mu \mathrm{m}$ corresponded to $19-24 \%$ of the initial $\mathrm{x}_{50}$. Hence, the percentage reduction in fibre length was higher for GF than for WF.

\subsubsection{Effect of screw design on fibre length degradation}

Changes in fibre breakage along the screw due to process conditions were not equal for both screw designs. With screw A the lower feed rates resulted in greater length reductions of GF (Figure 6.4A). With screw B the difference due to feed rate was smaller (Figure 6.4B). This illustrates a combined effect of SME, feed rate and screw design in reducing fibre length during the early stages of processing for GF, which was not seen for WF. The additional kneading block of screw A lead to $34-52 \%$ 
A

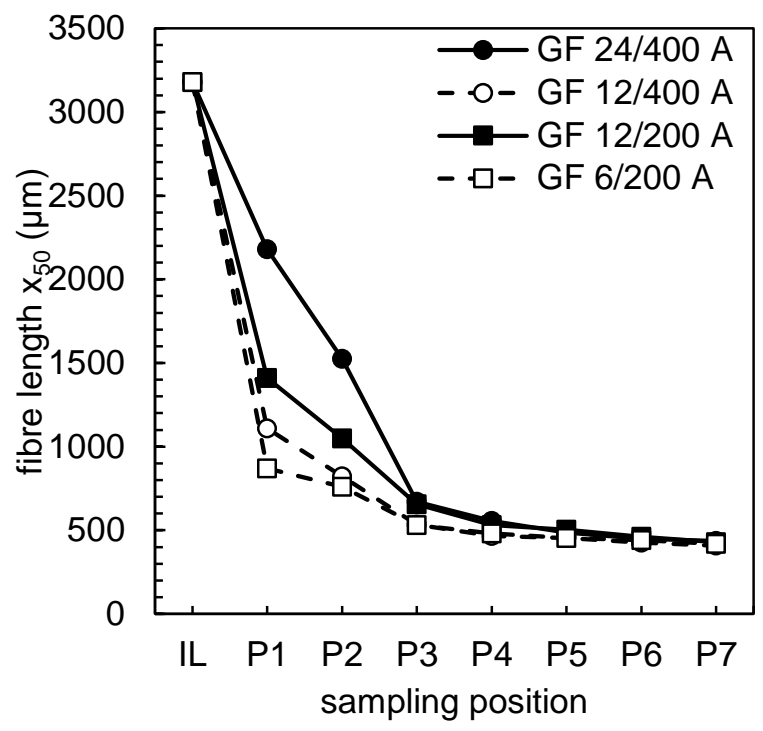

C

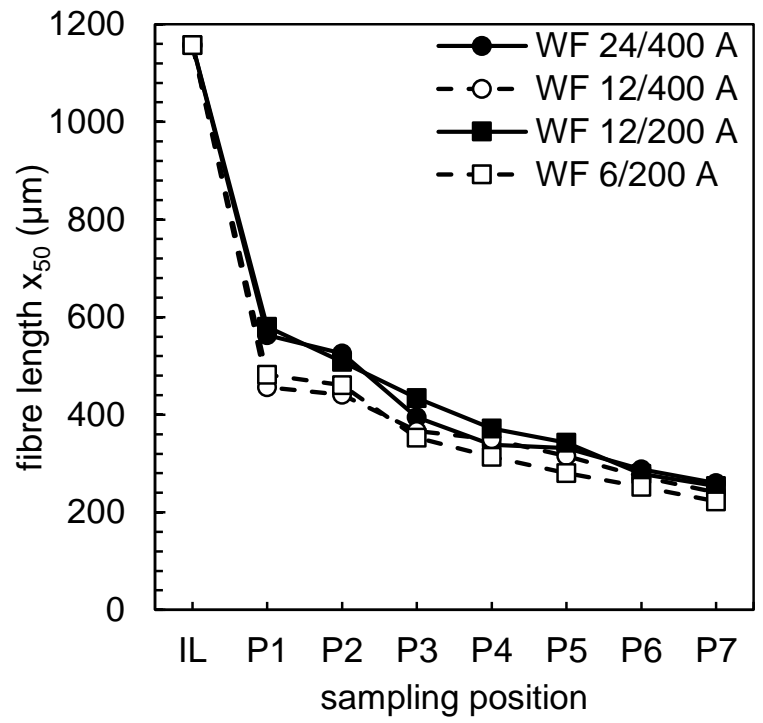

B

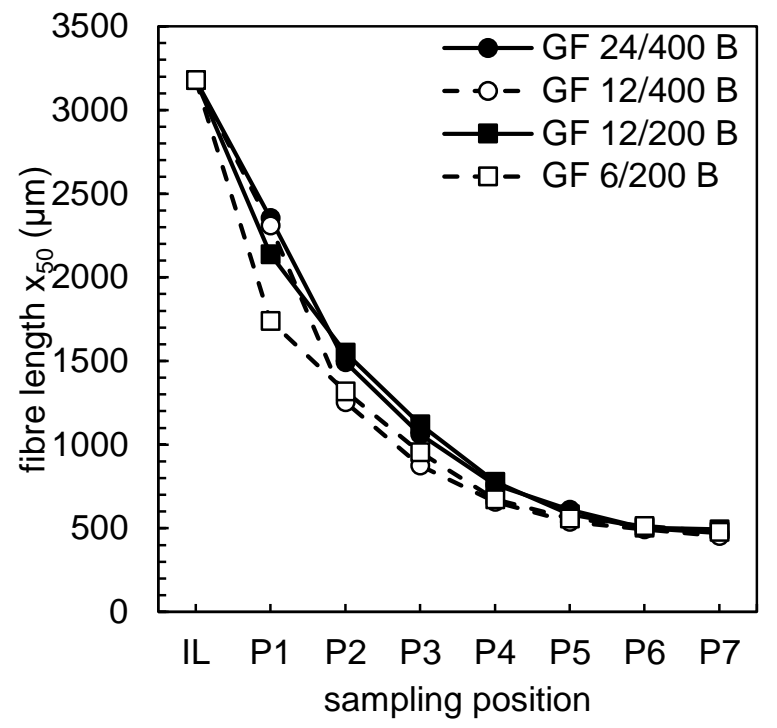

D

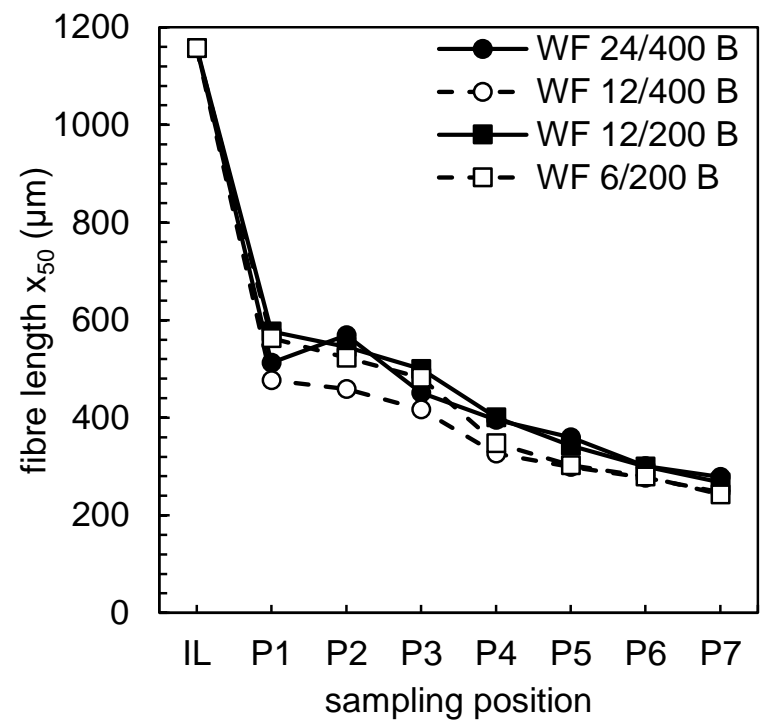

Figure 6.4: Change in median fibre length $x_{50}$ of GF ( $A$ and $B$ ) and WF ( $C$ and $D$ ) for screw $A(A$ and $C$ ) and screw B (B and D) at low (filled symbols) and high (empty symbols) SME. IL: initial length, P1-P6: sampling points along the screw, P7: final compound.

shorter GF at P1 compared to screw B (Figure 6.5B-D). The specific shape of kneading blocks, i.e., individual discs arranged with an offset to each other, interrupts the screw flight with separate disc tips which intensify the mixing action and increase shear (Kohlgrüber 2008). A high feed rate combined with a high screw speed (Figure 6.5A) appeared to be beneficial for preserving GF length with screw A since it was similar to that with screw B, but only until the reverse element before $\mathrm{P}_{3}$ was reached. The reverse element of screw A reduced GF length at $\mathrm{P}_{3}$ to $17-21 \%$ of initial $\mathrm{x}_{50}$, which is $37-44 \%$ shorter compared to screw $\mathrm{B}$. Reverse elements intensify mixing by pumping the material against the global transport direction and building up pressure (Kohlgrüber 2008).

Compared to the kneading and reverse elements positioned upstream of the screw, the elements positioned downstream had a reduced effect. The critical shear induced 
A

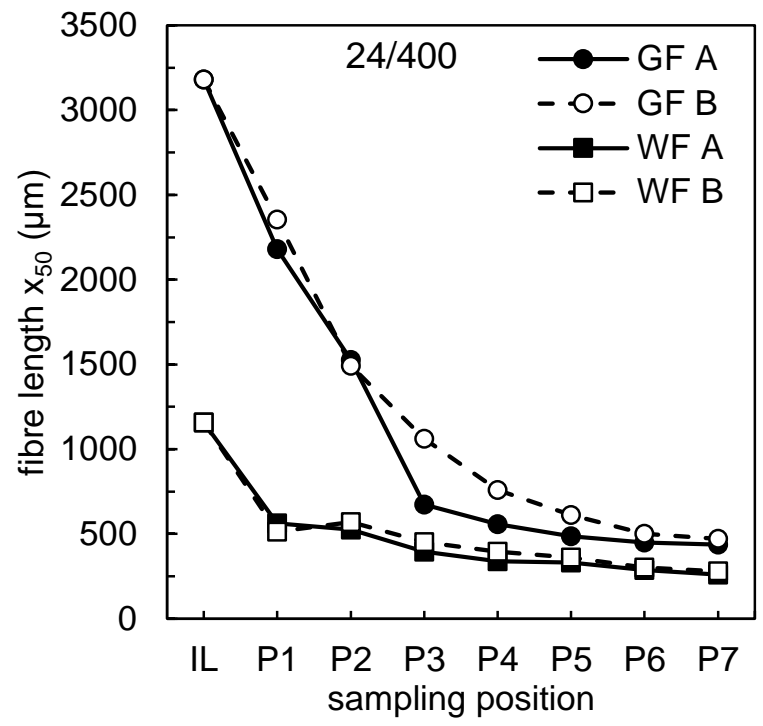

C

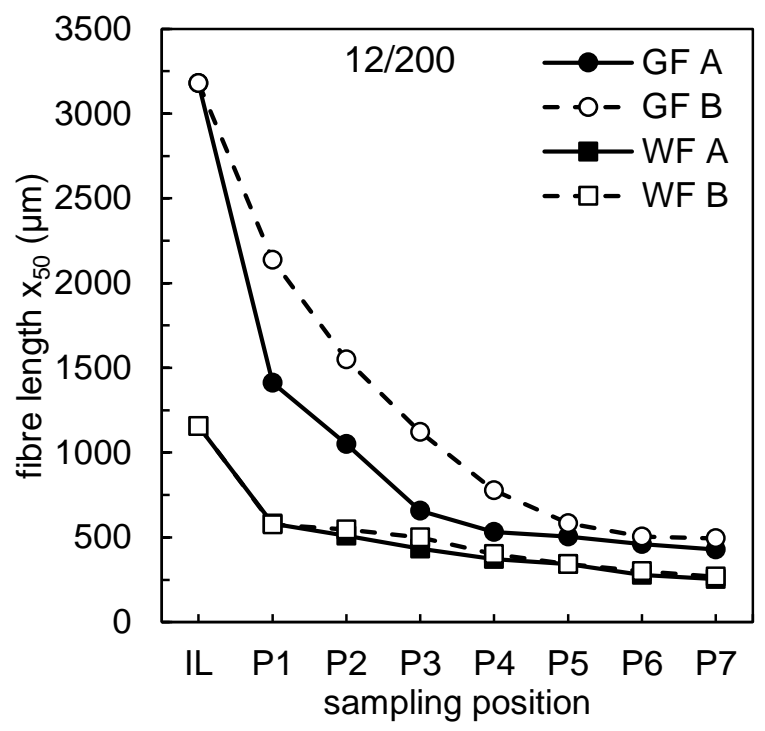

B

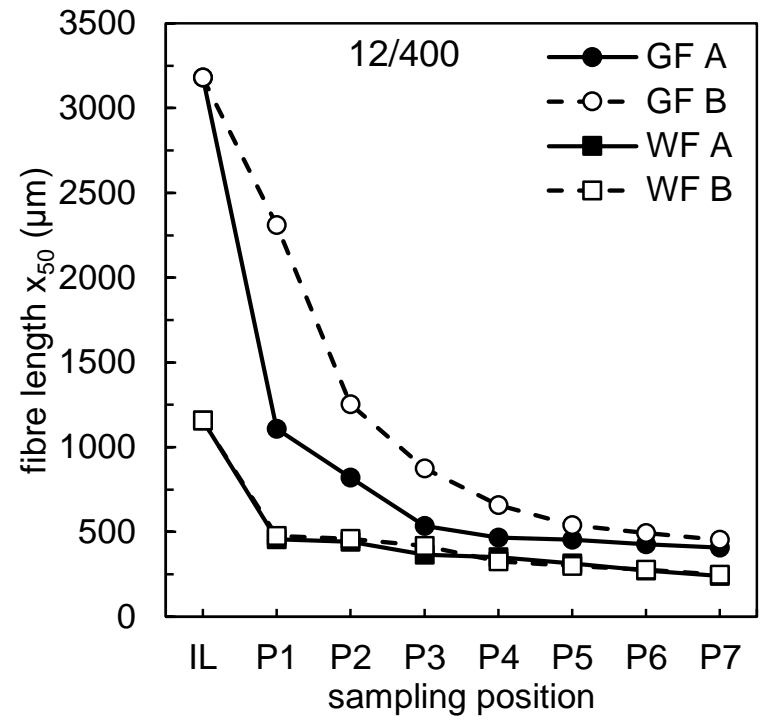

D

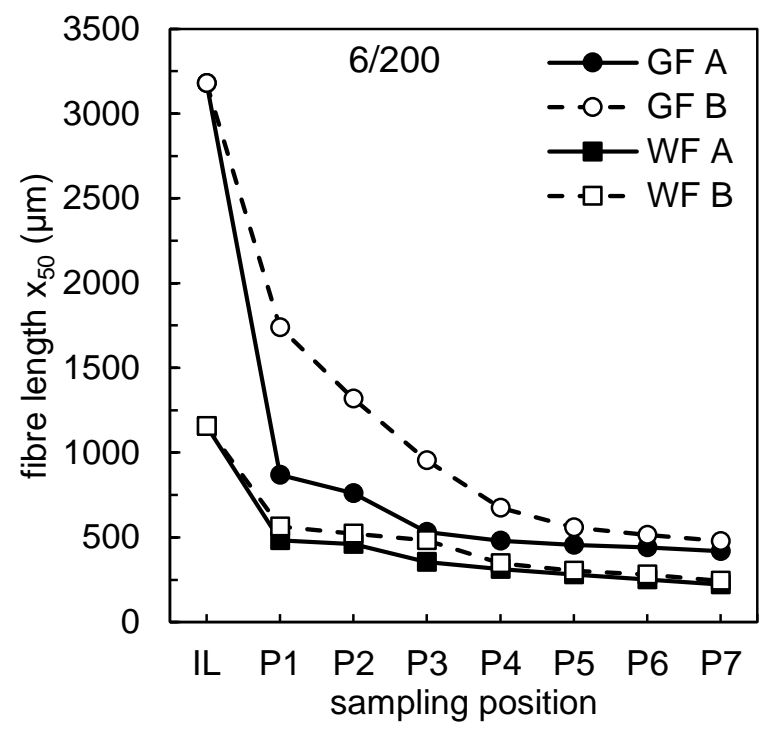

Figure 6.5: Change in median fibre length $x_{50}$ of GF (circles) and WF (squares) processed with severe screw A (filled symbols) and gentle screw B (empty symbols) at different process conditions (A-D)(Table 6.3). IL: initial length, P1-P6: sampling points along the screw, P7: final compound.

bending stress leading to fibre breakage depends on the intrinsic mechanical fibre properties as well as on the fibre length (Durin et al. 2013, Inceoglu et al. 2011, Ville et al. 2013). The stress that is necessary to damage the fibres increases when the fibre length decreases along the screw (Inceoglu et al. 2011, Ville et al. 2013). GonzálezSánchez \& González-Quesada (2015), for example, observed that Kraft pulp fibres suffered less damage in the compression zone of an extruder when they were already shorter before entering that zone.

For WF the effect of the kneading element before $\mathrm{P} 1$ and the reverse element before $\mathrm{P}_{3}$ in screw A was not as distinct as for GF (Figure 6.5). Towards the end of the screw (from $\mathrm{P}_{3}$ with screw $\mathrm{A}$ and $\mathrm{P}_{5}$ with screw $\mathrm{B}$ ), fibre length reduction occurred at a similar low rate for both fibre types. On the one hand, the difference between GF and WF (at the infeed end of the extruder) might be attributed to the difference in 
mechanical properties and breaking behaviour of the fibre types. On the other hand, the relatively short initial length of WF compared to GF made them less susceptible to breakage by shear induced loading. A similar result was seen during the reprocessing of WF (Dickson et al. 2014).

Overall, reduction of fibre length occurred at a slower rate with screw B, with the fibres generally longer at each sampling point compared to screw A. Final GF length (P7) was 8-15\% longer with screw B compared to screw A. For WF the overall effect of screw design was smaller due to the reasons stated above. Final WF were only 3$9 \%$ longer with screw B compared to screw A.

\subsubsection{Mechanical properties}

Mechanical and physical testing of the final composites was performed to determine if differences in TSE process conditions, screw design, and differences in final fibre lengths resulting thereof, were also represented by the composite properties. As the injection moulding process was kept constant for all samples, its impact on final fibre length was also considered to be constant.

Table 6.4 and Table 6.5 show the results for the mechanical and physical testing of GF and WF composites, respectively. Composite strength and stiffness were similar to composites with comparable fibre loadings and within the typical property ranges as reported by Sobczak et al. (2012). As expected, the 30 \% GF composite used here had tensile and flexural strength and moduli higher than the values reported by Dickson et al. (2014) for $20 \%$ filled composites. WF composite tensile and flexural properties were in between those reported by Stark (1999) for composites containing $20 \%$ and $40 \%$ wood fibres. Tensile strength and modulus, flexural modulus and impact strength were lower than that of $40 \%$ Kraft pulp fibre composites, but flexural strength was higher (Beg \& Pickering 2008a). Flexural and tensile strength were also better than those of $40 \%$ wood fibre composites shown in Stark \& Rowlands (2003).

The difference in final fibre length due to screw design for GF was also reflected by some significant differences in the GF composite properties, especially in composite strength. With screw B flexural strength and tensile modulus were 1-8\% higher, tensile strength was 3-7\% higher compared to screw A. For WF the composite properties showed no difference due to screw design. For wood fibre composites, good fibre dispersion has been recognised as an important factor influencing the mechanical properties (Le Baillif \& Echtermeyer 2010). It can be achieved by e.g. high screw speeds (Le Baillif \& Oksman 2009) or a more severe screw design (Beaugrand \& Berzin 2013). Rapid fibre dispersal was one of the design features of the WF pellets (Warnes \& Fernyhough 2011) used in the present study. Processing the WF with a gentler screw design had no effect on composite properties due to less aggressive fibre dispersal. González-Sánchez \& González-Quesada (2015) observed that differences in mechanical properties fit to differences in fibre length only when fibre length differed by more than $10 \%$. This would explain why longer fibres with screw $\mathrm{B}$ resulted in higher composite strength for GF but not for WF. 


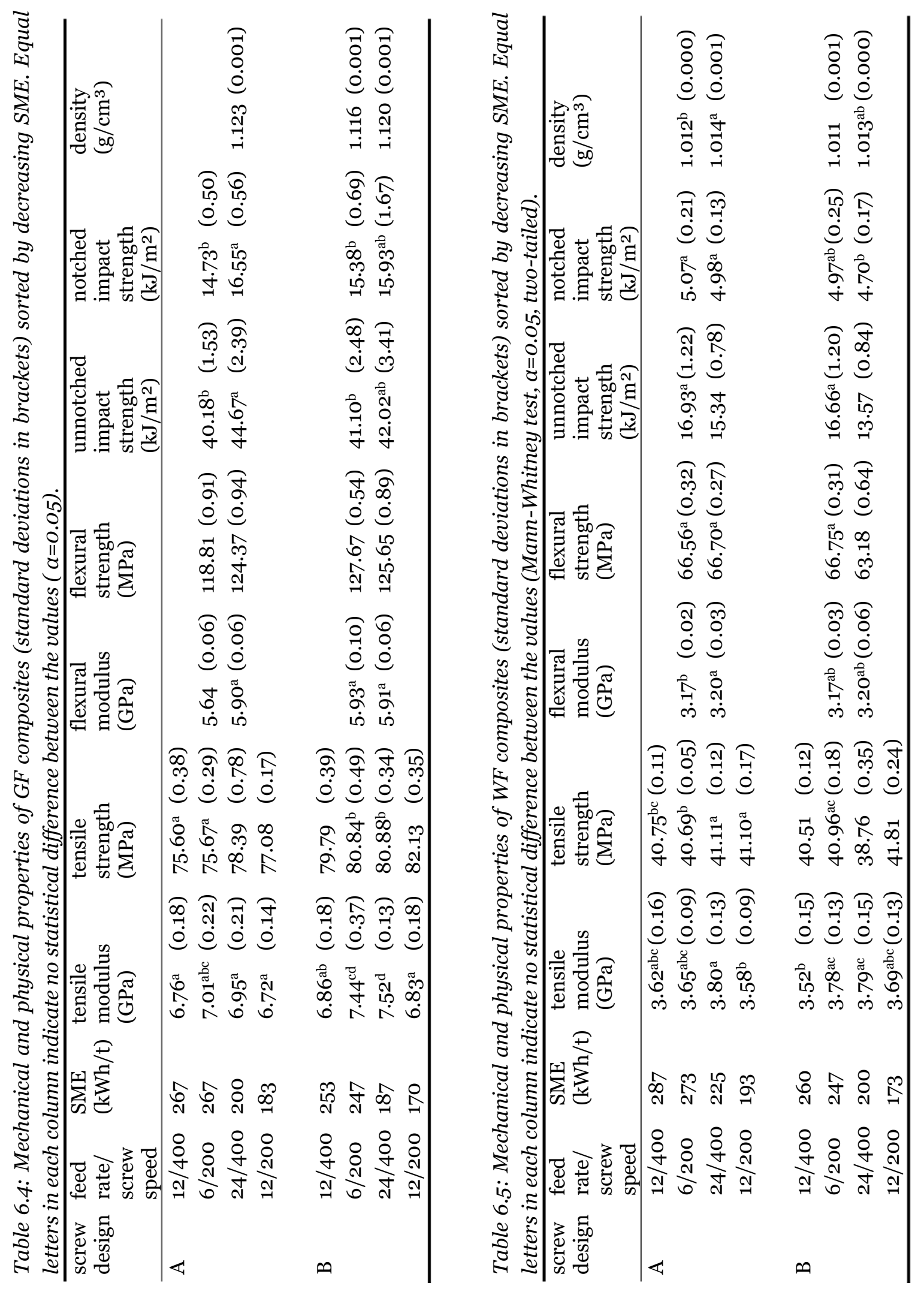




\subsection{Conclusions}

Industrial scale extrusion conditions were successfully mimicked on a laboratory scale twin-screw extruder by choosing feed rates and screw speeds that resulted in commercially relevant SME values. Fibre length analysis showed that severe fibre breakage occurred right after fibre feeding. Fibre breakage could be reduced by choosing process conditions related to low SME, especially in the early stages of mixing. However, the beneficial effect of low SME was largely lost further along the extruder and the final fibre length was similar for all conditions. WF were initially shorter than GF and were also shorter in the final composite. Largely due to their initially shorter lengths, WF showed a lower percentage length reduction during processing than the GF. This may also be the reason why WF fibre lengths and composite properties were less sensitive to different screw design than GF.

\subsection{Acknowledgements}

This research was supported by the German Research Foundation (DFG) (grant GRK 1703/1 for the Research Training Group "Resource Efficiency in Interorganizational Networks - Planning Methods to Utilize Renewable Resources"), the New Zealand Ministry of Business, Innovation and Enterprise (MBIE) and Scion core funding.The authors would like to thank Ross Anderson for technical assistance throughout the extrusion trials and mechanical testing and Doug Gaunt, Marc Gaugler and Hamish Pearson for comments on the manuscript. 


\section{Chapter 7}

\section{Results and Discussion}

\subsection{Method of filler morphology characterisation}

For the characterisation of filler morphology, dynamic image analysis with QICPIC was introduced in Chapter 4. The QICPIC is designed for the analysis of free-flowing powders or particulate material. In the present thesis it was successfully applied for the characterisation of wood particles and fibres. When using the vibrating chute to feed the particles it was possible to measure a high amount of particles in a few minutes (several thousand up to a few million particles per measurement). For nonfree-flowing fibres like the wood fibres and glass fibres used in Chapter 6, it was not possible to use the vibrating chute. These fibres first had to be spread manually on a tray, thereby thoroughly separating tight fibre agglomerates, before they were sucked into the measurement device via a flexible tube that was attached to the main dispersion unit. Compared to particle samples where no sample preparation prior to the measurement was necessary, the preparation and measurement of fibre samples was more time-consuming. However, it was still less time-consuming than the preparation necessary for static methods involving microscopes and scanners where fibre overlapping needs to be avoided (Ferreira et al. 1999). With the QICPIC full dispersion is achieved inside the laminar air jet of the main dispersion unit. Figure 7.1 exemplarily shows binary images from the measurements of wood particles (A), wood fibres (B and C) and glass fibres (D) after processing. In most cases the dispersion of particles/fibres was good (A, B, D). For the wood fibres, sometimes entanglements remained due to the fibres' rough surface and curly nature (C).

Particle/fibre length was described by using the geodesic length defined as the shortest path between the most distant end points of the projected area (Witt et al. 2007). This method was developed to describe especially the length of branched fibres (Witt et al. 2006). Figure 7.2 exemplarily shows images of wood fibres, glass fibres and wood particles with the length indicated within the projected area as calculated by the software. Especially in the case of particles the mathematically correct length sometimes does not correspond to the distance that would intuitively be chosen as length by a person.

As discussed in Chapter 4, the length-based size distribution was chosen throughout the thesis for the analysis of filler degradation during processing. The length of the filler is a crucial parameter with respect to technical application as it defines the filler aspect ratio, which in turn influences the mechanical properties of the composite (Nourbakhsh et al. 2010, Stark \& Rowlands 2003). In number-based distributions, the fines content dominates the distribution and changes in the longer part are not 


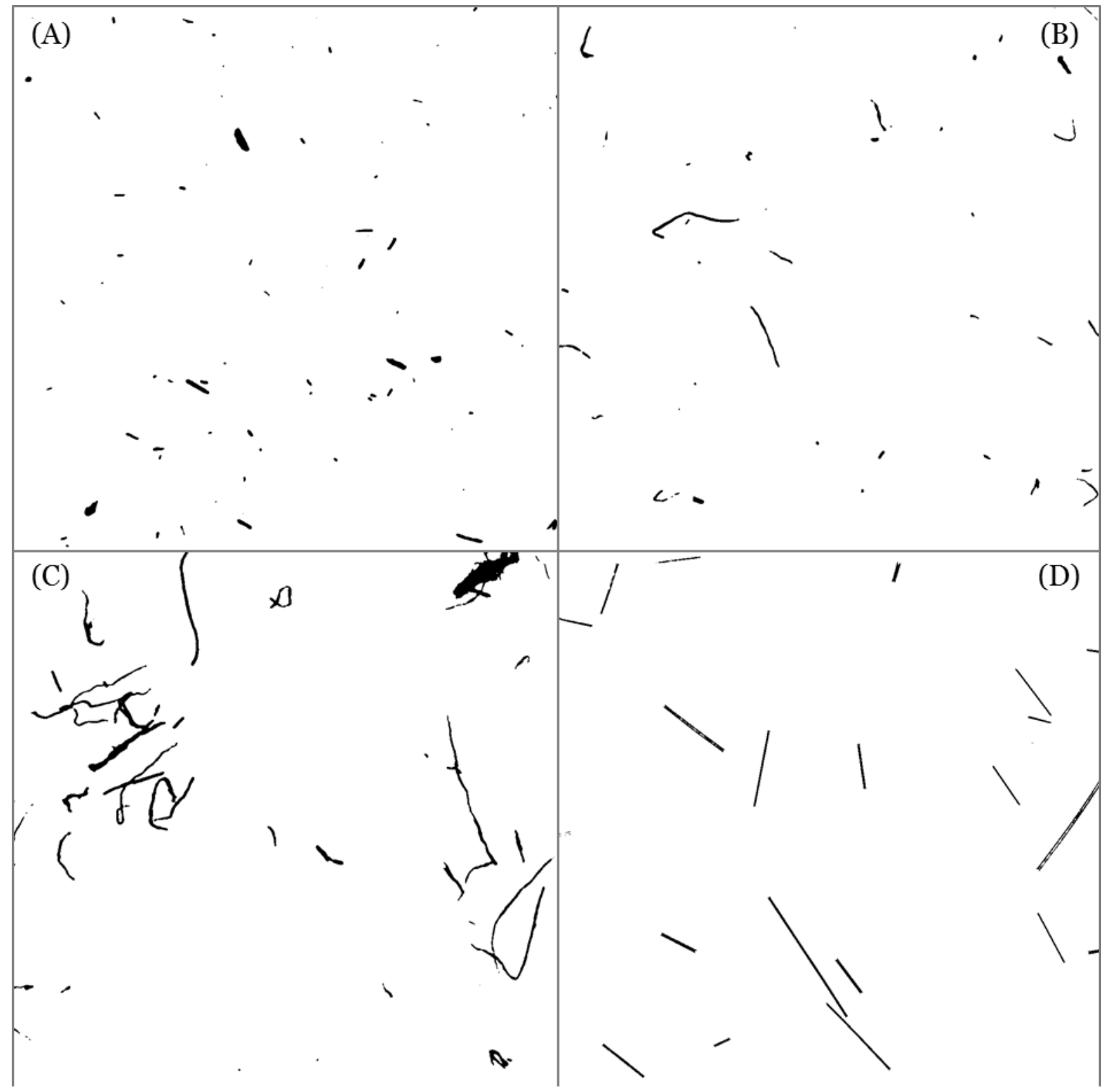

Figure 7.1: Binary images from the measurements of wood particles (A), wood fibres (B \& C) and glass fibres (D). Flow direction from left to right.

visible. Weighting the distribution with filler length leads to physically relevant results (compare Chapter 4). In the case of image analysis, also the analysis of areabased size distributions (where the projected particle/fibre area serves as type of quantity) is practical and realized by some authors (Plinke et al. 2012, Schirp et al. 2014, Schirp et al. 2015). The specific surface of the filler in the composite represents the site of stress transfer from the matrix to the filler (Ashori 2008) and the area of interaction for e.g. coupling agents (Krause \& Krause 2012). With the analysis of the area-based size distribution, the specific filler surface area can be estimated. This is especially true for static image analysis methods since the particles/fibres come to rest in their most stable position displaying their largest projected area (Merkus 2009) with the third dimension being the smallest. However, the length-based distribution was used in the present thesis because the WINDOX software that analyses the images obtained with the QICPIC calculates the area-based distribution 


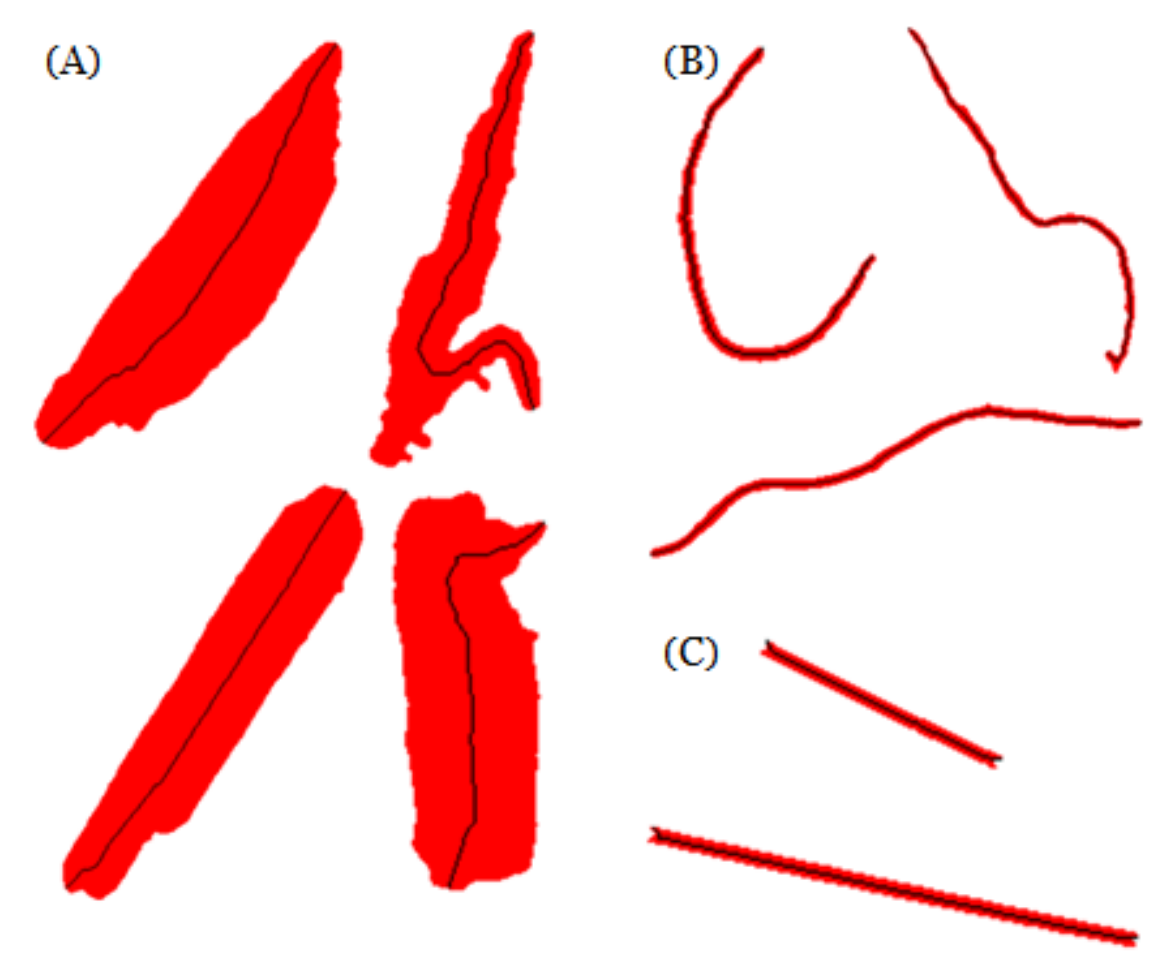

Figure 7.2: Images of wood particles (A), wood fibres (B) and glass fibres (C). The black line indicates the geodesic length as calculated by the WINDOX software (images not to scale).

from the particle length in the power of two instead of from the projected particle area. Like this, the area-based distribution is not a realistic representation of the specific filler surface area, especially in the case of fibres. Another limitation is the random orientation of particles/fibres in the measurement zone. Their position with respect to the third dimension cannot be estimated from the binary pictures. But especially long curly wood fibres might be at an angle to the flow producing projected areas that appear to be shorter than the fibres actually are or they might reach out of the measurement plane and appear as fragments on the binary images.

Nonetheless, the characterisation method used in the present thesis was sufficiently accurate to evaluate filler degradation during processing and to distinguish between different process conditions.

\subsection{Comparability of internal mixer and TSE}

Two different methods, i.e. internal batch mixer and TSE, have been applied to compound wood particles or fibres with thermoplastic matrices and to study the effect of different process parameters on filler length degradation. In the internal mixer, two counter-rotating, non-intermeshing rotors circulate the material around a figure-eight shaped chamber. The rotors thereby transport the material into opposite directions. At one end of the chamber the material is transferred from one rotor to the other and then transported to the other end of the chamber (White et al. 1988). Distributive mixing takes place in the large space between the rotors, dispersive mixing in the narrow gap between the edge of the rotor wings and the chamber wall (Iannace et al. 2001). 
In the TSE, the material is transported along and mixed by two co-rotating, intermeshing screws composed of individual elements that fulfil different tasks (compare section 2.2.2). Here, distributive mixing is realised by the exchange of material among partial flows across the screw flights and through the intermeshing zone. Dispersive mixing occurs at the flight tips, which are regions of high shear (Kohlgrüber 2008).

The very different flow fields in the two compounding systems lead to the states of stresses in the TSE being much more diverse than in the internal mixer. Even if the process settings are selected in a way to result in similar extent of shear rate and efficient energy consumptions, the direct comparability of both compounding processes is limited (Goharpey et al. 2008). Rozman et al. (2012), for example, showed that compounding kenaf core particles with PP either with an internal mixer or a TSE resulted in different compound flexural properties, although similar rotor/screw rotation speeds were applied. Better flexural properties from internal mixing were explained with better dispersive mixing performance leading to a higher degree of filler wetting and better particle/matrix interaction. However, they do not provide any information about material residence time in the extruder, making a comprehensive comparison of process conditions impossible.

In terms of fibre length reduction, Inceoglu et al. (2011) studied the effect of compounding GF/PA with an internal mixer and a TSE. They chose process conditions that resulted in comparable global strain and SME values for both process types. Internal mixing led to less fibre breakage than TSE which indicates that a direct comparison of the results obtained from the two processes is not possible. However, they found that the trends of processing effects on fibre length within the compounding systems are comparable. For example, increasing the rotor and screw speed both led to decreasing fibre length. The same was true for increasing the mixing time in the internal mixer or increasing the residence time (decreasing the feed rate) in the extruder. The SME turned out to be especially suitable for the evaluation of fibre breakage within both compounding systems (Inceoglu et al. 2011).

In Chapters 4 and Chapter 5, WPC with equal composition have been produced with an internal mixer and a TSE. The given process data does not allow to draw conclusions on the actual comparability of process conditions. Nevertheless, some similarities between the two processes with respect to particle degradation are visible, e.g. both processes resulted in a similar degree of particle degradation and in both processes particle degradation was higher for higher filler contents. Taking into account these findings and the findings of Inceoglu et al. (2011), it is assumed that results from internal mixing can at least be conceptually applied to extrusion processes. 


\subsection{Filler degradation during processing}

\subsubsection{Feeding method}

In Chapter 5, the influence of feeding method on wood particle degradation during compounding in an internal mixer was analysed. Although the effect was little compared to overall degradation, feeding the particles into the already molten polymer, rather than feeding wood particles and polymer as a dry blend, resulted in a lower degree of size reduction.

In extrusion compounding the filler material can be added to the process in either one of two ways. In Chapter 4, wood particles were added together with the polymer through the main infeed upstream of the extruder. In Chapter 6, wood and glass fibres have been added via a side-feeder into the polymer melt further downstream of the extruder. Feeding the filler material upstream increases the effective mixing length of the extruder and ensures a thorough incorporation of the filler into the matrix. Feeding the filler downstream into the polymer melt might lead to insufficient filler dispersion, especially in the case of fibres (Le Baillif \& Echtermeyer 2010). For the wood fibres in Chapter 6 this was not the case, since they were designed for rapid fibre dispersal. Yet, it also reduces the exposure to shear stresses and causes less fibre damage compared to feeding the fibres upstream (Shon \& White 1999). Hence, fibres should be fed to the compounding process after the melting zone of the extruder, while for e.g. fine wood flours exploiting the full length of the extruder can ensure breakup of particle agglomerates and proper particle dispersion.

\subsubsection{Polymer viscosity}

As explained in section 1.4, polymer viscosity plays an important role in compounding since it is affected by and affects the filler material. It has a direct influence not only on composites rheological properties but also on the composite homogeneity. Although polymer viscosity has almost no effect on the distribution of the filler in the matrix polymer, it is crucial for filler dispersion (Kohlgrüber 2008). High shear rates and shear stresses present with high viscosities are beneficial for breakup and dispersion of agglomerates but can also cause filler degradation.

Chapter 5 tested the influence of polymer viscosity on wood particle degradation during compounding. It was shown that the use of high MFR polymers reduced particle degradation since overall composite viscosity was decreased and friction between the particles was reduced through better filler wetting. In Chapter 6 a PP with comparatively high MFR (Table 2.1) was chosen as a matrix for wood and glass fibres. In view of the results from Chapter 5 this choice was beneficial for fibre length preservation and reducing the amount of shear during processing.

\subsubsection{Interrelation of process parameters}

Shear is the dominating factor responsible for filler degradation. The amount of shear acting on the filler is influenced not only by the polymer viscosity but by a variety of parameters, e.g. screw or rotor speed and filler content. These parameters in turn are not independent but influence each other and are influenced by additional factors 


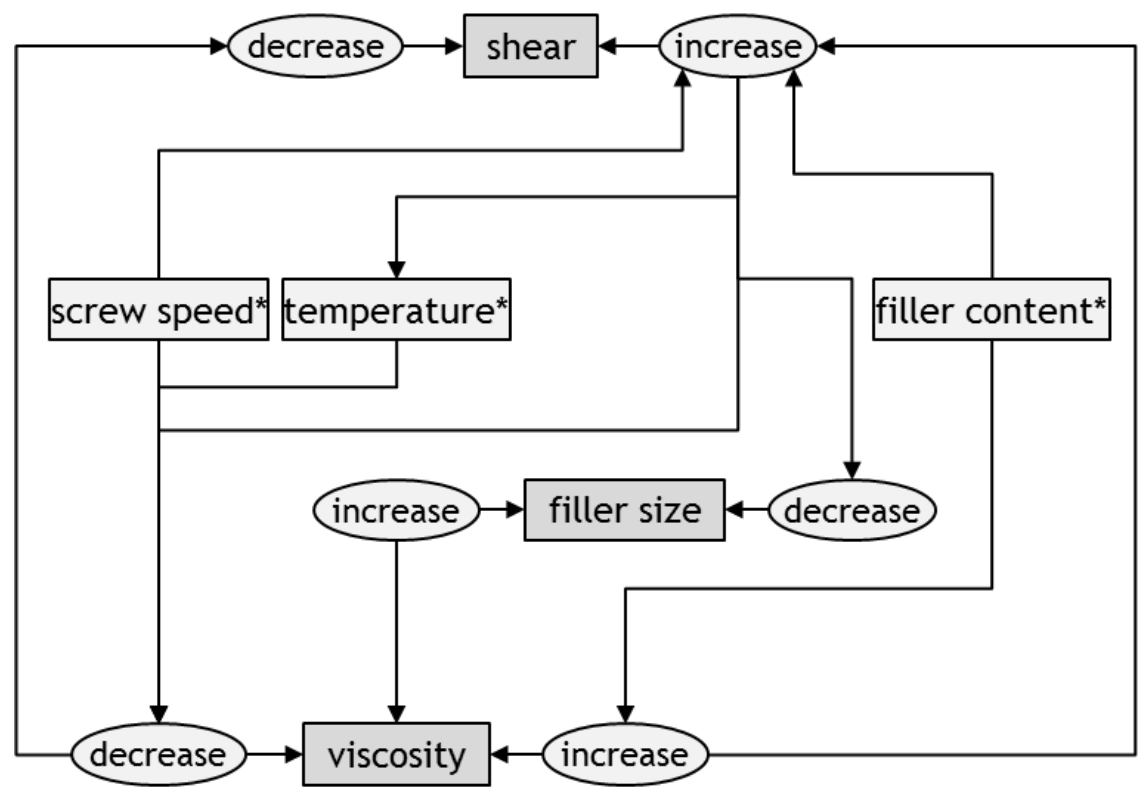

Figure 7.3: Interrelation of process parameters and their influence on filler degradation.

(Figure 7.3): the shear acting on the filler within the polymer melt increases with polymer viscosity (González-Sánchez \& González-Quesada 2015, Peltola et al. 2014). The melt viscosity increases with increasing filler content (Zhang et al. 2007). Increasing the screw/rotor speed increases the shear rate and thereby the shear forces acting on the filler, but at the same time the increase in shear rate reduces the viscosity due to the polymer melt's shear-thinning behaviour (Ville et al. 2013). Viscosity is also decreased by an increase in melt temperature due to viscous energy dissipation (Campanelli et al. 2004). As mentioned in section 1.4 filler size also plays a role in defining the composite rheological properties, but its effect is not fully understood, yet. An additional aggravating factor is the changeability of filler size during processing. Its effect therefore is not static but changes throughout the compounding process. Dependent on the compounding process type, additional parameters play a role in filler degradation, e.g. feed rate, SME and screw design in extrusion (Beaugrand \& Berzin 2013, Ville et al. 2013).

In Chapter 6, wood and glass fibres of the final compound did not show any differences in length related to twin-screw extrusion conditions. But along the extruder screws the change in fibre length varied with screw design, screw speed and feed rate: process conditions related to high SME generally resulted in lower fibre lengths, especially in the early stages of mixing. For the particles in Chapter 4 and Chapter 5, some trends in final length were visible. The strongest effect on particle degradation was related to filler content. The increase in particle degradation with increasing filler content was explained with an increase in particle-particle interaction (Azizi \& Ghasemi 2009, Gallagher \& McDonald 2013) and increased composite viscosity resulting in higher shear (Peltola et al. 2014). Increasing rotor speeds in internal mixing while keeping the mixing time constant lead to stronger particle degradation due to an increase in accumulated shear (Chapter 5). The effect of screw speed in TSE on particle degradation was ambiguous and varied with feed rate, filler content and screw design (Chapter 4). 


\subsubsection{Screw design}

The screws of TSE are designed to fulfil different tasks, e.g. solids conveying, melting, melt conveying, mixing, degassing, and building up pressure (Rauwendaal 2014). The screw configuration plays a crucial role for filler incorporation and has to be chosen in a way that balances filler dispersion and filler degradation (Gunning et al. 2014, Ramani et al. 1995). The effect of screw configuration on filler degradation was studied in Chapter 4 and Chapter 6. Screw designs differed by the amount and position of kneading and reverse elements (Table 2.2). In both studies, filler degradation was stronger with the more severe screw design that contained more kneading and reverse elements. A comparison of the combined lengths of kneading and reverse elements shows that screw designs used in Chapter 6 were gentler compared to screw designs used in Chapter 4. Also the overall effective screw length for filler incorporation was shorter since a side-feeder was used in Chapter 6 but not in Chapter 4.

In Chapter 6, it was shown that severe fibre breakage takes place right after fibre feeding - an effect that has also been reported by other authors (Ramani et al. 1995, Ville et al. 2013). The effect of high shear inducing kneading elements was clearly demonstrated by comparing fibre lengths before and after passing these elements. Also the reverse elements had a severe effect on fibre lengths and ruined improvements in the screw design further upstream. Kneading and reverse elements tend to increase the screw fill degree (Zhang et al. 2015). Also the compression zone of the extruder before the die has a high screw fill degree. This region has been reported to cause severe fibre shortening due to high shear stresses (GonzálezSánchez \& González-Quesada 2015). Kneading and reverse elements and regions of high screw fill degree have been recognized to raise the SME of the compounding process. Since high SME was related to more severe filler degradation (Chapter 6), these types of elements should be avoided, especially in the compression zone (González-Sánchez \& González-Quesada 2015), and as far as sufficient fibre dispersal can still be provided (Gunning et al. 2014).

From the results of Chapter 6, it is concluded that screw design is crucial for fibre length retention as its effect superimposed the effect of gentle process conditions. For the wood fibres the use of a reduced amount of kneading elements and thereby a reduced amount of dispersive mixing might be feasible to preserve fibre length. Since the fibre dice were designed for rapid and easy dispersal, fibre dispersion would possibly not be affected. Less dispersive mixing could also be beneficial for coarse wood particles like they were used in Chapter 4 to prevent their degradation by disintegration through high shear stresses.

\subsubsection{Laboratory scale vs. industrial scale TSE}

The aim of transferring operating parameters from a laboratory scale TSE process to an industrial scale process is to achieve a product with the same quality but at a higher production rate (Kohlgrüber 2008). As explained in Chapter 6, scale-up of the results from laboratory scale studies regarding compounding of fibres and polymers is usually difficult. Often low feed rates are used because fibre feeding is challenging 
(Ashori et al. 2011) but industrial scale processes require higher feed rates to be economically reasonable. Also the operating conditions with respect to heat transfer, shear (Kohlgrüber 2008, Lowinger 2011) and processing effects (Inceoglu et al. 2011) can be quite different.

A successful scale-up from the laboratory to the industrial scale requires process similarity with respect to extruder and screw geometry and operating conditions, i.e. similar average shear, similar residence times of the material in the screw sections, comparable heating/cooling power. If two extruders are geometrically similar, the screw speed may stay the same during scale-up while the throughput has to be changed with respect to screw speed, screw pitch and free volume (Kohlgrüber 2008). It has to be made sure that the degree of fill of the screw sections is similar from one extruder to another since the average shear increases with increasing screw fill degree (Lowinger 2011, Rauwendaal 2014).

A characteristic value to describe an extrusion process is the SME. The comparability of extrusion processes is greater when the SME at the laboratory scale is similar to that at the industrial scale (Giles et al. 2005, Rauwendaal 2014). In Chapter 6, commercially relevant SME values have been achieved by mimicking industrial scale process conditions on a laboratory scale extruder. The extruder was of a similar size (40D) as the extruder of the laboratory scale study in Chapter 4 but the chosen feed rates and screw speeds were much higher (6-24 $\mathrm{kgh}^{-1}$ and 200-400 rpm compared to 4-8 $\mathrm{kgh}^{-1}$ and 80-160 rpm). Also the SDF was higher (Table 2.2).

\subsubsection{Final filler size}

The experimental studies in Chapters 4 to 6 have in common that filler degradation during processing was enormous, independent of filler type, process type and processing conditions. The spruce wood particles in Chapter 4 and Chapter 5 were shortened to $<3 \%$ of their initial length before processing, the radiata pine wood fibres and glass fibres in Chapter 6 to $<24 \%$ and $<16 \%$, respectively. The variation in filler length among the processing conditions within each study was only marginal compared to the overall length reduction (Table 7.1).

In Chapter 6, it was concluded that the rate of fibre breakage seems to be more related to initial fibre length than to process conditions and intrinsic fibre properties. This assumption is further supported when considering the results just mentioned above. The initial particle and fibre lengths have been in a range of approx. 1-6 mm with wood particles being the longest followed by glass fibres and wood fibres. The longer the particles/fibres were initially, the higher was the percentage length reduction during processing. A strong sensitivity of fibre length to processing for fibres $>1 \mathrm{~mm}$ in length is a common phenomenon and has also been reported elsewhere for hemp fibres (Beaugrand \& Berzin 2013, Berzin et al. 2014), flax fibres (Ausias et al. 2013, Bourmaud et al. 2016, Le Duc et al. 2011), regenerated cellulose fibres (Le Duc et al. 2011), and glass fibres (Inceoglu et al. 2011). In contrast to that, Soccalingame et al. (2015) reported wood particles of initially $108 \mu \mathrm{m}$ and $68 \mu \mathrm{m}$ being reduced to $64 \%$ and $91 \%$ of their initial size, pointing out that initially smaller sized particles were less sensitive to processing. González-Sánchez \& González- 
Quesada (2015) came to a similar conclusion when they compounded kraft pulp fibres. The fibres suffered less damage in the compression zone of the extruder when they were already shorter before entering that zone.

Ausias et al. (2013) compounded flax fibres of different lengths with PP and subjected the compound to several extrusion cycles after which the fibres all ended up at similar lengths. Le Duc et al. (2011) showed the same effect when compounding regenerated cellulose fibres of different initial lengths. Iannace et al. (2001) showed that the length of sisal fibres did not decrease much further after a certain mixing time in a batch mixer was reached. In a study of Dickson et al. (2014), fibre length of MDF, flax, and glass fibres stabilised after subjection to multiple extrusion cycles and in a study of Hirata et al. (2013), glass fibre length reached a stable level after extrusion, although feed rate was further altered.

According to Ausias et al. (2013) and Bourmaud et al. (2011), these phenomena could be explained by a critical filler size for given process conditions below which the effect of further processing on filler size is not any longer significant. The level of this critical size thereby depends on the given process conditions and especially on the intrinsic fibre properties (Le Duc et al. 2011). With respect to the optimisation of process conditions to increase filler length retention, this means that more drastic changes in process parameters towards gentler process conditions are necessary to keep filler length above the critical length and to be able to distinguish between the processing effects of different parameters.

\subsection{Alternative raw materials}

A variety of possible raw material alternatives has been identified in Chapter 3, which proved to be suitable for the production of WPC with acceptable material properties. The use of recycled polymers and biopolymers as matrix material has been discussed, as well as the use of post-consumer and post-industrial wood wastes and agricultural residues. Each of these alternatives requires a thorough characterisation of the chemical, physical and mechanical material properties as they influence the process conditions each in their own specific way and thereby differently affect filler degradation. Recycled polymers might have different properties compared to their virgin equivalents due to changes of the chemical structure and to contaminations by other polymer types (Ares et al. 2010, Petchwattana, Covavisaruch \& Sanetuntikul 2012, Selke \& Wichman 2004). Thereof resulting changes, e.g. of the rheological properties, directly influence the amount of shear acting on the filler during

Table 7.1: Initial and final filler length as presented in the studies of Chapters 4 to 6.

\begin{tabular}{lllll}
\hline Chapter & process type & filler type & $\begin{array}{l}\text { initial median } \\
\text { length }[\mu \mathrm{m}]\end{array}$ & $\begin{array}{l}\text { median length after } \\
\text { processing }[\mu \mathrm{m}]\end{array}$ \\
\hline 4 & TSE & spruce wood particles & 6068 & $82-162$ \\
5 & internal mixer & spruce wood particles & 6068 & $59-125$ \\
6 & TSE & radiata pine wood fibres & 1157 & $223-279$ \\
6 & TSE & glass fibres & 3180 & $408-494$ \\
\hline
\end{tabular}


compounding (compare Chapter 5 and section 7.3.2). The flow properties of the composite melt might also change due to the chemical composition when different wood species are used (Li \& Wolcott 2004) and wood wastes may contain impurities like adhesives, resins and coatings (Daian \& Ozarska 2009) that likewise affect the compounding behaviour of the filler material or blend with the polymer matrix. Process parameters like temperature, screw design, screw speed, and feed rate require being adapted to the specific filler properties to maintain a good mixing performance of the process and to keep the degree of filler degradation as low as possible.

With the use of alternative raw material for the production of WPC, the compounding process has to be optimized for the specific materials used to result in high quality composite properties. Although these material alternatives affect the process conditions each in a specific way, the influence of processing on filler degradation for alternative fillers is not expected to differ a lot among different filler types. The results from Chapters 4 to 6 , as well as the results from other studies discussed in the previous section (7.3.6), suggest that the general filler degradation behaviour is similar independent of filler material type.

\subsection{Prediction of process conditions and final fibre length}

Some approaches for the predictions of process conditions and filler degradation already exist. Vergnes et al. (1998) developed a software to simulate the process conditions inside a co-rotating twin-screw extruder. The software is based on a model that calculates the evolution along the screws of flow parameters, i.e. pressure, residence time and energy, from the screw design, the material properties (rheological and thermal) and the process conditions (screw speed, feed rate, barrel temperature) (Vergnes et al. 1998, Ville et al. 2013). Inceoglu et al. (2011) introduced the modified Shon-Liu-White model, a model to predict final fibre length after compounding by taking into account SME, and applied it to glass fibre/polyamide composites. Ville et al. (2013) used the aforementioned software to calculate the evolution of SME along the screw and applied the results to the modified Shon-LiuWhite model to predict glass fibre length evolution along the screw. Final fibre length was in good correlation with experimental results but fibre length along the screw was overestimated by the model. This was explained by changing fibre breakage kinetics with changing fibre length along the screw which is not taken into account by the model (Ville et al. 2013). In addition, deviations might result from the simulation results, as the software calculates with the material properties as present in the final compound. But especially rheological properties can differ in the early stages of mixing. Beaugrand \& Berzin (2013) combined the simulation software and the modified Shon-Liu-White model to predict the degradation of hemp fibres during compounding. They correlated final fibre length to SME and could show that degradation is stronger for higher SME. 


\subsection{Effect of filler size on composite properties}

In section 1.4, the importance of filler morphology in defining the properties of WPC was introduced. While particles generally increase the polymer's stiffness and brittleness (Clemons 2002), fibres can have a reinforcing effect and improve the mechanical properties, especially when they have high aspect ratios (Ashori et al. 2011, Chen et al. 2006, Stark 1999, Stark \& Rowlands 2003). Reinforcement occurs above a critical fibre length that is dependent on fibre diameter, fibre strength and fibre/matrix adhesion (Sain \& Pervaiz 2008). Since fibre length is subject to changes during compounding with the polymer matrix and during further processing, the amount of fibres left with a length above the critical length is important for final composite mechanical properties.

In Chapter 6, the final fibre length of wood and glass fibres after having been subject to different compounding conditions was compared to resulting composite mechanical properties. Differences in fibre lengths resulted in more significant differences in mechanical properties for glass fibres than for wood fibres. Differences in fibre length seem to match differences in mechanical properties only when fibre length differs to a certain minimum degree (González-Sánchez \& González-Quesada 2015). This requirement was met by the glass fibre compounds but not by the wood fibre compounds.

In fact, the reinforcing effect of fibres does no only depend on fibre length or aspect ratio but also on fibre dispersion, fibre/matrix adhesion and fibre orientation with respect to the loading direction (Le Baillif \& Echtermeyer 2010, Migneault et al. 2008, Thumm \& Dickson 2013). Fibre length itself only has a considerable effect on mechanical properties when it drops below the critical length. Above the critical length the influence of changes in fibre length is only marginal and even if it results in statistically significant changes of the mechanical properties, these are not necessarily relevant from a technical point of view (Thumm \& Dickson 2013). 



\section{Chapter 8}

\section{Conclusions \& Outlook}

A lot of raw material alternatives for the wood component, as well as the polymer component, proved to be suitable for the production of WPC. When using wood wastes and by-products as filler material, WPC can contribute to enhancing the utilisation cascade of the wood industry.

For the morphological characterisation of wood filler materials, dynamic particle/fibre analysis using QICPIC was successfully introduced. With QICPIC, large sample sizes can be obtained with smaller sample preparation effort compared to static methods. Analysing particle/fibres sizes with respect to the length-based size distribution proved to be most adequate to study the effect of WPC processing on particle/fibre size since fines as well as coarse particles/fibres are well represented.

Filler degradation increased with increasing filler content and was generally stronger for processes that required more energy, i.e. that resulted in higher torque or SME values, and for screw designs containing more shear inducing elements. Screw design was identified to be crucial for filler degradation as it superimposed the filler length retention effect of gentle process conditions. With respect to the variety of possible raw material alternatives, processing effects on filler degradation are not expected to differ much among different filler material types.

Independent of process type and process settings, either laboratory or industrial scale, filler size was severely reduced in every case. This demonstrates the still huge potential to design more gentle compounding processes. To fully exploit the reinforcing potential of the filler material in the final composite, more drastic changes towards gentler compounding conditions are necessary. The biggest part of the degradation took place in the early stages of mixing, for example right after introducing the fibres into the TSE. The conditions and mechanisms of fibre breakage in these early stages of mixing need to be understood better and require more detailed analyses to successfully achieve an enhancement of fibre length retention. 



\section{References}

Abeykoon, C., Kelly, A. L., Brown, E. C., Vera-Sorroche, J., Coates, P. D., HarkinJones, E., Howell, K. B., Deng, J., Li, K. \& Price, M. (2014), 'Investigation of the process energy demand in polymer extrusion: A brief review and an experimental study', Applied Energy 136, 726-737.

Adhikary, K. B., Pang, S. \& Staiger, M. P. (2008), 'Long-term moisture absorption and thickness swelling behaviour of recycled thermoplastics reinforced with Pinus radiata sawdust', Chemical Engineering Journal 142(2), 190-198.

Agnantopoulou, E., Tserki, V., Marras, S., Philippou, J. \& Panayiotou, C. (2012), 'Development of biodegradable composites based on wood waste flour and thermoplastic starch', Journal of Applied Polymer Science 126, E272-E280.

Ahankari, S. S., Mohanty, A. K. \& Misra, M. (2011), 'Mechanical behaviour of agroresidue reinforced poly(3-hydroxybutyrate-co-3-hydroxyvalerate), (PHBV) green composites: A comparison with traditional polypropylene composites', Composites Science and Technology 71(5), 653-657.

Akdogan, A. \& Vanli, A. S. (2013), 'Material characterization of different-dimensioned wood particle-reinforced polymer composites', Journal of Thermoplastic Composite Materials 26(9), 1237-1248.

Akkoyun, M., Carrot, C. \& Blottiere, B. (2014), 'On the Use of An Internal Mixer To Study the Impregnation of Carbon Fillers By Organic Liquids', Applied Rheology 24(1), 13487.

Alemdar, A., Zhang, H., Sain, M., Cescutti, G. \& Müssig, J. (2008), 'Determination of fiber size distributions of injection moulded polypropylene/natural fibers using X-ray microtomography', Advanced Engineering Materials 1o(1-2), 126-130.

Andersen, P. (2013), Process Flexibility for Compounding Biopolymers, in 'EUROTECH 2013', Society of Plastics Engineers.

Ares, A., Bouza, R., Pardo, S. G., Abad, M. J. \& Barral, L. (2010), 'Rheological, Mechanical and Thermal Behaviour of Wood Polymer Composites Based on Recycled Polypropylene', Journal of Polymers and the Environment 18(3), 318-325.

Arnold, Y. E., Imanidis, G. \& Kuentz, M. T. (2011), 'Advancing in-vitro drug precipitation testing: new process monitoring tools and a kinetic nucleation and growth model', Journal of Pharmacy and Pharmacology 63(3), 333-341.

Ashori, A. (2008), 'Wood-plastic composites as promising green-composites for automotive industries!', Bioresource Technology 99(11), 4661-4667. 
Ashori, A., Kiani, H. \& Mozaffari, S. A. (2011), 'Mechanical Properties of Reinforced Polyvinyl Chloride Composites: Effect of Filler Form and Content', Journal of Applied Polymer Science 120(3), 1788-1793.

Ashori, A. \& Nourbakhsh, A. (2009), 'Mechanical Behavior of Agro-ResidueReinforced Polypropylene Composites', Journal of Applied Polymer Science 111(5), 2616-2620.

Ausias, G., Bourmaud, A., Coroller, G. \& Baley, C. (2013), 'Study of the fibre morphology stability in polypropylene-flax composites', Polymer Degradation and Stability 98(6), 1216-1224.

Azizi, H. \& Ghasemi, I. (2009), 'Investigation on the Dynamic Melt Rheological Properties of Polypropylene/Wood Flour Composites', Polymer Composites 30(4), 429-435.

Baillie, C. (2004), 1 - Why green composites?, in C. Baillie, ed., 'Green Composites', Woodhead Publishing Series in Composites Science and Engineering, Woodhead Publishing, pp. $1-8$.

Balasuriya, P. W., Ye, L. \& Mai, Y. W. (2001), 'Mechanical properties of wood flakepolyethylene composites. Part I: effects of processing methods and matrix melt flow behaviour', Composites Part A: Applied Science and Manufacturing 32(5), 619-629.

Beall, F. \& Eickner, H. (1970), 'Thermal Degradation of Wood Components: A Review of the Literature', USDA Forest Service Research Paper FPL 130.

Beaugrand, J. \& Berzin, F. (2013), 'Lignocellulosic Fiber Reinforced Composites: Influence of Compounding Conditions on Defibrization and Mechanical Properties', Journal of Applied Polymer Science 128(2), 1227-1238.

Beg, M. D. H. \& Pickering, K. L. (2008a), 'Reprocessing of wood fibre reinforced polypropylene composites. Part I: Effects on physical and mechanical properties', Composites Part A: Applied Science and Manufacturing 39(7), 1091-1100.

Beg, M. D. H. \& Pickering, K. L. (2008b), 'Reprocessing of wood fibre reinforced polypropylene composites. Part II: Hygrothermal ageing and its effects', Composites Part A: Applied Science and Manufacturing 39(9), 1565-1571.

Bengtsson, M., Le Baillif, M. \& Oksman, K. (2007), 'Extrusion and mechanical properties of highly filled cellulose fibre-polypropylene composites', Composites Part A: Applied Science and Manufacturing 38(8), 1922-1931.

Bergman, R., Sup-Han, H., Oneil, E. \& Eastin, I. (2013), 'Life-Cycle Assessment of Redwood Decking in the United States with Comparison to Three Other Decking Materials', CORRIM - The Consortium for Research on Renewable Industrial Materials.

Berton, M., Cellere, A. \& Lucchetta, G. (2010), 'A New Procedure For the Analysis of Fibre Breakage After Processing of Fibre-reinforced Thermoplastics', International Journal of Material Forming 3, 671-674. 
Berzin, F., Vergnes, B. \& Beaugrand, J. (2014), 'Evolution of lignocellulosic fibre lengths along the screw profile during twin screw compounding with polycaprolactone', Composites Part A: Applied Science and Manufacturing 59, 30-36.

Birol, F. (2012), World Energy Outlook, International Energy Agency, Paris.

Bodig, J. \& Jayne, B. (1993), Mechanics of Wood and Wood Composites, Krieger Publishing Company, Malabar, Florida.

Bolin, C. A. \& Smith, S. (2011), 'Life cycle assessment of ACQ-treated lumber with comparison to wood plastic composite decking', Journal of Cleaner Production 19(6-7), 620-629.

Bouafif, H., Koubaa, A., Perré, P. \& Cloutier, A. (2009), 'Effects of fiber characteristics on the physical and mechanical properties of wood plastic composites', Composites Part A: Applied Science and Manufacturing 40(12), 1975-1981.

Bourmaud, A., Duigou, A. L. \& Baley, C. (2011), 'What is the technical and environmental interest in reusing a recycled polypropylene-hemp fibre composite?', Polymer Degradation and Stability 96, 1732-1739.

Bourmaud, A., Åkesson, D., Beaugrand, J., Duigou, A. L., Skrifvars, M. \& Baley, C. (2016), 'Recycling of L-Poly-(lactide)-Poly-(butylene-succinate)-flax biocomposite', Polymer Degradation and Stability .

Bourne, P. \& Bajwa, S. (2007), 'Evaluation of Rice Hulls as a Lignocellulosic Substitute in Wood Plastic Composites', Inquiry: The University of Arkansas Undergraduate Research Journal 7, 66-72.

Bouza, R., Marco, C., Naffakh, M., Barral, L. \& Ellis, G. (2011), 'Effect of particle size and a processing aid on the crystallization and melting behavior of iPP/red pine wood flour composites', Composites Part A: Applied Science and Manufacturing 42(8), 935-949.

Béreaux, Y., Charmeau, J. Y. \& Moguedet, M. (2008), 'Modelling of fibre damage in single screw processing', International Journal of Material Forming 1, 827830.

Brown, J.H., Burnside, W. R., Davidson, A. D., DeLong, J. P., Dunn, W. C., Hamilton, M. J., Mercado-Silva, N., Nekola, J. C., Okie, J. G., Woodruff, W. H. \& Zuo, W.Y. (2011), 'Energetic Limits to Economic Growth', Bioscience 61(1), 19-26.

Burgstaller, C. (2007), 'Processing of thermal sensitive materials - a case study for wood plastic composites', Monatshefte für Chemie 138(4), 343-346.

Buyuksari, U., Ayrilmis, N. \& Akbulut, T. (2012), 'Compression Wood as a Source of Reinforcing Filler for Thermoplastic Composites', Journal of Applied Polymer Science 123(3), 1740-1745.

Campanelli, J. R., Gurer, C., Rose, T. L. \& Varner, J. E. (2004), 'Dispersion, temperature and torque models for an internal mixer', Polymer Engineering and Science 44(7), 1247-1257. 
Carus, M., Eder, A., Dammer, L., Korte, H., Scholz, L. \& Essel, R. and; Breitmayer, E. (2014), WPC/NFC Market Study 2014-03, Wood-Plastic Composites (WPC) and Natural Fibre Composites (NFC): European and Global Markets 2012 and future Trends, Technical report, nova Institute $\mathrm{GmbH}$.

Carus, M., Gahle, C. \& Korte, H. (2008), Market and future trends for wood-polymer composites in Europe: the example of Germany, in K. Niska \& M. Sain, eds, 'Wood-polymer composites', Woodhead Publishing Limited, chapter 14, pp. 300-330.

Chanda, M. \& Roy, S. K., eds (2007), Plastics Technology Handbook, 4th edn, Hanser Publishers, Munich.

Chavooshi, A., Madhoushi, M., Shakeri, A. \& Khazaeian, A. (2014), 'A Comparative Study on the Effects of Material Blending Method on the Physico-Mechanical Properties of WPCs Made from MDF Dust', Journal of Applied Polymer Science 131(15), 40513.

Chen, H., Chen, T. \& Hsu, C. (2006), 'Effects of wood particle size and mixing ratios of HDPE on the properties of the composites', Holz als Roh- und Werkstoff 64(3), 172-177.

Cicerchi, J. (2012), A practical guide to scale-up of new products from development to manufacturing, in '70st Annual Technical Conference of the Society of Plastics Engineers 2012 (ANTEC 2012)', Vol. 1 of 3, Society of Plastics Engineers.

Clemons, C. (2002), 'Wood-plastic composites in the United States - The interfacing of two industries', Forest Products Journal 52(6), 10-18.

Clemons, C. M. (2008), Raw materials for wood-polymer composites, in K. Niska \& M. Sain, eds, 'Wood-polymer composites', Woodhead Publishing Limited, chapter 1, pp. 1-22.

Cöpür, Y. \& Makkonen, H. (2007), 'Precision and Accuracy Studies with Kajaani Fibre Length Analyzer', Journal of Applied Sciences 7(7), 1043-1047. http://scialert.net/abstract/?doi=jas.2007.1043.1047

Czajkowska, M., Sznitowska, M. \& Kleinebudde, P. (2015), 'Determination of coating thickness of minitablets and pellets by dynamic image analysis', International Journal of Pharmaceutics 495(1), 347-353.

Daian, G. \& Ozarska, B. (2009), 'Wood waste management practices and strategies to increase sustainability standards in the Australian wooden furniture manufacturing sector', Journal of Cleaner Production 17(17), 1594-1602.

Derreza-Greeven, C., Vogt, R. \& Giegrich, J. (2013), Life Cycle Assessment of deckings: WPC vs. solid wood with focus on material composition and origin, in 'Fifth German WPC Congress', Cologne, Germany.

Dickson, A. R., Even, D., Warnes, J. M. \& Fernyhough, A. (2014), 'The effect of reprocessing on the mechanical properties of polypropylene reinforced with wood pulp, flax or glass fibre', Composites Part A: Applied Science and Manufacturing 61, 258-267. 
Diemert, J. (2013), Final Report - BIOSTRUCT (Complex Structural and Multifunctional Parts from Enhanced Wood-Based Composites - eWPC, CORDIS.

DIN ISO 9276-1 (2004), 'Darstellung der Ergebnisse von Partikelgrößenanalysen Teil 1: Graphische Darstellung (ISO 9276-1:1998)’.

DIN ISO 9276-6 (2008), 'Darstellung der Ergebnisse von Partikelgrößenanalysen Teil 6: Deskriptive und quantitative Darstellung der Form und Morphologie von Partikeln (ISO 9276-6:2008)'.

Domininghaus, H. (2012), Kunststoffe, 8 edn, Springer Verlag Berlin Heidelberg.

Dong, S., Sapieha, S. \& Schreiber, H. P. (1992), 'Rheological Properties of Corona Modified Cellulose Polyethylene Composites', Polymer Engineering and Science 32(22), 1734-1739.

Durin, A., De Micheli, P., Ville, J., Inceoglu, F., Valette, R. \& Vergnes, B. (2013), 'A matricial approach of fibre breakage in twin-screw extrusion of glass fibres reinforced thermoplastics', Composites Part A: Applied Science and Manufacturing 48, 47-56.

Ehrenstein, G., ed. (2006), Faserverbund-Kunststoffe. Werkstoffe - Verarbeitung Eigentschaften, Hanser Publishers, Munich.

El-Sabbagh, A. M. M., Steuernagel, L., Meiners, D. \& Ziegmann, G. (2014), 'Effect of extruder elements on fiber dimensions and mechanical properties of bast natural fiber polypropylene composites', Journal of Applied Polymer Science 131(12). http://dx.doi.org/10.1002/app.40435

Elliott, J. (2006), An Introduction to Sustainable Developments, Routledge, London.

Endres, H.-J. \& Siebert-Raths, A. (2009), Technische Biopolymere Rahmenbedingungen, Marktsituation, Herstellung, Aufbau und Eigentschaften, Carls Hanser Verlag, Munich.

Englund, K. \& Villechevrolle, V. (2011), 'Flexure and Water Sorption Properties of Wood Thermoplastic Composites Made with Polymer Blends', Journal of Applied Polymer Science 120(2), 1034-1039.

Englund, K. \& Wolcott, M. (2008), Processing performance of extruded woodpolymer composites, in K. Niska \& M. Sain, eds, 'Wood-polymer composites', Woodhead Publishing Limited, chapter 9, pp. 190-207.

Eshun, J. F., Potting, J. \& Leemans, R. (2012), 'Wood waste minimization in the timber sector of Ghana: a systems approach to reduce environmental impact', Journal of Cleaner Production 26, 67-78.

Faruk, O., Bledzki, A. K., Fink, H.-P. \& Sain, M. (2014), 'Progress Report on Natural Fiber Reinforced Composites', Macromolecular Materials and Engineering 299(1), 9-26.

Fasihi, M. \& Garmabi, H. (2011), 'Evaluation and Optimization of the Mechanical Properties of Highly Filled PVC/(Wood Flour) Composites by Using Experimental Design', Journal of Vinyl \& Additive Technology 17(2), 112-119. 
Felix, J.S., Domeno, C. \& Nerin, C. (2013), 'Characterization of wood plastic composites made from landfill-derived plastic and sawdust: Volatile compounds and olfactometric analysis', Waste Management 33(3), 645-655.

Ferreira, P., Matos, S. \& Figueiredo, M. (1999), 'Size characterization of fibres and fines in hardwood kraft pulps', Particle \& Particle Systems Characterization 16(1), 20-24.

Flandez, J., Gonzalez, I., Bayer Resplandis, J., El Mansouri, N.-E., Vilaseca, F. \& Mutje, P. (2012), 'Management of Corn Stalk Waste As Reinforcement For Polypropylene Injection Moulded Composites', Bioresources 7(2), 1836-1849.

Fonteyne, M., Soares, S., Vercruysse, J., Peeters, E., Burggraeve, A., Vervaet, C., Remon, J. P., Sandler, N. \& De Beer, T. (2012), 'Prediction of quality attributes of continuously produced granules using complementary pat tools', European Journal of Pharmaceutics and Biopharmaceutics 82(2), 429-436.

Fu, S. Y., Hu, X. \& Yue, C. Y. (1999), 'Effects of fiber length and orientation distributions on the mechanical properties of short-fiber-reinforced polymers', Materials Science Research International 5(2), 74-83.

Gaiani, C., Boyanova, P., Hussain, R., Pazos, I. M., Karam, M., Burgain, J. \& Scher, J. (2011), 'Morphological descriptors and colour as a tool to better understand rehydration properties of dairy powders', International Dairy Journal 21(7), $462-469$.

Gallagher, L. W. \& McDonald, A. G. (2013), 'The Effect of Micron Sized Wood Fibers In Wood Plastic Composites', Maderas-ciencia Y Tecnologia 15(3), 357-374.

Gamon, G., Evon, P. \& Rigal, L. (2013), 'Twin-screw extrusion impact on natural fibre morphology and material properties in poly(lactic acid) based biocomposites', Industrial Crops and Products 46, 173-185.

Giles, H. J., Wagner, J. J. \& Mount, E. I., eds (2005), Extrusion: The Definitive Processing Guide and Handbook, William Andrew, Inc., Norwich, NY.

Godavarti, S. \& Karwe, M. V. (1997), 'Determination of specific mechanical energy distribution on a twin-screw extruder', Journal of Agricultural Engineering Research 67(4), 277-287.

Godfray, H. C. J., Beddington, J. R., Crute, I. R., Haddad, L., Lawrence, D., Muir, J. F., Pretty, J., Robinson, S., Thomas, S. M. \& Toulmin, C. (2010), 'Food Security: The Challenge of Feeding 9 Billion People', Science 327(5967), 812818.

Goharpey, F., Foudazi, R., Nazockdast, H. \& Katbab, A. A. (2008), 'Determination of twin-screw extruder operational conditions for the preparation of thermoplastic vulcanizates on the basis of batch-mixer results', Journal of Applied Polymer Science 107(6), 3840-3847.

Gomez Yepes, M. \& Cremades, L. (2011), 'Characterization of Wood Dust from Furniture by Scanning Electron Microscopy and Energy-dispersive X-ray Analysis', Industrial Health 49(4), 492-500. 
González-Sánchez, C. \& González-Quesada, M. (2015), 'Novel automated method for evaluating the morphological changes of cellulose fibres during extrusioncompounding of plastic-matrix composites', Composites Part A: Applied Science and Manufacturing 69, 1-9.

Govoreanu, R., Saveyn, H., Van der Meeren, P., Nopens, I. \& Vanrolleghem, P. A. (2009), 'A methodological approach for direct quantification of the activated sludge floc size distribution by using different techniques', Water Science and Technology 6o(7), 1857-1867.

Gozdecki, C., Kiciszewski, M., Wilczynski, A. \& Zajchowski, S. (2011b), 'Mechanical properties of wood-polymer composites with different polymers', Annals of Warsaw University of Life Sciences - SGGW. Forestry and Wood Technology 74.

Gozdecki, C., Zajchowski, S., Kociszewski, M., Wilczynski, A. \& Mirowski, J. (2011a), 'Effect of wood particle size on mechanical properties of industrial wood particle-polyethylene composites', Polimery 56(5), 375-380.

Grosser, D. (1987), Pflanzliche und tierische Bau- und Werkholz-Schädlinge, DRWVerlag, Leinfelden-Echterdingen, Germany.

Gunning, M. A., Geever, L. M., Killion, J. A., Lyons, J. G. \& Higginbotham, C. L. (2014), 'The effect of processing conditions for polylactic acid based fibre composites via twin-screw extrusion', Journal of Reinforced Plastics and Composites 33(7), 648-662.

Hamilton, P., Littlejohn, D., Nordon, A., Sefcik, J. \& Slavin, P. (2012), 'Validity of particle size analysis techniques for measurement of the attrition that occurs during vacuum agitated powder drying of needle-shaped particles', Analyst 137(1), 118-125.

Hamilton, P., Littlejohn, D., Nordon, A., Sefcik, J., Slavin, P., Andrews, J. \& Dallin, P. (2013), 'Investigation of factors affecting isolation of needle-shaped particles in a vacuum-agitated filter drier through non-invasive measurements by Raman spectrometry', Chemical Engineering Science 101, 878-885.

Hassan, M. M., Mueller, M., Tartakowska, D. J. \& Wagner, M. H. (2011), 'Mechanical Performance of Hybrid Rice Straw/Sea Weed Polypropylene Composites', Journal of Applied Polymer Science 120(3), 1843-1849.

Heinicke, G. \& Schwartz, J. B. (2006), 'Assessment of dynamic image analysis as a surrogate dissolution test for a coated multiparticulate product', Pharmaceutical Development and Technology 11(4), 403-408.

Heinicke, G. \& Schwartz, J. B. (2007), 'Ammonio polymethacrylate-coated diltiazem: Drug release from single pellets, media dependence, and swelling behavior', Pharmaceutical Development and Technology 12(3), 285-296.

Hermann, B. G., Blok, K. \& Patel, M. K. (2010), 'Twisting biomaterials around your little finger: environmental impacts of bio-based wrappings', International Journal of Life Cycle Assessment 15(4), 346-358. 
Himmel, S. (2015), Formaldehyd in Holz und Holzwerkstoffen - Wirkmechanismen, Nachweis- und Vorhersagemethoden, PhD thesis, Georg-August Universität Göttingen.

Hirata, K., Ishida, H., Hiragohri, M., Nakayama, Y. \& Kajiwara, T. (2013), 'Experimental Assessment of Dispersion Failure of Glass Fiber Reinforced Plastics in a Twin Screw Extruder', International Polymer Processing 28(4), 368-375.

Ho, R., Naderi, M., Heng, J. Y. Y., Williams, D. R., Thielmann, F., Bouza, P., Keith, A. R., Thiele, G. \& Burnett, D. J. (2012), 'Effect of Milling on Particle Shape and Surface Energy Heterogeneity of Needle-Shaped Crystals', Pharmaceutical Research 29(10), 2806-2816.

Ho, R., Wilson, D. A. \& Heng, J. Y. Y. (2009), 'Crystal Habits and the Variation in Surface Energy Heterogeneity', Crystal Growth \& Design 9(11), 4907-4911.

Hottle, T. A., Bilec, M. M. \& Landis, A. E. (2013), 'Sustainability assessments of biobased polymers', Polymer Degradation and Stability 98(9), 1898-1907.

Hristov, V. \& Vlachopoulos, J. (2007), 'Influence of coupling agents on melt flow behavior of natural fiber composites', Macromolecular Materials and Engineering 292(5), 608-619.

Hristov, V. \& Vlachopoulos, J. (2008), 'Effects of polymer molecular weight and filler particle size on flow behavior of wood polymer composites', Polymer Composites 29(8), 831-839.

Huber, T., Misra, M. \& Mohanty, A. K. (2015), 'The effect of particle size on the rheological properties of polyamide 6/biochar composites', AIP Conference Proceedings 1664(1).

Hunt, R. (1991), 'Trying an authorship index', Nature 352, 187.

Iannace, S., Ali, R. \& Nicolais, L. (2001), 'Effect of processing conditions on dimensions of sisal fibers in thermoplastic biodegradable composites', Journal of Applied Polymer Science 79(6), 1084-1091.

Inceoglu, F., Ville, J., Ghamri, N., Pradel, J. L., Durin, A., Valette, R. \& Vergnes, B. (2011), 'Correlation Between Processing Conditions and Fiber Breakage During Compounding of Glass Fiber-Reinforced Polyamide', Polymer Composites 32(11), 1842-1850.

Ismail, M. R., Yassen, A. A. M. \& Afify, M. S. (2011), 'Mechanical Properties of Rice Straw Fiber-Reinforced Polymer Composites', Fibers and Polymers 12(5), 648656.

ISO 178 (2010), 'Plastics - Determination of flexural properties'.

ISO 180 (2000), 'Plastics - Determination of Izod impact strength'.

ISO 527-2 (1993), 'Plastics - Determination of tensile properties - Part 2: Test conditions for moulding and extrusion plastics'.

ISO/FDIS 16065-1 (2013), 'Pulps - Determination of fibre length by automated optical analysis - Part 1: Polarized light method'. 
Joffre, T., Miettinen, A., Berthold, F. \& Gamstedt, E. K. (2014), 'X-ray microcomputed tomography investigation of fibre length degradation during the processing steps of short-fibre composites', Composites Science and Technology 105, 127-133.

Kaltenbrunner, O., Cao, S., Freydell, E., Keener, N., Zhu, L., Jiao, N., Williamson, B., Snyder, M. A. \& Cummings, L. J. (2012), 'Monitoring ceramic hydroxyapatite media degradation using dynamic image analysis and uniaxial confined bulk compression', Biotechnology Journal 7(10), 1288-1296.

Khalil, H. P. S. A., Shahnaz, S. B. S., Ratnam, M. M., Ahmad, F. \& Fuaad, N. A. N. (2006), 'Recycle polypropylene (RPP) wood saw dust (WSD) composites - Part 1: The effect of different filler size and filler loading on mechanical and water absorption properties', Journal of Reinforced Plastics and Composites 25(12), 1291-1303.

Kim, M. H. \& Song, H. B. (2014), 'Analysis of the global warming potential for wood waste recycling systems', Journal of Cleaner Production 69, 199-207.

Klyosov, A. (2007), Wood-Plastic Composites, John Wiley \& Sons.

Kociszewski, M., Gozdecki, C., Wilczynski, A., Zajchowski, S. \& Mirowski, J. (2012), 'Effect of industrial wood particle size on mechanical properties of woodpolyvinyl chloride composites', European Journal of Wood and Wood Products 70(1-3), 113-118.

Kohlgrüber, K. (2008), Co-Ratating Twin-Screw Extruders, Carl Hanser Verlag Müchen Wien.

Koplin, T., Endres, H.-J. \& Ziegmann, G. (2013), Influence of the Melting Zone on Compounding of Cellulose Fiber Reinforced Polylactide, in '71st Annual Technical Conference of the Society of Plastics Engineers 2013 (ANTEC 2013)', Vol. 1 of 3, Society of Plastics Engineers.

Krause, A. \& Krause, C. (2012), Relation between surface area and optimal concentration of coupling agent in WPC, in '11th Pacific RIM Bio-Based Composites Symposium 2012', pp. 176-185.

Kumari, R., Ito, H., Takatani, M., Uchiyama, M. \& Okamoto, T. (2007), 'Fundamental studies on wood/cellulose-plastic composites: effects of composition and cellulose dimension on the properties of cellulose/PP composite', Journal of Wood Science 53(6), 470-480.

Kuo, P.-Y., Wang, S.-Y., Chen, J.-H., Hsueh, H.-C. \& Tsai, M.-J. (2009), 'Effects of material compositions on the mechanical properties of wood-plastic composites manufactured by injection molding', Materials \& Design 30(9), 3489-3496.

Le Baillif, M. \& Echtermeyer, A. (2010), 'Effect of the Preparation of Cellulose Pellets on the Dispersion of Cellulose Fibers Into Polypropylene Matrix During Extrusion', Journal of Applied Polymer Science 115(5), 2794-2805.

Le Baillif, M. \& Oksman, K. (2009), 'The Effect of Processing on Fiber Dispersion, Fiber Length, and Thermal Degradation of Bleached Sulfite Cellulose Fiber 
Polypropylene Composites', Journal of Thermoplastic Composite Materials 22(2), 115-133.

Le Digabel, F., Boquillon, N., Dole, P., Monties, B. \& Averous, L. (2004), 'Properties of thermoplastic composites based on wheat-straw lignocellulosic fillers', Journal of Applied Polymer Science 93(1), 428-436.

Le Duc, A., Vergnes, B. \& Budtova, T. (2011), 'Polypropylene/natural fibres composites: Analysis of fibre dimensions after compounding and observations of fibre rupture by rheo-optics', Composites Part A: Applied Science and Manufacturing 42(11), 1727-1737.

Le Moigne, N., van den Oever, M. \& Budtova, T. (2011), 'A statistical analysis of fibre size and shape distribution after compounding in composites reinforced by natural fibres', Composites Part A: Applied Science and Manufacturing 42(10), 1542-1550.

Lenzen, M., Moran, D., Kanemoto, K., Foran, B., Lobefaro, L. \& Geschke, A. (2012), 'International trade drives biodiversity threats in developing nations', Nature 486(7401), 109-112.

Leschonski, K. (1984), 'Representation and Evaluation of Particle Size Analysis Data', Particle \& Particle Systems Characterization 1(1-4), 89-95.

Leu, S.-Y., Yang, T.-H., Lo, S.-F. \& Yang, T.-H. (2012), 'Optimized material composition to improve the physical and mechanical properties of extruded wood-plastic composites (WPCs)', Construction and Building Materials 29, $120-127$.

Li, J., Tao, L., Buckley, D., Tao, J., Gao, J. \& Hubert, M. (2013), 'The Effect of the Physical State of Binders on High-Shear Wet Granulation and Granule Properties: A Mechanistic Approach to Understand the High-Shear Wet Granulation Process. Part IV. The Impact of Rheological State and Tip-speeds', Journal of Pharmaceutical Sciences 102(12), 4384-4394.

Li, T. Q. \& Wolcott, M. P. (2004), 'Rheology of HDPE-wood composites. I. Steady state shear and extensional flow', Composites Part A: Applied Science and Manufacturing 35(3), 303-311.

Li, T. Q. \& Wolcott, M. P. (2005), 'Rheology of wood plastics melt. Part 1. Capillary rheometry of HDPE filled with maple', Polymer Engineering and Science 45(4), 549-559.

Li, Y. (2012), 'Effect of Coupling Agent Concentration, Fiber Content, and Size on Mechanical Properties of Wood/HDPE Composites', International Journal of Polymeric Materials 61(11), 882-890.

Lohmann, U. (1987), Holz-Handbuch, DRW-Verlag, Leinfelden-Echterdingen, Germany.

Lowinger, M. (2011), 'Process Development: Scaling Melt Extrusion Process from Conception to Commercialization', American Pharmaceutical Review 14(2).

Mahalle, L., Alemdar, A., Mihai, M. \& Legros, N. (2014), 'A cradle-to-gate life cycle assessment of wood fibre-reinforced polylactic acid (PLA) and polylactic 
acid/thermoplastic starch (PLA/TPS) biocomposites', International Journal of Life Cycle Assessment 19(6), 1305-1315.

Manas-Zloczower, I. (2009), Mixing and Compounding of Polymers: Theory and Practice, Hanser Publishers, Munich.

Merkus, H. (2009), Particle Size Measurement, Springer Science+Business Media B.V.

Michaud, F., Castera, P., Fernandez, C. \& Ndiaye, A. (2009), 'Meta-heuristic Methods Applied to the Design of Wood-Plastic Composites, with Some Attention to Environmental Aspects', Journal of Composite Materials 43(5), Amer Soc Composites.

Migneault, S., Koubaa, A., Erchiqui, F., Chaala, A., Englund, K., Krause, C. \& Wolcott, M. (2008), 'Effect of fiber length on processing and properties of extruded wood-fiber/HDPE composites', Journal of Applied Polymer Science $\mathbf{1 1 0}(2), 1085-1092$.

Migneault, S., Koubaa, A., Erchiqui, F., Chaala, A., Englund, K. \& Wolcott, M. P. (2009), 'Effects of processing method and fiber size on the structure and properties of wood-plastic composites', Composites Part A: Applied Science and Manufacturing 40(1), 80-85.

Migneault, S., Koubaa, A. \& Perré, P. (2014), 'Effect of Fiber Origin, Proportion, and Chemical Composition on the Mechanical and Physical Properties of WoodPlastic Composites', Journal of Wood Chemistry and Technology 34(4), 241261.

Mondadori, N. M. L., Nunes, R. C. R., Zattera, A. J., Oliveira, R. V. B. \& Canto, L. B. (2008), 'Relationship between processing method and microstructural and mechanical properties of poly(ethylene terephthalate)/short glass fiber composites', Journal of Applied Polymer Science 109(5), 3266-3274.

Moya-Villablanca, C., Oses-Pedraza, R., Poblete-Wilson, H. \& Valenzuela-Hurtado, L. (2014), 'Effects of Wood and Bark Flour Content of Pinus Radiata On the Accelerated Decay of Wood-plastic Composites', Maderas-ciencia Y Tecnologia 16(1), 37-48.

Najafi, S. K., Kiaefar, A. \& Tajvidi, M. (2008), 'Effect of Bark Flour Content on the Hygroscopic Characteristics of Wood-Polypropylene Composites', Journal of Applied Polymer Science 110(5), 3116-3120.

Nalluri, V. R. \& Kuentz, M. (2010), 'Advancing Pharmaceutical Dry Milling by Process Analytics and Robustness Testing', Journal of Pharmaceutical Innovation 5(3), 100-108.

Nalluri, V. R., Schirg, P., Gao, X., Virdis, A., Imanidis, G. \& Kuentz, M. (2010), 'Different modes of dynamic image analysis in monitoring of pharmaceutical dry milling process', International Journal of Pharmaceutics 391(1-2), 107114.

Neto, A. G. V. D., Ganzerli, T. A., Cardozo, A. L., Favaro, S. L., Pereira, A. G. B., Girotto, E. M. \& Radovanovic, E. (2014), 'Development of composites based on 
recycled polyethylene/sugarcane bagasse fibers', Polymer Composites 35(5), 1022-1022.

Newman, R. H., Hebert, P., Dickson, A. R., Even, D., Fernyhough, A. \& Sandquist, D. (2014), 'Micromechanical modelling for wood-fibre reinforced plastics in which the fibres are neither stiff nor rod-like', Composites Part A: Applied Science and Manufacturing 65, 57-63.

Niemz, P. (1993), Physik des Holzes und der Holzwerkstoffe, DRW-Verlag, Leinfelden-Echterdingen.

Nourbakhsh, A. \& Ashori, A. (2009), 'Preparation and Properties of Wood Plastic Composites Made of Recycled High-density Polyethylene', Journal of Composite Materials 43(8), 877-883.

Nourbakhsh, A. \& Ashori, A. (2010), 'Wood plastic composites from agro-waste materials: Analysis of mechanical properties', Bioresource Technology 101(7), 2525-2528.

Nourbakhsh, A., Karegarfard, A., Ashori, A. \& Nourbakhsh, A. (2010), 'Effects of Particle Size and Coupling Agent Concentration on Mechanical Properties of Particulate-filled Polymer Composites', Journal of Thermoplastic Composite Materials 23(2), 169-174.

Nyambo, C., Mohanty, A. K. \& Misra, M. (2010), 'Polylactide-Based Renewable Green Composites from Agricultural Residues and Their Hybrids', Biomacromolecules 11(6), 1654-1660.

Ogah, A. O. \& Afiukwa, J. N. (2014), 'Characterization and comparison of mechanical behavior of agro fiber-filled high-density polyethylene bio-composites', Journal of Reinforced Plastics and Composites 33(1), 37-46.

Oksman Niska, K. \& Sanadi, A. (2008), Interactions between wood and synthetic polymers, in K. Niska \& M. Sain, eds, 'Wood-polymer composites', Woodhead Publishing Limited, chapter 3, pp. 41-71.

Osburg, V.-S., Strack, M. \& Toporowski, W. (2015), 'Consumer acceptance of WoodPolymer Composites: a conjoint analytical approach with a focus on innovative and environmentally concerned consumers', Journal of Cleaner Production 110(1), 180-190.

Panthapulakkal, S. \& Sain, M. (2007), 'Agro-residue reinforced high-density polyethylene composites: Fiber characterization and analysis of composite properties', Composites Part A: Applied Science and Manufacturing 38(6), 1445-1454.

Peltola, H., Paakkonen, E., Jetsu, P. \& Heinemann, S. (2014), 'Wood based PLA and PP composites: Effect of fibre type and matrix polymer on fibre morphology, dispersion and composite properties', Composites Part A: Applied Science and Manufacturing 61, 13-22.

Petchwattana, N., Covavisaruch, S. \& Chanakul, S. (2012), 'Mechanical properties, thermal degradation and natural weathering of high density polyethylene/rice 
hull composites compatibilized with maleic anhydride grafted polyethylene', Journal of Polymer Research 19(7), 9921.

Petchwattana, N., Covavisaruch, S. \& Sanetuntikul, J. (2012), 'Recycling of woodplastic composites prepared from poly(vinyl chloride) and wood flour', Construction and Building Materials 28(1), 557-560.

Plinke, B., Schirp, A. \& Weidenmüller, I. (2012), 'Methoden der Holzpartikelcharakterisierung - Von der technologischen Fragestellung zur aussagefähigen Statistik', Holztechnologie 53(4), 11-17.

Puglia, D., Terenzi, A., Barbosa, S. E. \& Kenny, J. M. (2008), 'Polypropylene-natural fibre composites. Analysis of fibre structure modification during compounding and its influence on the final properties', Composite Interfaces 15(2-3), 111-129.

QICPIC Manual (2009), QICPIC Bedienungsanleitung, Sympatec GmbH, ClausthalZellerfeld, Germany.

Quijano-Solis, C., Yan, N. \& Zhang, S. Y. (2009), 'Effect of mixing conditions and initial fiber morphology on fiber dimensions after processing', Composites Part A: Applied Science and Manufacturing 4o(4), 351-358.

Ramani, K., Bank, D. \& Kraemer, N. (1995), 'Effect of Screw Design On Fiber Damage In Extrusion Compounding and Composite Properties', Polymer Composites 16(3), 258-266.

Ramzy, A. Y., El-Sabbagh, A. M. M., Steuernagel, L., Ziegmann, G. \& Meiners, D. (2014), 'Rheology of natural fibers thermoplastic compounds: Flow length and fiber distribution', Journal of Applied Polymer Science 131(3). http://dx.doi.org/10.1002/app.39861

Ratanawilai, T., Nakawirot, K., Deachsrijan, A. \& Homkhiew, C. (2014), 'Influence of Wood Species and Particle Size on Mechanical and Thermal Properties of Wood Polypropylene Composites', Fibers and Polymers 15(10), 2160-2168.

Rauwendaal, C. (2014), Polymer Extrusion, 5 edn, Carls Hanser Verlag, Munich.

Ren, P. \& Dai, G. (2014), 'Fiber Dispersion and Breakage in Deep Screw Channel during Processing of Long Fiber-reinforced Polypropylene', Fibers and Polymers 15(7), 1507-1516.

Rowell, R. \& LeVan-Green, S. (2005), Thermal properties, in R. M. Rowell, ed., 'Handbook of Wood Chemistry and Wood Composites', CRC Press, Boca Raton, Florida, chapter 6.

Rowell, R. M. (2007), 'Challenges in biomass-thermoplastic composites', Journal of Polymers and the Environment 15(4), 229-235.

Rowell, R., Pettersen, R., Han, J., Rowell, J. \& Tshabalala, M. (2005), Cell wall chemistry, in R. M. Rowell, ed., 'Handbook of Wood Chemistry and Wood Composites', CRC Press, Boca Raton, Florida, chapter 3.

Rozman, H. D., Mulisa, A.S. \& Tay, G. S. (2012), 'A comparison study of lignocellulosic-thermoplastic composites prepared from different compounding techniques', Journal of Applied Polymer Science 124(6), 4547-4553. 
Saarinen, K. \& Muinonen, K. (2001), 'Light scattering by wood fibers', Applied Optics 40(28), 5064-5077.

Safdari, V., Khodadadi, H., Hosseinihashemi, S. K. \& Ganjian, E. (2011), 'The Effects of Poplar Bark and Wood Content On the Mechanical Properties of Woodpolypropylene Composites', Bioresources 6(4), 5180-5192.

Sain, M. \& Pervaiz, M. (2008), Mechanical properties of wood-polymer composites, in K. Niska \& M. Sain, eds, 'Wood-polymer composites', Woodhead Publishing Limited, chapter 5, pp. 101-117.

Salahudeen, S. A., Elleithy, R. H., AlOthman, O. \& AlZahrani, S. M. (2011), 'Comparative study of internal batch mixer such as cam, banbury and roller: Numerical simulation and experimental verification', Chemical Engineering Science 66(12), 2502-2511.

Sanetra, S. (2011), 'Particle Characterisation in Geological Applications', Akademie für Geowissenschaften und Geotechnologien e.V. Veröffentlichungen 28, 223229.

Satov, D. (2008), Additives for wood-polymer composites, in K. Niska, M. Sain, M. Institute of Materials \& Mining, eds, 'Wood-polymer composites', Woodhead Publishing Limited, chapter 2, pp. 23-40.

Schirp, A., Mannheim, M. \& Plinke, B. (2014), 'Influence of refiner fibre quality and fibre modification treatments on properties of injection-moulded beech woodplastic composites', Composites Part A: Applied Science and Manufacturing 61, 245-257.

Schirp, A., Plinke, B. \& Napolow, D. (2015), 'Effectiveness of organic and inorganic pigments for mass colouration of thermo-mechanical pulp used in wood-plastic composites', European Journal of Wood and Wood Products 73(1), 5-16.

Schirp, A. \& Stender, J. (2010), 'Properties of extruded wood-plastic composites based on refiner wood fibres (TMP fibres) and hemp fibres', European Journal of Wood and Wood Products 68(2), 219-231.

Schwendemann, D. (2008), Manufacturing technologies for wood-polymer composites, in K. Niska \& M. Sain, eds, 'Wood-polymer composites', Woodhead Publishing Limited, chapter 4, pp. 72-100.

Segerholm, K. (2007), Wood Plastic Composites made from Modified Wood - Aspects on Moisture Sorption, Macromorphology and Durability, Licentiate thesis, KTH Architecture and the Built Environment, Stockholm, Sweden.

Selke, S. E. \& Wichman, I. (2004), 'Wood fiber/polyolefin composites', Composites Part A: Applied Science and Manufacturing 35(3), 321-326.

Sewda, K. \& Maiti, S. N. (2007), 'Mechanical properties of HDPE/bark flour composites', Journal of Applied Polymer Science 105(5), 2598-2604.

Shahi, P., Behravesh, A. H., Daryabari, S. Y. \& Lotfi, M. (2012), 'Experimental investigation on reprocessing of extruded wood flour/HDPE composites', Polymer Composites 33(5), 753-763.

Shaw, M. T. (2012), Introduction to Polymer Rheology, John Wiley \& Sons, Inc. 
Shmulsky, R. \& Jones, P. D. (2011), Forest Products and Wood Science: An Introduction, 6th edn, John Wiley \& Sons, Inc.

Shon, K. J. \& White, J. L. (1999), 'A comparative study of fiber breakage in compounding glass fiber-reinforced thermoplastics in a Buss Kneader, modular co-rotating and counter-rotating twin screw extruders', Polymer Engineering and Science 39(9), 1757-1768.

Sinha, M. K. (1982), 'A review of processing technology for the utilisation of agrowaste fibres', Agricultural Wastes 4(6), $461-475$.

Sobczak, L., Lang, R. W. \& Haider, A. (2012), 'Polypropylene composites with natural fibers and wood - General mechanical property profiles', Composites Science and Technology 72(5), 550-557.

Soccalingame, L., Bourmaud, A., Perrin, D., Benezet, J. . C. \& Bergeret, A. (2015), 'Reprocessing of wood flour reinforced polypropylene composites: Impact of particle size and coupling agent on composite and particle properties', Polymer Degradation and Stability 113, 72-85.

Soucy, J., Koubaa, A., Migneault, S. \& Riedl, B. (2014), 'The potential of paper mill sludge for wood-plastic composites', Industrial Crops and Products 54, 248256.

Stark, N. (1999), 'Wood fiber derived from scrap pallets used in polypropylene composites', Forest Products Journal 49(6), 39-46.

Stark, N. M. \& Berger, M. J. (1997), Effect of Particle Size on Properties of WoodFlour Reinforced Polypropylene Composites, in 'Fourth International Conference on Woodfiber-Plastic Composites', Madison, Wisconsin, pp. 134143 .

Stark, N., Matuana, L. \& Clemons, C. (2004), 'Effect of processing method on surface and weathering characteristics of wood-flour/HDPE composites', Journal of Applied Polymer Science 93(3), 1021-1030.

Stark, N. \& Rowlands, R. (2003), 'Effects of wood fiber characteristics on mechanical properties of wood/polypropylene composites', Wood and Fiber Science 35(2), 167-174.

Steckel, V., Clemons, C. M. \& Thoemen, H. (2007), 'Effects of material parameters on the diffusion and sorption properties of wood-flour/polypropylene composites', Journal of Applied Polymer Science 103(2), 752-763.

Strondl, A., Lyckfeldt, O., Brodin, H. \& Ackelid, U. (2015), 'Characterization and Control of Powder Properties for Additive Manufacturing', JOM - The Journal of The Minerals, Metals \& Materials Society (TMS) 67(3), 549-554.

Sykacek, E., Hrabalova, M., Frech, H. \& Mundigler, N. (2009), 'Extrusion of five biopolymers reinforced with increasing wood flour concentration on a production machine, injection moulding and mechanical performance', Composites Part A: Applied Science and Manufacturing 40(8), 1272-1282.

TAPPI T 233 (1995), 'Fiber length of pulp by classification'. 
Teuber, L., Militz, H. \& Krause, A. (2013a), Characterisation of the wood component of WPC via dynamic image analysis, in 'First International Conference on Resource Efficiency in Interorganizational Networks -ResEff2013-', Universitätsdrucke Göttingen, Göttingen, Germany.

Teuber, L., Militz, H. \& Krause, A. (2013b), Characterisation of wood particle change during processing of WPC, in 'Proceedings of 6th International Wood Fibre Polymer Composites Symposium - Bio-based Composites Improving the Environment, Economy and Quality of Life', Biarritz.

Teuber, L., Osburg, V.-S., Toporowski, W., Militz, H. \& Krause, A. (2016), 'Wood polymer composites and their contribution to cascading utilisation', Journal of Cleaner Production 110, 9-15.

Thumm, A. \& Dickson, A. R. (2013), 'The influence of fibre length and damage on the mechanical performance of polypropylene/wood pulp composites', Composites Part A: Applied Science and Manufacturing 46, 45-52.

Treffer, D., Wahl, P. R., Hörmann, T. R., Markl, D., Schrank, S., Jones, I., Cruise, P., Mürb, R.-K., Koscher, G., Roblegg, E. \& Khinast, J. G. (2014), 'In-line implementation of an image-based particle size measurement tool to monitor hot-melt extruded pellets', International Journal of Pharmaceutics 466(12), $181-189$.

Tysmans, D., Claeys, P., Deriemaeker, L., Maes, D., Finsy, R. \& Van Molle, M. (2007), 'Size and shape analysis of sedimentary grains by automated dynamic image analysis', Particle \& Particle Systems Characterization 23(5), 381-387.

Ulusoy, U. \& Igathinathane, C. (2014), 'Dynamic image based shape analysis of hard and lignite coal particles ground by laboratory ball and gyro mills', Fuel Processing Technology 126, 350-358.

Ulusoy, U. \& Yekeler, M. (2014), 'Dynamic image analysis of calcite particles created by different mills', International Journal of Mineral Processing 133, 83-90.

Vergnes, B., Della Valle, G. \& Delamare, L. (1998), 'A global computer software for polymer flows in corotating twin screw extruders', Polymer Engineering and Science 38(11), 1781-1792.

Verhey, S. \& Laks, P. (2002), 'Wood particle size affects the decay resistance of woodfiber/thermoplastic composites', Forest Products Journal 52(11-12), 7881.

Ville, J., Inceoglu, F., Ghamri, N., Pradel, J. L., Durin, A., Valette, R. \& Vergnes, B. (2013), 'Influence of Extrusion Conditions on Fiber Breakage along the Screw Profile during Twin Screw Compounding of Glass Fiber-reinforced PA', International Polymer Processing 28(1), 49-57.

Vogt, D., Karus, M., Ortmann, S., Schmidt, C. \& Gahle, C. (2006), Wood-PlasticComposites (WPC), Märkte in Nordamerika, Japan und Europa mit Schwerpunkt auf Deutschland, Technische Eigenschaften - Anwendungsgebiete - Preise - Märkte - Akteure, Studie, nova-Institut GmbH, Goldenbergstraße 2, 50354 Hürth. 
Wang, W. H., Wang, Q. W., Xiao, H. \& Morrell, J. J. (2007), 'Effects of moisture and freeze-thaw cycling on the quality of rice-hull-PE composite', Pigment \& Resin Technology 36(6), 344-349.

Warnes, J. \& Fernyhough, A. (2011), 'Method for producing wood fibre-plastics composite products', Patent WO 2011/002314 A1.

White, J. L., KimM, J. K., Szydlowski, W. \& MinN, K. (1988), 'Simulation of Flow In Compounding Machinery - Internal Mixers and Modular Corotating Intermeshing Twin-screw Extruders', Polymer Composites 9(5), 368-377.

Wiedenhoeft, A. C. \& Miller R. B. (2005), Structure and Function of Wood, in R. M. Rowell, ed., 'Handbook of Wood Chemistry and Wood Composites', CRC Press, Boca Raton, Florida, chapter 2.

Winandy, J., Stark, N. \& Clemons, C. (2004), Considerations in Recycling of WoodPlastic Composites, in ' 5 th Global Wood and Natural Fiber Composites Symposium', Kassel, Germany, pp. A6-1 - A6-9.

WINDOX Manual (2010), WINDOX 5.6.1.3 Bedienungsanleitung, Sympatec GmbH, Clausthal-Zellerfeld, Germany.

Witt, W., Altrogge, D. \& Rutsch, O. (2006), High-Speed Image Analysis and Dispersion for Size and Shape Characterisation of Fibres, in '5th World Congress of Particle Technology', Orlando.

Witt, W., Köhler, U. \& List, J. (2007), Current Limits of Particle Size and Shape Analysis with High Speed Image Analysis, in 'PARTEC'.

Wolf, H. J. (1994), 'Screw Plasticating of Discontinuous Fiber Filled Thermoplastics Mechanisms and Prevention of Fiber Attrition', Polymer Composites 15(5), 375-383.

$\mathrm{Xu}$, R. L. \& Di Guida, O. A. (2003), 'Comparison of sizing small particles using different technologies', Powder Technology 132(2-3), 145-153.

Yam, K. L., Gogoi, B. K., Lai, C. C. \& Selke, S. E. (1990), 'Composites From Compounding Wood Fibers With Recycled High-density Polyethylene', Polymer Engineering and Science 30(11), 693-699.

Yates, M. R. \& Barlow, C.Y. (2013), 'Life cycle assessments of biodegradable, commercial biopolymers-A critical review', Resources Conservation and Recycling 78, 54-66.

Yeh, S.-K. \& Gupta, R. K. (2008), 'Improved wood-plastic composites through better processing', Composites Part A: Applied Science and Manufacturing 39(11), 1694-1699.

Yemele, M. C. N., Koubaa, A., Cloutier, A., Soulounganga, P. \& Wolcott, M. (2010), 'Effect of bark fiber content and size on the mechanical properties of bark/HDPE composites', Composites Part A: Applied Science and Manufacturing 41(1), 131-137.

$\mathrm{Yu}$, W. \& Hancock, B. C. (2008), 'Evaluation of dynamic image analysis for characterizing pharmaceutical excipient particles', International Journal of Pharmaceutics 361(1-2), 150 - 157. 
Yuan, Q., Wu, D., Gotama, J. \& Bateman, S. (2008), 'Wood fiber reinforced polyethylene and polypropylene composites with high modulus and impact strength', Journal of Thermoplastic Composite Materials 21(3), 195-208.

Yusriah, L., Sapuan, S. M., Zainudin, E. S. \& Mariatti, M. (2014), 'Characterization of physical, mechanical, thermal and morphological properties of agro-waste betel nut (Areca catechu) husk fibre', Journal of Cleaner Production 72, 174-180.

Zaini, M., Fuad, M., Ismail, Z., Mansor, M. \& Mustafah, J. (1996), 'The effect of filler content and size on the mechanical properties of polypropylene/oil palm wood flour composites', Polymer International 40(1), 51-55.

Zaiontz, C. (2015), '"Real Statistics using Excel"'. www.real-statistics.com

Zhang, B., Zhang, Y., Dreisoerner, J. \& Wei, Y. (2015), 'The effects of screw configuration on the screw fill degree and special mechanical energy in twinscrew extruder for high-moisture texturised defatted soybean meal', Journal of Food Engineering 157, 77-83.

Zhang, S. Y., Zhang, Y., Bousmina, M., Sain, M. \& Choi, P. (2007), 'Effects of raw fiber materials, fiber content, and coupling agent content on selected properties of polyethylene/wood fiber composites', Polymer Engineering and Science 47(10), Soc Plast Engineers.

Zhang, X.-M., Feng, L.-F., Chen, W.-X. \& Hu, G.-H. (2009), 'Numerical Simulation and Experimental Validation of Mixing Performance of Kneading Discs in a Twin Screw Extruder', Polymer Engineering and Science 49(9), 1772-1783.

Zhao, Y., Qiu, J., Feng, H. \& Zhang, M. (2012), 'The interfacial modification of rice straw fiber reinforced poly(butylene succinate) composites: Effect of aminosilane with different alkoxy groups', Journal of Applied Polymer Science 125(4), 3211-3220. 


\section{List of Figures}

Figure 1.1: Relationship between fibre length $l$, critical fibre length $l c$ and average stress in the fibre $\sigma f$ (modified from Ehrenstein, 2006).

Figure 1.2: Schematic set-up of the measuring principle as realized in the QICPIC (Sympatec GmbH).

Figure 2.1: Isometric view of the internal batch mixer chamber with hopper (A) and enlarged view of the Banbury rotors (B).

Figure 2.2: (A) Simplified principle of melt stream splitting in a stationary single screw with rotating barrel. a: Backward leakage melt flow of a primary "streamtube" across the clearance between screw flight tip and barrel wall results in formation of a secondary "streamtube". (B) Material transport in a double-flighted TSE (cross-sectional view) (modified from Kohlgrüber 2008).

Figure 2.3: Graphical demonstration of the algorithm for the calculation of the geodetic length as realized in the WINDOX software: (A) initial projected area of fibre, (B) skeletonisation, (C) identification of vertexes, (D) graph representing the fibre skeleton with segment lengths, (E) red line represents base for length calculation (longest path between the most distant end points) (modified from Witt et al. 2007).

Figure 4.1: Screw designs A and B (kneading elements in grey).

Figure 4.2: Particle length distribution based on number $\left(\mathrm{Q}_{0}\right)$, length $\left(\mathrm{Q}_{1}\right)$, area, $\left(\mathrm{Q}_{2}\right)$, and volume $\left(\mathrm{Q}_{3}\right)$ for particles before processing (b.p.) and after two different process variants (screw design $\mathrm{B}$ at $4 \mathrm{~kg} / \mathrm{h}$ and $80 \mathrm{rpm}$ with 30\% and 70\% wood content, respectively). The dotted red lines mark the initial median particle length $\mathrm{x}_{5}$

Figure 4.3: Change in particle length (left) and diameter (right) distribution values $\mathrm{x}_{10}, \mathrm{x}_{50}$ (median) and $\mathrm{x}_{90}$. Particles processed with screw design $\mathrm{A}$ at $8 \mathrm{~kg} / \mathrm{h}$ and $160 \mathrm{rpm}$. Error bars $= \pm 95 \%$ confidence intervals (generally small and obscured by the symbols).

Figure 4.4: Change in median particle length $\mathrm{x}_{50}$ for $30 \%, 50 \%$, and $70 \%$ filled composites when increasing feed rate and screw speed simultaneously. Error bars $= \pm 95 \%$ confidence intervals (generally small and obscured by the symbols).

Figure 4.5: Change in median particle length $\mathrm{x}_{50}$ for $30 \%, 50 \%$, and $70 \%$ filled composites when increasing the SDF at constant screw speed (left) and constant feed rate (right). Particles processed with screw B. Error 
bars $= \pm 95 \%$ confidence intervals (generally small and obscured by the symbols).

Figure 5.1: Size distributions of initial particle length (A) and elongation (B) as box-whisker-plots. The bottom and top of the box represent the $25 \%$ and $75 \%$ quartile. The ends of the whiskers represent the $10 \%$ and $90 \%$ quantile.

Figure 5.2: Progression of temperature and torque for selected process variants after adding WP into the polymer melt (h: preheated particles).

Figure 5.3: Final torque (A, B) and temperature (C, D) after 16.5 minutes of mixing when polymer and WP are fed together $(\mathrm{A}, \mathrm{C})$ or separately (B, D).

Figure 5.4: WP length and elongation after mixing (h: preheated particles)............... 63

Figure 5.5: Final torque and temperature after 7.5 minutes of mixing.

Figure 5.6: WP length and elongation depending on wood content and polymer matrix MFR.

Figure 6.1: Severe screw design A (top) and gentle screw design B (bottom) and sampling points along the screws (P1-P6; $\mathrm{P} 7$ represents the compound pellets). Kneading elements in green and reverse elements in red.

Figure 6.2: Initial length-based fibre length distributions of glass fibres (GF) and wood fibres (WF).The upper and lower bounds of the box represent the $\mathrm{x}_{75}$ and $\mathrm{x}_{25}$ respectively. The $\mathrm{x}_{50}$ crosses the box. The whiskers represent the $\mathrm{x}_{10}$ and $\mathrm{x}_{90}$.

Figure 6.3: SME for the processing of GF and WF for screw A and B at high (left) and low (right) specific throughput.

Figure 6.4: Change in median fibre length $\mathrm{x}_{50} \mathrm{O}$ of GF (A and $\mathrm{B}$ ) and $\mathrm{WF}$ (C and D) for screw A (A and C) and screw B (B and D) at low (filled symbols) and high (empty symbols) SME. IL: initial length, P1-P6: sampling points along the screw, $\mathrm{P} 7$ : final compound.

Figure 6.5: Change in median fibre length $\times 50$ of GF (circles) and WF (squares) processed with severe screw A (filled symbols) and gentle screw B (empty symbols) at different process conditions (A-D)(Table 6.3). IL: initial length, P1-P6: sampling points along the screw, P7: final compound.

Figure 7.1: Binary images from the measurements of wood particles (A), wood fibres (B \& C) and glass fibres (D). Flow direction from left to right.

Figure 7.2: Images of wood particles (A), wood fibres (B) and glass fibres (C). The black line indicates the geodesic length as calculated by the WINDOX software (images not to scale).

Figure 7.3: Interrelation of process parameters and their influence on filler degradation. 


\section{List of Tables}

Table 1.1: Examples of size parameters and shape factors to describe the morphology of particles and fibres (modified from DIN ISO 9276-6 2008 and WINDOX Manual 2010).

Table 1.2: Examples of commercially available dynamic image analysis devices for the characterisation of particle size and shape. ................................. 9

Table 2.1: Polymer types used in the different studies. ...........................................14

Table 2.2: Extruders and process settings ..........................................................15

Table 3.1: Contribution of co-authors (Himmel 2015 as modified from Hunt 1991)

Table 3.2: Production of WPC in the European Union 2012 in tonnes (Carus et al. 2014).

Table 3.3: Overview of exemplary alternative raw materials for the production of WPC.

Table 3.4: Research related to reinforcing polymers with agricultural byproducts.

Table 4.1: Contribution of co-authors (Himmel 2015 as modified from Hunt 1991)

Table 4.2: Parameters of the compounding process.

Table 4.3: Particle size and elongation in dependence of process settings. Particle length and diameter results refer to the length-based distribution $\mathrm{Q}_{1}$. Elongation results are based on number. Equal letters within groups of screw A or screw B indicate that there is no statistical difference between the samples. Asterisks indicate that there is no statistical difference of samples processed at equal conditions but with different screw design ( $\alpha=0,05)$.

Table 5.1: Contribution of co-authors (Himmel 2015 as modified from Hunt 1991)

Table 5.2: Process variants.

Table 5.3: Polymers used in the study. All polymers obtained from SABIC. MFR as specified in the product data sheets and determined at $230^{\circ} \mathrm{C}$ and $2.16 \mathrm{~kg}$ for PP and at $190^{\circ} \mathrm{C}$ and $2.16 \mathrm{~kg}$ for HDPE.

Table 5.4: Summary of results.

Table 5.5: Particle size and elongation after process with different matrix polymers. 
Table 6.1: Contribution of co-authors (Himmel 2015 as modified from Hunt 1991)

Table 6.2: Feed rates, screw speeds, SME and extruder screw diameters for twin-screw extrusion of lignocellulosic fibre compounds in the literature.

Table 6.3: Combinations of feed rate and screw speed chosen in this study. 75

Table 6.4: Mechanical and physical properties of GF composites (standard deviations in brackets) sorted by decreasing SME. Equal letters in each column indicate no statistical difference between the values ( $\alpha=0.05$ ).

Table 6.5: Mechanical and physical properties of WF composites (standard deviations in brackets) sorted by decreasing SME. Equal letters in each column indicate no statistical difference between the values (Mann-Whitney test, $\alpha=0.05$, two-tailed).

Table 7.1: Initial and final filler length as presented in the studies of Chapters 4 to 6 . 
Appendix A 



\section{Characterisation of wood particle change during processing of WPC}

Laura Teuber ${ }^{1}$, Holger Militz ${ }^{1}$, Andreas Krause ${ }^{1,2}$

${ }^{1}$ Georg-August-University Göttingen, Germany

Department of Wood Biology and Wood Products

DFG Research Training Group "Resource Efficiency in Corporate Networks"

laura.teuber@forst.uni-goettingen.de

${ }^{2}$ University of Hamburg

Department of Wood Sciences

Institute of Mechanical Wood Technology

In Proceedings of

6th International Wood Fibre Polymer Composites Symposium - Bio-based Composites Improving the Environment, Economy and Quality of Life

Biarritz, September 23-24, 2013 


\section{Abstract}

Particle size and shape play an important role in defining the mechanical and physical properties of WPC. Therefore, it is important to know up to which degree the particle characteristics change during the production process of WPC and if the initial particle characteristics affect the degree of change.

WPCs with PP and spruce as well as beech wood have been produced with varying wood loading and different processing methods. Afterwards, the wood has been separated from the PP via Soxhlet extraction. The original and the extracted wood particles have been analysed via dynamic image analysis concerning the effect of each processing step on the particle size distribution and particle shape. The dynamic image analysis resulted in size values and shape factors for every single particle. The particle length distributions of the samples after the different processing steps have been compared, as well as their width to length ratio depending on particle length. A noteworthy degradation of bigger particles could be detected. Its intensity strongly depends on the processing step and processing method resulting in a shortening of long particles.

\section{Introduction}

Wood plastic composites (WPC) are an innovative material which is applied especially in the decking and siding/cladding market [1]. WPC's main components are thermoplastic polymers (e.g. PP, PE, PVC) and wood in form of particles and fibres. Furthermore, coupling agents, lubricants, pigments, and other additives may be added to adjust specific properties of the production process and the resulting material [2].

Like neat thermoplastic polymer WPC may be given shape via extrusion, injection moulding, and compression moulding. Often the single components are dry blended before processing or they undergo a compounding step via extrusion to form WPC pellets which are then fed to the final manufacturing process [3][4].

As the wood content of the WPC may vary to more than $70 \%$ [1], this component strongly affects the properties of the material [5]. Several authors examined the effect of wood fibre particle size and shape on the mechanical properties of WPC. Ashori et al. (2011) found out that notched impact strength of wood flour and fibre filled PVC increases with increasing particle size [6]. Stark \& Rowlands (2003) state the same for PP as a matrix [7]. Stark (1999) observed that wood-fibre-filled PP exhibits improved tensile and flexural strength compared to wood-flour-filled PP [8]. Chen et al. (2006) showed that HDPE composites have better strength properties when larger sized wood particles are used [9]. Contrary to that, Yam et al. (1990) and Shahi et al. (2012) state that short fibres result in better mechanical properties as they are easier to disperse in the matrix [3][10].

However, these results are based on particle sizes and shapes measured before processing the WPC. But the WPC's properties result from the final wood particle size and shape after processing. As Stark et al. (2004) state, the processing method and the process settings have a strong effect on the final constitution of the wood 
component and the morphology and physical properties of the composite [11]. For the compounding of WPC the most commonly used systems are the counter-rotating and the co-rotating twin-screw extruder [4]. For further manufacturing injection moulding, compression moulding, and extrusion are used [11]. During processing the WPC is objected to high shear forces and high temperature which degrade the wood particles. Le Baillif \& Oksman (2009) state that wood fibre length is reduced by half after pelletisation and the extrusion process causes a shortening of fibres but leaves the fibre diameter unaffected [12]. Yeh \& Gupta (2008) and Yam et al. (1990) observed that a long residence time during extrusion results in a strong fibre damage and shorter particles [10][13]. According to Michaeli \& Menges (1989) the material is stronger loaded during extrusion than during compression moulding. In injection moulding the shearing and the pressure level are said to be even higher [14]. A screw design and an injection speed adapted to the WPC material have to be considered to reduce the shear rate during injection moulding [4].

The present work directly compares the WPC processing methods extrusion, injection moulding and compression moulding concerning their influence on different wood-PP composites. Hereby, the focus lies on the change of wood particle morphology (size and shape) after compounding and after processing. The PP is extracted from the WPC via Soxleth extraction and the wood particles are characterized via dynamic image analysis.

\section{Materials \& Methods}

\subsection{WPC Production}

Norway spruce (Picea abies) and European beech (Fagus sylvatica) was ground with a hammer mill (Electra VS1 N, France) with an aperture size of $1 \mathrm{~mm}$. After drying the wood particles were compounded with polypropylene (PP) (Sabic PP 575P, Saudi Basic Industries Corporation, Riyadh, Saudi Arabia) in a Leistritz MICRO27GL/GG4OD co-rotating twin-screw extruder (Leistritz Extrusionstechnik $\mathrm{GmbH}$, Germany) with a gravimetric feeder and a hot-cut pelletizer. The temperature profile ranged from $165^{\circ} \mathrm{C}$ to $175^{\circ} \mathrm{C}$, the screw speed was $81 \mathrm{rpm}$, and the throughput was $4 \mathrm{~kg} / \mathrm{h}$. WPCs with varying wood content and varying concentration of polypropylene grafted with maleic acid anhydride (MAPP) as coupling agent (Licocene PP MA 7452, Clariant International Ltd., Muttenz, Switzerland) were produced. Further processing of the WPC pellets was done via extrusion, injection moulding and compression moulding. The extrusion of a profile of WPC with size $4 \mathrm{~mm} \times 50 \mathrm{~mm}(\mathrm{~h} \mathrm{x} \mathrm{w})$ was done with the same machine as the compounding but in a counter-rotating mode with a temperature profile ranging from $170^{\circ} \mathrm{C}$ to $185^{\circ} \mathrm{C}$, a screw speed of 18-20 rpm, and a throughput of $0.6-0.8 \mathrm{~kg} / \mathrm{h}$. For injection moulding an Arburg ALLROUNDER $320^{\circ} \mathrm{C} 600-250$ one-part injection moulding machine (Arburg $\mathrm{GmbH}+\mathrm{Co} \mathrm{KG}$, Germany) with a die for tensile test specimens according to EN ISO 527-1 was used. The temperature was $180^{\circ} \mathrm{C}$ and the nozzle pressure 1500 to 2200 bar. For compression moulding a Joos HB20O LAB (Joos Maschinenfabrik GmbH \& Co. KG, Germany) was used. The WPC pellets were placed in a mould of size 
$34 \mathrm{~cm} \mathrm{x} 28 \mathrm{~cm} \mathrm{x} 0.4 \mathrm{~cm} \mathrm{(l} \mathrm{x} \mathrm{w} \mathrm{x} \mathrm{h)} \mathrm{and} \mathrm{pre-heated} \mathrm{at} 180^{\circ} \mathrm{C}$ for $6 \mathrm{~min}$. Then they were pressed for $2 \mathrm{~min}$ at $180^{\circ} \mathrm{C}$ and 50 bar. After cooling down to $100^{\circ} \mathrm{C}$ the WPC board was de-moulded. The different WPC variations examined are listed in Table A.1.

\subsection{Soxhlet extraction}

For separating the polymer from the wood particles the WPC specimens were fragmented via sawing and subjected to a Soxhlet extraction with xylene (technical grade from AppliChem, Darmstadt, Germany) for $8 \mathrm{~h}$. After extraction the particles were dried at $103^{\circ} \mathrm{C}$ to remove excess solvent and moisture.

\subsection{Particle characterisation}

The change of particle size and shape of the dried wood particles after processing and extraction compared to the original material was characterised using a QICPIC optical dynamic image analysis sensor with dry dispersion unit VIBRI (Sympatec $\mathrm{GmbH}$, Germany). The size and shape of each single particle were calculated from binary $2 \mathrm{D}$ images taken at a frame rate of $450 \mathrm{fps}$ at a resolution of $5 \mu \mathrm{m}$. The particles have been examined as to the length based size distribution $\left(\mathrm{Q}_{1}\right)$ and the elongation with the particle length as equivalent diameter. According to Witt et al. (2007) [15] the particle length is calculated as the shortest path between the most distant endpoints of the particle after skeletonising its binary image via a complex evaluation algorithm. The particle elongation is the ratio of width to length with the width being calculated as the projected particle area divided by the added length of all skeleton paths.

In addition to the processed particles the original wood particles and the original particles after the extraction process have been characterised as a reference. Several millions of particles have been measured per sample (from approx. 1.7 Mio. for spruce original material up to approx. 14 Mio. for B70-oGR).

Table A.1: WPCs examined in this study. GR: granulation; EX: extrusion, IM: injection moulding, CM: compression moulding

\begin{tabular}{ccccc}
\hline wood species & wood content & MAPP content & processing method & abbrev. \\
\hline spruce & $50 \%$ & - & GR & S50-oGR \\
spruce & $50 \%$ & - & EX & S50-oEX \\
spruce & $50 \%$ & - & IM & S50-oIM \\
spruce & $50 \%$ & $3 \%$ & GR & S50-3GR \\
spruce & $50 \%$ & $3 \%$ & EX & S50-3EX \\
\hline beech & $50 \%$ & - & GR & B50-oGR \\
beech & $50 \%$ & - & IM & B50-oIM \\
beech & $50 \%$ & - & CM & B50-oCM \\
beech & $70 \%$ & - & GR & B70-oGR \\
beech & $70 \%$ & - & IM & B70-oIM \\
beech & $70 \%$ & - & CM & B70-OCM \\
\hline
\end{tabular}




\section{Results}

Figure A.1 and Figure A.2 show the length based cumulative distributions of the particle size from beech and spruce particles before processing and after extraction. A comparison of the original beech and spruce particle material before and after extraction shows a shift in the distribution to bigger particle lengths indicating an influence of the extraction method. This influence might be an elution of fines or an aggregation of smaller particles sticking together.

For the beech particles it can be seen that there are differences in the particle lengths of non-processed and processed particles only in the upper $20 \%$ of the distribution. $95 \%$ of the particle length of the original material is shorter than $650 \mu \mathrm{m}$ while this number shifts to $525 \mu \mathrm{m}$ after granulation with $50 \%$ wood content. This means that coarse particles are degraded during processing.

The strongest effect on the particle size distribution has the granulation process with a dependence on wood content. The higher the wood content, the stronger is the degradation of bigger particles. For $50 \%$ beech wood content there is only small change concerning particle length after injection and compression moulding (95\% smaller than $500 \mu \mathrm{m}$ ) compared to after the granulation step. For $70 \%$ beech wood content a shift to higher particle lengths for the distributions after injection and compression moulding ( $95 \%$ smaller than $450 \mu \mathrm{m}$ ) is shown compared to the sample after the granulation step (95\% smaller than $425 \mu \mathrm{m}$ ). With respect to the particle form, more precisely the width to length ratio represented as elongation, it can be observed that the overall curve progression does not change due to processing of the particles (Figure A.3). The bigger the particles are, the smaller is the elongation. All in all, the processed particles have a lower elongation than the original material for small particle lengths $(<100 \mu \mathrm{m})$, meaning they are slimmer at the same length. 


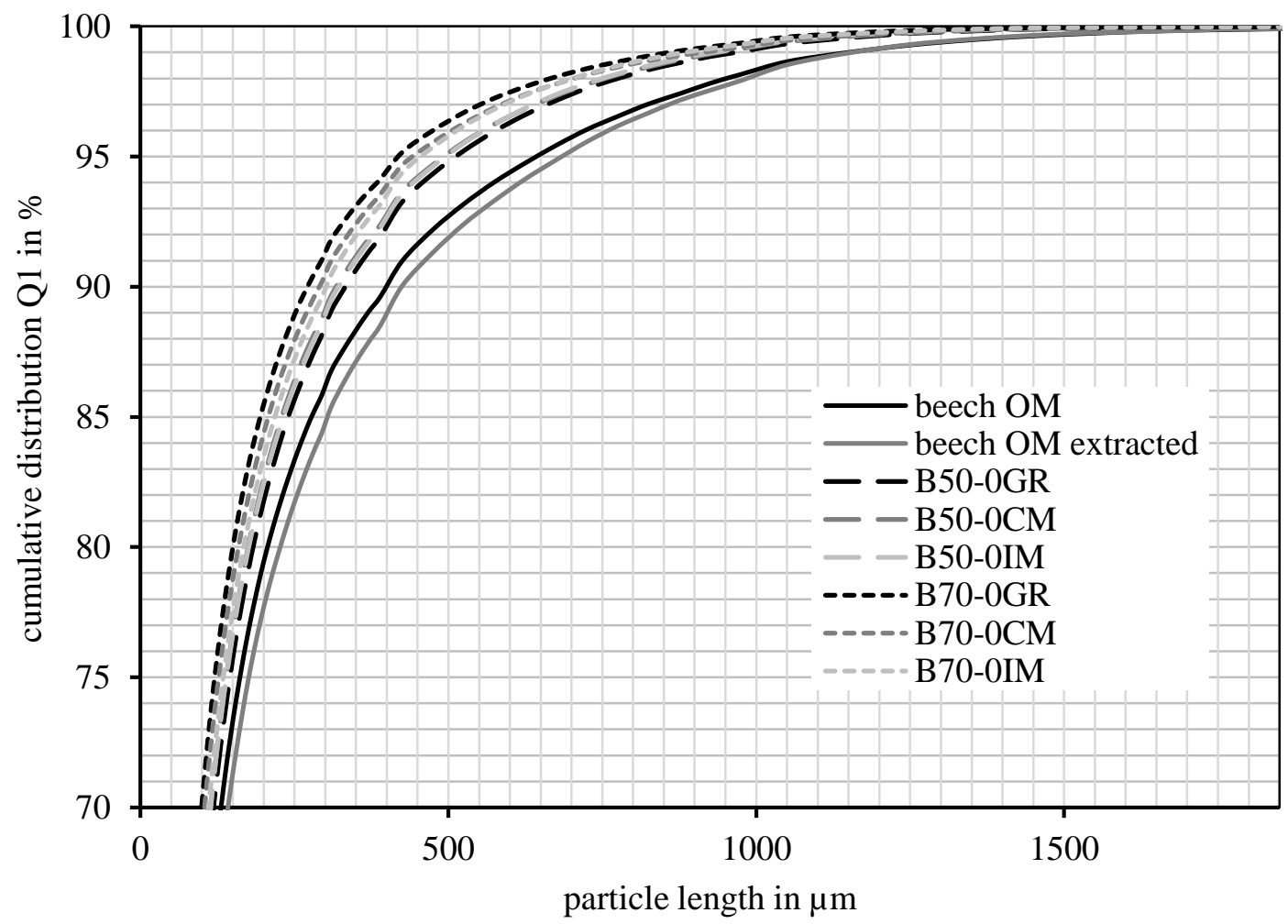

Figure A.1: Length-based cumulative distribution $Q_{1}$ of beech wood particles before processing and after each processing step (OM: original material).

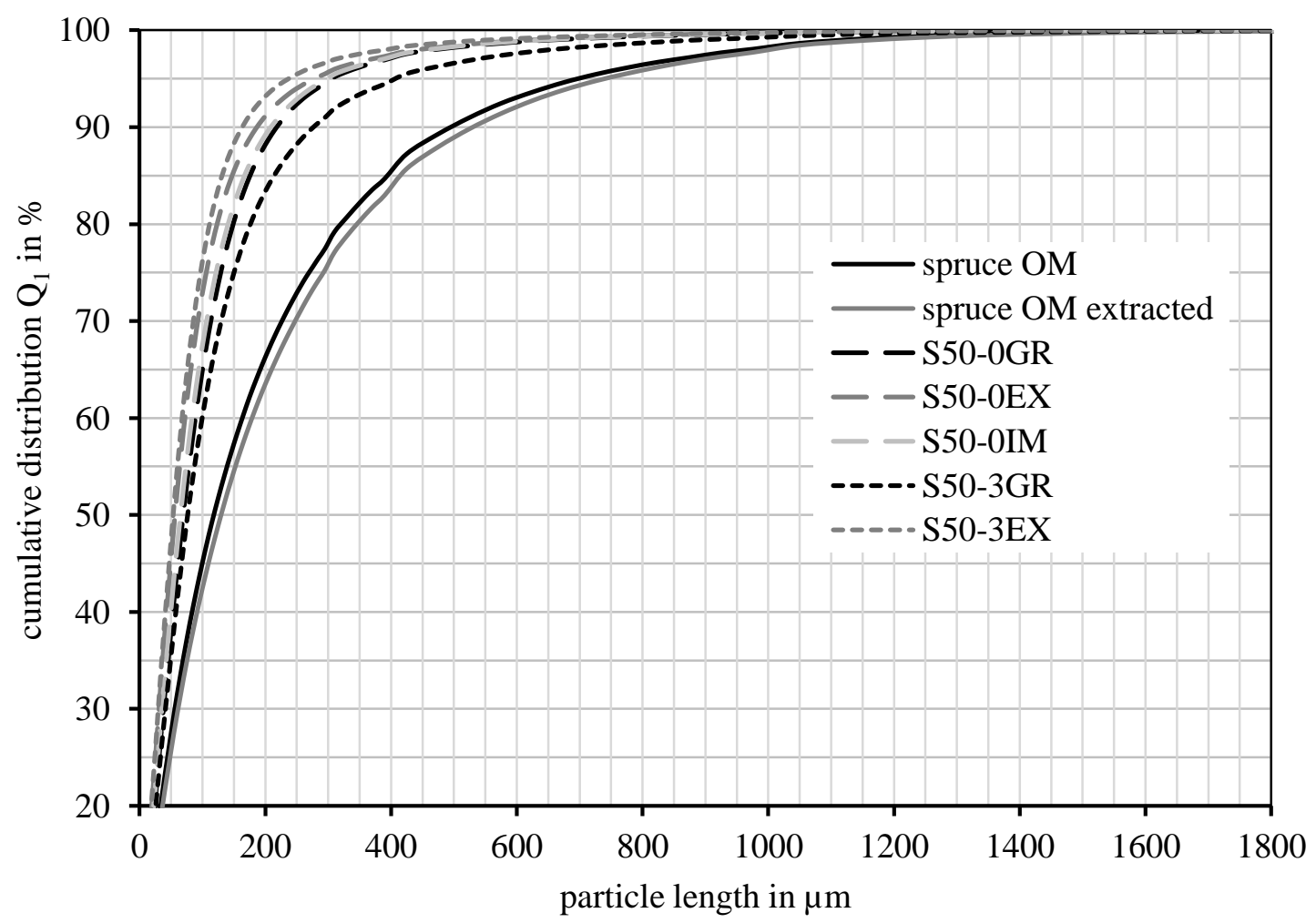

Figure A.2: Length-based cumulative distribution $\left(Q_{1}\right)$ of spruce wood particles before processing and after each processing step (OM: original material). 
Concerning the spruce wood particles a strong effect of the WPC production process on the particle size is evident. $95 \%$ of the particle length of the original material is smaller than $700 \mu \mathrm{m}$. This number decreases to $300 \mu \mathrm{m}$ after granulation without MAPP and to $400 \mu \mathrm{m}$ after granulation with MAPP. Without MAPP only a small degradation of the particles takes place during extrusion and injection moulding (95\% smaller than $280 \mu \mathrm{m}$ and $300 \mu \mathrm{m}$, respectively) compared to the material after the granulation step, with extrusion being the more aggressive process. The samples with MAPP show a different case. Although the degradation of particles processed with MAPP is less than without MAPP after granulation, the distribution of the particles extruded with MAPP shifts to even smaller particle lengths (95\% smaller than $240 \mu \mathrm{m}$ ) than the distribution of the sample without MAPP (Figure A.2).

Concerning the elongation there is a contrary effect visible for spruce particles compared to the beech particles. After processing the particles have a higher elongation than before processing, meaning that they are broader at the same length (Figure A.4). This is especially true for higher particle lengths, which comprise only a small fraction of the particle length distribution.

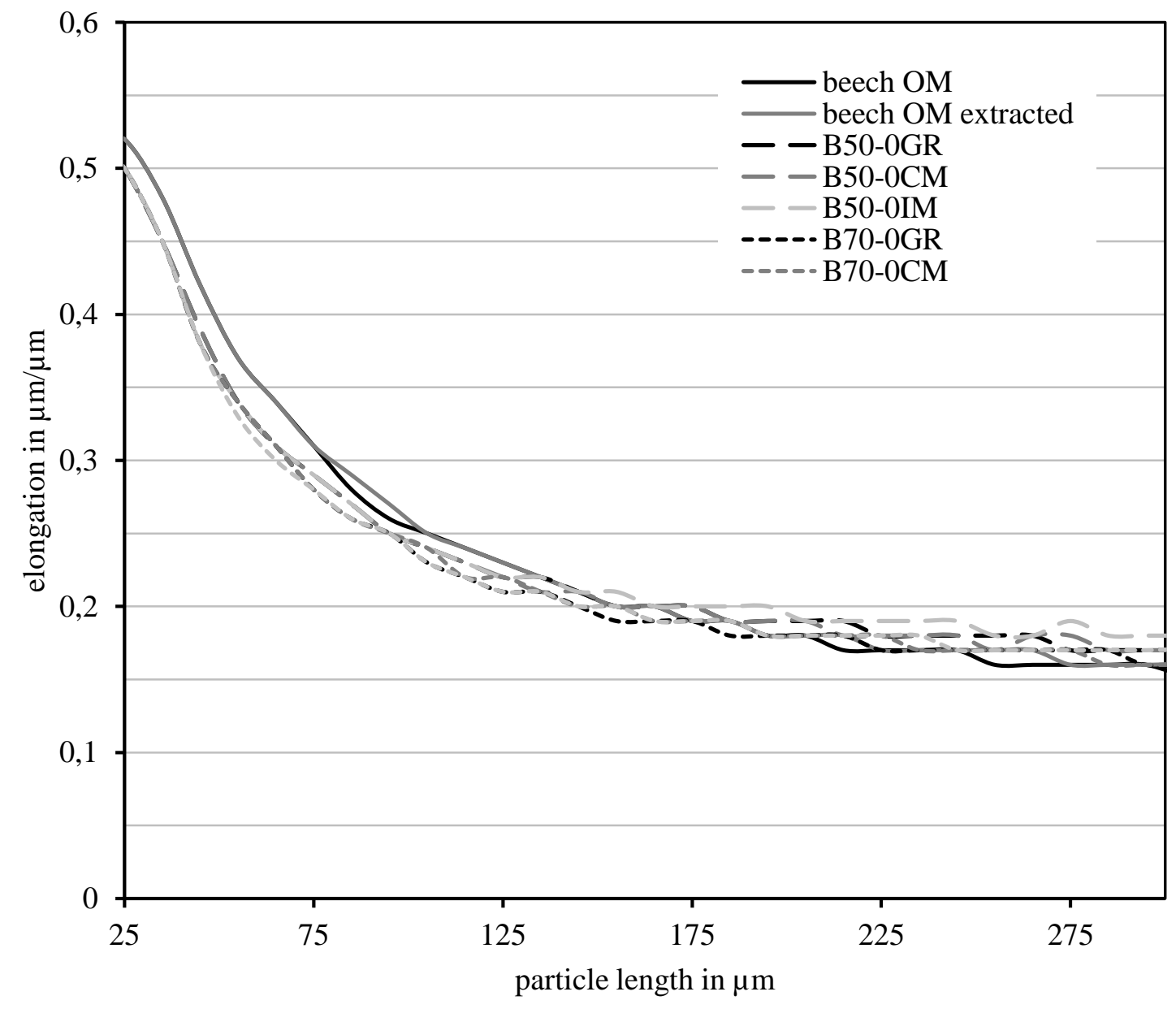

Figure A.3: Particle elongation of beech wood particles before processing and after each processing step (OM: original material). 


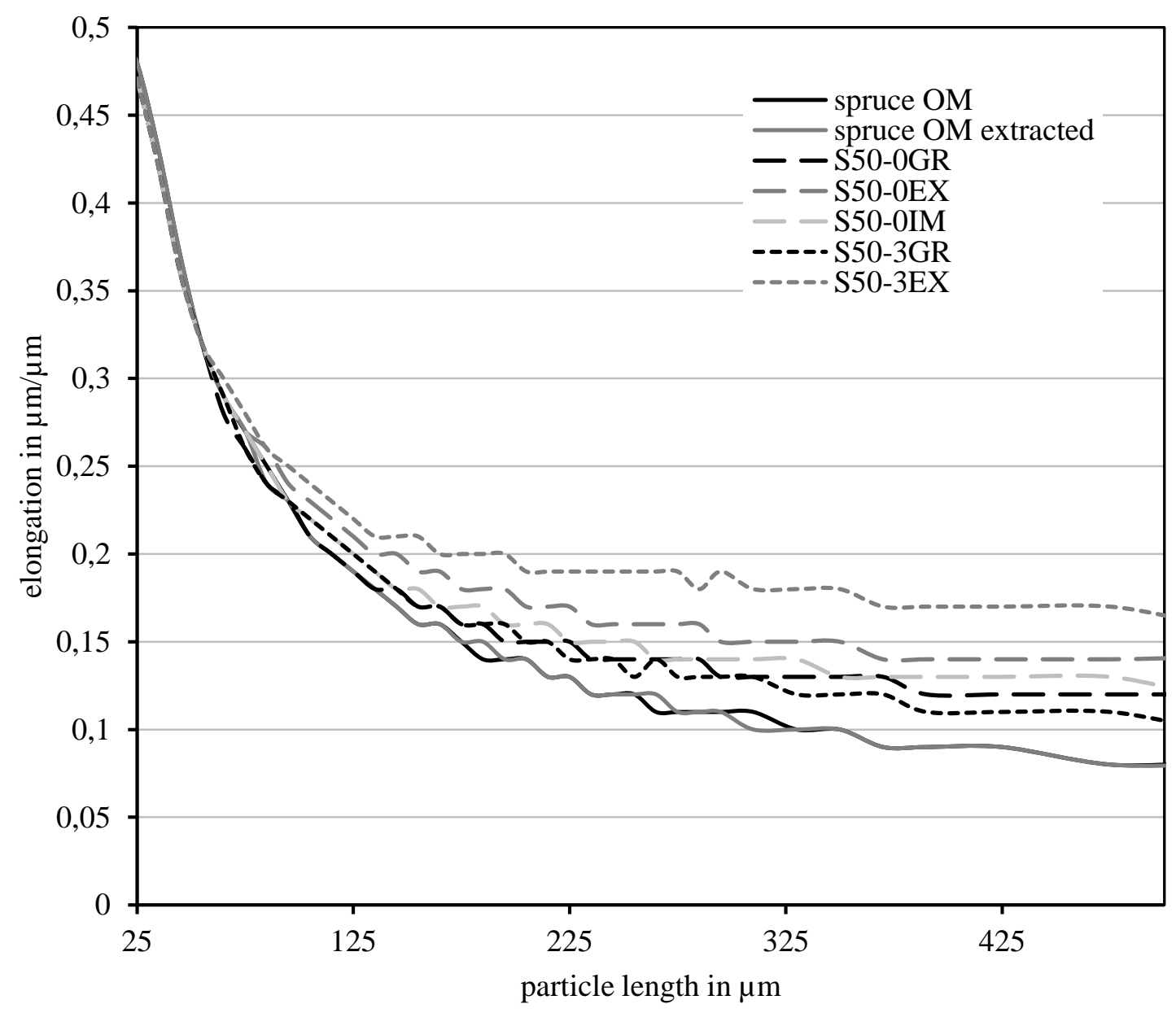

Figure A.4: Particle elongation of spruce wood particles before processing and after each processing step (OM: original material).

\section{Discussion}

Based on the results above it could clearly be shown that the wood component in WPC undergoes a dramatic change during processing resulting in a reduction of wood particle size. The strongest degradation of wood particles already occurs during the compounding step. Further processing via compression moulding, injection moulding and extrusion does not affect the particle size as much. This indicates that possibly due to intrinsic structural and mechanical properties of the wood there might be a threshold particle size below which further reduction of particle size is unlikely.

Unlike Michaeli \& Menges (1989) state [14] we found out that extrusion is the more aggressive process compared to injection moulding. Furthermore we could show that apart from the processing methods and the process settings [11] also the wood content of the WPC has a strong effect on the particle morphology. However, it still has to be investigated which factors (process parameters, compound composition, etc.) are most crucial concerning particle size change [16]. 
Concerning the width-to-length ratio we observed that a shortening of the particles while leaving the particle width unchanged [12][17] (meaning broader particles at the same length) is true for spruce wood but not for beech wood. Beech wood particles had a lower elongation, being slimmer at the same length, indicating that particle breakage took place also in longitudinal direction. Therefore, the sensitivity of different wood species to the WPC production process needs further investigation.

The influence of using MAPP as coupling agent on the particle length distribution is not distinct. With MAPP the degradation of particles during the compounding step is reduced but after further processing steps the degradation is even stronger than without MAPP. The causes of this effect have to be further investigated.

\section{Conclusion}

Different WPC compounds of beech and spruce wood with PP and partly MAPP have been processed via compression moulding, injection moulding, and extrusion. Afterwards the wood component has been separated from the polymer via Soxleth extraction. The wood particles before and after processing have been characterised via dynamic image analysis to compare the influence of the processing methods on the particle size and shape. It was shown that the strongest change in particle morphology occurred after the compounding step. Further processing caused only little additional particle degradation with extrusion being the most affective process. Beech wood and spruce wood displayed a different behaviour concerning the processing.

Further investigation on the crucial processing parameters, on the role of wood species, and on the effect of using a coupling agent concerning the change of particle morphology during processing of WPC is necessary.

\section{Acknowledgements}

This work was funded by the DFG - Deutsche Forschungsgemeinschaft (German Research Foundation) in the context of the Research Training Group "Resource Efficiency in Interorganizational Networks". 


\section{References}

[1] Carus, M., Gahle, C. Korte, H. (2008): Market and future trends for woodpolymer composites in Europe: the example of Germany, In: Oksman Niska, K., Sain, M. (2008): Wood-polymer composites, Woodhead Publishing Limited, Cambridge, England, pp. 300-330.

[2] Satov, D.V. (2008): Additives for wood-polymer composites, In: Oksman Niska, K., Sain, M. (2008): Wood-polymer composites, Woodhead Publishing Limited, Cambridge, England, pp. 23-40.

[3] Shahi, P., Behravesh, A. H., Daryabari, S.Y., Lofti, M. (2012): Experimental Investigation on Reprocessing of Extruded Wood Flour/HDPE Composites, Polymer Composites, 33(5): 753-763.

[4] Schwendemann, D. (2008): Manufacturing technologies for wood-polymer composites, In: Oksman Niska, K., Sain, M. (2008): Wood-polymer composites, Woodhead Publishing Limited, Cambridge, England, pp. 72-100.

[5] Kociszewski, M., Gozdecki, C., Wilczynski, A., Zajchowski, S., Mirowski, J. (2012): Effect of industrial wood particle size on mechanical properties of woodpolyvinyl chloride composites, Eur. J. Wood Prod., 70: 113-118.

[6] Ashori, A., Kiani, H., Mozaffari, S. A. (2011): Mechanical Properties of Reinforced Polyvinyl Chloride Composites : Effect of Filler Form and Content, Journal of Applied Polymer Science, 120: 1788-1793.

[7] Stark, N.M., Rowlands, R.E. (2003): Effects of wood fiber characteristics on mechanical properties of wood/polypropylene composites, Wood and Fiber Science, 35(2): 167-174.

[8] Stark, N.M. (1999): Wood fibre derived from scrap pallets used in polypropylene composites, Forest Products Journal, 49(6): 39-46.

[9] Chen, H.C., Chen, T.Y., Hsu, C.H. (2006): Effects of Wood Particle Size and Mixing Ratios of HDPE on the Properties of the Composites, Holz als Roh- und Werkstoff, 64: 172-177.

[10] Yam, K.L., Gogoi, B.K., Lai, C.C., Selke, S.E. (1990): Composites From Compounding Wood Fibers With Recycled High Density Polyethylene, Polymer Engineering and Science, 30(11): 693-699.

[11] Stark, N.M., Matuana, L.M., Clemons, C.M. (2004): Effect of Processing Method on Surface and Weathering Characteristics of Wood-Flour/HDPE Composites, Journal of Applied Polymer Science, 93:1021-1030. 
[12] Le Baillif, M., Oksman, K. (2009): The Effect of Processing on Fiber Dispersion, Fiber Length, and Thermal Degradation of Bleached Sulfite Cellulose Fiber Polypropylen Composites, Journal of Thermoplastic Composite Materials, 22: 115-133.

[13] Yeh, S.-K., Gupta, R.K. (2008): Improved wood-plastic composites through better processing, Composites: Part A, 39: 1694-1699.

[14] Michaeli, W., Menges, G. (1989): Prediction of Product Properties in Extrusion and Injection Molding, Advances in Polymer Technology, 9(1): 69-85.

[15] Witt, W., Köhler, U., List, J. (2007): Current limits of particle size and shape analysis with high speed image analysis, PARTEC 2007.

[16] Migneault, S., Koubaa, A., Erchiqui, F., Chaala, A., Englund, K., Wolcott, M.P. (2009): Effects of processing method and fibre size on the structure and properties of wood-plastic composites, Composites: Part A, 40: 80-85.

[17] Klyosov, A.A. (2007): Wood-plastic composites, John Wiley \& Sons, Inc., Hoboken, New Jersey. 

Appendix B 



\section{Characterisation of the wood component of WPC via dynamic image analysis}

Laura Teuber ${ }^{1}$, Holger Militz ${ }^{1}$, Andreas Krause ${ }^{1,2}$

${ }^{1}$ Faculty of Forest Sciences and Forest Ecology, Wood Biology and Wood Products Dpt., DFG Research Training Group "Resource Efficiency in Interorganizational Networks"

Georg-August University of Göttingen, Germany

2Institute of Mechanical Wood Technology

Department of Wood Sciences

University of Hamburg

Originally published in:

First International Conference on Resource Efficiency in Interorganizational Networks - RessEff 2013-

November 13th $-14^{\text {th }}, 2013$

Georg-August-Universität Göttingen

Geldermann, J., Schumann, M. (eds.)

Universitätsdrucke Göttingen, ISBN: 978-3-86395-142-9 


\section{Abstract}

The wood component of WPC is a decisive factor influencing the material properties of the WPC. Dynamic image analysis can help to characterise the morphological constitution of the wood particles or fibres at every processing step. As an example of use, different WPC granulate materials with varying wood content have been produced via extrusion with varying screw speeds and throughputs. After separating the wood particles from the polymer via Soxhlet extraction, the processed particles have been characterised via dynamic image analysis concerning their particle size and shape distributions. The wood content during processing has the strongest effect on particle size resulting in smaller particles at higher wood content. Low screw speeds impose higher degradation on the wood component especially at a low wood content. No influence of the level of throughput on the wood particle size and shape could be detected.

\section{Keywords}

particle size distribution, particle shape, wood plastic composites, WPC processing

\section{Introduction}

Wood plastic composites (WPC) are a group of innovative new materials which are mainly used for deckings and claddings but as well for window frames, furniture, other consumer goods, and conversion parts for the automotive industry. Raw materials for the production of WPC are beside different polymers and additives wood particles, wood fibres, and wood shavings (Carus et al., 2008). The variable shape variants of the wood that can potentially be used in WPC could help towards an enhanced cascade use in wood industry and hence an increased resource efficiency. By- and waste products of wood industry could be applied to WPC production before using them for the production of energy.

It has to be evaluated beforehand which properties those by-products require to be a suitable raw material for the production of WPC with a performance that matches the application. One factor that influences the performance of WPC is the morphological constitution of the wood component. For example, the tensile and flexural strength of wood-fibre-filled WPC is improved compared to wood-flour-filled WPC (Stark 1999). But shorter particles are easier to disperse in the polymer matrix and result in a more homogenous material (Yam et al., 1990; Shahi et al., 2012).

One way to gain information on the constitution of the wood component is to characterise the wood fibres or particles by means of dynamic image analysis. The dynamic image analysis delivers particle size and shape distributions by calculation of several size and shape descriptors from binary 2D pictures, allowing detailed description of the particle material.

Particle characterisation enables to study the changes of the wood component of WPC in every processing step. It permits to study the milling behaviour and particle formation of different wood species (Plinke et al., 2012). A comparison of different 
processing methods for WPC - i.e. extrusion, injection moulding, and compression moulding - as to the changes the wood component undergoes being exposed to shear forces, friction, and high temperature is possible (Stark et al., 2004). Even more, particle analysis allows for the possibility to examine the relation between particle size and shape of the wood component and the mechanical properties of WPC (Ashori et al., 2011; Stark \& Rowlands, 2003).

As an example of use of dynamic image analysis the present work focuses on the characterisation of wood particles extracted from WPC granulate material having been processed under different conditions. The aim is to identify relevant processing parameters influencing the wood particle change during WPC processing.

\section{Materials \& Methods}

\subsection{WPC production}

Norway spruce (Picea abies) was ground with a cutting mill (FDR 112M/8A (SM 2000), Retsch $\mathrm{GmbH}$, Germany) with an aperture size of $4 \mathrm{~mm}$. To obtain a medium particle size fraction, sieve separation was done with two sieves of aperture size $1 \mathrm{~mm}$ and $2 \mathrm{~mm}$. The shavings were then washed in water between two sieves of aperture size $0.71 \mathrm{~mm}$ and $1.6 \mathrm{~mm}$ to remove dust. Afterwards, the washed wood particles were dried in a hot air oven to a moisture content of $<3 \%$.

The dried wood particles were compounded with polypropylene (PP) (Sabic PP 575P, Saudi Basic Industries Corporation, Saudi Arabia) in a Leistritz MICRO27GL/GG40D co-rotating twin-screw extruder (Leistritz Extrusionstechnik $\mathrm{GmbH}$, Germany) with gravimetric feeders and a hot-cut pelletizer. The temperature profile was ranging from $150^{\circ} \mathrm{C}$ to $180^{\circ} \mathrm{C}$ and the nozzle temperature was at $136^{\circ} \mathrm{C}$. Seven WPC granulates were produced at different screw speeds, throughputs and with varying wood content (see Table B.1).

\subsection{Soxhlet extraction}

For separating the polymer from the wood particles the WPC granulate was subjected to a Soxhlet extraction with xylene (technical grade from AppliChem, Darmstadt, Germany) for $8 \mathrm{~h}$. After extraction the particles were dried at $103{ }^{\circ} \mathrm{C}$ to remove excess solvent and moisture.

Table B.1: Setting of the WPC granulates produced in this study.

\begin{tabular}{cccc}
\hline wood content [\%] & screw speed [rpm] & throughput [kg] & sample \\
\hline 30 & 80 & 4 & $30 \%-80-4$ \\
30 & 160 & 8 & $30 \%-160-8$ \\
50 & 80 & 4 & $50 \%-80-4$ \\
50 & 160 & 8 & $50 \%-160-8$ \\
70 & 80 & 4 & $70 \%-80-4$ \\
70 & 160 & 8 & $70 \%-160-8$ \\
70 & 160 & 4 & $70 \%-160-4$ \\
\hline
\end{tabular}




\subsection{Particle characterisation}

The change of particle size and shape of the dried wood particles due to different process settings during granulation was characterised using the optical dynamic image analysis sensor QICPIC with dry dispersion unit VIBRI (Sympatec GmbH, Germany). The size and shape of each single particle were calculated from binary 2D images taken at a frame rate of $450 \mathrm{fps}$ at a resolution of $10 \mu \mathrm{m}$. The extracted particles have been analysed as to the length-based size distribution $\left(\mathrm{Q}_{1}\right)$ and the elongation with the particle length and the particle width as equivalent diameters. As described in Witt et al. (2007) the particle length is calculated as the shortest path between the most distant endpoints of the particle after skeletonising its binary image via a complex evaluation algorithm. The width is calculated as the projected particle area divided by the added length of all skeleton paths. The particle elongation represents the ratio of width to length. The number of particles examined per sample varied between 1 million and 5 million. As a reference the length-based size distribution of the raw material particles before processing as been determined at a resolution of $20 \mu \mathrm{m}$.

\section{Results}

Figure B.1 shows the length-based cumulative distribution of the particle width of the extracted particle material after granulation at varying wood content, screw speed and throughput compared to the width distribution of the raw material particles. The displayed size range comprises only $50 \%$ of the raw material's particle width whereas it comprises $100 \%$ of the processed particles' width. This indicates a strong degradation of the particle size during granulation. In addition, the varying processing parameters have a more or less distinctive influence on the distribution. The strongest effect is related to the wood content of the WPC. Processed at a wood content of $30 \%$, ca. $55 \%$ of the particle width is smaller than $30 \mu \mathrm{m}$. Processed at $50 \%$ content this number rises to $63 \%$ and processed at $70 \%$ it rises up to $70 \%$ indicating a decreasing particle width with increasing wood content during processing. The screw speed and the throughput show no distinctive influence on the particle width.

Figure B.2 presents the length-based cumulative distribution of the particle length of the different wood particle samples. The size range displayed covers only $17 \%$ of the particle length of the raw material while it comprises $100 \%$ of the particle length of the processed particles revealing a great shortening of the particles during granulation. Similar to the width distribution, the length distribution is distinctively influenced by the wood content during processing. Processed at $30 \%$ wood content $75 \%$ to $79 \%$ of the particle length is smaller than $300 \mu \mathrm{m}$. At $50 \%$ wood content it is $85 \%$ and at $70 \%$ wood content it is $88 \%$ to $89 \%$. At constant wood content also a slight effect of the screw speed is visible in a shift of the distribution to smaller particle lengths for the lower screw speed. This is especially obvious for a wood content of $30 \%$. 
Figure B.3 displays the particle elongation of the processed wood particles depending on the particle length. For all particle samples bigger particles are more elongated than smaller particles. A distinctive influence of the varying processing conditions on the elongation cannot be observed.

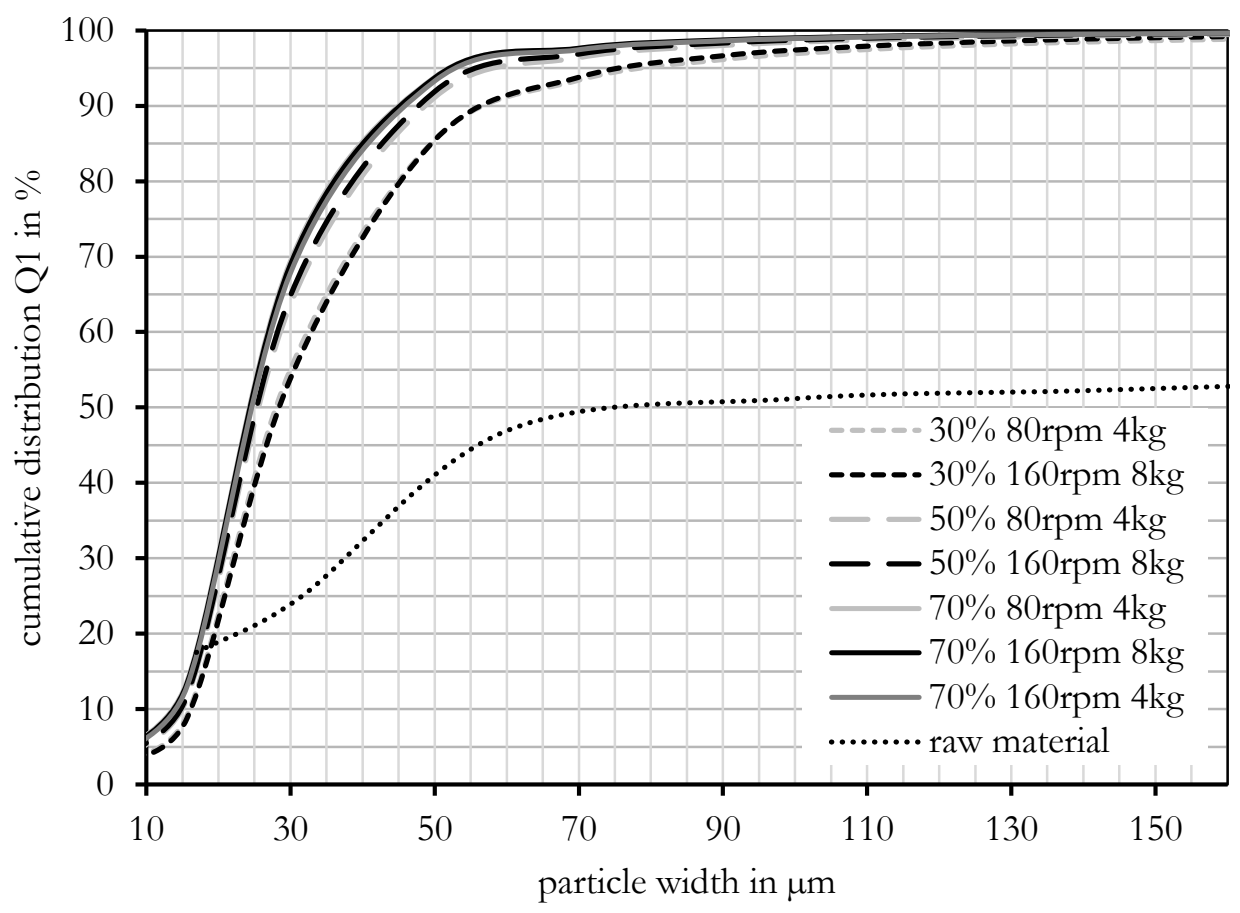

Figure B.1: Length-based cumulative distribution $\left(Q_{1}\right)$ of spruce wood particle width after granulation with varying wood content, screw speed, and throughput.

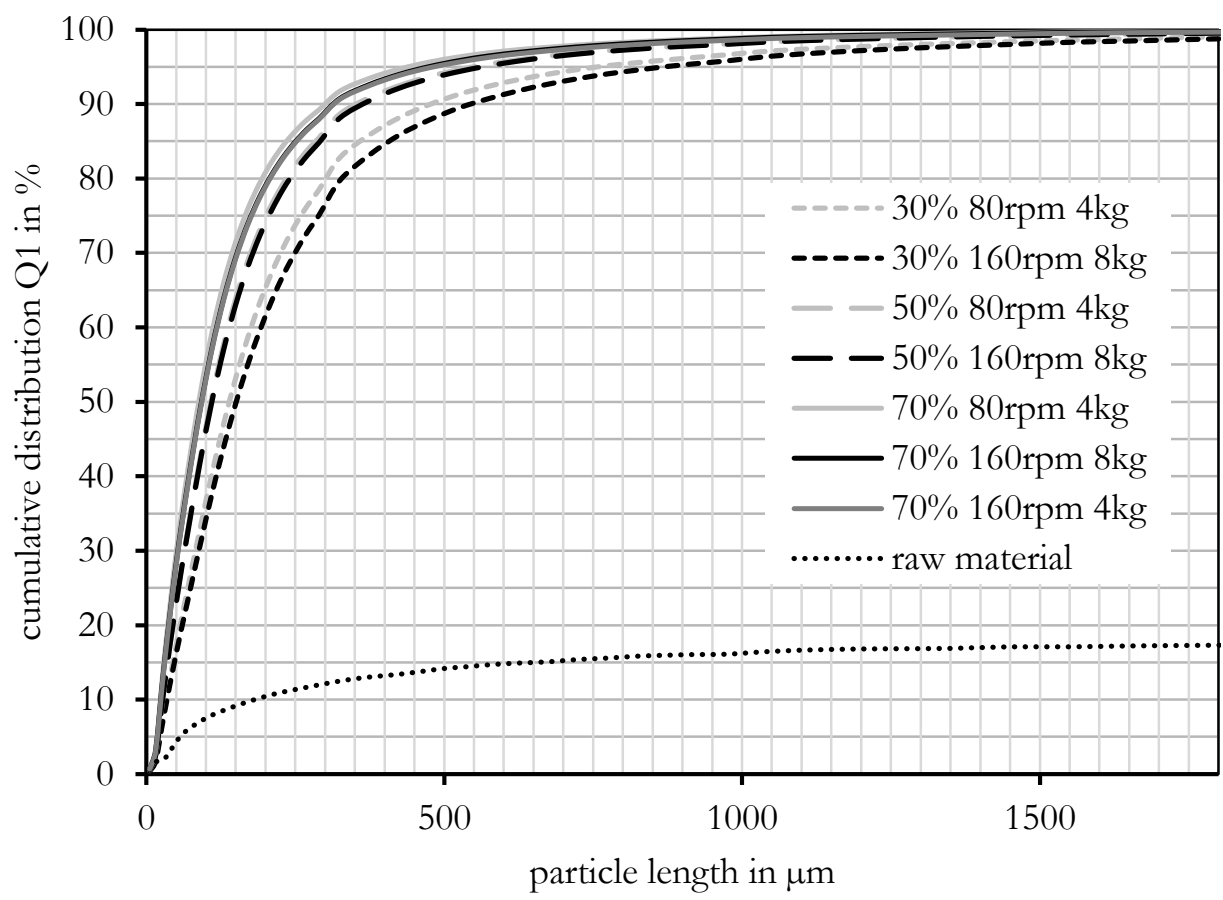

Figure B.2: Length-based cumulative distribution $\left(Q_{1}\right)$ of spruce wood particle length after granulation with varying wood content, screw speed, and throughput. 


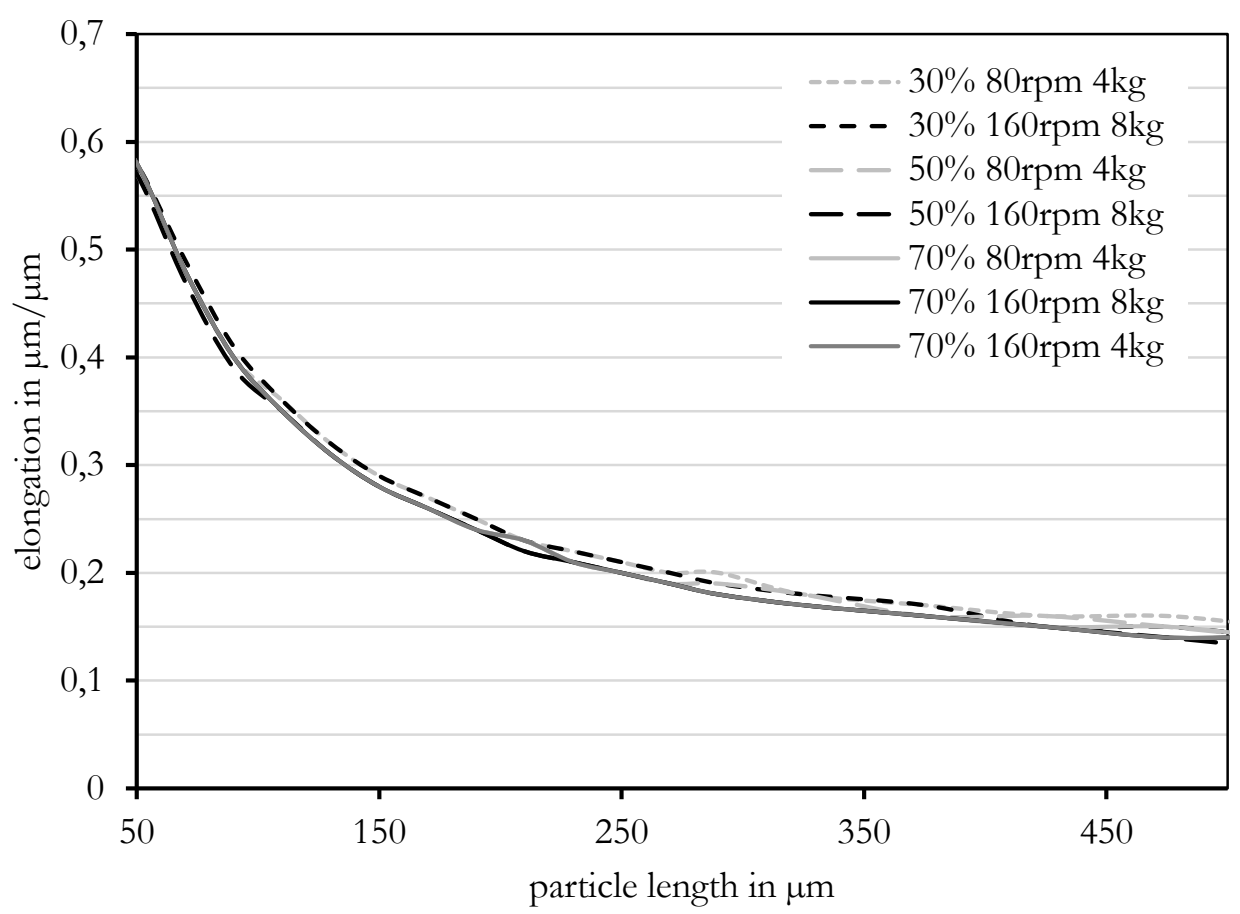

Figure B.3: Particle elongation depending on particle length of spruce wood particles after granulation with varying wood content, screw speed, and throughput.

\section{Discussion}

Producing WPC granulate material via extrusion process as a pre-processing step is a common way to compound wood and polymer before producing profiles or injection moulding parts (Shahi et al., 2012). During compounding the material is subjected to high temperatures and to shear forces affecting the morphology of the wood component (Michaeli \& Menges, 1989). As shown by Yam et al. (1990) and confirmed by the results above, the reduction of wood particle size strongly depends on the wood content. With rising wood content the viscosity of the filled polymer melt increases and higher shear stresses are imposed on the material resulting in a more severe degradation of the wood particles. The viscosity of polymeric materials is even higher at low shear rates which are directly related to the screw speed (Klyosov, 2007). Thus, a low screw speed leads to high shear forces and, in addition, to a longer residence time of the material being subjected to the process conditions. This is confirmed by the results above as there is a dependency of particle size on screw speed, especially for the $30 \%$ wood filled material. At higher wood content the viscosity might already be at a level where the effect of screw speed is only small.

No differences in particle size attributed to the throughput could be detected in this study. It was expected that a higher throughput would lead to a stronger degradation of particles due to higher shear forces and pressure imposed by an increased filling of the free volume in the extruder. The results might be explained by the fact that the levels of throughput chosen for this study are at the lower end of the throughput range possible for the used extruder. So, the fillings of the free volume at a throughput of $4 \mathrm{~kg} / \mathrm{h}$ and $8 \mathrm{~kg} / \mathrm{h}$ probably differ only marginally. 


\section{Conclusions}

As an example for the application of dynamic image analysis for the characterisation of wood particles, different WPC granulate materials have been produced via extrusion. The wood content of the WPC and processing conditions (screw speed and throughput) have been varied. Afterwards, the processed particles have been separated from the polymer via Soxhlet extraction. The dynamic image analysis of the processed particles resulted in particle size and shape distributions revealing a strong influence of the wood content during processing on the particle size. Processed at a high wood content the particles are smaller due to higher shear forces caused by an increased viscosity of the polymer melt. In addition, it was shown that a low screw speed leads to higher particle degradation, especially at a low wood content. No influence of the throughput level on the particle size and shape could be detected.

This study shows a good example of how the research on WPC can benefit from dynamic image analysis. It can help to characterise and understand raw material properties and the influence of production processes of WPC on the wood component.

\section{References}

Ashori, A., Kiani, H. \& Mozaffari, S.A., 2011. Mechanical Properties of Reinforced Polyvinyl Chloride Composites: Effect of Filler Form and Content. Journal of Applied Polymer Science, 120: 1788-1793.

Carus, M., Gahle, C. \& Korte, H., 2008. Market and future trends for wood-polymer composites in Europe: the example of Germany. In: K. Oksman Niska \& M. Sain eds. 2008. Wood-polymer composites. Cambridge: Woodhead Publishing Limited, pp. 300-330.

Klyosov, A.A., 2007. Wood-plastic composites. Hoboken, NJ: John Wiley \& Sons, Inc.

Michaeli, W. \& Menges, G., 1989. Prediction of Product Properties in Extrusion and Injection Molding. Advances in Polymer Technology, 9(1): 69-85.

Plinke, B., Schirp, A. \& Weidenmüller, I., 2012. Review: Methoden der Holzpartikelgrößenmessung - Von der technologischen Fragestellung zur aussagefähigen Statistik. Holztechnologie, 53(4): 11-17.

Shahi, P., Behravesh, A.H., Daryabari, S.Y. \& Lofti, M., 2012. Experimental Investigation on Reprocessing of Extruded Wood Flour/HDPE Composites. Polymer Composites, 33(5): 753-763. 
Stark, N.M., 1999. Wood fibre derived from scrap pallets used in polypropylene composites. Forest Products Journal, 49(6):39-46.

Stark, N.M. \& Rowlands, R.E., 2003. Effects of wood fiber characteristics on mechanical properties of wood/polypropylene composites. Wood and Fibre Science, 35(2): 167-174.

Stark, N.M., Matuana, L.M. \& Clemons, C.M., 2004. Effect of Processing Method on Surface and Weathering Characteristics of Wood-Flour/HDPE Composites. Journal of Applied Polymer Science, 93: 1021-1030.

Witt, W., Köhler, U. \& List, J., 2007. Current limits of particle size and shape analysis with high speed image analysis. PARTEC 2007.

Yam, K.L., Gogoi, B.K., Lai, C.C. \& Selke, S.E., 1990. Composites From Compounding Wood Fibres With Recycled High Density Polyethylene. Polymer Engineering and Science, 30(11): 693-699. 


\section{The author}

Laura Teuber, M.Eng.

Laura.Teuber@gmx.net

$*_{1}{ }^{\text {st }}$ July 1986 in Delmenhorst, Germany

\section{Education}

04/2012 - 07/2016 PhD program "Wood Biology \& Wood Technology"

Georg-August-University Göttingen, Germany

03/2010-10/2011 Master's degree in Lightweight Construction and Simulation (M.Eng.)

University of Applied Sciences Landshut, Germany

Thesis: Influence of different surface modifications on the fibre/matrix adhesion of regenerated cellulose fibre/polymer composites

09/2006 - 02/2010 Bachelor's degree in Biomimetics (B.Sc.)

University of Applied Sciences Bremen, Germany

Thesis: Analysis of the wettability of four moth (Lepitoptera) species' hair-like scales concerning their suitability as a model for a multifunctional material

\section{Work History}

04/2012 - 03/2015 Research associate at Georg-August-University Göttingen, Section of Wood Biology \& Wood Products, DFG Research Training Group 1703 "Resource Efficiency in Interorganizational Networks", Germany

09/2014 - 12/2014 Visiting researcher at SCION, Rotorua, New Zealand

02/2012 - 03/2012 Student research assistant at FIBRE - Faserinstitut Bremen e.V., Germany

04/2010-10/2010 Student research assistant at Competence Centre for Lightweight Design, University of Applied Sciences Landshut, Germany

03/2009-06/2009 Student research assistant at International Course of Studies Biomimetics, University of Applied Sciences Bremen, Germany

09/2008 - 12/2008 Visiting student at Mahatma Gandhi University, School of Chemical Sciences, Kottayam (Kerala), India 